2010

\title{
Analysis and scaling of a two-stage fluidized bed for drying of fine coal particles using Shannon entropy, thermodynamic exergy and statistical methods
}

Steven Lee Rowan

West Virginia University

Follow this and additional works at: https://researchrepository.wvu.edu/etd

\section{Recommended Citation}

Rowan, Steven Lee, "Analysis and scaling of a two-stage fluidized bed for drying of fine coal particles using Shannon entropy, thermodynamic exergy and statistical methods" (2010). Graduate Theses, Dissertations, and Problem Reports. 2985.

https://researchrepository.wvu.edu/etd/2985 


\title{
Analysis and Scaling of a Two-Stage Fluidized Bed for Drying of Fine Coal Particles Using Shannon Entropy, Thermodynamic Exergy and Statistical Methods
}

\author{
Steven Lee Rowan \\ Dissertation Submitted to the \\ College of Engineering and Mineral Resources \\ at \\ West Virginia University \\ In Partial Fulfillment of Requirements \\ For the Degree of
}

\author{
Doctor of Philosophy \\ In \\ Mechanical Engineering \\ Eric Johnson, Ph.D. Chair \\ Bruce Kang, Ph.D. \\ John Kuhlman, Ph.D. \\ Matthew Valenti, Ph.D. \\ Frank Saus, Ph.D. \\ Lawrence Shadle, Ph.D. \\ Department of Mechanical and Aerospace Engineering
}

Morgantown, West Virginia

2010

Keywords: Coal Drying, Fluidization, Shannon Entropy, Exergy

Copyright 2010 Steven L. Rowan 


\section{Abstract \\ Analysis and Scaling of a Two-Stage Fluidized Bed for Drying of Fine Coal Particles Using Shannon Entropy, Thermodynamic Exergy and Statistical Methods}

\section{Steven Lee Rowan}

Liquid water (moisture) in coal causes a number of economic and environmental issues for the mining and electrical power generation industries. Coal preparation plants utilize large amounts of water for cleaning coal and removing unwanted materials such as clay, sulfur, pyrite and mercury. After the cleaning process, it is necessary to separate as much of the water from the coal as possible. Unfortunately, current dewatering techniques are not effective with particle sizes below $150 \mu \mathrm{m}$, which compromises $6-8 \%$ of the total energy found in mined coal. In most cases, these fine coal particles end up in slurry waste ponds. Additionally, coal-fired power plants typically purchase coal on a per btu of heating value basis. In many cases, coal can reabsorb moisture during transportation from mine to power plant, and some pulverized coal plants operate with moisture contents as high as $40 \%$. It has been shown previously that a $1 \%$ reduction in the moisture content of coal leads to approximately a $0.1 \%$ increase in the heating value of coal.

To address this issue, two two-stage, variable-area fluidized bed prototypes have been constructed. The first bed is a steam-jacketed warm-air dryer for fine particles (WADFP) with a lower riser stage bed diameter of 5" and an upper riser stage bed diameter of 8". The second is a half-scale transparent model. One of the primary objectives of this study is to utilize the scalemodel fluidized bed to study the unique fluidization characteristics of a large scale fluidized bed consisting of a lower small-diameter riser stage and an upper large-diameter riser stage with secondary air injection. The second objective of this study is to develop a simplified set of scaling relationships that allow for the scaling of fluidization regime transition velocities between different fluidized beds. The final objective of this study is to perform a thermodynamic exergy analysis on the fluidized bed drying process.

Preliminary test results show a similar trend of secondary air injection being the controlling factor of fluidization regime determination for both the large scale dryer and the small scale model riser. A proposed scaling method using riser area-normalized mass flow rates resulted in good matching between the two systems. Experiments with fluidizing wet coal also resulted in significant reductions in the moisture content of coal after drying. 


\section{Acknowledgements}

I would like to express my appreciation and gratitude to my advisor, Dr. Eric Johnson. I Can't begin to express how fortunate I consider myself to be for his mentorship during my time studying under him. It would not be an exaggeration to say that his influences have transformed me into a much better-rounded engineer.

I am likewise thankful to both Dr. Bruce Kang and Dr. Frank Saus for being there to provide the proverbial boot to the rear when I needed extra motivation, as well as their financial support without which much of this research may never have taken place.

I would like to thank the remaining members of my dissertation committee: Dr. John Kuhlman, Dr. Lawrence Shadle and Dr. Matthew Valente.

I would also like to express my thanks to everyone at Wilson Works, Chuck Coleman and Clifford Judy from the MAE electrical and machine shops, as well as Liviu Magean and everyone in the chemical engineering department's analytical lab.

I would like to thank my fellow graduate students: Eric, Jackson, Rajiv and Femi. Without your assistance I do not know where I'd be today.

Most of all I'd like to thank my wife, Melissa. Without your support and understanding none of this would have been possible.

Finally, I would like to say thank you to all of the faculty, secretaries and other staff members in the Mechanical and Aerospace Engineering Department for their help and support over the years. 


\section{Table of Contents}

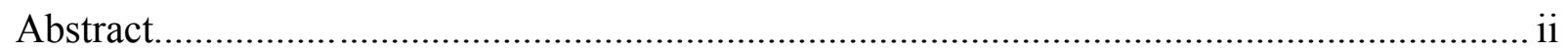

Acknowledgments.....................................................................................................

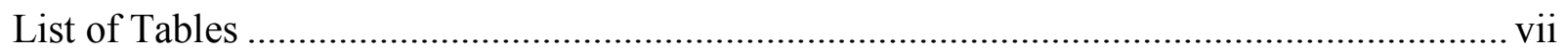

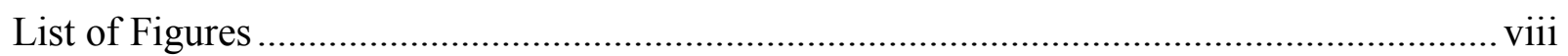

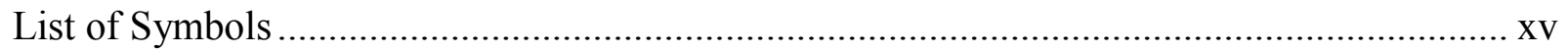

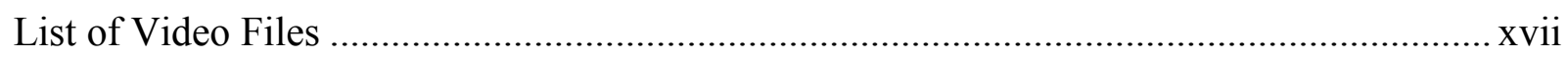

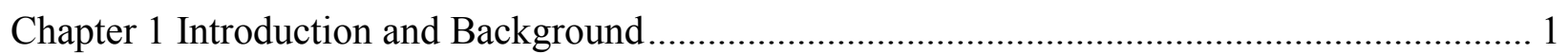

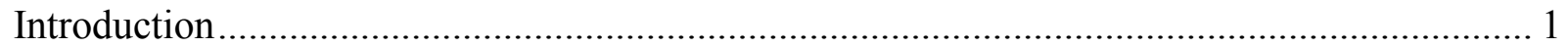

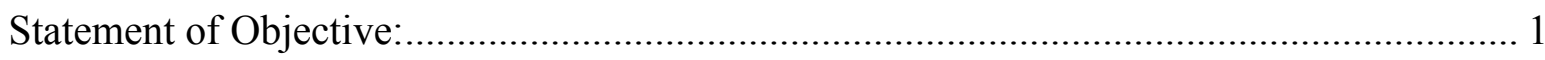

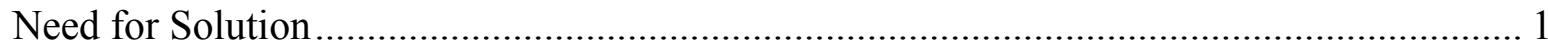

Experimental Approach …………………………................................................. 3

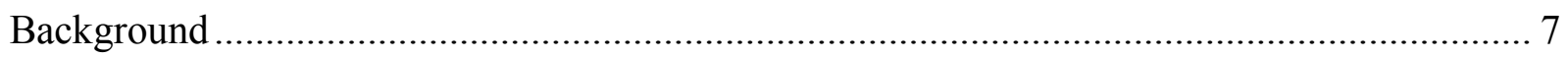

General types and applications of fluidized bed dryers ................................................. 7

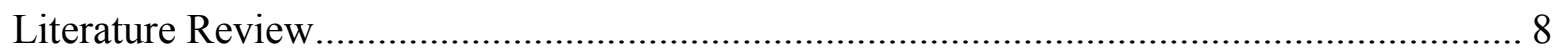

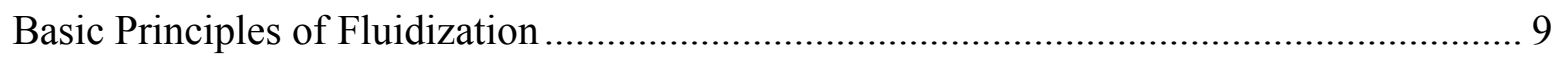

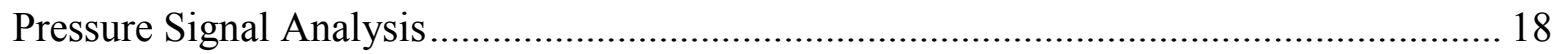

Chapter 2 Theoretical Approach for Fluidized Bed Drying ………………………….............. 28

Principles of Fluidized Bed Drying ............................................................................... 28

Droplet evaporation/film drying model ........................................................................ 30

Thermodynamic Analysis of Fluidized Bed Drying ................................................................ 35

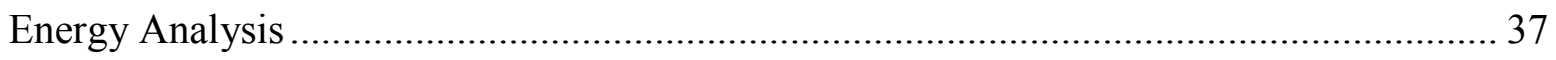

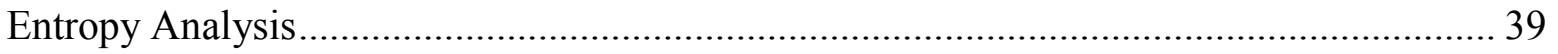

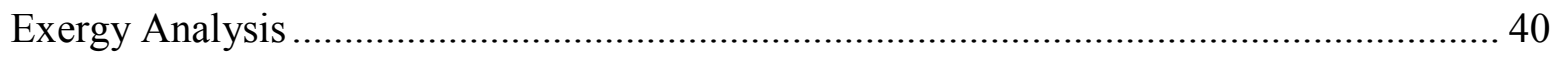

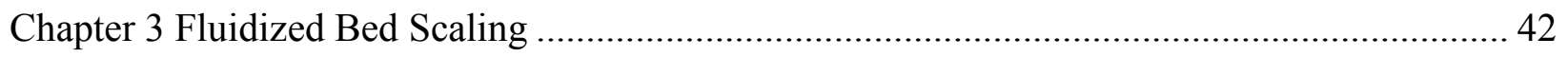

Hydrodynamic Scaling Relationships ............................................................................ 42

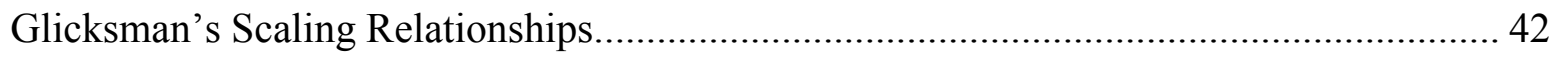

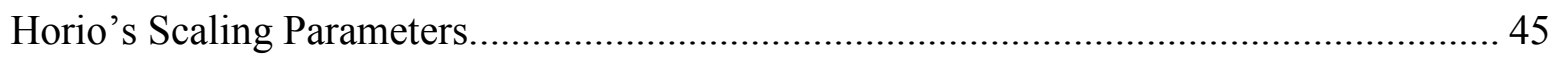

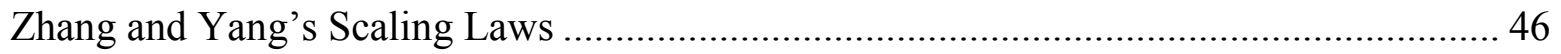

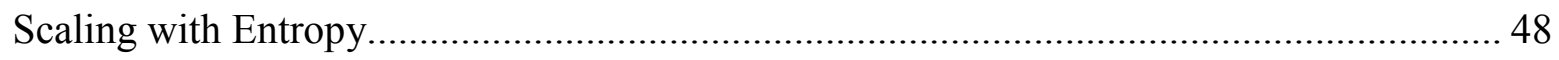

Experimental Verification Techniques of Scaling Laws ........................................................ 48 


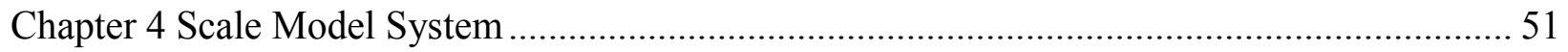

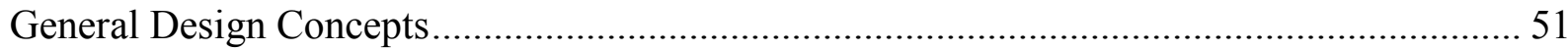

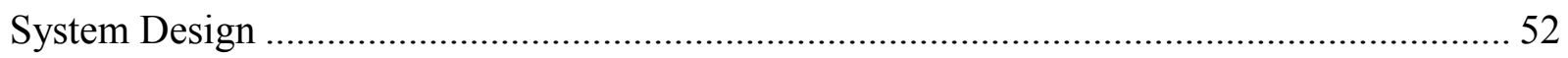

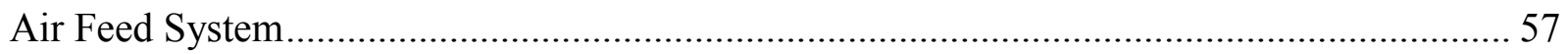

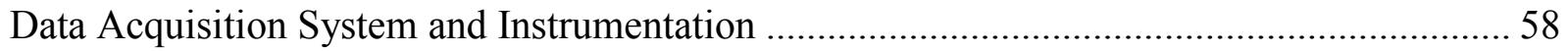

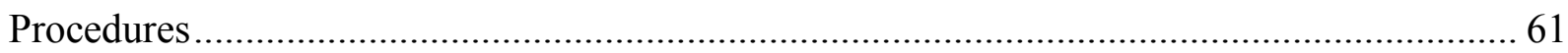

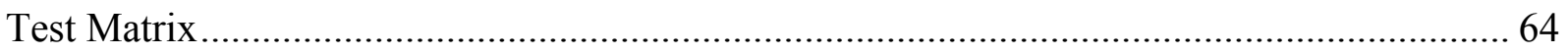

Chapter 5 Scale Model Experimental Results ………............................................................ 67

Lower Riser Stage Turbulent Fluidization Mapping and Characterization ............................... 67

Upper Riser Stage Fast Fluidization Mapping and Characterization........................................ 79

Effects of Secondary Air Injection on the Lower Riser Stage Fluidization .............................. 86

Comparison of Standard Deviation of Pressure with Riser Stage Pressure Drop..................... 97

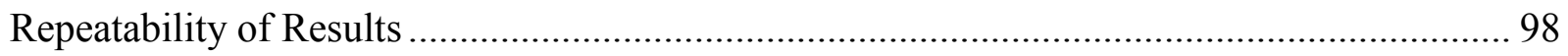

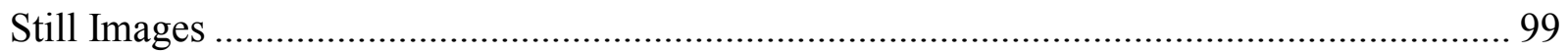

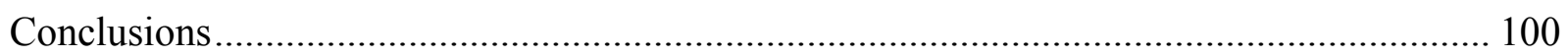

Chapter 6 Warm Air Dryer Experimental System .............................................................. 102

General Design Concepts................................................................................................. 102

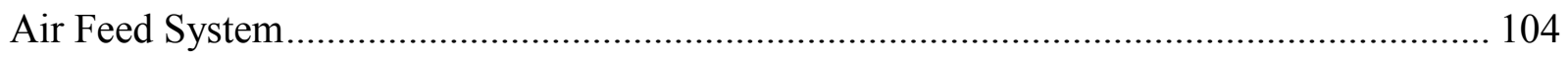

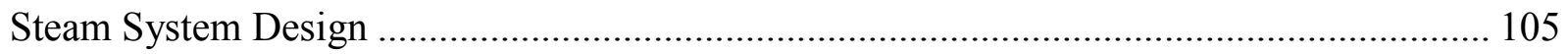

Data Acquisition System and Instrumentation …………..................................................... 106

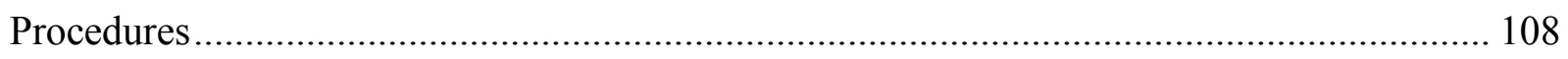

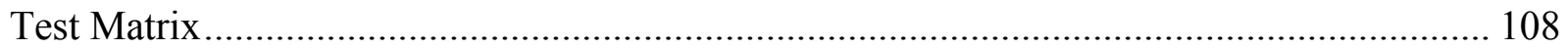

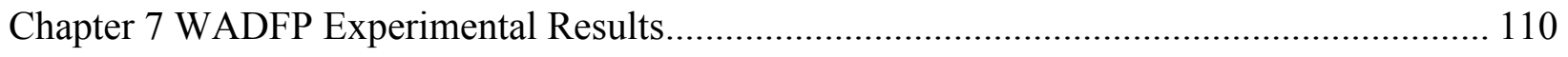

Lower Riser Stage Turbulent Fluidization Mapping and Characterization ............................ 110

Upper Riser Stage Fast Fluidization Mapping and Characterization..................................... 119

Effects of Secondary Air Injection on Lower Riser Stage Fluidization ................................ 124

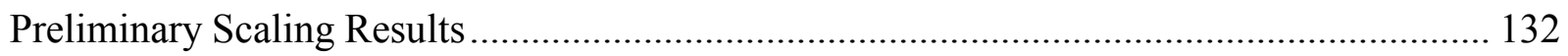

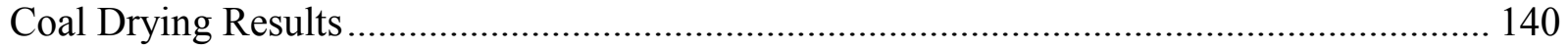

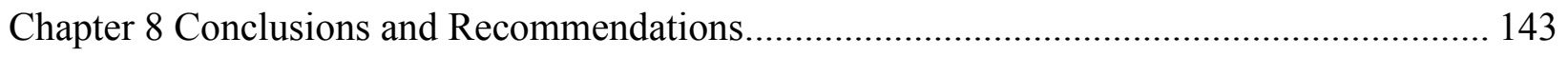

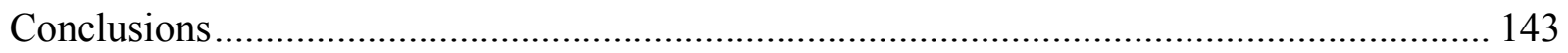

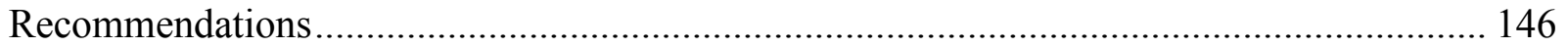


Chapter 9 Bibliography. 


\section{List of Tables}

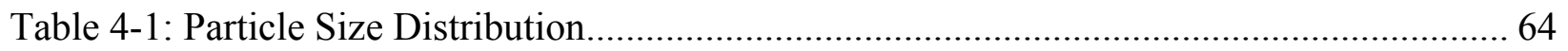

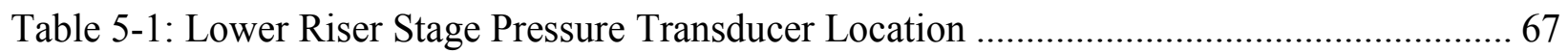

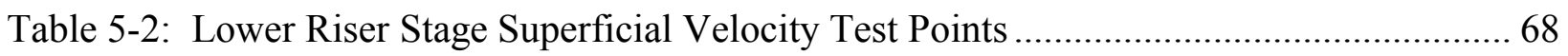

Table 5-3: Upper Riser Stage Superficial Velocity Test Points …………….............................. 79

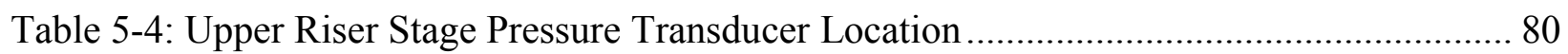

Table 7-1: WADFP Lower Riser Stage Pressure Transducer Locations ..................................... 110

Table 7-2: WADFP Lower Riser Stage Superficial Velocity Test Points .................................. 111

Table 7-3: WADFP Upper Riser Stage Pressure Transducer Location ........................................ 119

Table 7-4: WADFP Upper Riser Stage Superficial Velocity Test Points .................................... 119

Table 7-5: Scaling comparison coal particle size distribution.................................................... 139

Table 7-6: Sub-bituminous Underflow Tailings Particle Size Distribution................................. 141

Table 7-7: Coal Sample Proximate Analysis Moisture Content Results (* samples not ignitable at

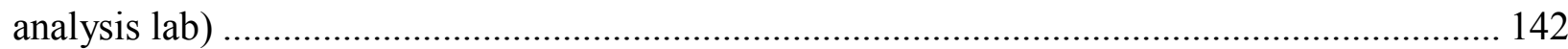

Table 7-8: WADFP Thermal and Exergy Efficiencies for Coal Drying Runs ........................... 142 


\section{List of Figures}

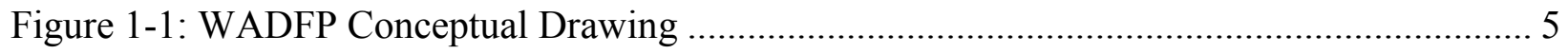

Figure 1-2: Effect of Secondary Air Injection on Specific Humidity .......................................... 7

Figure 1-3: Geldart's classification of fluidized particles [24] ............................................... 10

Figure 1-4: Dense fluidization regimes (a) Particulate; (b) Bubbling; (c) Turbulent; (d) Slugging;

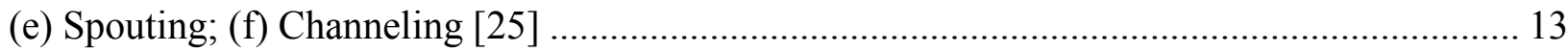

Figure 1-5: Variations of pressure drop per unit riser length with solids circulation rate and gas

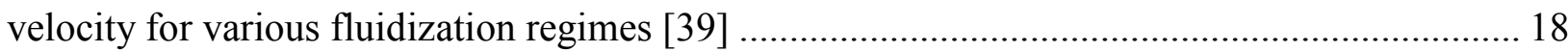

Figure 1-6: Variation of pressure fluctuations with velocity for dense-phase fluidization [40]... 19

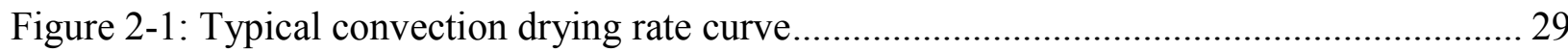

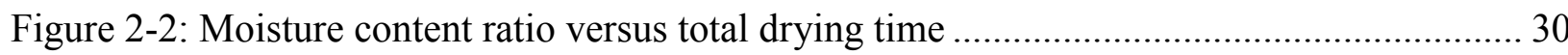

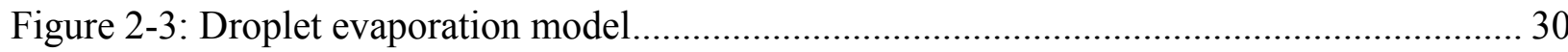

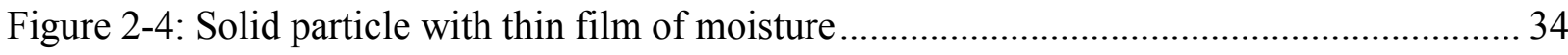

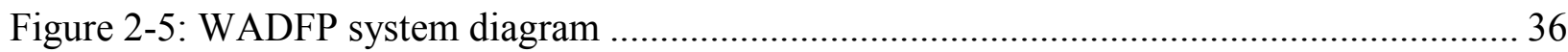

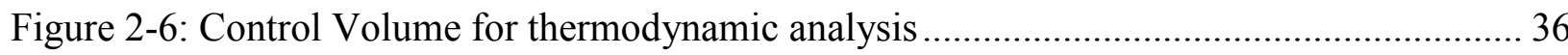

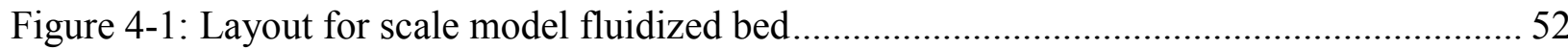

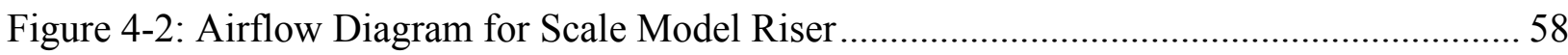

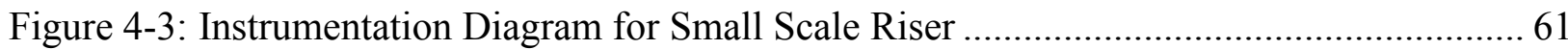

Figure 5-1 : Standard Deviation vs Superficial Velocity for Lower Riser Stage Pressures: (a) Lbottom (b) Lmid (c) Ltop; poly-dispersed sand, 3.5 psig feed hopper pressure, no secondary air

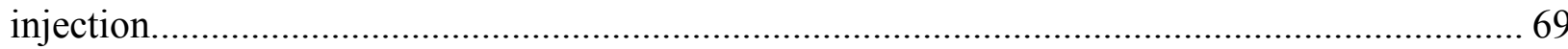

Figure 5-2: Skew vs Superficial Velocity for Lower Riser Stage Pressures: (a) Lbottom (b) Lmid (c) Ltop; poly-dispersed sand, 3.5 psig feed hopper pressure, no secondary air injection. ........... 70 Figure 5-3: Kurtosis vs Superficial Velocity for Lower Riser Stage Pressures: (a) Lbottom (b) Lmid (c) Ltop; poly-dispersed sand, 3.5 psig feed hopper pressure, no secondary air injection. 71 Figure 5-4: Shannon Entropy vs Superficial Velocity for Lower Riser Stage Pressures: (a) Lbottom (b) Lmid (c) Ltop; poly-dispersed sand, 3.5 psig feed hopper pressure, no secondary air

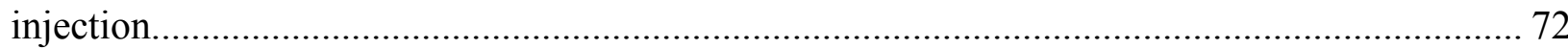

Figure 5-5: Autocorrelation of scale model Lbottom Pressure: poly-dispersed sand, 3.5 psig feed hopper pressure, no secondary air injection, $\mathrm{U}_{\mathrm{L}}=$ : (a) 0.57 (b) 0.76 (c) 1.14 (d) 1.52 (e) 1.90 (f) 2.29 (g) 2.67 (h) 3.05 (i) $3.43 \mathrm{~m} / \mathrm{s}$.

Figure 5-6: Autocorrelation of scale model Lmid Pressure: poly-dispersed sand, 3.5 psig feed hopper pressure, no secondary air injection, $\mathrm{U}_{\mathrm{L}}=$ : (a) 0.57 (b) 0.76 (c) 1.14 (d) 1.52 (e) 1.90 (f) 2.29 (g) 2.67 (h) 3.05 (i) $3.43 \mathrm{~m} / \mathrm{s}$. 75

Figure 5-7: Autocorrelation of scale model Ltop Pressure: poly-dispersed sand, 3.5 psig feed hopper pressure, no secondary air injection, $\mathrm{U}_{\mathrm{L}}=$ : (a) 0.57 (b) 0.76 (c) 1.14 (d) 1.52 (e) 1.90 (f) 2.29 (g) 2.67 (h) 3.05 (i) $3.43 \mathrm{~m} / \mathrm{s}$. 76

Figure 5-8: Mutual Information of scale model Lbottom Pressure: poly-dispersed sand, $3.5 \mathrm{psig}$ feed hopper pressure, no secondary air injection, $U_{L}=$ : (a) 0.57 (b) 0.76 (c) 1.14 (d) 1.52 (e) 1.90 (f) 2.29 (g) 2.67 (h) 3.05 (i) $3.43 \mathrm{~m} / \mathrm{s}$. 
Figure 5-9: Mutual Information of scale model Lmid Pressure: poly-dispersed sand, 3.5 psig feed hopper pressure, no secondary air injection, $\mathrm{U}_{\mathrm{L}}=:$ : (a) 0.57 (b) 0.76 (c) 1.14 (d) 1.52 (e) 1.90 (f) 2.29 (g) 2.67 (h) 3.05 (i) $3.43 \mathrm{~m} / \mathrm{s}$. 77

Figure 5-10: Mutual Information of scale model Ltop Pressure: poly-dispersed sand, 3.5 psig feed hopper pressure, no secondary air injection, $U_{L}=$ : (a) 0.57 (b) 0.76 (c) 1.14 (d) 1.52 (e) 1.90 (f) 2.29 (g) 2.67 (h) 3.05 (i) $3.43 \mathrm{~m} / \mathrm{s}$. 77

Figure 5-11: Power Spectral Density Plot of scale model Lbottom Pressure: poly-dispersed sand, 3.5 psig feed hopper pressure, no secondary air injection, $\mathrm{U}_{\mathrm{L}}=$ : (a) 0.57 (b) 0.76 (c) 1.14 (d) 1.52 (e) 1.90 (f) 2.29 (g) 2.67 (h) 3.05 (i) $3.43 \mathrm{~m} / \mathrm{s}$. 78

Figure 5-12: Power Spectral Density Plot of scale model Lmid Pressure: poly-dispersed sand, 3.5 psig feed hopper pressure, no secondary air injection, $\mathrm{U}_{\mathrm{L}}=:$ : (a) 0.57 (b) 0.76 (c) 1.14 (d) 1.52 (e) 1.90 (f) 2.29 (g) 2.67 (h) 3.05 (i) $3.43 \mathrm{~m} / \mathrm{s}$. 78 Figure 5-13: Power Spectral Density Plot of scale model Ltop Pressure: poly-dispersed sand, 3.5 psig feed hopper pressure, no secondary air injection, $\mathrm{U}_{\mathrm{L}}=$ : (a) 0.57 (b) 0.76 (c) 1.14 (d) 1.52 (e) 1.90 (f) 2.29 (g) 2.67 (h) 3.05 (i) $3.43 \mathrm{~m} / \mathrm{s}$. 79

Figure 5-14: Standard Deviation of model upper riser stage pressures (a) Ubottom (b) Utop: poly-dispersed sand, feed hopper pressure $3.5 \mathrm{psig}, \mathrm{U}_{\mathrm{L}}=2.36 \mathrm{~m} / \mathrm{s}$. 80

Figure 5-15: Skew of model upper riser stage pressures (a) Ubottom (b) Utop: poly-dispersed sand, feed hopper pressure $3.5 \mathrm{psig}, \mathrm{U}_{\mathrm{L}}=2.36 \mathrm{~m} / \mathrm{s}$.

Figure 5-16: Kurtosis of model upper riser stage pressures (a) Ubottom (b) Utop: poly-dispersed sand, feed hopper pressure $3.5 \mathrm{psig}, \mathrm{U}_{\mathrm{L}}=2.36 \mathrm{~m} / \mathrm{s}$. 81

Figure 5-17: Shannon Entropy of model upper riser stage pressures (a) Ubottom (b) Utop: polydispersed sand, feed hopper pressure $3.5 \mathrm{psig}, \mathrm{U}_{\mathrm{L}}=2.36 \mathrm{~m} / \mathrm{s}$...... 82 Figure 5-18: Autocorrelation of model Ubottom pressure: poly-dispersed sand, $3.5 \mathrm{psig}$ feed hopper pressure, $\mathrm{U}_{\mathrm{L}}=2.36 \mathrm{~m} / \mathrm{s}, \mathrm{U}_{\mathrm{U}}=$ : (a) 1.42 (b) 1.74 (c) 2.06 (d) 2.38 (e) 2.70 (f) 3.02 (g) $3.35 \mathrm{~m} / \mathrm{s}$.

Figure 5-19: Autocorrelation of model Utop pressure: poly-dispersed sand, $3.5 \mathrm{psig}$ feed hopper pressure, $\mathrm{U}_{\mathrm{L}}=2.36 \mathrm{~m} / \mathrm{s}, \mathrm{U}_{\mathrm{U}}=$ : (a) 1.42 (b) 1.74 (c) 2.06 (d) 2.38 (e) 2.70 (f) 3.02 (g) $3.35 \mathrm{~m} / \mathrm{s}$.

Figure 5-20: Mutual Information Function of model Ubottom pressure: poly-dispersed sand, 3.5 psig feed hopper pressure, $\mathrm{U}_{\mathrm{L}}=2.36 \mathrm{~m} / \mathrm{s}, \mathrm{U}_{\mathrm{U}}=$ : (a) 1.42 (b) 1.74 (c) 2.06 (d) 2.38 (e) 2.70 (f) $3.02(\mathrm{~g}) 3.35 \mathrm{~m} / \mathrm{s}$. 84

Figure 5-21: Mutual Information Function of model Utop pressure: poly-dispersed sand, $3.5 \mathrm{psig}$ feed hopper pressure, $U_{\mathrm{L}}=2.36 \mathrm{~m} / \mathrm{s}, \mathrm{U}_{\mathrm{U}}=$ : (a) 1.42 (b) 1.74 (c) 2.06 (d) 2.38 (e) 2.70 (f) 3.02 (g) $3.35 \mathrm{~m} / \mathrm{s}$.

Figure 5-22: Spectral Density Plot for model Ubottom pressure: poly-dispersed sand, 3.5 psig feed hopper pressure, $U_{\mathrm{L}}=2.36 \mathrm{~m} / \mathrm{s}, \mathrm{U}_{\mathrm{U}}=$ : (a) 1.42 (b) 1.74 (c) 2.06 (d) 2.38 (e) 2.70 (f) 3.02 (g) $3.35 \mathrm{~m} / \mathrm{s}$. 85 
Figure 5-23: Spectral Density Plot for model Utop pressure: poly-dispersed sand, 3.5 psig feed hopper pressure, $\mathrm{U}_{\mathrm{L}}=2.36 \mathrm{~m} / \mathrm{s}, \mathrm{U}_{\mathrm{U}}=$ : (a) 1.42 (b) 1.74 (c) 2.06 (d) 2.38 (e) 2.70 (f) 3.02 (g)

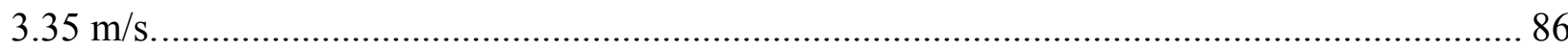
Figure 5-24: Effect of varying secondary air injection on lower riser stage average pressures (a) Lbottom (b) Lmid $\quad$ (c) Ltop: poly-dispersed sand, 3.5 psig feed hopper pressure, $U_{L}=2.36$ $\mathrm{m} / \mathrm{s}$.

Figure 5-25: Effect of secondary air injection on lower riser voidage profile: poly-dispersed sand, $3.5 \mathrm{psig}$ feed hopper pressure, $\mathrm{U}_{\mathrm{L}}=2.36 \mathrm{~m} / \mathrm{s}$. . . . 88

Figure 5-26: Effects of varying secondary air injection on model lower riser stage standard deviation of pressures (a) Lbottom (b) Lmid (c) Ltop: poly-dispersed sand, 3.5 psig feed hopper pressure, $\mathrm{U}_{\mathrm{L}}=2.36 \mathrm{~m} / \mathrm{s}$. 89

Figure 5-27: Effects of varying secondary air injection on model lower riser stage skew of pressures (a) Lbottom (b) Lmid (c) Ltop: poly-dispersed sand, 3.5 psig feed hopper pressure, $\mathrm{U}_{\mathrm{L}}$ $=2.36 \mathrm{~m} / \mathrm{s}$. 90

Figure 5-28: Effects of varying secondary air injection on model lower riser stage kurtosis of pressures (a) Lbottom (b) Lmid (c) Ltop: poly-dispersed sand, 3.5 psig feed hopper pressure, $\mathrm{U}_{\mathrm{L}}$ $=2.36 \mathrm{~m} / \mathrm{s}$. 90

Figure 5-29: Effects of varying secondary air injection on model lower riser stage Shannon entropy of pressures (a) Lbottom (b) Lmid (c) Ltop: poly-dispersed sand, 3.5 psig feed hopper pressure, $\mathrm{U}_{\mathrm{L}}=2.36 \mathrm{~m} / \mathrm{s}$.

Figure 5-30: Autocorrelation plots for model Lbottom Pressure with Secondary Air Injection, poly-dispersed sand, 3.5 psig feed hopper pressure, $\mathrm{U}_{\mathrm{L}}=2.36 \mathrm{~m} / \mathrm{s}, \mathrm{U}_{\mathrm{U}}=$ : (a) 1.42 (b) 1.74 (c) 2.06 (d) 2.38 (e) 2.70 (f) 3.02 (g) $3.35 \mathrm{~m} / \mathrm{s}$.

Figure 5-31: Autocorrelation plots for model Lmid Pressure with Secondary Air Injection, polydispersed sand, 3.5 psig feed hopper pressure, $U_{L}=2.36 \mathrm{~m} / \mathrm{s}, U_{U}=:$ (a) 1.42 (b) 1.74 (c) 2.06 (d) 2.38 (e) 2.70 (f) 3.02 (g) $3.35 \mathrm{~m} / \mathrm{s}$.

Figure 5-32: Autocorrelation plots for model Ltop Pressure with Secondary Air Injection, polydispersed sand, 3.5 psig feed hopper pressure, $U_{\mathrm{L}}=2.36 \mathrm{~m} / \mathrm{s}, \mathrm{U}_{\mathrm{U}}=:$ (a) 1.42 (b) 1.74 (c) 2.06 (d) 2.38 (e) 2.70 (f) 3.02 (g) $3.35 \mathrm{~m} / \mathrm{s}$. 94

Figure 5-33: Mutual Information plots for model Lbottom pressure with secondary air injection, poly-dispersed sand, 3.5 psig feed hopper pressure, $\mathrm{U}_{\mathrm{L}}=2.36 \mathrm{~m} / \mathrm{s}, \mathrm{U}_{\mathrm{U}}=$ : (a) 1.42 (b) 1.74 (c) 2.06 (d) 2.38 (e) 2.70 (f) 3.02 (g) $3.35 \mathrm{~m} / \mathrm{s}$.

Figure 5-34: Mutual Information plots for model Lmid pressure with secondary air injection, poly-dispersed sand, 3.5 psig feed hopper pressure, $U_{L}=2.36 \mathrm{~m} / \mathrm{s}, \mathrm{U}_{\mathrm{U}}=$ : (a) 1.42 (b) 1.74 (c) 2.06 (d) 2.38 (e) 2.70 (f) 3.02 (g) $3.35 \mathrm{~m} / \mathrm{s}$.

Figure 5-35: Mutual Information plots for model Ltop pressure with secondary air injection, poly-dispersed sand, 3.5 psig feed hopper pressure, $\mathrm{U}_{\mathrm{L}}=2.36 \mathrm{~m} / \mathrm{s}, \mathrm{U}_{\mathrm{U}}=$ : (a) 1.42 (b) 1.74 (c) 2.06 (d) 2.38 (e) 2.70 (f) 3.02 (g) $3.35 \mathrm{~m} / \mathrm{s}$. 95 
Figure 5-36: Spectral Density plots for model Lbottom pressure with secondary air injection, poly-dispersed sand, $3.5 \mathrm{psig}$ feed hopper pressure, $\mathrm{U}_{\mathrm{L}}=2.36 \mathrm{~m} / \mathrm{s}, \mathrm{U}_{\mathrm{U}}=$ : (a) 1.42 (b) 1.74 (c) 2.06 (d) 2.38 (e) 2.70 (f) 3.02 (g) $3.35 \mathrm{~m} / \mathrm{s}$. 96 Figure 5-37: Spectral Density plots for model Lmid pressure with secondary air injection, polydispersed sand, $3.5 \mathrm{psig}$ feed hopper pressure, $\mathrm{U}_{\mathrm{L}}=2.36 \mathrm{~m} / \mathrm{s}, \mathrm{U}_{\mathrm{U}}=$ : (a) 1.42 (b) 1.74 (c) 2.06 (d) 2.38 (e) 2.70 (f) 3.02 (g) $3.35 \mathrm{~m} / \mathrm{s}$. 96

Figure 5-38: Spectral Density plots for model Ltop pressure with secondary air injection, polydispersed sand, $3.5 \mathrm{psig}$ feed hopper pressure, $\mathrm{U}_{\mathrm{L}}=2.36 \mathrm{~m} / \mathrm{s}, \mathrm{U}_{\mathrm{U}}=$ : (a) 1.42 (b) 1.74 (c) 2.06 (d) 2.38 (e) 2.70 (f) 3.02 (g) $3.35 \mathrm{~m} / \mathrm{s}$.

Figure 5-39: Relationship between Lbottom standard deviation of pressure and lower riser stage pressure drop for (a) no secondary air injection (b) secondary air injection. 97

Figure 5-40: Relationship between Ubottom standard deviation of pressure and upper riser stage pressure drop for (a) no secondary air injection (b) secondary air injection. 98

Figure 5-41: Still images for lower riser stage mapping (a) slugging (b) turbulent (c) fast fluidization 99

Figure 5-42: Still pictures of upper riser stage mapping (a) turbulent (b) fast fluidization........ 100 Figure 6-1: Layout WADFP fluidized bed ........................................................................... 103

Figure 6-2: Airflow Diagram for WADFP Fluidized Bed .................................................... 105

Figure 6-3: WADFP Steam System Diagram ...................................................................... 106

Figure 6-4: Instrumentation Diagram for WADFP Fluidized Bed ...................................... 107

Figure 7-1: Standard deviation of WADFP lower riser stage pressures (a) Lbottom (b) Lmid (c)

Ltop: poly-dispersed sand, feed rate $120 \mathrm{lb} / \mathrm{hr}$, no secondary air injection............................ 112

Figure 7-2: Shannon entropy of WADFP lower riser stage pressures (a) Lbottom (b) Lmid (c) Ltop: poly-dispersed sand, feed rate $120 \mathrm{lb} / \mathrm{hr}$, no secondary air injection. ........................... 113 Figure 7-3: Autocorrelation of WADFP Lbottom pressure, poly-dispersed sand, feed rate 120 $\mathrm{lb} / \mathrm{hr}$, no secondary air injection, $\mathrm{U}_{\mathrm{L}}=$ : (a) 1.43 (b) 1.65 (c) 1.93 (d) 2.22 (e) 2.79 (f) 3.50 (g) $4.10 \mathrm{~m} / \mathrm{s}$ 114 Figure 7-4: Autocorrelation of WADFP Lmid pressure, poly-dispersed sand, feed rate $120 \mathrm{lb} / \mathrm{hr}$, no secondary air injection, $\mathrm{U}_{\mathrm{L}}=$ : (a) 1.43 (b) 1.65 (c) 1.93 (d) 2.22 (e) 2.79 (f) 3.50 (g) $4.10 \mathrm{~m} / \mathrm{s}$.

Figure 7-5: Autocorrelation of WADFP Ltop pressure, poly-dispersed sand, feed rate $120 \mathrm{lb} / \mathrm{hr}$, no secondary air injection, $\mathrm{U}_{\mathrm{L}}=$ : (a) 1.43 (b) 1.65 (c) 1.93 (d) 2.22 (e) 2.79 (f) 3.50 (g) $4.10 \mathrm{~m} / \mathrm{s}$.

Figure 7-6: Mutual Information of WADFP Lbottom Pressure, poly-dispersed sand, feed rate 120 $\mathrm{lb} / \mathrm{hr}$, no secondary air injection, $\mathrm{U}_{\mathrm{L}}=$ : (a) 1.43 (b) 1.65 (c) 1.93 (d) 2.22 (e) 2.79 (f) 3.50 (g)

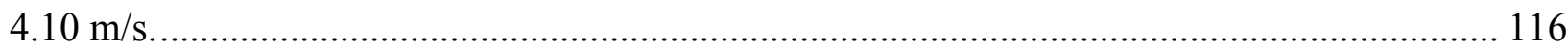
Figure 7-7: Mutual Information of WADFP Lmid Pressure, poly-dispersed sand, feed rate 120 lb/hr, no secondary air injection, $\mathrm{U}_{\mathrm{L}}=$ : (a) 1.43 (b) 1.65 (c) 1.93 (d) 2.22 (e) 2.79 (f) 3.50 (g) $4.10 \mathrm{~m} / \mathrm{s}$. 
Figure 7-8: Mutual Information of WADFP Ltop Pressure, poly-dispersed sand, feed rate 120 $\mathrm{lb} / \mathrm{hr}$, no secondary air injection, $\mathrm{U}_{\mathrm{L}}=$ : (a) 1.43 (b) 1.65 (c) 1.93 (d) 2.22 (e) 2.79 (f) 3.50 (g) $4.10 \mathrm{~m} / \mathrm{s}$

Figure 7-9: Spectral Density Plots of WADFP Lbottom Pressure, poly-dispersed sand, feed rate $120 \mathrm{lb} / \mathrm{hr}$, no secondary air injection, $\mathrm{U}_{\mathrm{L}}=$ : (a) 1.43 (b) 1.65 (c) 1.93 (d) 2.22 (e) 2.79 (f) 3.50 (g) $4.10 \mathrm{~m} / \mathrm{s}$.

Figure 7-10: Spectral Density Plots of WADFP Lmid Pressure, poly-dispersed sand, feed rate $120 \mathrm{lb} / \mathrm{hr}$, no secondary air injection, $\mathrm{U}_{\mathrm{L}}=$ : (a) 1.43 (b) 1.65 (c) 1.93 (d) 2.22 (e) 2.79 (f) 3.50 (g) $4.10 \mathrm{~m} / \mathrm{s}$.

Figure 7-11: Spectral Density Plots of WADFP Ltop Pressure, poly-dispersed sand, feed rate 120 $\mathrm{lb} / \mathrm{hr}$, no secondary air injection, $\mathrm{U}_{\mathrm{L}}=$ : (a) 1.43 (b) 1.65 (c) 1.93 (d) 2.22 (e) 2.79 (f) 3.50 (g)

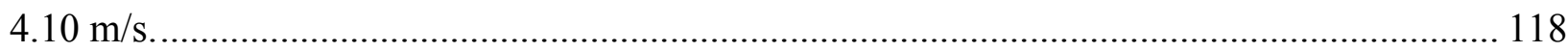
Figure 7-12: Standard deviation of WADFP upper riser stage pressures (a) Ubottom (b) Utop:

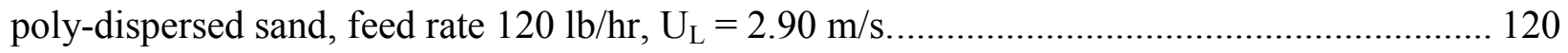
Figure 7-13: Shannon entropy of WADFP upper riser stage pressures (a) Ubottom (b) Utop:

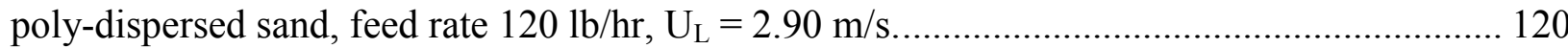
Figure 7-14: Autocorrelation of WADFP Ubottom pressure, poly-dispersed sand, feed rate 120 $\mathrm{lb} / \mathrm{hr}, \mathrm{U}_{\mathrm{L}}=2.90 \mathrm{~m} / \mathrm{s}, \mathrm{U}_{\mathrm{U}}=$ : (a) 1.81 (b) 2.04 (c) 2.27 (d) 2.49 (e) 2.72 (f) 2.95 (g) 3.17 (h) 3.40 $\mathrm{m} / \mathrm{s}$.

Figure 7-15: Autocorrelation of WADFP Ubottom pressure, poly-dispersed sand, feed rate 120 $\mathrm{lb} / \mathrm{hr}, \mathrm{U}_{\mathrm{L}}=2.90 \mathrm{~m} / \mathrm{s}, \mathrm{U}_{\mathrm{U}}=$ : (a) 1.81 (b) 2.04 (c) 2.27 (d) 2.49 (e) 2.72 (f) 2.95 (g) 3.17 (h) 3.40 $\mathrm{m} / \mathrm{s}$.

Figure 7-16: Mutual Information of WADFP Ubottom pressure, poly-dispersed sand, feed rate $120 \mathrm{lb} / \mathrm{hr}, \mathrm{U}_{\mathrm{L}}=2.90 \mathrm{~m} / \mathrm{s}, \mathrm{U}_{\mathrm{U}}=$ : (a) 1.81 (b) 2.04 (c) 2.27 (d) 2.49 (e) 2.72 (f) 2.95 (g) 3.17 (h) $3.40 \mathrm{~m} / \mathrm{s}$. 122

Figure 7-17: Mutual Information of WADFP Utop pressure, poly-dispersed sand, feed rate 120 $\mathrm{lb} / \mathrm{hr}, \mathrm{U}_{\mathrm{L}}=2.90 \mathrm{~m} / \mathrm{s}, \mathrm{U}_{\mathrm{U}}=$ : (a) 1.81 (b) 2.04 (c) 2.27 (d) 2.49 (e) 2.72 (f) 2.95 (g) 3.17 (h) 3.40 $\mathrm{m} / \mathrm{s}$.

Figure 7-18: Power Spectral Density of WADFP Ubottom pressure, poly-dispersed sand, feed rate $120 \mathrm{lb} / \mathrm{hr}, \mathrm{U}_{\mathrm{L}}=2.90 \mathrm{~m} / \mathrm{s}, \mathrm{U}_{\mathrm{U}}=$ : (a) 1.81 (b) 2.04 (c) 2.27 (d) 2.49 (e) 2.72 (f) 2.95 (g) 3.17 (h) $3.40 \mathrm{~m} / \mathrm{s}$.

Figure 7-19: Power Spectral Density of WADFP Ubottom pressure, poly-dispersed sand, feed rate $120 \mathrm{lb} / \mathrm{hr}, \mathrm{U}_{\mathrm{L}}=2.90 \mathrm{~m} / \mathrm{s}, \mathrm{U}_{\mathrm{U}}=$ : (a) 1.81 (b) 2.04 (c) 2.27 (d) 2.49 (e) 2.72 (f) 2.95 (g) 3.17

(h) $3.40 \mathrm{~m} / \mathrm{s}$. . .

Figure 7-20: Effects of varying secondary air injection on WADFP lower riser stage average pressures (a) Lbottom $\quad$ (b) Lmid (c) Ltop: poly-dispersed sand, feed rate $120 \mathrm{lb} / \mathrm{hr}, \mathrm{U}_{\mathrm{L}}=2.90$ $\mathrm{m} / \mathrm{s}$. 124

Figure 7-21: Effects of varying secondary air injection on WADFP lower riser stage average voidage: poly-dispersed sand, feed rate $120 \mathrm{lb} / \mathrm{hr}, \mathrm{U}_{\mathrm{L}}=2.90 \mathrm{~m} / \mathrm{s}$. 125 
Figure 7-22: Effects of varying secondary air injection on WADFP lower riser stage standard deviation of pressures (a) Lbottom (b) Lmid (c) Ltop: poly-dispersed sand, feed rate 120 $\mathrm{lb} / \mathrm{hr}, \mathrm{U}_{\mathrm{L}}=2.90 \mathrm{~m} / \mathrm{s}$.

Figure 7-23: Effects of varying secondary air injection on WADFP lower riser stage Shannon entropy of pressures $\quad$ (a) Lbottom (b) Lmid (c) Ltop: poly-dispersed sand, feed rate 120 $\mathrm{lb} / \mathrm{hr}, \mathrm{U}_{\mathrm{L}}=2.90 \mathrm{~m} / \mathrm{s}$.

Figure 7-24: Autocorrelation of WADFP Lbottom pressure, poly-dispersed sand, feed rate 120 $\mathrm{lb} / \mathrm{hr}, \mathrm{U}_{\mathrm{L}}=2.90 \mathrm{~m} / \mathrm{s}, \mathrm{U}_{\mathrm{U}}=$ : (a) 1.81 (b) 2.04 (c) 2.27 (d) 2.49 (e) 2.72 (f) 2.95 (g) 3.17 (h) 3.40 .

Figure 7-25: Autocorrelation of WADFP Lmid pressure, poly-dispersed sand, feed rate $120 \mathrm{lb} / \mathrm{hr}$, $\mathrm{U}_{\mathrm{L}}=2.90 \mathrm{~m} / \mathrm{s}, \mathrm{U}_{\mathrm{U}}=$ : (a) 1.81 (b) 2.04 (c) 2.27 (d) 2.49 (e) 2.72 (f) 2.95 (g) 3.17 (h) $3.40 \ldots . .128$ Figure 7-26: Autocorrelation of WADFP Ltop pressure, poly-dispersed sand, feed rate $120 \mathrm{lb} / \mathrm{hr}$, $\mathrm{U}_{\mathrm{L}}=2.90 \mathrm{~m} / \mathrm{s}, \quad \mathrm{U}_{\mathrm{U}}=:$ (a) 1.81 (b) 2.04 (c) 2.27 (d) 2.49 (e) 2.72 (f) 2.95 (g) 3.17 (h) 3.40 128

Figure 7-27: Mutual Information of WADFP Lbottom pressure, poly-dispersed sand, feed rate $120 \mathrm{lb} / \mathrm{hr}, \mathrm{U}_{\mathrm{L}}=2.90 \mathrm{~m} / \mathrm{s}, \mathrm{U}_{\mathrm{U}}=$ : (a) 1.81 (b) 2.04 (c) 2.27 (d) 2.49 (e) 2.72 (f) 2.95 (g) 3.17 (h) 3.40

Figure 7-28: Mutual Information of WADFP Lmid pressure, poly-dispersed sand, feed rate 120 $\mathrm{lb} / \mathrm{hr}, \mathrm{U}_{\mathrm{L}}=2.90 \mathrm{~m} / \mathrm{s}, \quad \mathrm{U}_{\mathrm{U}}=$ : (a) 1.81 (b) 2.04 (c) 2.27 (d) 2.49 (e) 2.72 (f) 2.95 (g) 3.17 (h) 3.40 .

Figure 7-29: Mutual Information of WADFP Ltop pressure, poly-dispersed sand, feed rate 120 $\mathrm{lb} / \mathrm{hr}, \mathrm{U}_{\mathrm{L}}=2.90 \mathrm{~m} / \mathrm{s}, \quad \mathrm{U}_{\mathrm{U}}=$ : (a) 1.81 (b) 2.04 (c) 2.27 (d) 2.49 (e) 2.72 (f) 2.95 (g) 3.17 (h) 3.40 130

Figure 7-30: Spectral Density Plots of WADFP Lbottom pressure, poly-dispersed sand, feed rate $120 \mathrm{lb} / \mathrm{hr}, \mathrm{U}_{\mathrm{L}}=2.90 \mathrm{~m} / \mathrm{s}, \quad \mathrm{U}_{\mathrm{U}}=$ (a) 1.81 (b) 2.04 (c) 2.27 (d) 2.49 (e) 2.72 (f) 2.95 (g) 3.17 (h) 3.40 .

Figure 7-31: Spectral Density Plots of WADFP Lmid pressure, poly-dispersed sand, feed rate $120 \mathrm{lb} / \mathrm{hr}, \mathrm{U}_{\mathrm{L}}=2.90 \mathrm{~m} / \mathrm{s}, \quad \mathrm{U}_{\mathrm{U}}=$ (a) 1.81 (b) 2.04 (c) 2.27 (d) 2.49 (e) 2.72 (f) 2.95 (g) 3.17 (h) 3.40 .

Figure 7-32: 7-33: Spectral Density Plots of WADFP Ltop pressure, poly-dispersed sand, feed rate $120 \mathrm{lb} / \mathrm{hr}, \mathrm{U}_{\mathrm{L}}=2.90 \mathrm{~m} / \mathrm{s}, \quad \mathrm{U}_{\mathrm{U}}=$ (a) 1.81 (b) 2.04 (c) 2.27 (d) 2.49 (e) 2.72 (f) 2.95 (g) 3.17 (h) 3.40 . 131

Figure 7-34: Scaling comparisons of WADFP and scale model standard deviation of pressure as a function of $\mathrm{U}_{\mathrm{mf}}$-normalized mass flux rate, lower riser mapping: (a) Lbottom (b) Lmid (c) Ltop.

Figure 7-35: Scaling comparisons of WADFP and scale model Shannon entropy of pressure as a function of $\mathrm{U}_{\mathrm{mf}}$-normalized mass flux rate, lower riser mapping: (a) Lbottom (b) Lmid (c) Ltop. 
Figure 7-36: Scaling comparisons of WADFP and scale model standard deviation of pressure as a function of $U_{m f}$-normalized mass flux rate, upper riser mapping: (a) Lbottom (b) Lmid (c) Ltop (d) Ubottom (e) Utop.

Figure 7-37: Scaling comparisons of WADFP and scale model Shannon entropy of pressure as a function of $U_{m f}$-normalized mass flux rate, upper riser mapping: (a) Lbottom (b) Lmid (c) Ltop (d) Ubottom (e) Utop. 138

Figure 7-38: Results of applying scaling method to coal, Lbottom pressure location, cleaned coal, feed rate $55 \mathrm{lb} / \mathrm{hr} ; \quad \mathrm{U}_{\mathrm{L}}=2.0 \mathrm{~m} / \mathrm{s}, \mathrm{U}_{\mathrm{U}}=1.65 \mathrm{~m} / \mathrm{s}$ (a) autocorrelation (b) spectral density; $\mathrm{U}_{\mathrm{L}}=$ $3.13 \mathrm{~m} / \mathrm{s}, \mathrm{U}_{\mathrm{U}}=2.56 \mathrm{~m} / \mathrm{s}$ (c) autocorrelation (d) spectral density..... 140 


\section{List of Symbols}

Symbol Definition Units

Equations Used In (for alternate definitions)

Letters:

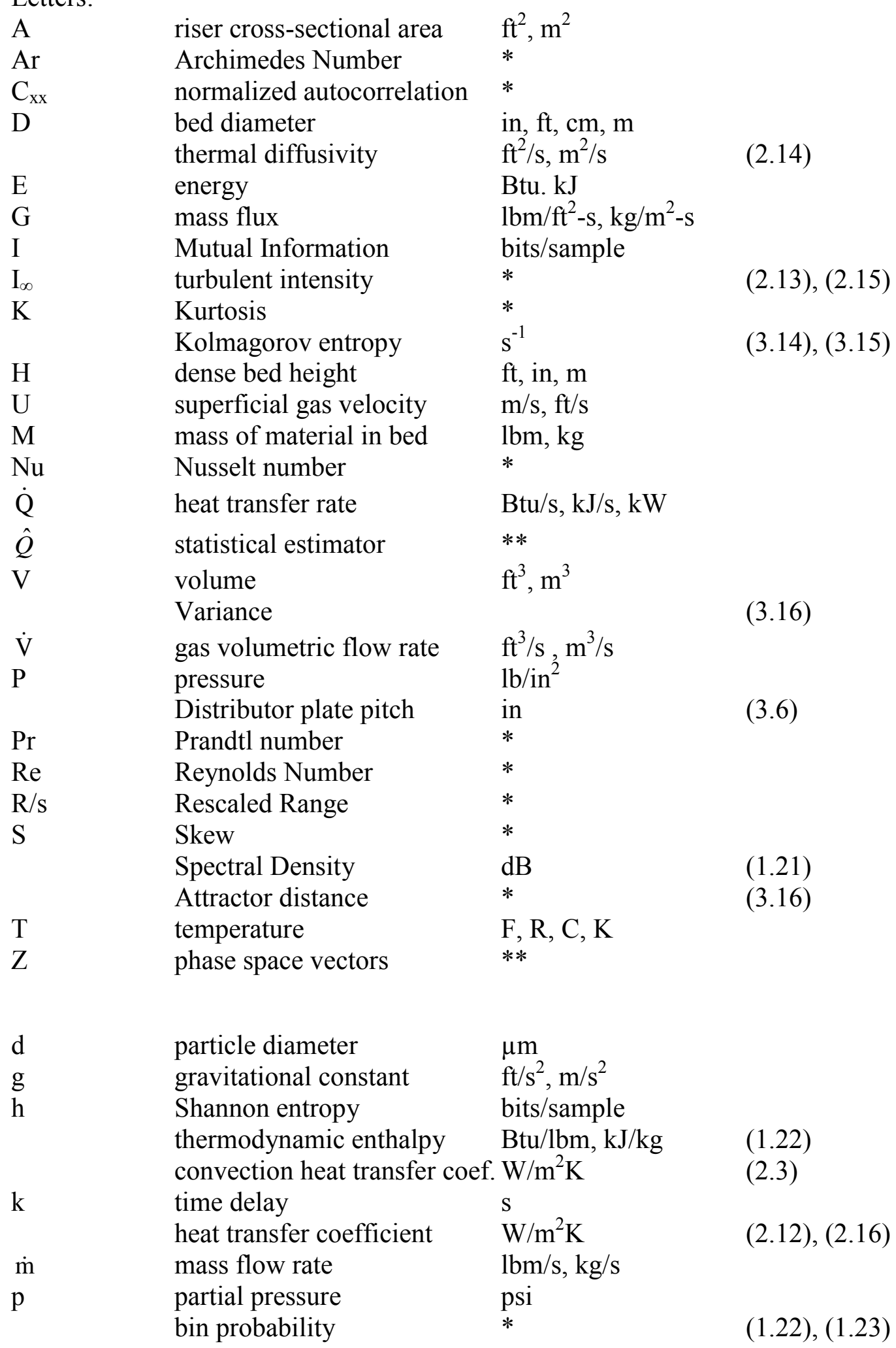




$\begin{array}{lll}\mathrm{u} & \text { internal energy } & \mathrm{kJ} \\ \mathrm{u}_{\mathrm{o}} & \text { superficial gas velocity } & \mathrm{m} / \mathrm{s} \\ \mathrm{u}_{\mathrm{mf}} & \text { min. fluidization velocity } & \mathrm{m} / \mathrm{s} \\ \mathrm{s} & \text { thermodynamic entropy } & \mathrm{Btu} / \mathrm{lbm}-\mathrm{R}, \mathrm{kJ} / \mathrm{kg}-\mathrm{K} \\ \mathrm{t} & \text { time } & \mathrm{s} \\ \mathrm{z} & \text { height } & \text { in } \\ \mathrm{c}_{\mathrm{xx}} & \text { autocorrelation } & * *\end{array}$

Greek:

$\begin{array}{lll}\rho & \text { density } & \mathrm{lbm} / \mathrm{ft}^{3}, \mathrm{~kg} / \mathrm{m}^{3} \\ \varepsilon & \text { bed voidage } & * \\ \mu & \text { gas viscosity } & \mathrm{lbm}-\mathrm{s} / \mathrm{ft}^{2}, \mathrm{~N}-\mathrm{s} / \mathrm{m}^{2} \\ \sigma & \text { standard deviation } & * * \\ \tau & \text { time delay } & \mathrm{s} \\ \xi & \text { moisture content } & * \\ \varpi & \text { specific humidity } & * \\ \eta & \text { efficiency } & * \\ \phi & \text { particle sphericity } & * \\ \Pi_{1} & \text { mass flux scaling term } & \mathrm{lbm} / \mathrm{ft}^{2}-\mathrm{s}, \mathrm{kg} / \mathrm{m}^{2}-\mathrm{s} \\ \Pi_{2} & \text { mass flow rate scaling term } & *\end{array}$

Subscripts:

c

d

f

ex

$\mathrm{mb}$

$\mathrm{mf}$

$\mathrm{p}$

$\mathrm{s}$

th

tr

0

* dimensionless

** $\quad$ same units as original time series turbulent transition

droplet

fluid

exergy

minimum bubbling

minimum fluidization

particle

solid

thermal

fast fluidization transition

reference state (standard temp, pressure) 


\section{List of Video Files}

Filename:

LRMT1.wmv

LRMT2.wmV

LRMT3.wmv

LRMT4.wmv

LRMT5.wmv

LRMT6.wmv

LRMT7.wmv

LRMT8.wmv

LRMT9.wmv

URMT1.wmv

URMT2.wmv

URMT3.wmv

URMT4.wmv

URMT5.wmv

URMT6.wmv

URMT7.wmv
Description

Lower Riser Mapping Test 1

Lower Riser Mapping Test 2

Lower Riser Mapping Test 3

Lower Riser Mapping Test 4

Lower Riser Mapping Test 5

Lower Riser Mapping Test 6

Lower Riser Mapping Test 7

Lower Riser Mapping Test 8

Lower Riser Mapping Test 9

Upper Riser Mapping Test 1

Upper Riser Mapping Test 2

Upper Riser Mapping Test 3

Upper Riser Mapping Test 4

Upper Riser Mapping Test 5

Upper Riser Mapping Test 6

Upper Riser Mapping Test 7 


\section{Chapter 1 Introduction and Background}

\section{Introduction}

\section{Statement of Objective:}

The objective of this research effort was explore the fluidization characteristics of a novel twostage, variable area fluidized bed riser by constructing a cold-flow, transparent scale model of an existing two-stage, continuous feed, fluidized bed for drying fine coal particles, as well as the development of a simplified set of relationships for scaling the fluidization regime transition points between the two systems. A secondary object was to carry out preliminary experiments with drying coal in the large scale riser to test the feasibility of using a fluidized bed for the drying of coal.

\section{Need for Solution}

Approximately $6-8 \%$ of the energy found in mined coal is located in particle size fractions of less than 150 micron $(\mu \mathrm{m})$, or 100 -mesh [1]. Due to the inherent difficulties in dewatering material within this size range, most coal preparation plants discard the minus $150 \mu \mathrm{m}$ size fraction of their run-of-mill coal into slurry ponds will little or no attempt to recover the cleaned coal of this size fraction [2]. In the United States alone, this has resulted in the discharge of approximately 23 billion tons of fine coal into abandoned ponds, as well as 500-800 million tons in active ponds [3]. On an annual basis, coal producers in the U.S. discard roughly 30-40 million tons of fresh fine coal. In addition to the many environmental issues brought about by discarding this material into waste ponds, it has been shown that effective means of recovering fine coal can lead to increased profitability in mining operations. Patwardhan et al. [1] has shown that profits can be increased by as much as $\$ 2.5$ (\$US) million annually for a single $2.4 \mathrm{Mt} /$ year mining operation. 
In addition to the economic aspects associated with recovery of coal fines from waste slurry at preparation plants, drying of small coal particles is also of interest in regards to operation of pulverized coal (PC) boilers used to generate electricity. In a recent report generated for the U.S. Department of Energy's (DOE) National Energy Technology Laboratory (NETL) regarding the use of low rank coals in various gasifier systems, the following information was presented. From an operational perspective, PC boilers can handle fuels with a wide range of moisture content, encompassing both lignite and subbituminous coal with $25-45 \%$ moisture [4]. This report goes on to state that, ultimately, the choice of whether or not to dry the coal is a tradeoff between achieving higher efficiencies within the boiler at the expense of the increased cost inherent in using current drying methods. Historically, coal prices within the United States have been low enough that the "business as usual" approach has been to simply burn the coal as received with minimal attempts to dry it beforehand, and there was little incentive to add cost to improve efficiency. However, the combination of increased coal costs and more stringent emissions requirements has made drying options more common.

Dewatering of fine coal particles is typically accomplished by utilizing either a screen-bowl centrifuge or filters operating under vacuum or pressure [5]. In both cases, wet coal fines from the cleaning process are introduced into these systems in the form of froth from flotation columns. This froth typically has an initial moisture content of approximately $80 \%$, with $20 \%$ solids content [6].

In the case of a screen-bowl centrifuge, a filter cake forms along the side walls of the centrifuge chamber. This filter cake acts like a dense packed bed with parallel capillaries of varying size [5]. The centrifugal force created from the revolution of the centrifugal chamber forces water out 
of the capillaries and through a filter cloth. Because moisture located in small pores is difficult to remove due to high capillary pressure, a flocculant is typically added to the froth. This flocculant causes a "clumping together" of the fine particles, thus increasing the size of the cake pores and decreasing the capillary pressure, resulting in better dewatering. In general, this method results in final cake moistures of $20-25 \%$. Recent innovations in the area of screen-bowl centrifuges have lead to the addition of hyperbaric pressure into the centrifuge chamber during operation $[3,7]$. Laboratory testing of this method has resulted in cake moisture contents as low as $10 \%$ for particle sizes typically found in industrial fine coal dewatering operations.

The second commonly used method for dewatering fine coal particles involves the use of filtration combined with either vacuum or pressure. The two most common applications of this principle are the plate and press filter and the belt filter. In both cases, a cake layer is formed and then pressed between two surfaces (plates in the press filter, belts in the belt filter). The pressure resulting from this compression forces moisture out of the capillaries formed within the cake. Dewatering is typically enhanced by the addition of flocculants and utilization of vacuum filtration in the case of the belt filter $[\mathbf{8 , 2}]$ has lead to results in a mean moisture content of $24 \%$. Similarly, flocculants and pressure filtration are typically incorporated into the plate and press filters, resulting in cake moisture contents between $20-27 \%$ [1].

\section{Experimental Approach}

The basic approach to drying is to heat the particles, thus increasing the water vapor pressure on/in the particle. When the water vapor pressure is greater than that in the surrounding air, the water vapor will then diffuse into the air. Consequently, the higher the particle temperature is and the drier the surrounding air, the quicker the particle will dry. 
For this study, a fluidized bed dryer (referred to from this point on as the WADFP, or Warm Air Dryer of Fine Particles) has been built and utilized for the drying of fine coal particles. Fluidized beds are extremely efficient vehicles for implementation of convective drying of small particles due to several factors; including large heat transfer surfaces, uniform temperature distributions, excellent temperature control and a continuous supply of drying air with low moisture content [9].

The ability to closely control the temperature within a fluidized bed is of great importance when drying fine coal particles. The reason for this being that there is a limit to the temperature that may be employed in the drying process. Temperatures just above $150^{\circ} \mathrm{C}\left(302^{\circ} \mathrm{F}\right)$ may ignite a dust layer $(<75 \mu \mathrm{m}$ diameter) of highly volatile coal $[\mathbf{1 0}]$. Therefore, it is imperative that any dryer design for coal fines should operate with all dryer surfaces and dry air flows below the lowest ignition temperature. The WADFP concept incorporates all three of these considerations, resulting in an improved coal or mineral drying system.

Figure 1-1 shows the conceptual design of the WADFP system. The WADFP unit consists of 2 riser sections of different diameter; these are referred to as the lower and upper riser stages. The small diameter lower stage will be operated such that a turbulent fluidization regime is maintained. Turbulent fluidization is desired in this portion of the riser based upon the fact that free stream turbulence results in an earlier transition to turbulence in the boundary layer surrounding the individual particles. This earlier onset of turbulence results in higher average convective heat transfer coefficients and thus enhances the drying process $[\mathbf{1 1}, \mathbf{1 2}, \mathbf{1 3}]$. The large diameter upper stage of the WADFP unit will be operated within the fast fluidization, or coreannulus, flow regime. This will allow the drying process to continue until such time as the individual coal particles become light enough (through loss of mass due to evaporation of 
moisture) to be transported out of the riser by the exhaust gases. Once the dry coal particles exit the fluidized bed riser, they will be separated from the fluidizing air by way of a cyclone, and will be deposited into a collection bin for analysis of moisture content.

During operation of the WADFP, dry air enters the system and is divided into three streams. The three steams are heated to about $105^{\circ} \mathrm{C}\left(221^{\circ} \mathrm{F}\right)$ in a heat exchanger using steam as a heat source. Two air streams then enter the bottom of the riser and one stream enters the riser through the injection ring. One of the two bottom streams forms a jet rising up through the riser. The second bottom air stream flows through a distributor plate and dries the particles moving down along the riser wall. The wet coal particles are introduced into the air stream entering the bottom of the riser via a motor-driven auger feed system. The particles are then pneumatically transported via the airstream into the lower stage of the riser, and are then swept upwards by the induced air circulation pattern within the lower turbulent riser stage. As the particles dry, they become lighter and are carried to the upper stage of the riser. Here the particles interact with the drier air from the injection ring. The drying process is completed in the enlarged flow area of the riser.

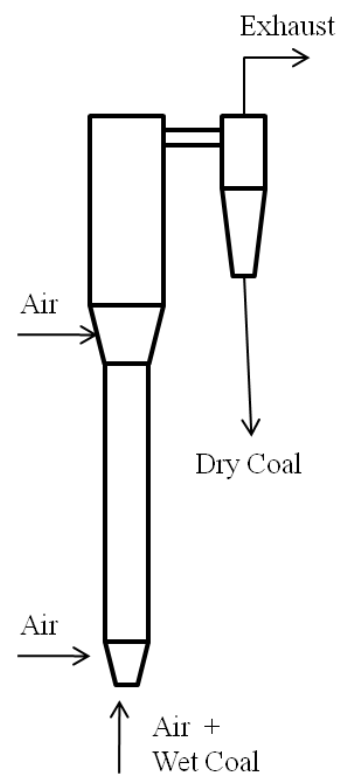

Figure 1-1: WADFP Conceptual Drawing 
In a fluidized bed of constant diameter, the radial introduction of additional feed air creates two regions within the fluidized bed riser whose flow conditions can be maintained such that each section can be treated as separate fluidized beds with distinctly different fluidization regimes [14]. In the WADFP unit, a conical injection ring located between the upper and lower riser stages operates with essentially the same function. By introducing additional air through the injection ring, it is expected that the upper riser stage can be operated at a different superficial velocity that the lower stage, allowing for the possibility of having different fluidization conditions above the injection ring than what exists below it.

In addition to allowing for the establishment of different flow regimes in the upper and lower riser sections, the secondary air injection via the injection ring provides another enhancement to the drying process. As seen in Figure 1-2, as the drying air moves up through the riser, it experiences an increase in specific humidity as moisture evaporates off of the bed particles and is transported upwards along with the rising air. This increase in specific humidity results in a decrease in driving force for the rate of drying higher within the riser. The addition of more dry air via the injection ring lowers the specific humidity, thus increasing the drying rate of particles in the upper stage of the riser.

At this point, it must be noted that operation of the WADFP system depends upon the assumptions of creating and maintaining specific fluidization (regimes) conditions within the riser itself. In order to more easily address this issue, a half-scale transparent model of the WADFP system has been designed and constructed. Initial testing using the scale model system was carried out in order to map out the various fluidization regimes that can exist within the system. These initial tests provided a comprehensive set of visual records of the interactions between particles and fluidizing gas at different gas velocities, as well as time histories of 
pressures and other statistical data that can be used to describe the hydrodynamic characteristics of the WADFP system.

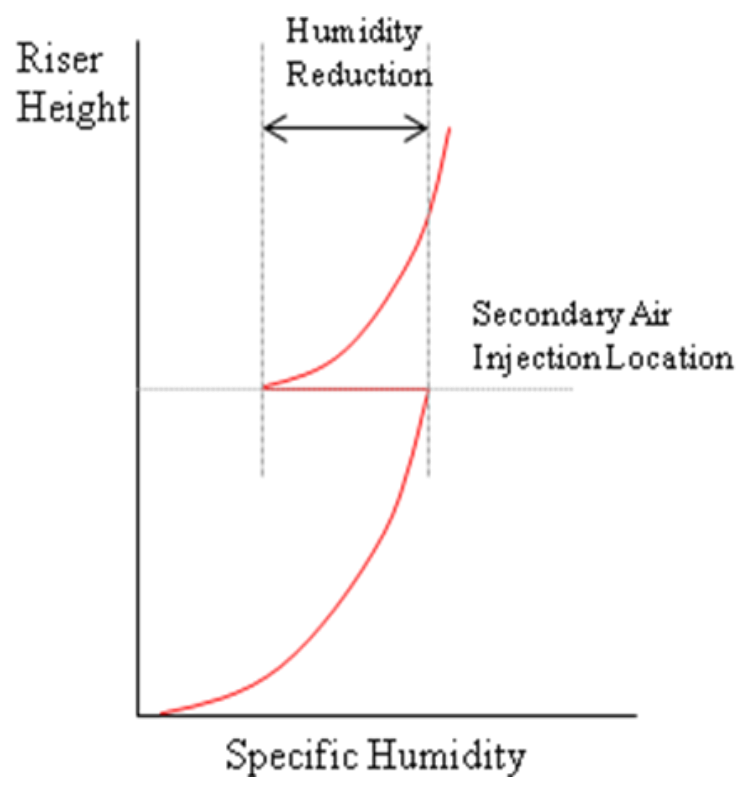

Figure 1-2: Effect of Secondary Air Injection on Specific Humidity

Finally, a method for scaling the laboratory-scale drying process up to industrial use has been developed and verified.

\section{Background}

\section{General types and applications of fluidized bed dryers}

Although not currently used for commercial drying of fine coal particles, many other industries have utilized fluidized beds for the drying of granular materials such as grains, fertilizers and chemicals $[15,16,17,18]$. Fluidized beds possess many advantages over more conventional drying techniques, among these advantages are: better temperature control, more uniform temperature distribution, higher thermal efficiency and intensity of drying, better gas-particle 
contact and less degradation of the particles. Unfortunately, there are also disadvantages associated with fluidized bed drying. These disadvantages include high pressure drops, nonuniform moisture content in the product (when operated in continuous mode) and the inability to adapt to counter-current operations $[\mathbf{1 9 , 2 0 , 2 1 , 1 7 , 9 ]}$.

\section{Literature Review}

While not utilized in commercial coal drying applications, there has been some research conducted to study aspects of fluidized bed drying of coal. Diamond [21] concluded in a study to determine the effects of temperature and particle size on the fluidized bed drying of northern Ireland lignite coal that drying rates increased as air temperatures increases, as well as when particle sizes decreased. Calban [19] obtained similar results while studying the drying characteristics of Turkish lignite in a batch bubbling fluidized bed. In addition to temperature and particle size considerations, Calban determined that the velocity of the drying air had no significant effect on drying rates. In another study, Calban [20] investigated the effects of bed height and initial moisture concentration on drying rates of Turkish lignite. In this study he determined that drying rates increased with decreasing bed height, and decreased with decreasing initial moisture concentration of the coal.

CFD Models for Fluidized Bed Drying of Coal

The majority of available literature related to numerical models of coal-based applications of fluidized beds deals more with the subject of coal combustion or gasification in fluidized bed combustors than with fluidized bed drying of coal. Chen, Agarwal and Agnew [22] presented a numerical model utilizing a two-phase hydrodynamic model to simulate the drying of coal in a bed fluidized with superheated steam. The use of a superheated steam drying process reduces 
the likelihood of fire and explosive hazards because steam-dried coal is less liable to spontaneous combustion due to a decrease in reactivity to oxygen in the atmosphere. Similarly, Stakic and Tsotsas [23] present a numerical model of a packed bed used for cooling warm coal particles that have been previously dried via a superheated steam drying process.

\section{Basic Principles of Fluidization}

\section{Geldart Particle Classification}

Geldart [24] classified solid particles into four groups based upon average particle diameter and the difference between particle and fluidizing gas densities. The four groups described by Geldart (A, B, C, and D) have been widely adopted for gas-solid fluidized bed design and research and are shown in Figure 1-3.

Group A particles, commonly known as "aeratable" particles, have a typical particle size range of 30-100 microns and are easily fluidized. These particles can be fluidized in the particulate fluidization regime in the absence of bubbling, as well as within the bubbling regime when bubbles are present. This leads to the minimum fluidization velocity being less than the minimum bubbling velocity. [25] In addition, group A particle fluidization exhibits a maximum stable bubble size when the gas velocity is greater than the minimum bubbling velocity.

Group B particles, like Group A, are easily fluidized and are commonly known as "bubbling" particles. However, for Group B particles, the minimum fluidization velocity equals the minimum bubbling velocity so there is no particulate phase. Finally, for Group B, there is not a maximum stable bubble size.

Group C (or "cohesive") consists of small particles which are highly cohesive. These particles are difficult to fluidize due to the dominance of inter-particle and electrostatic forces over 
hydrodynamic forces. Channeling and high bed expansions are characteristics of Group C fluidization.

Group D particles are coarse and do not mix well when fluidized. These particles are normally processed via spouted beds instead of fluidized beds.

In the tests described in later chapters, the poly-dispersed sand and coal was primarily Geldart Type B particles; however, coal particles with diameters smaller than $150 \mu \mathrm{m}$ behaved more like type C (cohesive) particles.

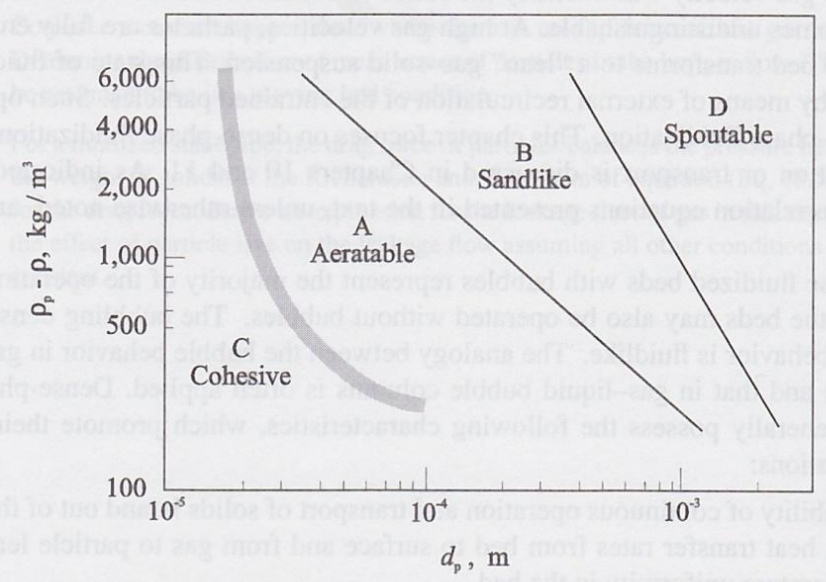

Figure 1-3: Geldart's classification of fluidized particles [24] (reproduced with permission)

\section{Fluidization Regimes}

Gas-solid systems are classified according to the basis of the state of motion of the solid particles within the system [25]. For a batch-solids system, the low velocity gasses percolate through the voids between the packed particles while the particles themselves are motionless. In this situation, the solid particles are said to be in the fixed bed state. As the gas velocity increases, the particles begin to move apart and become suspended. This suspended state is known as fluidization. The term fluidization encompasses a number of categories which exhibit a range of 
different particle motions and behaviors. These different sets of behaviors are commonly referred to as fluidization regimes.

The fluidization regimes of fluidized beds have been the subject of numerous studies and attempts at characterization. Investigations have confirmed the existence of six primary fluidization regimes during fluidized bed operations; these regimes are: particulate fluidization (Geldart A particles only), bubbling, slugging, turbulent, fast fluidization and pneumatic conveying. These regimes are dependent upon such factors as size and density of solid particles, superficial gas velocity, physical properties of the fluidizing gas, temperature, pressure, settled bed height, diameter of the fluidization column, as well as the type of gas distributor and the pressure drop across it $[\mathbf{2 6}, \mathbf{2 7}, \mathbf{2 8}, \mathbf{2 9}, \mathbf{3 0}, \mathbf{3 1}, \mathbf{3 2}]$.

Three of the most commonly used concepts for the characterization and description of fluidization are the superficial gas velocity $(\mathrm{U})$, bed voidage $(\varepsilon)$ and solids circulation (or flux) $\operatorname{rate}\left(\mathrm{G}_{\mathrm{s})}\right.$

The superficial gas velocity $(\mathrm{U})$ is a commonly used reference velocity in fluidization literature. In many cases, it is difficult to measure the actual fluidization gas velocities within a fluidized bed system. In physical terms, the superficial gas velocity is the theoretical velocity at which the fluidization gas would travel in the absence of any solids material. In practice, $U$ is calculated by dividing volumetric flow rate of gas into the bed by the bed cross-sectional area.

$$
U=\frac{\dot{V}_{a i r}}{A_{b e d}}
$$

In fluidized bed systems, the solid particles are suspended within the bed riser by the fluidizing gas. The spaces between the individual particles can be filled by either the fluidizing gas or bubbles that may form within the bed. The ratio of the volume of these spaces to the volume of 
the fluidized bed is commonly referred as the bed voidage ( $($ ). Monazam and Shadle [29]

provide the following relationship between the voidage and the average pressure drop across the fluidized bed:

$\frac{d P}{d z}=\rho_{s}(1-\varepsilon) g$,

where $g$ is the acceleration due to gravity and $\rho_{\mathrm{s}}$ is the density of the solid.

Additionally, the rate at which solid material is being introduced into the bed is known as the solids flux rate $\left(\mathrm{G}_{\mathrm{s})}\right.$. For the study, the solids flux is the product of the solid feed rate and the cross-sectional area of the lower riser stage.

$$
G_{s}=\frac{d W}{d t} / A
$$

Fluidization regimes can be divided into two generic categories: dense-phase and dilute-phase. Dense-phase fluidization is characterized by the existence of a distinct dense bed of solids material and an upper dilute freeboard area. This category of fluidization regimes consists of the particulate (Geldart A only), bubbling, slugging and turbulent regimes (shown in Fig 1-4a-d). The dilute-phase category consists of the fast fluidization and dilute transport (or pneumatic conveying) regimes. 


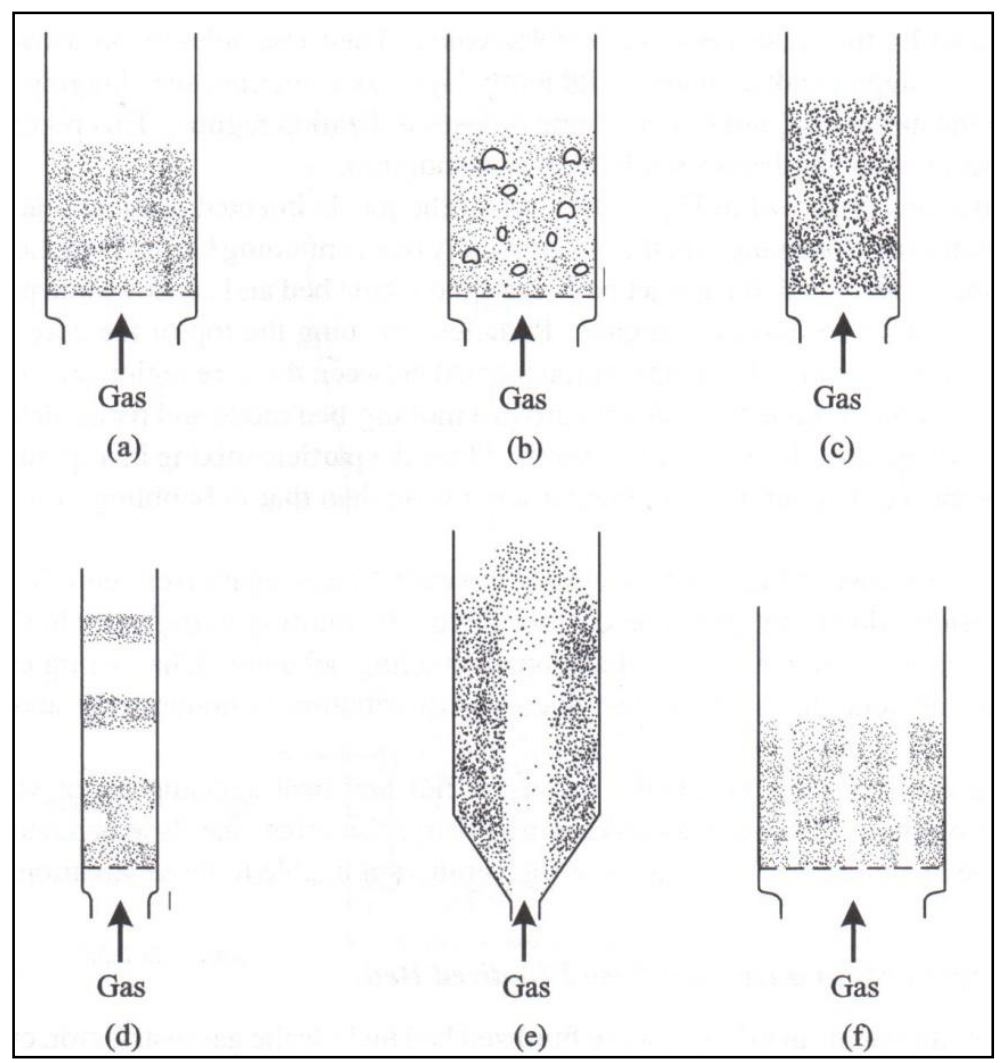

Figure 1-4: Dense fluidization regimes (a) Particulate; (b) Bubbling; (c) Turbulent; (d) Slugging; (e) Spouting; (f) Channeling [25] (reproduced with permission)

\section{Dense Phase Fluidization}

The various dense-phase fluidization regimes are bounded by an array of values of superficial gas velocities. When the bed material consists of Geldart type A particles, particulate fluidization occurs at the minimum fluidization velocity $\left(\mathrm{U}_{\mathrm{mf}}\right)$. In this flow regime, the fluidizing gas passes through the interstitial space between particles without bubbles and the bed appears to be homogeneous in nature [25]. The upper bound of this flow regime is characterized by the minimum superficial gas velocity that leads to the formation of bubbles within the bed. This velocity is known as the minimum bubbling velocity $\left(\mathrm{U}_{\mathrm{mb}}\right)$. For the Geldart type A particles, this velocity range between $U_{m g}$ and $U_{m b}$ is very narrow. For coarser particles, such as Geldart type $\mathrm{B}$ and $\mathrm{D}$ particles, the minimum fluidization velocity equals the minimum bubbling velocity. 
Wen and $\mathrm{Yu}[\mathbf{3 3}]$ proposed the following semi-empirical correlation relating the particle

Reynolds number for minimum fluidization and the Archimedes number $\operatorname{Ar}$ (for low pressures):

$$
\operatorname{Re}_{m f}=\sqrt{(33.7)^{2}+0.0408 A r}-33.7,
$$

where the Archimedes number is defined as:

$$
A r=\frac{\rho\left(\rho_{p}-\rho\right) g d_{p}^{3}}{\mu^{2}}
$$

and:

$$
\operatorname{Re}=\frac{\rho U d_{p}}{\mu}
$$

In addition, the bed voidage at minimum fluidization can be found via the following expression provided by the Ergun equation [25],

$$
A r=150 \frac{\left(1-\varepsilon_{m f}\right)}{\varepsilon_{m f}^{3} \varphi^{2}} \operatorname{Re}_{p m f}+\frac{1.75}{\varepsilon_{m f}^{3} \varphi} \operatorname{Re}_{p m f}^{2}
$$

and the height of the dense bed region at the minimum fluidization velocity is given by [25]

$$
H_{m f}=\frac{M_{p}}{A_{t} \rho_{p}\left(1-\varepsilon_{m f}\right)}
$$

where $M_{p}$ is the mass of the solid material in the bed and $A_{t}$ is the cross-sectional area of the riser. Additionally, as the gas velocity increases, the dense bin begins to expand, or increase in bed height. The amount of this expansion can be predicted by the following [34]

$$
\frac{H_{f}}{H_{m f}}=1+\frac{21.4\left(U-U_{m f}^{*}\right)^{0.738} d_{p}^{1.006} \rho_{p}^{0.376}}{\left(U_{m f}^{*}\right)^{0.937}\left(w_{g} \frac{p}{p_{a}}\right)^{0.126}}
$$

During the bubbling fluidization regime, the bubbles exhibit a tendency to continually coalesce and break up. As the gas velocity increases, this tendency towards bubble coalescence is 
enhanced and the bed begins to form larger and larger bubbles. Once the bubbles become large enough in size to be comparable to the bed diameter the slugging regime emerges. This slugging phase normally only occurs in fluidized beds with either a small bed diameter or a large heightto-diameter ratio.

Abrahamsen and Geldart [35] determined the following expression for the minimum bubbling velocity:

$$
U_{m b}=2.07 e^{0.716 \phi_{f}} \frac{d_{p} \rho^{0.06}}{\mu^{0.347}}, \quad \text { (MKS units) }
$$

where $\varphi_{\mathrm{f}}$ is the mass fraction of the particles smaller than $45 \mu \mathrm{m}$.

If the superficial velocity of the fluidizing gas continues to increase beyond the slugging velocity $\left(U_{s}\right)$ the bubbles begin to lose their coherency and shape. When this happens, the bubbles are replaced within the bed material by irregularly-shaped voids. These voids undergo rapid change in shapes and locations. This is known as the onset of the turbulent fluidization regime. Cai, et al [36] provided the following correlation for determining the velocity corresponding to the onset of transition to turbulence $\left(\mathrm{U}_{\mathrm{c}}\right)$,

$$
\frac{U_{c}}{\sqrt{g d_{p}}}=\left(\frac{\mu_{a}}{\mu}\right)^{0.2}\left[\left(\frac{\rho_{a}}{\rho}\right)\left(\frac{\rho_{p}-\rho}{\rho}\right)\left(\frac{K D_{f}}{d_{p}}\right)\right]^{0.27},
$$

where

$$
K D_{f}=d\left(\frac{0.211}{d^{0.27}}+\frac{2.42 \times 10^{-3}}{d^{1.27}}\right)^{\frac{1}{0.27}}, \text { and }
$$

where eqn. 1.12 is applicable for bed diameters $57 \mathrm{~mm} \leq \mathrm{d} \leq 475 \mathrm{~mm}$. Also note that eqn. 1.11 is applicable for group A and B particles within the range of $293<\mathrm{T}<773 \mathrm{~K}$ and $0.1<\mathrm{p}<0.8$ MPa. Equations (1.11) and (1.12) both use MKS units. 
The turbulent fluidization regime is of great interest for many fluidization aspects, as this is the regime in which the greatest amount of mixing and solid-gas heat transfer occurs. Because of this, there have been many methods for predicting or determining the onset of turbulent fluidization proposed in fluidization literature and will be discussed later.

\section{Dilute Phase Fluidization}

As mentioned previously, the second broad category of fluidization regimes is commonly referred to as dilute fluidization. As opposed to dense phase fluidization, dilute fluidization is characterized by the absence of a densely-packed bed of particles. Instead, the dilute phase is characterized by the presence of much more widely spaced particles. These particles can exhibit a circulatory pattern of motion (as in core-annulus flow) or be fully entrained and carried along by the fluidization gas (as in pneumatic transport). For this research project, as in the case of turbulent fluidization, the fast fluidization regime is also of interest as it is intended that the upper, larger diameter riser section of both the WADFP and the small scale model will operate within this fluidization regime.

Fast fluidization occurs as the superficial velocity is increased sufficiently beyond $U_{k}$ that the fluidization column undergoes a transition from a dense bed of particles to a dilute flow pattern commonly known as core-annulus flow. This regime is characterized by a central "core" of rapidly upwards flowing gas and entrained particles, as well as an outer "annulus" counter flow of slower moving particles and gas. It is this circulating flow pattern that gives name to circulating fluidized beds.

The minimum required fluidization velocity for fast fluidization is known as the transport velocity, or $\mathrm{U}_{\mathrm{tr} .}$. The transport velocity can be estimated from the following empirical formula provided by Bi and Fan [37]: 


$$
R e_{t r}=2.28 A r^{0.419}
$$

When characterizing the fast fluidization regime, the variables of interest are pressure drop per unit length of the fluidization column $(\Delta \mathrm{P} / \Delta \mathrm{L})$, voidage $(\varepsilon)$ and solids circulation rate $\left(\mathrm{G}_{\mathrm{s}}\right)$. When $\Delta \mathrm{P} / \Delta \mathrm{L}$ is plotted against $\mathrm{G}_{\mathrm{s}}$, the well-documented " $\mathrm{S}$ " curve is generated.

According to Monazam and Shadle $[\mathbf{2 9 , 3 8}$, the fast fluidization regime is characterized by a relatively stable solids circulation rate that shows little dependence upon changes in the pressure drop across the bed riser. This relationship can also be related to the expression for $\mathrm{G}_{\mathrm{s}}$ given in eqn. 1.3 by noting that the solids circulation is only constant when $\mathrm{d} \Delta \mathrm{P} / \mathrm{dt}$ is constant. Also, as shown in Figure 1-5 below, the fast fluidization regime is characterized by a decrease in overall bed pressure drop with increasing superficial velocity. As the pressure drop approaches a minimum value, the bed begins to undergo a transition towards the dilute (or pneumatic) transport regime. Once the bed has fully transitioned to the transport regime, the overall bed pressure drop begins to increase.

The lower portion of Figure 1-5 shows the effect of the gas velocity $U$ and the solids circulation rate $\mathrm{G}_{\mathrm{s}}\left(\mathrm{J}_{\mathrm{p}}\right.$ in the figure $)$ on the flow regime. As can be seen in the figure, as the solids circulation rate and gas velocity decrease, the upper and lower bounds of the fast fluidization (core-annulus) flow regime contract towards a critical point denoted by $\mathrm{U}_{\mathrm{tr}}$ and $\mathrm{J}_{\mathrm{p}, \mathrm{tr}}$. Any further decrease in either solids circulation rate or gas velocity will result in a collapse back into a dense fluidization regime. 


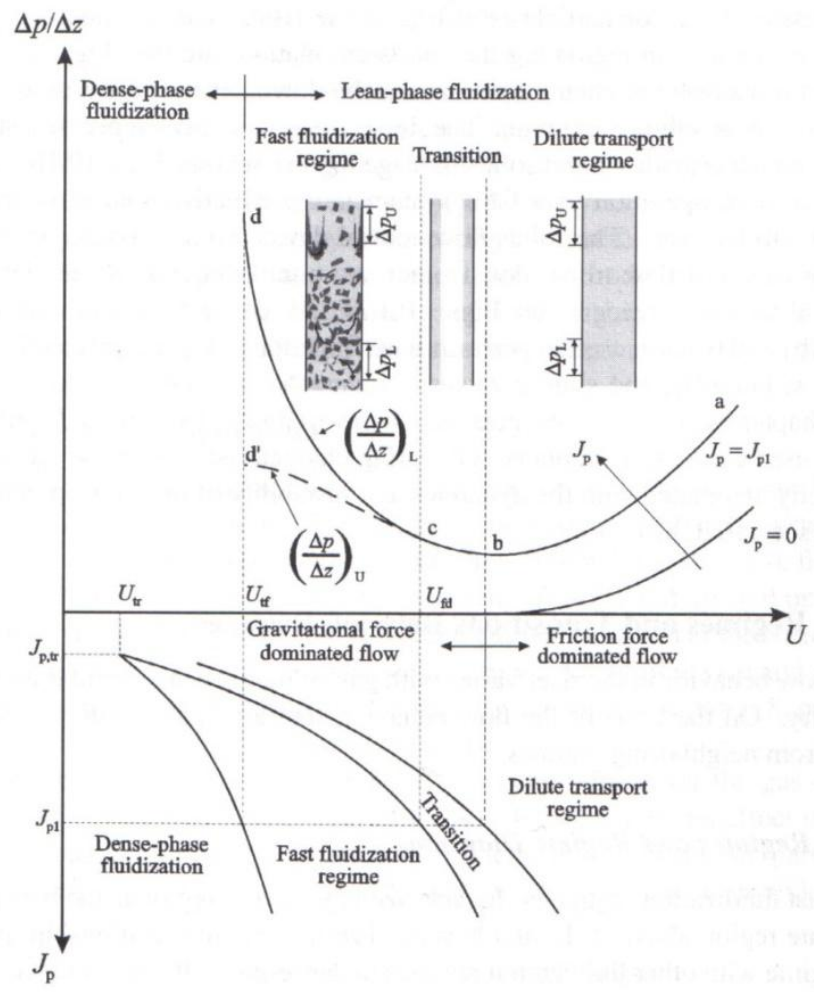

Figure 1-5: Variations of pressure drop per unit riser length with solids circulation rate and gas velocity for various fluidization regimes [39] (reproduced with permission)

\section{Pressure Signal Analysis}

Multiple methods for determining and characterizing the transition points between fluidization regimes via analysis of bed pressure signals have been developed and appear in the fluidization literature. Many of these various methods are presented here and are grouped into the following broad categories: statistical analysis, time domain analysis, frequency domain analysis and chaos analysis.

\section{Statistical Analysis of pressure}

Statistical methods of pressure data analysis include plotting three statistical moments (standard deviation, skewness and kurtosis) against superficial velocity, as well as examination of the autocorrelation function, Rescaled Range and Hurst exponent. 


\section{Standard Deviation}

The amplitude of the signal, $\mathrm{x}$, can be expressed by the standard deviation (or square root of the second-order statistical central moment) $\sigma$, as defined by equation (1.14).

$$
\sigma=\sqrt{\frac{1}{N-1} \sum_{n=1}^{N}(x(n)-\bar{x})^{2}},
$$

where $\mathrm{N}$ is the number of samples and $\bar{x}$ is the sample mean.

In fluidization research, the most common method (proposed by Bi and Fan [37]) for experimentally determining the velocity at which the transition from bubbling to turbulent fluidization begins $\left(\mathrm{U}_{\mathrm{c}}\right)$ is by plotting the standard deviation of pressure fluctuations versus the superficial velocity (U). Figure 1-6 depicts such a plot. As the value of U increases through the bubbling and slugging regimes towards the turbulent regime, the standard deviation likewise increases until it reaches a maximum value and then begins to decrease. This maximum value of $\sigma$ corresponds to the onset of the transition to turbulence. The corresponding superficial velocity at this point is $\mathrm{U}_{\mathrm{c}}$.

These pressure fluctuations will decrease until the fluidized bed passes through the transition zone and into turbulent fluidization regime itself, where the pressure fluctuations will tend to level off. The velocity at which this occurs is commonly referred to as $U_{k}$.

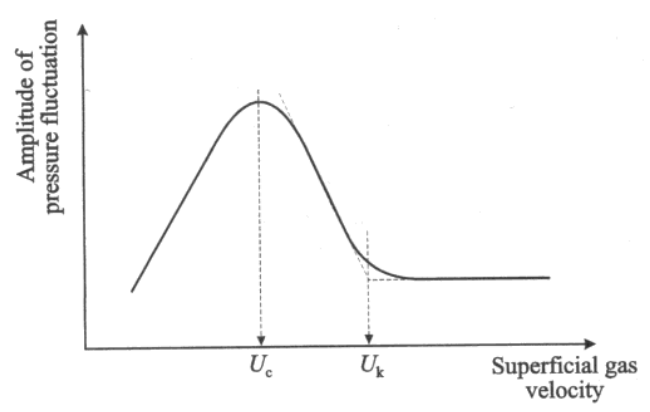

Figure 1-6: Variation of pressure fluctuations with velocity for dense-phase fluidization [40]. (reproduced with permission) 
However, Rhodes and Geldart [41] dispute this method. While valid for Group A particles, Rhodes and Geldart state that for Group B particles, the $\mathrm{U}_{\mathrm{k}}$ value obtained from the Bi and Fan method above actually yields the velocity at which the dense bed disappears and the bed transitions to dilute fluidization. In other words, for Group B particles, the $\mathrm{U}_{\mathrm{k}}$ velocity in figure 1-6 is actually the transport velocity, or $U_{\text {tr }}$.

Additionally, Bi and Grace [42] showed that $U_{c}$ is a strong function of the method used to measure bed pressures. Their findings showed that absolute pressure fluctuations differed from differential pressure fluctuations.

\section{Skewness}

The skewness of a set of data is an indicator of the amount of asymmetry about the mean of that data set. Skewness is defined as:

$$
S=\frac{1}{N \sigma^{3}} \sum_{n=1}^{N}(x(n)-\bar{x})^{3}
$$

When the data is normally distributed about the mean, the value of skewness is 0 . However, if the skew is negative, then the majority of the data will be distributed to the right of the sample probability distribution with a long tail on the left side; whereas a positive skew suggests that the majority of the data will be distributed to the left of the distribution with a long tail on the right side.

Lee and Kim [43] examined skew and kurtosis for analysis of pressure signals in a dense bed. They discovered that as the bed transitioned to turbulence, there was a shift from negative to positive skew and a maximum in the flatness (kurtosis) of the data. They considered the point of zero skew to correspond to the transition velocity, $\mathrm{U}_{\mathrm{c}}$. 


\section{Kurtosis}

In statistical analysis, kurtosis (the fourth order statistical moment) is the measure of the "peakedness" of the probability distribution of a real-valued random variable. A high value of kurtosis means that a large portion of the variance of a given data set is due to infrequent but large deviations. Kurtosis is given by the following expression:

$$
K=\frac{1}{N \sigma^{4}} \sum_{n=1}^{N}(x(n)-\bar{x})^{4}
$$

When applied to pressure signals from a fluidized bed, the kurtosis provides a good indication of the presence of large magnitude fluctuations due to large bubbles passing the pressure transducer. The kurtosis can also be seen as a measure of the ratio of time the system remains at a quiescent state to the time it spends at an active state. [44]

\section{Autocorrelation Function}

The autocorrelation function of a signal, given by equation (1.17) [44], depicts the correlation between two points within the signal that are separated by a time lag, $\mathrm{k} \Delta \mathrm{t}$. The autocorrelation function is an excellent tool for determining whether or not a given signal (or data set) is periodic in nature. If the signal is periodic, then the autocorrelation will also be periodic. Additionally, the autocorrelation is additive, so that a signal that consists of combinations of periodic functions will also have an autocorrelation that is a combination of multiple periodicities.

$$
c_{x x}(k)=\sum_{n=0}^{N-|k|-1}(x(n)-\bar{x})(x(n-k)-\bar{x})
$$

When normalized with the autocorrelation value at zero lag, equation (1.17) becomes 


$$
C_{x x}(k)=\frac{c_{x x}(k)}{c_{x x}(0)}
$$

The autocorrelation function has traditionally been used for verification of hydrodynamic scaling between fluidized beds. This application will be discussed further in Chapter 3 .

\section{Rescaled Range and Hurst Exponent}

The Rescaled Range is a statistical measure of the variability of a time series, and how that variability changes as the time period being considered increases. For a given time series $\left\{X_{n}\right\}$ from time $(t)$ to $(t+\tau)$, The Rescaled Range is defined as:

$$
R / s(t, \tau)=\frac{\max \left(\left\{X_{n}\right\}\right)-\min \left(\left\{X_{n}\right\}\right)}{\sigma_{\left\{X_{n}\right\}}},
$$

It has been noted [http://en.wikipedia.org/wiki/Rescaled_range] that, as the sample size, $n$, increases, so too does the value of $R / s$. If $R / s$ is calculated for a range of different sample sizes and plotted against $n$ on a $\log -\log$ plot, the resulting slope is equal to the Hurst Exponent, $H$.

The Hurst Exponent is an estimate of the predictability of a time series. The Hurst Exponent can take on a value between 0 and 1 . In cases where its value is in the range $0 \geq \mathrm{H}>0.5$, the time series from which it is calculated will exhibit a tendency to reverse trends. In other words, an increase in the value of the series parameter will be followed by a decrease, then an increase, etc. For $0.5>\mathrm{H} \geq 1$, the time series exhibits a tendency to continue a trend (i.e. continue to increase, etc.). A value of $\mathrm{H}=0$ is indicative of a Brownian series, in which one point in the time series has no correlation to future time steps. 


\section{Frequency Domain Analysis}

Given that the hydrodynamic nature of a fluidized bed operating at a given dense fluidization condition is strongly affected by the nature of the bubbling within the bed (i.e. bubble frequency), another tool for analyzing the pressure data from fluidized beds is the Power Spectral Density (PSD) plot. This tool converts the time domain pressure data into the frequency domain and then plots the power associated with a given frequency versus frequency. By examining the distribution of power within the frequency spectrum, the nature of the pressure fluctuations due to bubble frequencies can easily be seen. For instance, a bubbling or slugging fluidization regime is dominated by a primary bubble frequency which will show up in the PSD as the dominant frequency. However, the turbulent regime is characterized by a breakup of the bubbling dynamics as the large bubbles in the earlier regimes are broken apart and lead to a range of different frequencies. This results in a wider range of power distribution and a lack of a dominant frequency in the PSD.

The PSD, or spectral density, is related to the autocorrelation function via the following relationship:

$$
S(f)=\sum c_{x x}(\tau) e^{-2 \pi f f \tau},
$$

where $\tau$ is a given time step in the autocorrelation and $f$ is the frequency.

The spectral density is a commonly used method of verifying hydrodynamic similarity and will be discussed further in Chapter 3. 


\section{Chaos Analysis}

The final broad category of methods of analyzing fluidized bed pressure fluctuations is the application of deterministic chaos theory. Kang et al. [45] utilized the mutual information function, phase-space portraits (or strange attractors) and the correlation dimension to study the effects of gas velocity and pressure on bubble properties (chord length, frequency and rising velocity) in a pressurized gas-water bubble column. Zhong et al. [46] applied Shannon entropy analysis (including entropy increment and increment rate) to differential pressure fluctuations in order to determine the fluidization regime transition velocities in a fluidized bed with cylindrical biomass fuels. Zhong and Zhang [47] applied Shannon entropy analysis to pressure data from multiple locations within a spouted bed in order to study the effects of spouting and fluidizing gas velocities on the fluidization characteristics of a spouted bed of biomass particles. Kang et al. [48] applied the Hurst Exponent, Spectral exponent and Shannon entropy to the study of a three-phase fluidized bed with water, air and glass beads. Zhang and Shi [49] applied the analysis of negative Shannon entropy (or negentropy) to the study of density wave instability in a 200 MW nuclear heating reactor. They compared their entropy calculations, derived from the spectral density of pressure fluctuations from more than 500 operational runs of the reactor that operators had pre-determined were either stable or unstable and found that the unstable operating conditions contained high levels of negentropy. Finally, van den Bleek et al. [50] noted that regime transitions were characterized by a "dip" in entropy. In addition, they suggested that the phase-space portrait (or strange attractor) and entropy be used for scaling and hydrodynamic similarity verification between fluidized beds.

As can be seen from this brief literature review of chaos analysis of fluidized beds, entropy, mutual information and phase-space portraits are common tools. 


\section{Shannon (Kolmogorov) Entropy}

When applied to signal processing, entropy is a measure of the uncertainty within a signal. The concept is taken from the Boltzmann relation/definition of entropy from the second law of thermodynamics, which defines entropy in terms of the uncertainty of the energy states of a system. The Boltzmann relationship is given by:

$$
h=-k \sum p \ln (p)
$$

where $k$ is the Boltzmann constant and $p$ is the probability of the occurrence of a given energy state. [51]. Claude Shannon applied the concept of entropy to information theory and signal analysis, thus giving his name to entropy in that field (i.e. Shannon Entropy) [52]. In addition, entropy analysis applied to chaotic systems is commonly referred to as Kolmogorov Entropy.

In fluidized bed literature, both Shannon and Kolmogorov entropy are referenced, and are interchangeable. For the purposes of simplification, it will be referred to as Shannon Entropy throughout the remainder of this dissertation, and is given by:

$$
h=-\sum_{i=1}^{n} p\left(x_{i}\right) \log _{2}\left[p\left(x_{i}\right)\right],
$$

where $x_{i}$ is a given range of values, $n$ is the total number of possible outcomes, and $p$ is the individual bin probabilities of the elements of a histogram of the data/signal probability distribution . When examining a signal, such as pressure data, Shannon Entropy is a function of the probability distribution of the signal and not the magnitude of the signal itself. It is used as both a measure of uncertainty within a signal, as well as a measure of the information contained within that signal. Given that $\log _{2}(0)$ is infinity, the Shannon Entropy is defined as " 0 " for this 
case. In addition, when the signal contains a constant value (i.e. $\left.\mathrm{p}\left(\mathrm{x}_{\mathrm{i}}\right)=1\right)$ there is no information transmitted in terms of information theory, and Shannon Entropy is " 0 ". The value of Shannon Entropy increases with increasing signal variability or uncertainty.

\section{Mutual Information Function}

Similar to the autocorrelation function, the mutual information function is a measure of the correlation of a signal with itself as a function of time, and is given by:

$$
I(a, b)=h(a)+h(b)-h(a, b)
$$

where $b$ is a subset of $a$, separated by a given time lag $\tau$. In other words, for a given time series

$\mathrm{X}(\mathrm{a})$, then $\mathrm{X}(\mathrm{b})=\mathrm{X}(\mathrm{a}+\tau)$ for a given time lag. Additional, $h(a, b)$ is the entropy of the joint probability of $a$ and $b$.

\section{Phase-Space Portraits}

The following definition of a Phase-Space is from http://en.wikipedia.org/wiki/Phase_space.

In mathematics and physics, a phase space, introduced by Willard Gibbs in 1901, is a space in which all possible states of a system are represented, with each possible state of the system corresponding to one unique point in the phase space. For mechanical systems, the phase space usually consists of all possible values of position and momentum variables. A plot of position and momentum variables as a function of time is sometimes called a phase plot or a phase diagram. Phase diagram, however, is more usually reserved in the physical sciences for a diagram showing the various regions of stability of the thermodynamic phases of a chemical system, which consists of pressure, temperature, and composition.

In a phase space, every degree of freedom or parameter of the system is represented as an axis of a multidimensional space. For every possible state of the system, or allowed combination of values of the system's parameters, a point is plotted in the multidimensional space. Often this succession of plotted points is analogous to the system's state evolving over time. In the end, the phase diagram represents all that the system can be, and its shape can easily elucidate qualities of the system that might not be obvious otherwise. A phase space may contain 
very many dimensions. For instance, a gas containing many molecules may require a separate dimension for each particle's $x, y$ and $z$ positions and velocities as well as any number of other properties.

Phase-space portraits, also known as strange attractors, are a common tool used to describe a deterministic chaotic system. A number of authors have utilized attractors to visualize the states of fluidization in fluidized beds. $[\mathbf{5 0 , 5 3 , 4 4 ] ~ I n ~ a d d i t i o n , ~ v a n ~ d e n ~ B l e e k ~ e t ~ a l . ~ [ 5 0 ] ~ s u g g e s t ~ a ~}$ method for using the attractor as a basis for a feedback control system for reactor operation. This will be discussed in greater detail in Chapter 3.

The phase-space portrait of a pressure fluctuation time series can be constructed by means of the time delay method, as presented by Kang et al. [45]. In this method, the time series $\mathrm{X}(\mathrm{t})$ is digitized with a timestep $\Delta \mathrm{t}$. This results in the following $(\mathrm{m}+1)$ values

$\{X(0 \Delta t), X(1 \Delta t), X(2 \Delta t), \ldots, X(m \Delta t)\}$

A series of vectors, $Z_{i}(t)$ can be constructed such that

$\mathrm{Z}_{\mathrm{i}}(\mathrm{t})=[\mathrm{X}(i \Delta t), \mathrm{X}(i \Delta t+\tau), \mathrm{X}(i \Delta t+2 \tau), \ldots, \mathrm{X}(i \Delta t+(p-1) \tau)]$

$i=0,1,2, \ldots,[m-(p-1) k]$

where

$\tau=k \Delta t, k=1,2,3, \ldots$

and $\mathrm{p}$ is the embedded phase-space dimension of the reconstructed attractor, $\mathrm{Z}(\mathrm{t})$.

As a final note, it is a common practice to set the time lag, $\tau$, equal to the time corresponding to the first minimum of the mutual information function. [45] 


\section{Chapter 2 Theoretical Approach for Fluidized Bed Drying}

\section{Principles of Fluidized Bed Drying}

Fluidized beds are commonly found in industrial applications used in drying granular materials such as grains, cereals, fertilizers, crystalline products, minerals and chemicals. Some of the reasons for this include large heat transfer surface areas between the material to be dried and the fluidizing gas and the fact that the high degree of mixing in fluidized beds tends to result in negligible temperature and concentration gradients within the fluidizing column [17]. The drying rates of solids in fluidized beds are much higher than other drying methods, such as conventional hot air drying due to higher heat and mass transfer rates on the surface of the drying materials [18]. There are, however, disadvantages to using a fluidized bed dryer. Among these disadvantages are high-pressure drops, attrition of the solids and erosion of surfaces due to particle-particle and particle-surface collisions, as well as the possibility of non-uniform moisture content in the product as a result of varying residence times of individual particles [54].

Fluidized bed drying of solid materials can be either batch-wise or continuous. Batch operations are preferred for small-scale production as well as for heat-sensitive materials, whereas continuous fluidized beds are normally used for large-scale operations [15]. In cases of batch drying, which is typically carried out in the dense bubbling or slugging regimes, the final moisture content of the product is more uniform due to the fact that the particles tend to be of uniform temperature and residence times, whereas continuously operating fluidized beds vary widely in particle residence times and temperatures due to the continuous introduction of new material into the system. 
Due to the operational nature of fluidized bed dryers (i.e., a continuous flow of warmer gas passing through the drying particles) the primary form of heat transfer between the particles and the fluidizing gas is that of convection heat transfer. According to Nonhebel and Moss [9], if the hot gas used in convection drying is supplied at a constant temperature and humidity, the drying process will occur in two distinct stages.

The initial stage is characterized by a constant drying rate in which moisture is transported to the heat transfer surface from within the solid material being dried at the same rate as moisture is evaporating from this surface. The second stage is characterized by a diminishing drying rate until the particle is completely dry. The moisture content at which the drying rate begins to decrease is referred to as the critical moisture content.

In the constant drying rate period, the controlling factors are the temperature, velocity and humidity of the drying gas; during the falling drying rate period, the factor controlling the drying rate become the rate at which moisture migrates to the drying surface. Figure 2-1 illustrates a set of typical convection drying rate curves showing both the constant and falling rate periods, as well as the critical moisture content region.

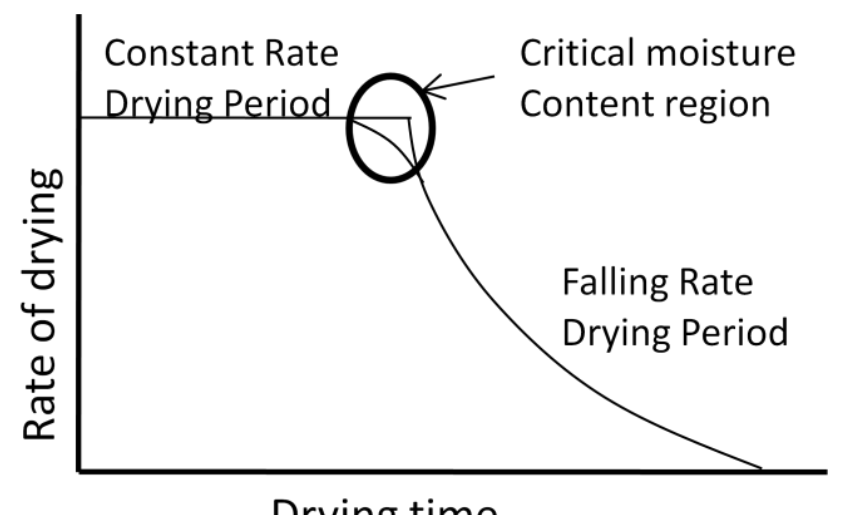

Drying time

Figure 2-1: Typical convection drying rate curve 
A common method of analyzing the drying rates of fluidized bed dryers in the relevant literature is to plot the normalized ratio of product to initial moisture content, $\mathrm{C} / \mathrm{C}_{\mathrm{o}}$ versus the total drying time. An example of this can be seen in Figure 2-2.

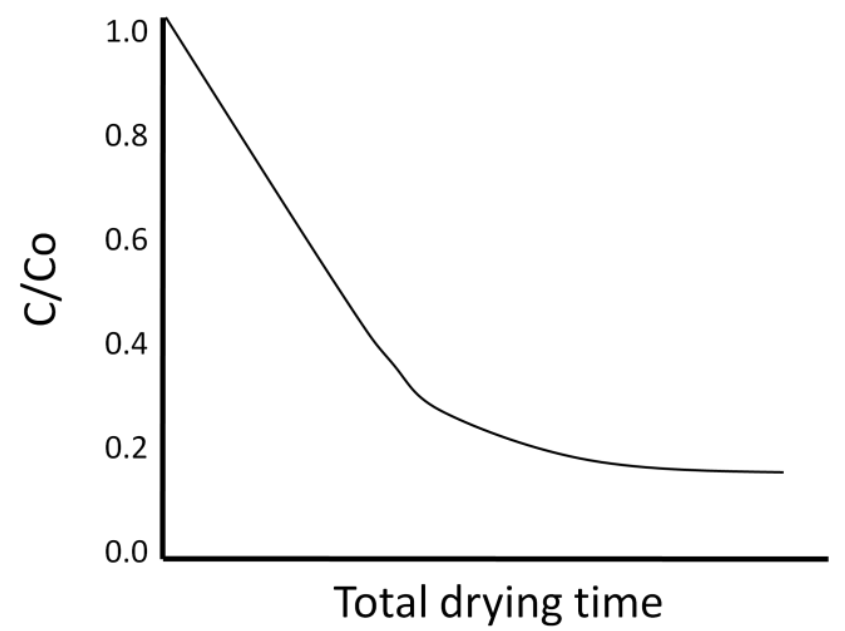

Figure 2-2: Moisture content ratio versus total drying time

\section{Droplet evaporation/film drying model}

The following drying model for a single particle assumes that the particle is at a constant, uniform temperature, and that the moisture resides within a thin film on the particle surface. In addition, it is assumed that drying is taking place during the constant rate period.

To develop this model, one need first examine the nature of the evaporation of a homogenous droplet of fluid at uniform temperature, $T_{d}$, into a surrounding gas at $T_{\infty}$ due to convective heat transfer. An example of such a droplet is shown in Figure 2-3.

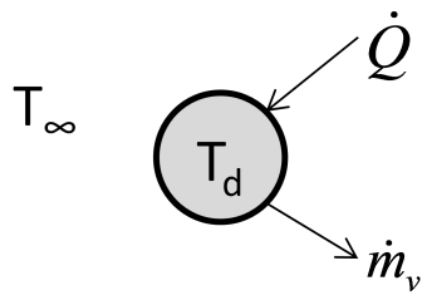

Figure 2-3: Droplet evaporation model 
Neglecting all work except for moving boundary work (simulating the shrinking of the droplet as it evaporates), as well as kinetic and potential energy, the energy balance for this system is given by:

$$
\left.\frac{d E}{d t}\right|_{s y s}=\dot{Q}-\dot{m}_{v} h_{v}-p \frac{d V_{d}}{d t}
$$

Where

$$
\left.\frac{d E}{d t}\right|_{s y s}=\frac{d\left(m_{d} u_{d}\right)}{d t}=m_{d} \frac{d u_{d}}{d t}+u_{d} \frac{d m_{d}}{d t}
$$

where $\mathrm{u}_{\mathrm{d}}$ and $\mathrm{m}_{\mathrm{d}}$ are the internal energy (per unit mass) and the mass of the droplet, respectively.

In addition, the heat transfer to the droplet is convective in nature, so

$$
\dot{Q}=h A_{d}\left(T_{\infty}-T_{d}\right)
$$

and $\mathrm{V}_{\mathrm{d}}$ is the volume of the droplet, given by:

$$
V_{d}=\frac{m_{d}}{\rho_{d}}
$$

Combining Equations (2.1)-(2.4) and rearranging terms yields:

$$
m_{d} \frac{d u_{d}}{d t}=h A_{d}\left(T_{\infty}-T_{d}\right)-\dot{m}_{v} h_{v}-p \frac{d\left(\frac{m_{d}}{\rho_{d}}\right)}{d t}-u_{d} \frac{d m_{p}}{d t}
$$


Noting that the droplet properties are a function of the temperature and pressure, which are held constant in this model, the density can be pulled out of the partial derivative in the boundary work term in (2.5). In addition, the following substitution can be made:

$$
\frac{d u_{d}}{d t}=c_{p, d} \frac{d T_{d}}{d t}
$$

Now (2.5) takes the following form:

$$
m_{d} c_{p, d} \frac{d T_{d}}{d t}=h A_{d}\left(T_{\infty}-T_{d}\right)-\dot{m}_{v} h_{v}-\frac{p}{\rho} \frac{d m_{d}}{d t}-u_{d} \frac{d m_{p}}{d t}
$$

In addition, by making the following substitutions

$$
v_{d}=\frac{1}{\rho_{d}},-\dot{m}_{v}=\frac{d m_{p}}{d t}
$$

(2.7) can be rewritten as:

$$
m_{d} c_{p, d} \frac{d T_{d}}{d t}=h A_{d}\left(T_{\infty}-T_{d}\right)-\dot{m}_{v} h_{v}+\dot{m}_{v}\left(p v_{d}+u_{d}\right)
$$

The quantity in the parenthesis in the last term of (2.9) is by definition the enthalpy of the droplet, or $h_{d}$. One final simplification making use of the fact that $h_{f g}=h_{v}-h_{d}$, yields:

$$
m_{d} c_{p, d} \frac{d T_{d}}{d t}=h A_{d}\left(T_{\infty}-T_{d}\right)-\dot{m}_{v} h_{f g}
$$

Assuming a constant droplet temperature, the LHS of (2.10) is zero, leading to the following expression for the evaporation rate of the droplet: 


$$
\dot{m}_{v}=\frac{h A_{d}\left(T_{\infty}-T_{d}\right)}{h_{f g}}
$$

The convective heat transfer coefficient, $\mathrm{h}$, can be found in terms of the Nusselt number, $\mathrm{Nu}$, such that:

$$
h=\frac{k N u}{d_{d}}
$$

For a droplet exposed to a turbulent flow, Lavender and Pei [12] propose the following empirical expression for the Nusselt number:

$$
N u=2+0.717 \operatorname{Re}^{1 / 2} \operatorname{Pr}^{1 / 3}\left(\operatorname{Re} I_{\infty}\right)^{0.035}
$$

Where Pr is the Prandtl number, or the ratio of momentum diffusivity over thermal diffusivity, and is given by:

$$
\operatorname{Pr}=\frac{\mu / \rho}{D_{t}}
$$

$I_{\infty}$ is the turbulent intensity of the flow field, given by:

$$
I_{\infty}=\frac{u^{\prime}}{U_{\infty}}
$$

Substituting (2.12) and the expression for the surface area of a sphere into (2.11) yields:

$$
\dot{m}_{v}=\frac{\pi N u k d_{d}\left(T_{\infty}-T_{d}\right)}{h_{f g}}
$$

In addition, 


$$
\frac{d m_{p}}{d t}=\rho_{d} \frac{d}{d t}\left(\frac{4}{3} \pi r_{d}^{3}\right)=-\dot{m}_{v}
$$

Combining (2.16) and (2.17) gives:

$$
-\frac{\pi N u k d_{d}\left(T_{\infty}-T_{d}\right)}{h_{f g}}=\rho_{d} \frac{d}{d t}\left(\frac{4}{3} \pi r_{d}^{3}\right)
$$

Upon rearranging

$$
-\left[\frac{3 \pi N u k\left(T_{\infty}-T_{d}\right)}{2 \rho_{d} h_{f g}}\right] d t=\frac{1}{r_{d}} d\left(r_{d}^{3}\right)
$$

By making the following substitutions

$$
x=r_{d}^{3}, x^{-1 / 3}=\frac{1}{r_{d}}
$$

(2.19) can be integrated from $\mathrm{t}=0$ to and arbitrary time $\mathrm{t}$ to give the following solution:

$$
r_{d}^{2}(0)-r_{d}^{2}(t)=\frac{N u k\left(T_{\infty}-T_{d}\right)}{\rho_{d} h_{f g}} t
$$

Equation (2.20) is commonly known in combustion literature as the Radius-Squared Rule [55].

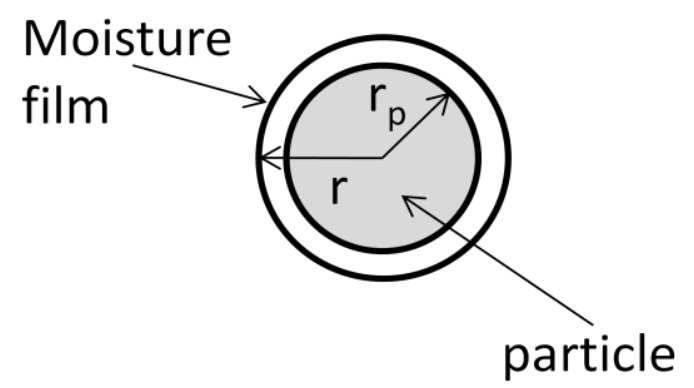

Figure 2-4: Solid particle with thin film of moisture 
Figure 2-4 shows a single solid particle surrounded by a thin film of liquid moisture. If the particle and moisture film are at the same temperature, and $r \geq r_{p}$, then (2.20) can be modified in the following manner:

$$
r_{d}^{2}(0)-r_{p}^{2}=\frac{N u k\left(T_{\infty}-T_{p}\right)}{\rho_{l} h_{f g}} t
$$

Solving (2.21) for $\mathrm{t}$ yields the time required for a moisture film of known thickness to evaporate from the surface of a solid particle.

\section{Thermodynamic Analysis of Fluidized Bed Drying}

The following sections discuss the operation of the WADFP system during steady state operation from a thermodynamic perspective. This analysis is based upon the basic principles of the conservation of mass, energy, thermodynamic entropy and exergy (or availability). For this

analysis, the riser and cyclone are treated as a control volume. Entering and leaving this control volume are air, coal and moisture. It is assumed here that all moisture entering the system is with the wet coal, and that the air entering is dry air only. It is further assumed, due to the homogeneous nature of temperature distributions within a fluidized bed, that the air, coal and moisture leaving the system do so at the same temperature.

\section{Conservation of Mass}

From the principles of conservation of mass for a control volume operating at steady state conditions, the rates of airflow, dry coal and moisture entering and exiting the system must be equal. This is expressed in the following equations.

$$
\begin{aligned}
& \left(\dot{m}_{\text {air }}\right)_{\text {in }}=\left(\dot{m}_{\text {air }}\right)_{\text {out }} \Rightarrow \dot{m}_{a 1}+\dot{m}_{a 2}+\dot{m}_{a 3}=\dot{m}_{a 4} \\
& \left(\dot{m}_{\text {coal }}\right)_{\text {in }}=\left(\dot{m}_{\text {coal }}\right)_{\text {out }} \Rightarrow \dot{m}_{\text {coal }, 2}=\dot{m}_{\text {coal }, 3}
\end{aligned}
$$




$$
\left(\dot{m}_{\text {water }}\right)_{\text {in }}=\left(\dot{m}_{\text {watervapor }}\right)_{\text {out }}+\left(\dot{m}_{\text {water }}\right)_{\text {out }} \Rightarrow \dot{m}_{\text {water }, 2}=\dot{m}_{\text {water }, 3}+\dot{m}_{\text {vapor }, 4}
$$

where Figure 2-6 depicts the control volume and associated subscript locations.

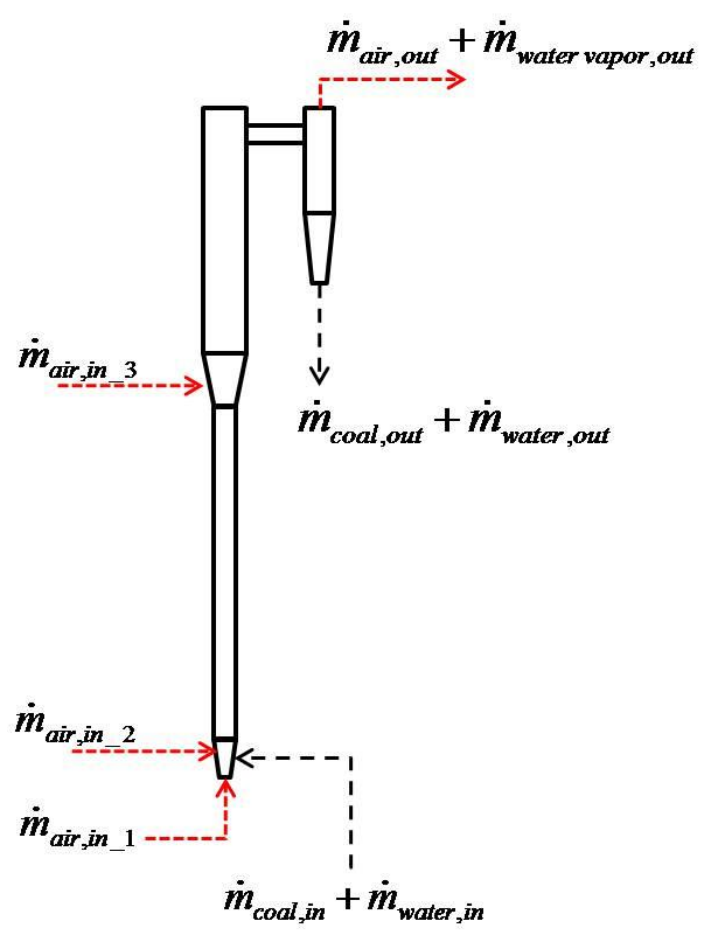

Figure 2-5: WADFP system diagram

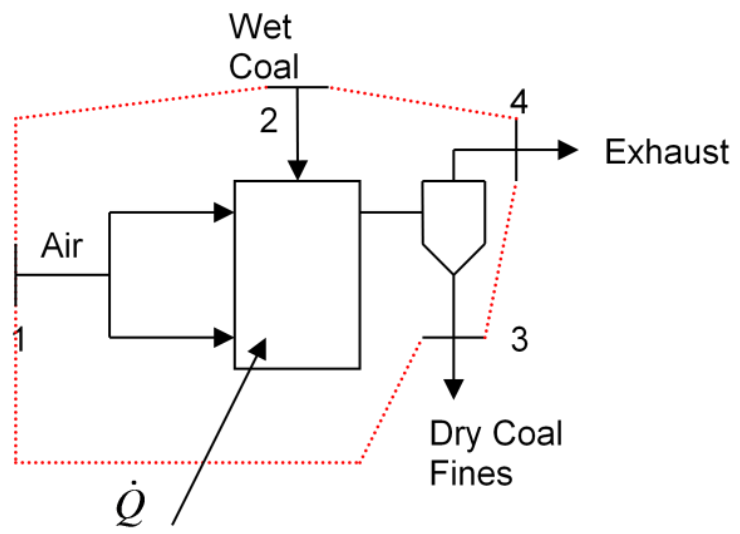

Figure 2-6: Control Volume for thermodynamic analysis 


\section{Energy Analysis}

Based upon the notation used in Figure 2-6, the steady state energy equation for the system is given by:

$$
0=\dot{Q}+\dot{m}_{1} h_{1}+\dot{m}_{2} h_{2}-\dot{m}_{3} h_{3}-\dot{m}_{4} h_{4}
$$

However, due to the fact that the mass flow rates, $\dot{m}$, at locations 2 and 3 consist of moisture as well as solids material, it is necessary to decompose the third and fourth terms of the RHS of the above equation into their constituent parts.

$$
\begin{aligned}
& \dot{m}_{2} h_{2}=\xi_{2} \dot{m}_{2} h_{f 2}+\left(1-\xi_{2}\right) \dot{m}_{2} h_{2 c} \\
& \dot{m}_{3} h_{3}=\xi_{3} \dot{m}_{3} h_{f 3}+\left(1-\xi_{3}\right) \dot{m}_{3} h_{3 c}
\end{aligned}
$$

where $\xi$ is the percent moisture content at each location, written as a decimal fraction. The subscripts "c" and "f" denote coal and fluid (water), respectively.

Similarly, the exhaust at location 4 must be decomposed into its air and water vapor components.

$$
\dot{m}_{4} h_{4}=\dot{m}_{4 a} h_{4 a}+\dot{m}_{4 v} h_{4 v}
$$

However, for steady state operation and assuming that the specific humidity at location 1 is 0 , conservation of mass requires:

$$
\dot{m}_{4 a}=\dot{m}_{1}
$$

In addition, the mass flow of vapor at 4 can be written in terms of the air flow rate into the system at location one by:

$$
\dot{m}_{4 v}=\bar{\omega}_{4} \dot{m}_{1}
$$

Where $\bar{\omega}_{4}$ is the specific humidity at location 4 .

Substituting these relations into Equation (2.28) leads to the following: 


$$
\dot{m}_{4} h_{4}=\dot{m}_{1} h_{4 a}+\bar{\omega}_{4} \dot{m}_{1} h_{4 v}
$$

Combining equations (2.25), (2.26), (2.27) and (2.31) yields:

$$
\begin{aligned}
0= & \dot{Q}+\dot{m}_{1} h_{1}+\xi_{2} \dot{m}_{2} h_{2 f}+\left(1-\xi_{2}\right) \dot{m}_{2} h_{2 c}-\xi_{3} \dot{m}_{3} h_{3 f} \\
& -\left(1-\xi_{3}\right) \dot{m}_{3} h_{3 c}-\dot{m}_{1} h_{4}-\bar{\omega}_{4} \dot{m}_{1} h_{4 v}
\end{aligned}
$$

Upon rearranging and solving for the rate of heat transfer, $\dot{Q}$, this can be rewritten as:

$$
\dot{Q}=-\left[\begin{array}{l}
\dot{m}_{1}\left(h_{1}-h_{4 a}-\bar{\omega}_{4} h_{4 v}\right)+\dot{m}_{2}\left(\xi_{2} h_{2 f}+\left(1-\xi_{2}\right) h_{2 c}\right) \\
-\dot{m}_{3}\left(\xi_{3} h_{3 f}+\left(1-\xi_{3}\right) h_{3 c}\right)
\end{array}\right]
$$

The heat transfer term $\dot{Q}$ can be further broken down into;

$$
\dot{Q}=\dot{Q}_{\text {evap }}-\dot{Q}_{\text {loss }}
$$

$\dot{Q}_{\text {evap }}$ is the rate of heat transfer due to evaporation of moisture and is given by:

$$
\dot{Q}_{\text {evap }}=\bar{\omega}_{4} \dot{m}_{1} h_{f g},
$$

where $\mathrm{h}_{\mathrm{fg}}$ is the latent heat of vaporization of water at the average temperature of the wet material.

$\dot{Q}_{\text {loss }}$ is the rate of heat lost to the system surroundings; in the case of an insulated system with no losses, this term can be neglected.

\section{Energy Efficiency}

Giner and Calvelo [56] defined the thermal efficiency of the fluidized bed drying process as:

$$
\eta_{t h}=\frac{\text { Energy transmitted to the solid }}{\text { Energy incorporated in the drying air }}
$$

Syrahrul, et al. [57] propose the following expression (modified for current symbols usage) of the thermal efficiency in terms of the energy rate balance equation: 


$$
\eta_{\text {th }}=\frac{\dot{m}_{\text {coal }}\left\lfloor h_{f g}\left(\xi_{2}-\xi_{3}\right)+c_{\text {coal }}\left(T_{\text {coal }, \text { out }}-T_{\text {coal,in }}\right)\right]}{\dot{m}_{\text {air }}\left(h_{\text {air, in }}-h_{0}\right)}
$$

\section{Entropy Analysis}

While mass and energy are conserved quantities, this is not true of entropy. To account for the changes in entropy, the entropy balance must be taken into consideration. An analysis of the entropy balance within the fluidized bed drying process can be approached in a manner similar to that provided for the energy analysis provided in the previous section.

For a steady-state, open system based upon the design of the WADFP unit, the entropy balance can be written as:

$$
0=\frac{\dot{Q}}{T}+\dot{m}_{1} s_{1}+\dot{m}_{2} s_{2}-\dot{m}_{3} s_{3}-\dot{m}_{4} s_{4}+\dot{S}_{g e n}
$$

However, as in the previous section, the quantities at locations 2,3 and 4 consist of combinations of solid material, air and moisture; which must be broken down into their constituent components.

Following the same procedure used for the energy balance discussion yields

$$
\begin{aligned}
0= & \frac{\dot{Q}}{T}+\dot{m}_{1} s_{1}+\xi_{2} \dot{m}_{2} s_{2 f}+\left(1-\xi_{2}\right) \dot{m}_{2} s_{2 c}-\xi_{3} \dot{m}_{3} s_{3 f} \\
& -\left(1-\xi_{3}\right) \dot{m}_{3} s_{3 c}-\dot{m}_{1} s_{4}-\bar{\omega}_{4} \dot{m}_{1} s_{4 v}+\dot{S}_{g e n}
\end{aligned}
$$

Rearranging and combining terms yields the following expression for the rate of entropy generation within the fluidized bed. 


$$
\dot{S}_{g e n}=-\left[\begin{array}{l}
\dot{m}_{1}\left(s_{1}-s_{4 a}-\bar{\omega}_{4} s_{4 v}\right)+\dot{m}_{2}\left(\xi_{2} s_{2 f}+\left(1-\xi_{2}\right) s_{2 c}\right) \\
-\dot{m}_{3}\left(\xi_{3} s_{3 f}+\left(1-\xi_{3}\right) s_{3 c}\right)+\frac{\dot{Q}}{T}
\end{array}\right]
$$

\section{Exergy Analysis}

Exergy is a term describing the availability of useful work potential within a system without violating any thermodynamic laws. [58] The energy balance equation for a steady state control volume based upon the WADFP fluidized bed is obtained by multiplying the entropy equation (2.40) by a reference temperature, $\mathrm{T}_{0}$, and subtracting it from the energy equation (2.32). This yields the following:

$$
\begin{aligned}
& 0=\dot{Q}\left(1-\frac{T_{0}}{T}\right)+\dot{m}_{1}\left[\left(h_{1 a}-h_{4 a}-\bar{\omega}_{4} h_{4 v}\right)-T_{0}\left(s_{1}-s_{4 a}-\bar{\omega}_{4} s_{4 v}\right)\right]+ \\
& \dot{m}_{2}\left[\left(\xi_{2} h_{2 f}+\left(1-\xi_{2}\right) h_{2 c}\right)-T_{0}\left(\xi_{2} s_{2 f}+\left(1-\xi_{2}\right) s_{2 c}\right)\right]- \\
& \dot{m}_{3}\left[\left(\xi_{3} h_{3 f}+\left(1-\xi_{3}\right) h_{3 c}\right)-T_{0}\left(\xi_{3} s_{3 f}+\left(1-\xi_{3}\right) s_{3 c}\right)\right]-T_{0} \dot{S}_{g e n}
\end{aligned}
$$

Or, in a more simplified form:

$$
0=\dot{E}_{2 c}-\dot{E}_{3 c}+\dot{E}_{2 f}-\dot{E}_{3 f}+\dot{E}_{1 a}-\dot{E}_{4 a}-\dot{E}_{4 v}+\dot{E}_{\text {evap }}-\dot{E}_{D}
$$

where $\dot{E}_{D}$ is the rate of exergy destruction in the dryer.

Syrahrul et al. [59] gives the rate exergy transfer due to evaporation as:

$$
\dot{E}_{\text {evap }}=\left[1-\frac{T_{0}}{T}\right] \dot{Q}_{\text {evap }}=\left[1-\frac{T_{0}}{T}\right] \bar{\omega}_{4} \dot{m}_{1} h_{f g}
$$

In addition, Syrahrul et al. states that the exergy efficiency, based upon the exergy rate balance, is given by: 
$\eta_{e x}=\frac{\text { rate of exergy transfer due to evaporation }}{\text { rate of exergy transfer of entering air }}$

Or

$$
\eta_{e x}=\frac{\left[1-\frac{T_{0}}{T}\right] \bar{\omega}_{4} \dot{m}_{1} h_{f g}}{\dot{m}_{1}\left[\left(h_{1}-h_{0}\right)-T_{0}\left(s_{1}-s_{0}\right)\right]}
$$




\section{Chapter 3 Fluidized Bed Scaling}

When utilizing a smaller scale fluidized bed operating at low temperatures and atmospheric pressure to model the processes taking place within a larger bed operating at higher temperatures and pressures, one must be careful to accurately account for the differences between the two operating regimes. In addition to ensuring that both fluidized beds have similar geometric features, it is necessary to incorporate the effects of temperature and pressure upon the material properties of fluidizing gas, as changes in density and viscosity can have drastic effects upon the performance characteristics of a fluidized bed.

Over the last couple of decades, there have been many attempts to develop a set of scaling relationships between high temperature and pressure fluidized bed combustors and reactors and smaller "cold" scale models operated at atmospheric conditions. The following sections provide a summary of some of the more well-known works related to hydrodynamic scaling of fluidized beds, including scaling relationships and common techniques for experimental verification of hydrodynamic similitude.

\section{Hydrodynamic Scaling Relationships}

The following sections provide a detailed review of bubbling fluidized bed scaling literature by such authors as Glicksman, Horio, Zhang and Yang $[\mathbf{6 0 , 6 1 , 6 2 , 6 3 , 6 4 , 6 5 ] . ~ I n ~ a d d i t i o n , ~ a n ~}$ alternate approach suggested by van den Bleek et al. [50] utilizing entropy and chaos analysis is presented.

\section{Glicksman's Scaling Relationships.}

Leon Glicksman [60] developed a set of scaling relationships for fluidized beds by nondimensionalizing the governing equations of the conservation of mass and momentum for the fluidizing gas and bed particles. The resulting non-dimensional parameters are: 


$$
\frac{\rho_{s} \rho_{f} d_{p}^{3} g}{\mu^{2}}, \frac{u_{0}^{2}}{g d_{p}}, \frac{\rho_{f}}{\rho_{s}}, \frac{L}{d_{p}}, \frac{D}{d_{p}}, \phi_{s}
$$

Glicksman then goes on to consider a pair of extreme situations in his analysis. The first extreme occurs when particles are closely spaced and the bed approaches a packed bed, resulting in low Reynolds number $(\operatorname{Re} \leq 4)$ and Ergun equation is dominated by the viscous term. In this situation, the effect of the density ratio term in equation 3.1 becomes negligible and the list of scaling parameters can be reduced to the following.

$$
\frac{u_{0}^{2}}{g d_{p}}, \frac{\rho_{s}^{2} d_{p}^{3} g}{\mu^{2}}, \frac{L}{d_{p}}, \frac{D}{d_{p}}, \phi_{s}
$$

For the inertia-driven condition (for high Reynolds number), the governing parameters become:

$$
\frac{u_{0}^{2}}{g d_{p}}, \frac{\rho_{f}}{\rho_{s}}, \frac{L}{d_{p}}, \frac{D}{d_{p}}, \phi_{s} \text { (as well as particle size distribution and bed geometry) }
$$

Finally, between the upper and lower Reynolds number limits, both the viscous and inertial forces are important to the fluid dynamics of the system and no simplifications can be made.

In summary, according to Glicksman, to attain completely similar behavior between a hot bed and a model at atmospheric temperature, the value of each of the non-dimensional parameters must be the same for the two beds. If the hot bed operates in the viscous or inertial dominated regions, then the number of parameters can be reduced to those provided in 3.2 and 3.3, respectively.

In a subsequent paper, Nicastro and Glicksman [63] provided experimental verification of the scaling laws put forth for the low Reynolds number viscous regime [60]. In that study, tests 
carried out on an atmospheric fluidized bed combustor operating at $1050 \mathrm{~K}$ and its scale model operating at ambient temperature showed good agreement between fluid dynamic characteristics measured by minimum fluidization velocity and pressure fluctuations caused by bubbles.

\section{Alternative Glicksman Scaling Laws for the Viscous Limit}

In response to an alternative method suggested by Horio, et al. [64], Glicksman [61] later proposed an alternate set of scaling laws for the viscous-dominated regime. In this alternative method, he proposed non-dimensionalizing all of the length coordinates in the equations of motion and conservation of mass by a bed dimension, $L$, instead of by the particle diameter, $d_{p}$. This method of non-dimensionalization results in the following governing parameters:

$$
\frac{u_{0}^{2}}{g L}, \frac{u_{0}}{u_{m f}}, \frac{L}{D}, \frac{L_{1}}{L_{2}}, \phi_{s} \text {, as well as particle size distribution }
$$

According to Glicksman [61], when applied within the viscous limit, these scaling parameters are identical to those proposed by Horio [64].

\section{Glicksman's Simplified Scaling Relationships}

In his 1993 publication, Glicksman et al. [62] introduced a new, "simplified" approach to fluidized bed scaling. The purpose of this approach was to ease the stricter requirement for similar geometry between the hot and cold beds in order to allow the scaling parameters to cover a wider range of scaling options. Glicksman concludes that for all cases (including viscous and enertial dominant), similititude can be obtained by maintaining constant values for the following list of dimensionless parameters:

$$
\frac{u_{0}^{2}}{g L}, \frac{\rho_{s}}{\rho_{f}}, \frac{u_{0}}{u_{m f}}, \frac{L_{1}}{L_{2}}, \frac{G_{s}}{\rho_{s} u_{0}}, \phi \text {, and particle size distribution. }
$$




\section{Horio's Scaling Parameters.}

Whereas Glicksman $[\mathbf{6 0}, \mathbf{6 1}, \mathbf{6 2}]$ formulated his fluidized bed scaling parameters by nondimensionalizing the basic momentum and mass conservation equations and examining the resulting non-dimensional groupings, Horio et al. [64] proposed an alternative approach to fluidized bed scaling. The set of scaling parameters derived by Horio et al. are based primarily upon maintaining geometric similarity between a large bed operating at high temperatures and pressures and a scale model operating at ambient conditions. Horio et al, approach the issue from the perspective of the bubble behavior within the fluidized bed. This approach attempts to insure similarity in bubble geometry, splitting frequency, rise time as well as similarity of the flow field around each bubble between the two beds under comparison.

With this approach, it is assumed that the bed height $L$, column diameter $D$, distributor orifice diameter $d$, orifice pitch $P$ and other structural aspects of the bed design are changed by the same proportional amount, $m$. In other words, for two beds of differing sizes,

$$
m=\frac{L}{L^{\prime}}=\frac{D}{D^{\prime}}=\frac{P}{P^{\prime}}=\frac{d}{d^{\prime}}
$$

The final scaling parameters proposed by Horio et al. include not only those listed in equation (3.6), but also includes the following:

$$
\begin{aligned}
& \frac{u_{m f}}{\sqrt{g D}}=\frac{u_{m f}^{\prime}}{\sqrt{g D^{\prime}}} \\
& u_{0}-u_{m f}=\sqrt{m}\left(u_{o}-u_{m f}\right)^{\prime}
\end{aligned}
$$

for bubble coalescence, and 


$$
u_{m f}=\sqrt{m} u_{m f}^{\prime}
$$

for geometrically similar flow field around bubble and for similar bubble splitting.

The full derivation method of Horio's scaling parameters is not included as these results are nearly identical to the alternate viscous limit scaling parameters as discussed by Glicksman [61]. In fact, Glicksman states that one of the purposes of his short paper is to show that the Horio scaling parameters can be obtained via non-dimensionalizing the basic momentum and mass conservation equations by a characteristic bed length (such as bed height or column diameter) and simplifying the Ergun equation for the low Reynolds number case.

\section{Zhang and Yang's Scaling Laws}

Another set of dimensionless scaling laws for fluidized bed similarity was proposed by Zhang and Yang [65] for bubbling beds. Following an approach similar to that utilized by Glicksman, Zhang and Yang presented a set of scaling parameters for a bubbling bed operating in the intermediate, viscous and inertial ranges.

For the viscous dominant region, i.e., $\mathrm{Re}<4$, Zhang and Yang concluded that similarity between two fluidized beds could be maintained by keeping the following similarity groups identical:

$$
\frac{g D}{U_{0}^{2}} \text { and } \frac{\rho_{s}^{2} g\left(\phi_{s} d\right)^{4}}{\mu_{f}^{2} D}
$$

For the inertially-dominant region, i.e., $\mathrm{Re}>400$, the required similarity groups become:

$$
\frac{g D}{U_{0}^{2}} \text { and } \frac{\rho_{f} D}{\rho_{s} \phi_{S} d}
$$


Finally, in the transition region where both viscous and inertial forces are significant, the governing groups are given as:

$$
\frac{g D}{U_{0}^{2}}, \frac{\rho_{s}^{2} g\left(\phi_{s} d\right)^{4}}{\mu_{f}^{2} D}, \frac{\rho_{f} D}{\rho_{s} \phi_{S} d}
$$

One major difference between this method proposed by Zhang and Yang and the similarity laws proposed by Glicksman is that the similarity groups of Zhang and Yang do not require a constant particle density to fluid density ratio between the beds being compared. Under the Glicksman approach, maintaining a constant $\rho_{s} / \rho_{f}$ requires the use of a different solids material in the scale model than that used in the full-scale fluidized bed. However, the approach described by Yang and Zhang allow for the same solids material to be used in both beds. This is possible due to the fact that their approach does not require a set particle-to-bed diameter ratio.

Zhang and Yang justify this by noting that $g D / U_{0}^{2}$ and $U_{0} / U_{m f}$ are equivalent to $g D / U_{m f}^{2}$ and $U_{0} / U_{m f}$, thus

$$
\frac{U_{m f, A}}{U_{m f, B}}=\left(\frac{D_{A}}{D_{B}}\right)^{1 / 2}
$$

where the subscripts A and B denote the two fluidized beds being compared. Zhang and Yang utilize equation (3.13) by determining the required minimum fluidization velocity to satisfy (3.13) and selecting an appropriate particle size to obtain that velocity. 


\section{Scaling with Entropy}

During their exploration of the application of chaos analysis to multiphase reactors, van den Bleek et al. [50] demonstrated that application of the Glicksman scaling parameters can lead to drastic differences in Shannon entropy values even when the Glicksman scaling guidelines are followed.

To address this issue, a dimensionless entropy number is introduced:

$$
K \sqrt{H_{b} / g}
$$

Where $\mathrm{K}$ is the Kolmagorov entropy, and

$$
K \sqrt{\frac{H_{b}}{g}}=\left(\frac{\left(U_{o}-U_{m f}\right)^{2}}{g H_{b}}\right)^{m}\left(\frac{H_{b}}{D_{t}}\right)^{n}
$$

In equation (3.15), $H_{b}$ is the dense bed height and $D_{t}$ is the riser diameter. The exponents " $m$ " and " $n$ " are experimentally determined and vary with fluidization regime.

van den Bleek et al. go on to state that scaling for entropy similarity should take priority, and to do so, it is necessary to ensure that the Froude number and bed aspect ratios are maintained constant between fluidized beds. The general approach suggested by van den Bleek is to pick a known scaling method (such as that proposed by Glicksman) and follow it as closely as possible; however give priority to the Froude number and bed aspect ratio, even if doing so means other scaling parameters are not maintained.

\section{Experimental Verification Techniques of Scaling Laws}

Several of the authors mentioned in the previous sections of this Chapter, as well as others $[63,66,67,65]$, have provided experimental verification of the scaling laws previously discussed. 
Nicastro and Glicksman $[\mathbf{6 3}]$ and Westphalen [66] analyzed fluctuating pressure signals to determine the mean, standard deviation, probability density and power spectral density functions for each fluidized bed being tested, and then compared the results between the them. Westphalen [66] also compares the probability density function of the solids fractions between beds. Ellis, et al. [67] utilizes the probability density of the bed voidage, radial voidage profiles and particle velocity versus bed voidage comparisons in determining bed similarity. Zhang and Yang $[\mathbf{6 5}]$ compare bed properties such as collapsed bed height, pressure drop, particle entrainment rate and minimum fluidization velocities to determine similarity.

The most common method of hydrodynamic similarity verification found in literature is to compare the probability distribution function (PDF), autocorrelation and power spectral density (PSD). However, nearly all of the literature pertaining to these methods is given in reference to a fluidized bed operating in the bubbling fluidization regime. In a bubbling bed, the bubble formation is periodic in nature where the frequency of bubble formation is driven by a single dominant frequency. Because of this, the periodic nature of the autocorrelation function can easily be seen, as can the presence of a dominate frequency in the spectral density plot. Unfortunately, these methods are less than ideal for turbulent fluidization conditions. In turbulent fluidization, the bubble formation is non-periodic and occurs over a wide range of frequencies with no single frequency dominant.

To address this, van den Bleek et al. [50] proposes use of the strange attractor and nondimensional entropy number for verification of hydrodynamic similarity in turbulent fluidization. A common method for comparing different attractors in order to determine whether or not they originate from similar dynamic systems is by application of the Diks test [68]. This test calculates a dimensionless distance, $\mathrm{S}$, between two attractors. If the value of "S" is less than 3 , 
then the attractors are based upon similar physical systems. The dimensionless distance, $\mathrm{S}$, is defined by Diks et al. [69] as:

$$
S=\frac{\hat{Q}}{\sqrt{V_{c}(\hat{Q})}}
$$

Where $\hat{Q}$ is a statistical estimator of the distance between two distributions, and $V_{c}$ is the variance. This method is described in greater detail by Diks et al. [69]. 


\section{Chapter 4 Scale Model System}

As stated previously, there are two different fluidized beds utilized in this study. The first system is a steam jacketed fluidized bed known as the Warm Air Dryer for Fine Particles, or WADFP. The second system, which is the subject of this chapter, is a small half scale model of the WADFP that was designed and constructed with the intent of being used to first establish the feasibility of operating the WADFP within the desired fluidization regimes, as well as provide data for scaling analysis and verification for the larger fluidized bed.

\section{General Design Concepts}

Both fluidized beds utilize a design that incorporates two multiple-section stages of differing diameters. The lower stage of each bed consists of three removable "small-diameter" pipe sections; while the upper stage of each bed consists of two "large-diameter" pipe sections (one of which is removable). The two stages are connected via a conical injection ring which serves as both a transition from the smaller to larger diameter stages as well as the means by which additional airflow is to be introduced into the upper section of the riser. Similarly, the fluidizing gas (air) is introduced into the lower section of the riser via a distributor section. The fluidizing gas (and entrained particles) exits the top of the riser via an outflow port, where the particulate matter is separated from the exhaust gas via a cyclone. Finally, a feed hopper supplies particulate matter into the riser. Figure 4-1 is a schematic illustration of the basic design of the scale model fluidized bed, as well as shows the general placement of the components discussed above.

A detailed description of the various components of the scale model is given in the following sections; a similar description of the WADFP unit can be found in Chapter Six. 


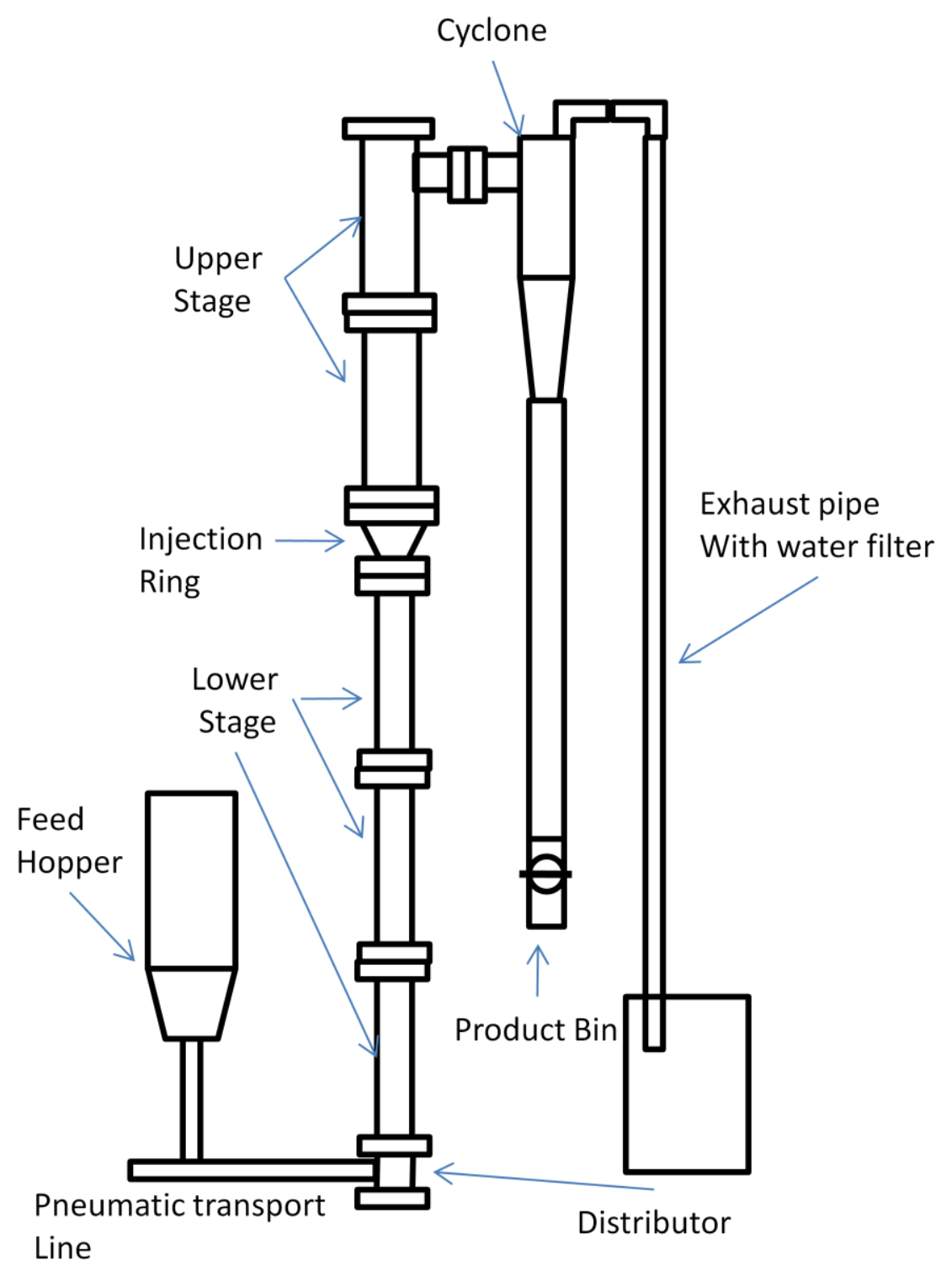

Figure 4-1: Layout for scale model fluidized bed

\section{System Design}

\section{Design Criteria}

The primary consideration behind the design of the scale model fluidized bed was that it was a close physical representation of the larger warm air dryer of fine particles (WADFP) fluidized bed. The scale model riser and cyclone have been designed to maintain a $0.5: 1$ dimensional ratio with the WADFP. The "tube" sections of the lower and upper stages of the riser are constructed 
of transparent acrylic PVC in order to allow for visual inspection and video recording of the fluidization conditions within the riser during operation. The distributor, injection ring and cyclone were unable to be manufactured out of acrylic PVC due to manufacturing limitations and were thus manufactured of carbon steel by Wilson Works in Morgantown, WV.

The scale model fluidized bed experimental system consists of four sections: the riser, cyclone, product bin and feed hopper. Detailed engineering drawings of the scale model system were generated with Autocad and are included on the accompanying dvd.

\section{Riser}

The fluidized bed riser is characterized by two distinct stages of differing diameters, as well as a lower air distributor at the bottom of the lower stage and a conical secondary air injection ring located between the upper and lower stages.

\section{Lower Riser Stage}

The lower stage of the riser consists of the 3 small diameter pipe sections. Each of the pipe sections are approximately 18.375 inches in height and have an inside diameter of 2.29 inches and are made of transparent acrylic pipe. The original design called for 2.5 inch diameters for these sections; however, material availability necessitated the use of 2.29 ID pipe as that was the closest available size. In addition, the top and bottom of each section has 0.5 inch thick flanges

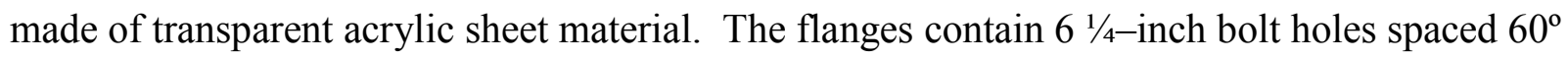
apart so that the sections can be bolted together.

\section{Bottom Air Distributor}

The distributor consists of two components. The lower component is simply a circular flange to which is welded a $3 / 4$-inch steel Tee (positioned vertically). The lower vertical hole of the tee is 
plugged with 3/4-inch plug that can be removed to allow solid particles to drain from the bottom of the riser. The horizontal section of the tee is connected to the air feed/solids feed systems via schedule 80 plastic $3 / 4$ " pipe nipple and serves as one of the two air feeds into the distributor, as well as the location at which the bed solids material enters the riser. The top vertical portion of the tee is welded to the flange so that it matches up to a $3 / 4$-inch hole in the flange.

The upper component of the distributor consists of an inner cone-shaped section with a lower inner diameter of $3 / 4$-inches and an upper inner diameter of 2.29 inches. This inner cone is perforated with three levels of 0.07 inch diameter holes (each level consists of a horizontal plane of holes spaced equidistantly around the cone). The first, second and third sets of holes have 8 , 16 and 32 holes, respectively. In addition, the inner cone is surrounded by an outer cylindrical tube. The second of the two lower air injection ports is located horizontally on this tube. The air entering this port is distributed throughout the cavity between the outer cylindrical shell and the interior cone, and then passes through the perforations in the cone and into the riser. As the perforations are positioned so that each hole is offset radially by an opposing hole, it is assumed that the air entering through these holes will help keep the bottom jet of air aligned with the centerline of the riser.

\section{Secondary Air Injection Ring}

The secondary air injection ring is located at the transition point between the lower and upper riser stages. It consists of two cone-shaped sections, one inside the other with a separation of $1 / 4-$ inch. The inner cone has a lower diameter of 2.29 inches and an upper diameter of 4.0 inches (matching the lower and upper riser stage diameters). Like the distributor section, the inside cone of the injection ring is perforated with two rows of 30 3/16-inch diameter holes close to the top of the cone through which air will enter the riser radially. The outer cone section has a 
horizontally-placed $3 / 4$ " female threaded pipe fitting that that serves as the connection for the secondary air source.

\section{Upper Riser Stage Components}

The upper phase of the riser consists of 2 large diameter pipe sections. Each of the pipe sections are approximately 18.375 inches in height and have an inside diameter of 4.0 inches with 0.5 inch thick flanges and are made of transparent acrylic pvc pipe. The flanges contain $6 \frac{1 / 4-i n c h}{1}$ bolt holes spaced $60^{\circ}$ apart so that the sections can be bolted together. The second pipe section also has a 2.29 inch ID side outflow port located 3 inches below the top of the section. This port attaches to the system's cyclone.

\section{Feed Hopper}

The solid particle material used in this experimental work are introduced into the fluidized bed riser by means of a feed hopper mounted adjacent to the riser. Solids material is passed out of the hopper and into a pneumatic transport line. This pneumatic transport line doubles as one of the lower air feed lines for the lower riser distributor section.

The feed hopper for the scale model system was taken from the experimental system designed and used by a previous graduate student and is described in greater detail in his Thesis [70]. In summary, this feed hopper is constructed of a 36 " long section of 5 " inner diameter, $1 / 2$ " thick clear acrylic tubing. At the bottom of the hopper clay-to-plastic pipe rubber boot connects a $4 \times 2$ inch reducing coupling to the hopper. The coupling uses a $2 x^{1 / 2-i n c h ~ s t r a i g h t ~ t o ~ t h r e a d e d ~ b u s h i n g ~}$ to connect to the pneumatic transport line. In addition, an adapter was required to connect this hopper to the pneumatic transport line. This adapter will be discussed in the next section. 


\section{Pneumatic Transport Line}

The pneumatic transport line (PTL) consists of a $3 / 4$ " schedule 80 plastic tee with a 3 "long schedule 80 threaded pipe nipple attached to either end. The left nipple is attached to a $3 / 4$ " threaded coupling with a $3 / 4$ " to $1 / 2$ " brass bushing and a $1 / 2$ " to $1 / 4$ " brass bushing. Inside this final bushing is a $1 / 4 " x 1$ " pipe nipple to which one of the three air lines is connected via a pipe clamp. A 6" section of 1"-ID flexible hose connects the pipe nipple to the right of the $3 / 4$ " tee to the $3 / 4$ " pipe nipple connected to the lower distributor of the riser.

In order to make use of the feed hopper discussed previously, an adapter was required to connect the hopper to the PTL. To do this, a schedule $40 \frac{1}{2}$ " threaded ball valve was used in conjunction with a $1 / 2 " x$ " $"$ and a $1 / 2 " x 2 "$ threaded pipe nipple and a $3 / 4 " x 1 / 2 "$ threaded brass bushing. In order to help prevent solids material from clogging this adapter, the 4" pipe nipple was drilled and tapped so that $2 \frac{1 / 4}{4}$ male quick-disconnects could be added. These allow for small amounts of air to be injected into the adapter to aid in solids flow and help break up any clogs that may form.

\section{Cyclone}

The cyclone for the scale model riser was designed so that its major dimensions are $1 / 2$ that of the cyclone for the WADFP system. The cyclone has a 5-inch id at the top, tapering down to 1.5inches at the bottom and an overall length of 24 inches. The cyclone connects to the riser outflow pipe via a 2.5 -inch id flanged pipe and is supported via an L-shaped mounting bracket that bolts to the strut channel rack upon which the entire fluidized bed is mounted. A 1.5-inch id pipe elbow exits the top of the cyclone. During operation, particle-laden air enters through the $2 \frac{1 / 2}{2}$ pipe and the particulate matter falls down throw the bottom and the air exits through the top. 


\section{Product Bin}

The product collection bin is constructed of 3 inch id, 60 inch long SCH 80 PVC piping. The top of the product bin connects to the cyclone via a $3 \times 2$ inch reducing coupling. The bottom of the product bin has a 3 inch PVC ball valve to prevent solids and gas flow during testing, as well as allow for easy removal of solids after testing.

\section{Exhaust Gas Filtration}

The exhaust gasses exiting the top of the cyclone are piped away from the cyclone via a $1 \frac{1 / 2}{2}$ SCH 40 PVC pipe, and then through a section of flexible 2" ID discharge hose into a 32 gallon container partially filled with water. As the exhaust gas exits the hose at the bottom of the container, it is assumed that any remaining solids particles not separated by the cyclone will be dissolved into the water reservoir as the air bubbles to the surface of the water.

\section{Air Feed System}

Figure 4-2 demonstrates the general airflow for the scale model fluidized bed riser unit. The supply air is provided via a compressor capable of providing up to 300 SCFM at 120 psi. This house air is regulated to a maximum of $120 \mathrm{psi}$ via a regulator valve and then is introduced into a manifold with three exit ports. At each of the exit ports is a 0-100 SCFM piston style flow meter. High pressure rubber hose connects one of these flow meters to the secondary air injection inlet port in the injection ring located between the upper and lower riser stages. Another of the 0-100 SCFM flow meters is connected to a second manifold, where the air is split into three different flows. One of these feeds a 0-60 SCFM flow meter that controls airflow into the lower air distributor. The second feeds a 0-8 SFCM flow meter that controls airflow into the pneumatic transport line. The final airflow out of the 0-100 SCFM flow meter is regulated to a 
maximum of 15 psig and then split into two further flows. One of these provides back pressure within the feed hopper, and the second can be used for optional aeration air to assist the flow of particles between the feed hopper and pneumatic transport line.

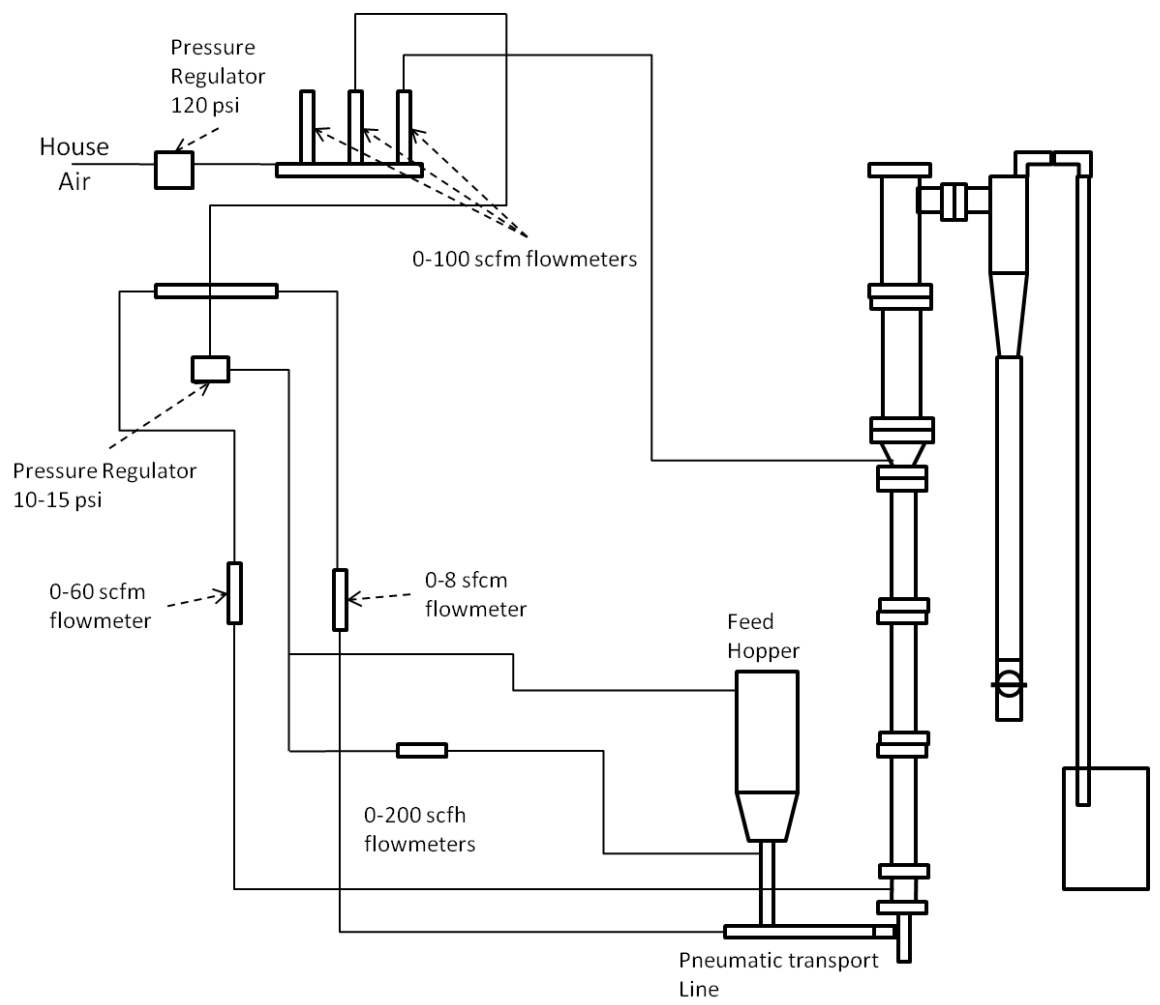

Figure 4-2: Airflow Diagram for Scale Model Riser

\section{Data Acquisition System and Instrumentation}

The following paragraphs detail the data acquisition system and instrumentation utilized in conjunction with the scale model fluidized bed. The data acquisition system and pressure transducers described here were used with the large fluidized bed dryer once testing was completed with the scale model system. 


\section{Data Acquisition System}

The data logging system used to collect and record experimental data includes a Dell GX270 computer with a Intel dual-core Pentium 2.86Gz processor with $3070 \mathrm{MB}$ of memory with an Omega Engineering OMB-DAQ-3000 usb data acquisition system with an Omega Engineering OMB-PDQ30 expansion module. The data acquisition system and expansion module allows for a combined total of 32 differential or 64 single-ended inputs that support input voltages ranging from $+/-31 \mathrm{mV}$ to $+/-10 \mathrm{~V}$, as well as 2 analog output channels. The system incorporates onboard signal conditioning and optional oversampling and 50/60 Hz noise cancellation features. The system also supports several thermocouple types. Finally, the maximum sample rate combined over all channels is 1 million samples per second.

The system utilizes Omega Engineering's Personal Daqview software suite. This software displays all channels in a spreadsheet-like format, allowing the user to activate/deactivate specific channels, as well as assign channel names and engineering units. Sampling rates, number of samples to record, triggering events, oversampling rates and noise cancellation options are also user-selectable.

\section{Pressure Gages and Transducers}

Pressure measurements throughout the riser are made with a series of 4 Omega Engineering PX35K1-030AV (0-30 psia), 1 Omega Engineering PX35K1-050AV (0-50 psia) and 1 Omega Engineering PX35K1-100AV (0-100 psia) pressure transducers. These transducers are capable of operating at temperatures of up to $325^{\circ} \mathrm{F}$ and were purchased for use in the WADFP coal drying fluidized bed. 
For the larger-diameter upper stage of the riser, two of the -030AV are located approximately 1" above the bottom flange and 1" below the outflow port for measuring bed pressures at these locations, as well as determining the pressure drop across the upper stage.

Pressures within the smaller-diameter lower stage of the riser are determined via two of the $030 \mathrm{AV}$ and the $-050 \mathrm{AV}$ transducers. The $-050 \mathrm{AV}$ transducer and one of the remaining $-030 \mathrm{AV}$ transducers are installed approximately 1" above and below the bottom-most and top-most flanges of the transparent tube sections, respectively. The difference between the readings of these transducers provides the total pressure drop across the lower stage. The final -030AV transducer is installed at the midpoint of the lower stage of the riser. The $-100 \mathrm{AV}$ transducer is installed in the lower air distributor to measure plenum chamber pressure. All of the pressure transducers have a factory specified accuracy of $+/-0.25 \%$ full scale value.

\section{Load Cell}

The feed hopper system is connected to the support frame via an Omegadyne LC101-200 load cell. This load cell has a maximum weight capacity of 200 pounds with an output voltage of 3 $\mathrm{mV} /$ Volt and an excitation voltage of 12 Volts. The solids flux rate into the riser will be calculated from the rate of change in the weight of the feed hopper as recorded by the load cell. 


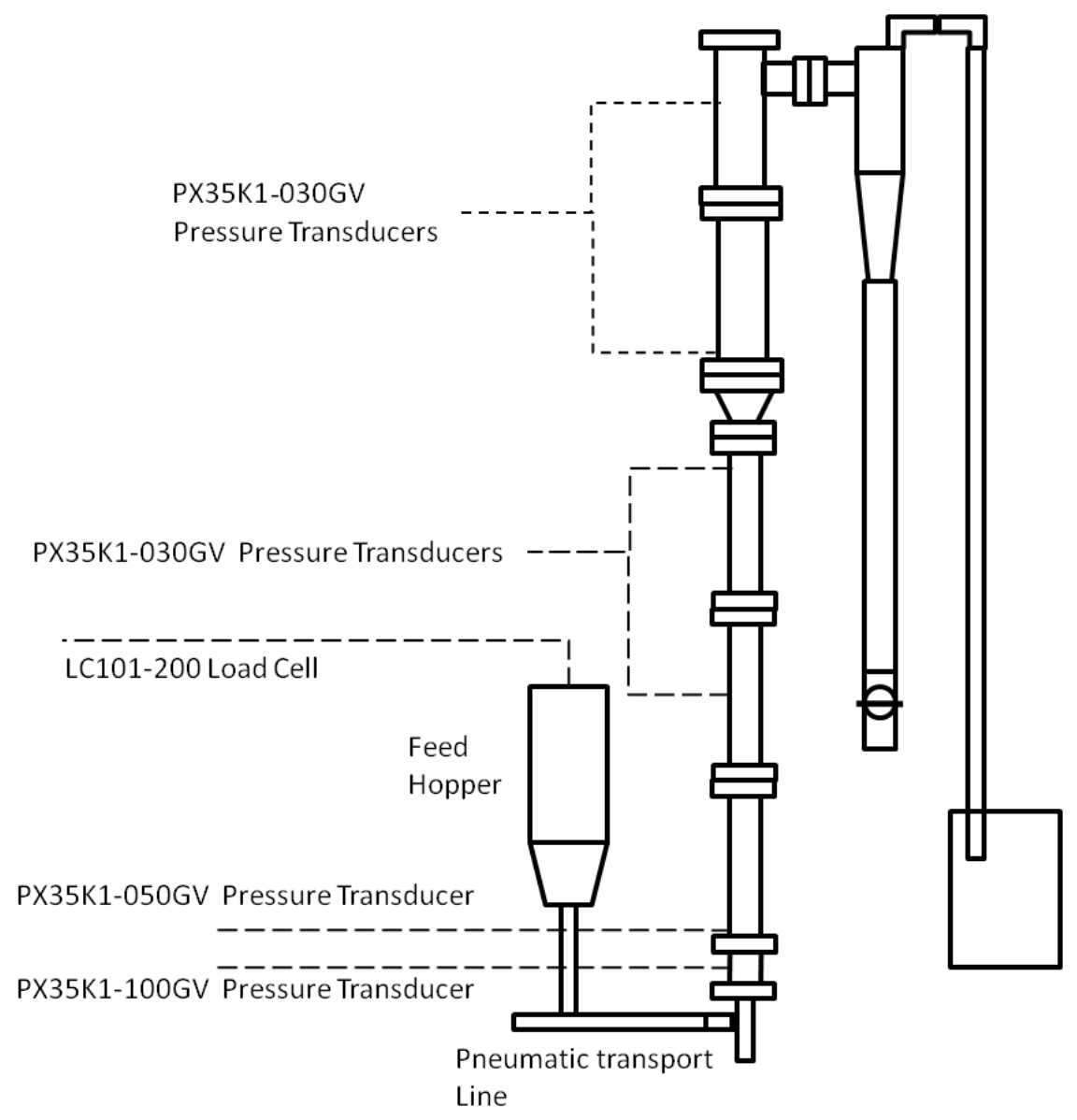

Figure 4-3: Instrumentation Diagram for Small Scale Riser

\section{Procedures}

The following directions describe the startup, shutdown and observation procedures adhered to while operating the small scale model fluidized bed riser.

\section{Start-up Procedure}

The following steps are to be followed when starting the system.

1. Check that all valves are closed.

2. Turn on the computer and open the Daqview software.

3. Turn on the instrumentation power supply.

4. Pour sand into feed hopper. 
5. Open house air supply valve completely.

6. Open air supply valve prior to 100-SCFM flow meter manifold completely.

7. Open valve to allow air to pass through the 100-SCFM flow meter to second manifold.

8. Open second manifold valves to allow air to pass to the 8 and 60 SCFM rotameters.

9. Set flow rates through the 8 and 60 SCFM rotameters to desired level for pneumatic transport line and lower distributer.

10. Set desired flow rate through the 100 SCFM rotameter controlling airflow to injection ring.

11. Set pressure regulator to desired pressure for airflow to feed hopper.

12. Open feed hopper valve

\section{Observations}

For each data point to be collected, the following steps are carried out after the fluidized bed has attained steady state conditions at the desire test conditions.

1. Assign filename, sample rate and number of samples for Daqview data logging.

2. Start Daqview data logging.

3. Acquire video of fluidization conditions within riser.

\section{Shutdown Procedures}

The following steps outline the proper system shutdown procedure.

1. Shut off airflow into feed hopper.

2. Close feed hopper valve.

3. Shut off airflow to riser.

4. Close all valves.

5. Turn off power to instrumentation. 


\section{Calibration}

Prior to the start of testing with the scale model fluidized bed riser, the pressure transducers and load cell were calibrated in order to reduce the amount of error in the measurements taken. In each case, the resulting data were fitted with a linear regression with a resulting minimum $\mathrm{R}^{2}$ value of .996 .

\section{Pressure transducer}

In order to calibrate the 50 and 100 psig pressure transducers, one of the pressure gages installed in the manifold containing the three 100 SCFM flow meters was removed and replaced with a pressure transducer. The pressure regulator upstream of the manifold was then set to a minimum of 5 pressures within the range of the transducers (verified by the gages on the regulator and the other two flow meters). Transducer voltage output was recorded for each pressure. Since the regulator and flow meter pressure gages are given in gage pressure, atmospheric pressure was read from a portable weather station and added to the psig pressure to obtain absolute pressures.

These absolute pressures where then plotted against the output voltage of the transducer to obtain a linear calibration. The same procedure was used with the 30 psia transducers, with the exception on using the $0-15$ psig pressure regulator.

\section{LC101-200 Load Cell}

The feed hopper load cell was calibrated by using a series of known calibration weights and recording the resulting voltage recorded by the data acquisition system. For each known weight, the voltage was plotted and a linear regression was applied to the resulting curve. 


\section{Test Matrix}

The following paragraphs provide a brief description of the solids materials used for testing in the scale model fluidized bed, as well as two primary test procedures for determination of turbulent fluidization in the lower stage of the riser, and core-annular flow in the upper stage.

\section{Initial Particle Sizing}

The solids material used in this study was Quickrete medium sand specified by the manufacturer as being in the $300-500 \mu \mathrm{m}$ range. However, a 100 gram sample was sieved and table $4-1$ shows the resulting particle size distribution. The scale used possessed a resolution of 5 grams, so it can be assumed that the values given below have a $+/-2.5 \mathrm{~g}$ margin of error.

\begin{tabular}{|c|c|}
\hline Screen Size (microns) & \# of grams retained by screen \\
\hline 450 & 5 \\
\hline 425 & 5 \\
\hline 315 & 25 \\
\hline 300 & 5 \\
\hline 250 & 5 \\
\hline 210 & 20 \\
\hline 150 & 40 \\
\hline 75 & 5 \\
\hline
\end{tabular}

Table 4-1: Particle Size Distribution

\section{Turbulent Regime Investigation}

The objective of this portion of the study is to determine the upper and lower bounds of the turbulent fluidization regime in the lower (small diameter) stage of the scale model riser. With air entering the riser from the lower two feeds, the solid material was fed from the feed hopper into the system via the pneumatic transport line. Material was introduced into the system at a constant rate until a dense bed of material is formed. The material feed rate out of the feed 
hopper was controlled by the back pressure in the top of the hopper (as controlled by the $0-15$ psig pressure regulator). Varying the regulator pressure setting leads to different solids flux rates. The volumetric flow rate of air into the pneumatic transport line was held at a constant $2 \mathrm{scfm}$ (corrected for line pressure and atmospheric conditions) while the volumetric flow rate of air into the lower distributor was set to one of the following scfm values for a given test: $1,2,3,4,5,6$, $8,10,12,14,16,18$

For each test condition, pressure and load cell data were recorded for a minimum of 4 minutes to ensure that the bed reached steady state conditions. In addition to collecting system pressure and load cell data, video of the fluidization conditions within the riser was recorded with a handheld digital camcorder.

The pressure data collected during this task was subjected to the analysis methods discussed in Chapter 1 in order to determine the superficial velocities corresponding to the upper and lower bounds of the turbulent fluidization regime.

\section{Fast Fluidization Regime Investigation}

Upon establishing the required operating superficial velocities for the turbulent regime for the lower stage of the riser, the next requirement was to determine the superficial velocities corresponding to the upper and lower bounds for fast fluidization, or core-annulus flow, in the upper stage of the riser.

For this phase of testing, the superficial velocity in the lower stage of the riser was maintained within the upper and lower bounds for turbulent fluidization as determined in the previous section. The operating conditions were held constant within the lower (turbulent) section of the riser while the secondary air inlet volumetric flow rate was set to the following values (in scfm): $10,15,20,25,30,35,40$. As in the fluidization regime testing, digital video of the system was taken 
during the tests and pressure and load cell data was recorded. The recorded data was likewise analyzed via the techniques discussed in Chapter 1. 


\section{Chapter 5 Scale Model Experimental Results}

Presented in this chapter are the experimental results for the small scale transparent model. These results are separated into three sections. The first section discusses the mapping and characterization of the turbulent fluidization regime in the lower riser stage. The second section discusses the mapping and characterization of the fast fluidization, or core-annulus regime in the upper riser stage. The third section examines the effects of varying secondary air injection on the lower riser stage.

\section{Lower Riser Stage Turbulent Fluidization Mapping and Characterization}

The data presented in this section was obtained from experimental runs conducted with the polydispersed sand particles fed continuously with a feed hopper back pressure of 3.5 psi.

Additionally, for the mapping of the turbulent fluidization regime in the lower riser stage only primary air injection into the two lower air inlets was used. No air was introduced into the secondary air injection ring between the lower and upper riser stages for the lower riser stage mapping.

As stated in the Chapter 4, there are a total of 3 pressure transducers located in the lower riser stage between the two air injection rings. Table 5.1 lists these transducers, as well as their designations and distance above the lower injection ring.

\begin{tabular}{|c|c|c|c|}
\hline Transducer & Pressure Range (psi) & Designation & $\begin{array}{c}\text { Distance above lower } \\
\text { injection ring (inches) }\end{array}$ \\
\hline PX35K1-G050AV & $0-50$ & Lbottom & 2.0 \\
\hline PX35K1-G030AV & $0-30$ & Lmid & 27.5 \\
\hline PX35K1-G030AV & $0-30$ & Ltop & 53 \\
\hline
\end{tabular}

Table 5-1: Lower Riser Stage Pressure Transducer Location 
Table 5-2 lists the superficial velocities (lower riser stage) for which data is presented in this section.

\begin{tabular}{|c|c|c|c|c|c|c|c|c|c|}
\hline Test \# & 1 & 2 & 3 & 4 & 5 & 6 & 7 & 8 & 9 \\
\hline $\mathrm{U}_{\mathrm{L}}(\mathrm{m} / \mathrm{s})$ & 0.57 & 0.76 & 1.14 & 1.52 & 1.90 & 2.29 & 2.67 & 3.05 & 3.43 \\
\hline
\end{tabular}

Table 5-2: Lower Riser Stage Superficial Velocity Test Points

\section{Statistical Mapping}

Fluidization regime mapping via statistical methods was carried out upon the experimental data as detailed in Chapter 1. Figure 5-1 depicts the variation of the standard deviation of pressure with the superficial velocity within the lower riser stage. As stated in Chapter 1, the maximum value of the standard deviation of pressure corresponds to the velocity at which a dense bed fluidization system undergoes transition to turbulent fluidization. From the point of maximum value, the magnitude of the standard deviation first decreases sharply and then levels off. For Geldart Type B particles, the superficial velocity at which this leveling off occurs is commonly accepted to be the velocity at which the fluidized bed transitions from turbulence to fast fluidization, or core-annular flow.

In Figure 5-1, the portion of the plots located between the dashed lines (labeled as Region II) depicts the turbulent fluidization regime as determined from analysis of the standard deviation of pressure signals.

Figure 5-2 shows the variation of the skew of the pressure signals from the lower riser stage. While Lee and Kim [43] suggest that the transition from bubbling fluidization to turbulent fluidization is characterized by a transition from negative to positive skew, this does not appear to be the case in this instance. In all but the first data point in the Lbottom skew plot, the values 
of skew are greater than zero and increase towards a maximum value. For each pressure transducer location, there is a sudden decrease in value beyond the maximum value. The location of this lower skew value corresponds to the onset of fast fluidization in Figure 5-1. This suggests that the third order statistical moment (i.e. skew) of a pressure signal can be used to locate the transition from dense fluidization to dilute fluidization regimes.

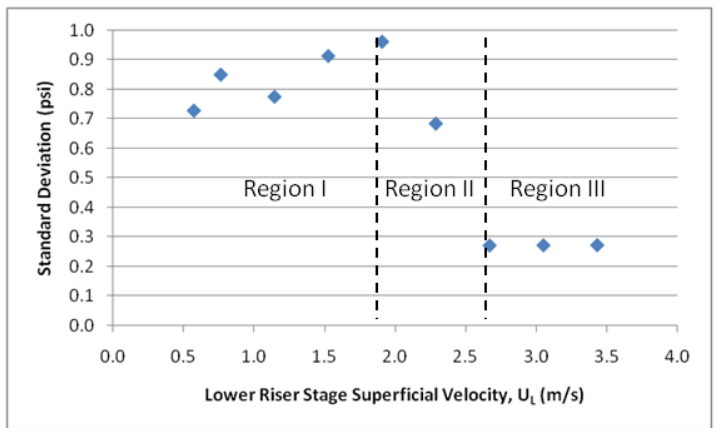

(a)

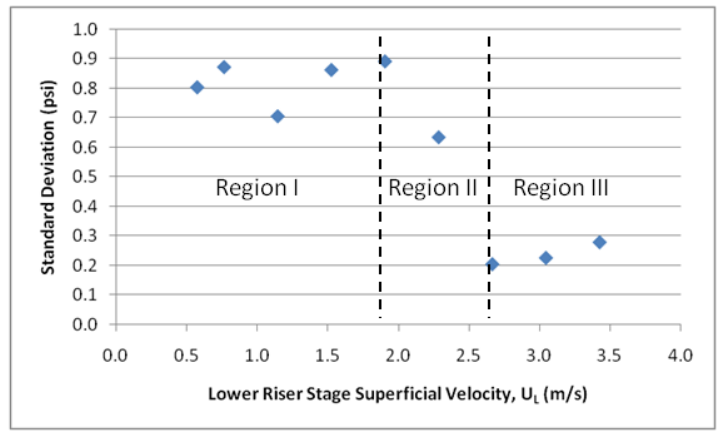

(b)

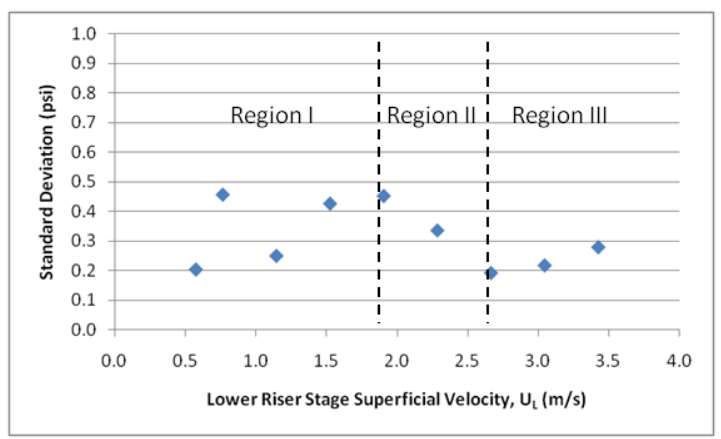

(c)

Figure 5-1 : Standard Deviation vs Superficial Velocity for Lower Riser Stage Pressures: (a) Lbottom (b) Lmid (c) Ltop; poly-dispersed sand, 3.5 psig feed hopper pressure, no secondary air injection. 


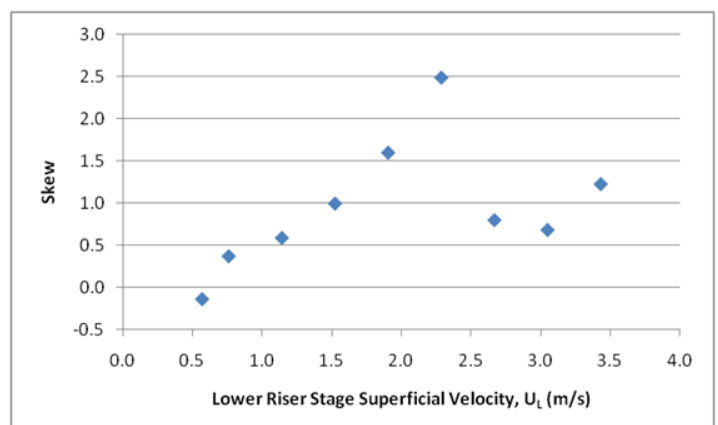

(a)

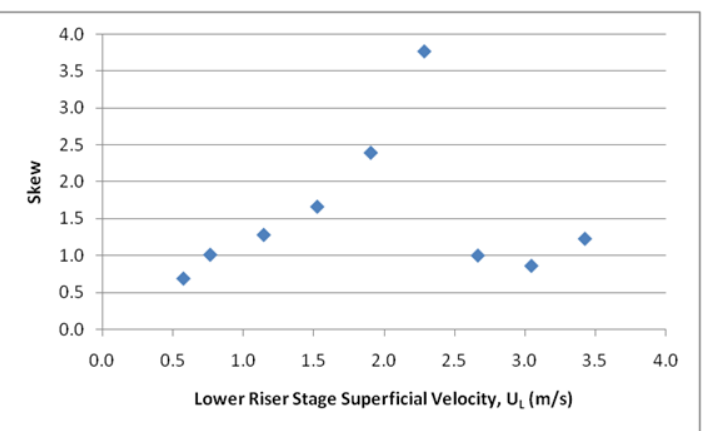

(b)

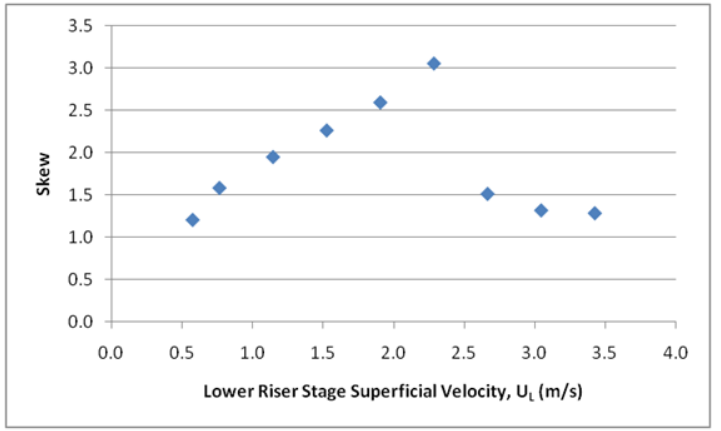

(c)

Figure 5-2: Skew vs Superficial Velocity for Lower Riser Stage Pressures: (a) Lbottom (b) Lmid (c) Ltop; poly-dispersed sand, 3.5 psig feed hopper pressure, no secondary air injection.

Figure 5-3 shows the variation of the fourth statistical moment (kurtosis) of pressure data as a function of the superficial velocity in the lower riser stage of the scale model fluidized bed. In general, the kurtosis follows a trend similar to that seen in the values of skew. Of particular interest is the apparent initial horizontal trend near zero in the Lbottom and Lmid plots. The test points at which this initial linear trend occurs are within the bubbling/slugging fluidization regimes, and the velocity region corresponding to the increasing values of kurtosis is similar to the turbulent region depicted in Figure 5-1. From this it can be inferred that the turbulent fluidization regime is characterized by increased skew. One possible explanation for this might be the fact that the turbulent regime is characterized by the breakup of large bubbles into many smaller ones. This would lead to more rapid pressure fluctuations with smaller magnitudes of fluctuation, and thus a more "spiky" signal. 


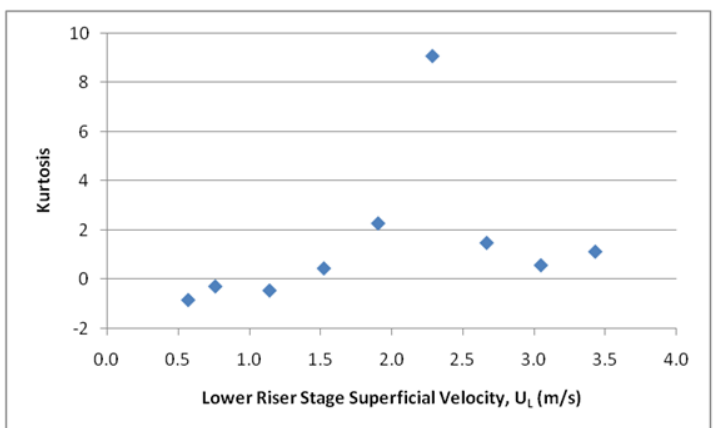

(a)

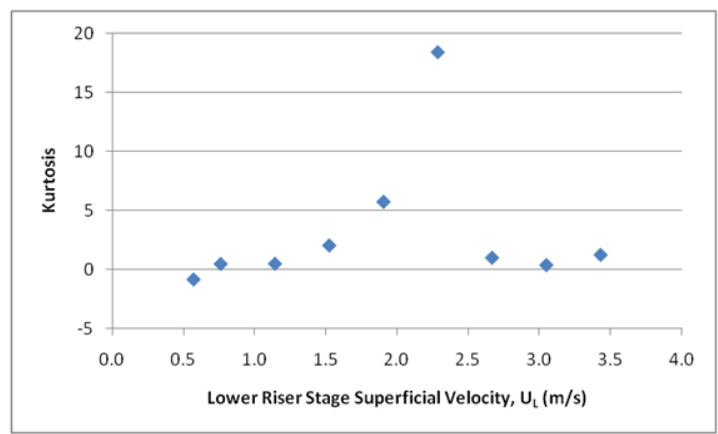

(b)

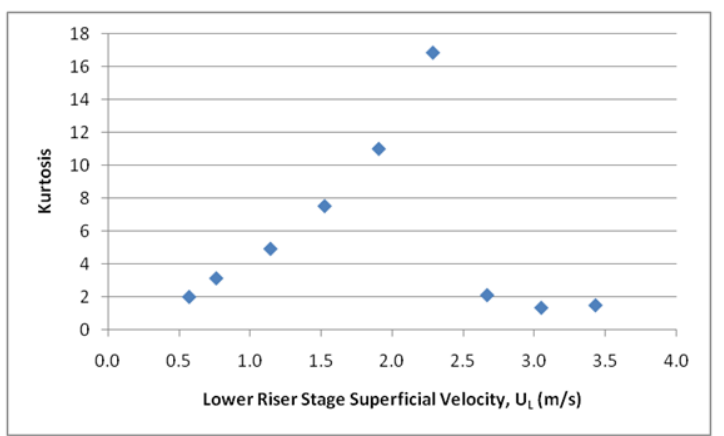

(c)

Figure 5-3: Kurtosis vs Superficial Velocity for Lower Riser Stage Pressures: (a) Lbottom (b) Lmid (c) Ltop; polydispersed sand, 3.5 psig feed hopper pressure, no secondary air injection.

\section{Regime Mapping with Shannon Entropy Analysis}

As previously discussed in Chapter 1, analysis of Shannon entropy has recently been used to map out the different fluidization regimes in spouted beds with non-spherical biomass fuels, bubble columns, three-phase fluidized beds, as well as nuclear reactors. For this study, the Shannon entropy values of each pressure transducer were calculated at each superficial velocity for approximately 1 minute (6000 points) of data using 600 bins. The results are shown in Figure 54.

By dividing the velocity range of each figure into the three regions delineated in Figure 5-1, it becomes apparent that the Shannon entropy plots exhibit differing and unique linear slopes within each of the three areas. This observation agrees with similar trends observed by Zhong et al. $[\mathbf{4 7 , 4 6 ]}$. It must be noted that the results of this study agree with those of Zhong et al. only in 
that each fluidization regime is characterized by a linear trend whose slope differs from that of the adjacent regimes in the Shannon entropy plots. In contrast to their results, the results presented here suggest that entropy is at its highest in the slugging regime, which is characterized by large pressure fluctuations. As the bed transitions to turbulent fluidization, the large bubbles that lead to slugging are broken apart and the magnitude of pressure fluctuations decreases. This decrease results in a corresponding decrease in the entropy values. In each of the figures below, the value of Shannon entropy reaches a minimum value in the fast fluidization, or core-annulus, regime.

On a final note, as can be seen in Figure 5-4, the maximum value of Shannon entropy decreases as the height above the lower injection ring increases. It is speculated that this might be the result of the variation of solids holdup or dampening of pressure fluctuations with vertical distance, but this was not investigated.

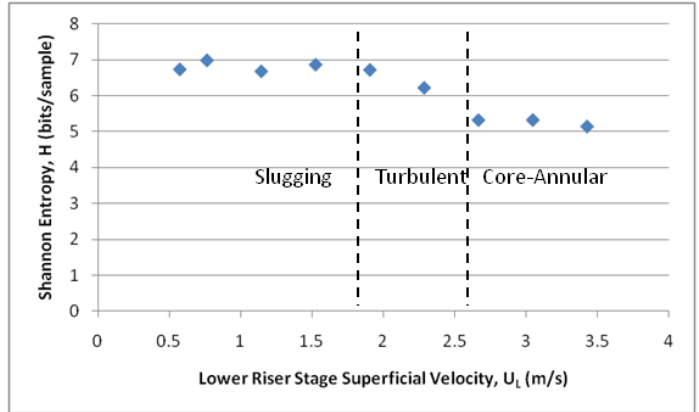

(a)

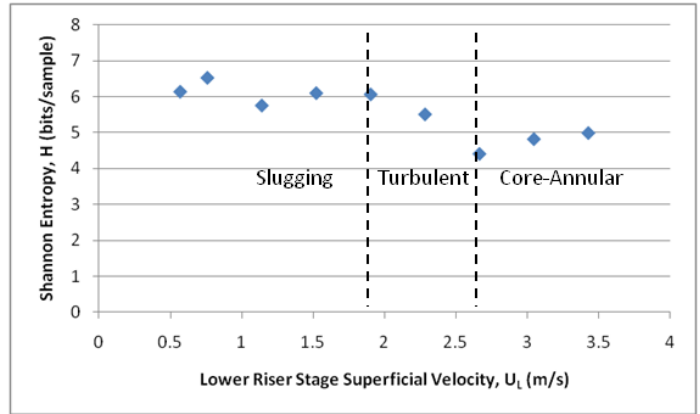

(b)

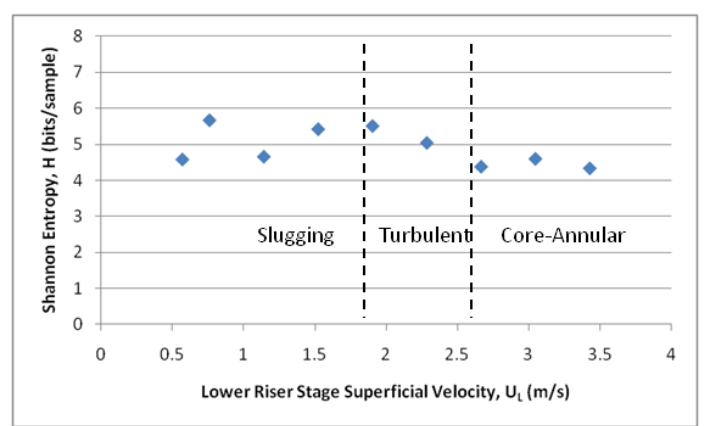

(c)

Figure 5-4: Shannon Entropy vs Superficial Velocity for Lower Riser Stage Pressures: (a) Lbottom (b) Lmid (c) Ltop; poly-dispersed sand, 3.5 psig feed hopper pressure, no secondary air injection. 


\section{Autocorrelation, Mutual Information and Power Spectral Density}

\section{Autocorrelation}

Figures 5-5, 5-6 and 5-7 depict the autocorrelation for each of the three pressure transducers located within the lower riser stage of the scale model fluidized. As can be seen from the figures, the autocorrelations of the Lbottom and Lmid locations exhibit an initial trend of periodicity and smoothness. This trend decays between $\mathrm{U}_{\mathrm{L}}=1.52 \mathrm{~m} / \mathrm{s}$ and $\mathrm{U}_{\mathrm{L}}=2.29 \mathrm{~m} / \mathrm{s}$ (the turbulent fluidization region), and is replaced by a pattern of very spiky low magnitude fluctuations between $U_{L}=2.67 \mathrm{~m} / \mathrm{s}$ and $U_{L}=3.43 \mathrm{~m} / \mathrm{s}$ (the fast fluidization, or core-annular, regime). The Ltop location plot (Figure 5-7) exhibits a pattern that more closely matches those seen in the core-annulus regime, suggesting that the upper region of the lower riser stage transitions to that fluidization regime at earlier velocities than the bottom and middle regions.

\section{Mutual Information Function}

Figures 5-8 through 5-10 show the effects varying lower riser stage superficial velocity $\left(\mathrm{U}_{\mathrm{L}}\right)$ on the mutual information function of the three lower riser stage pressures. As can be seen in all three locations, there is an initial increase in mutual information between $\mathrm{U}_{\mathrm{L}}=0.57 \mathrm{~m} / \mathrm{s}$ and $\mathrm{U}_{\mathrm{L}}=$ $0.76 \mathrm{~m} / \mathrm{s}$, followed by a sharp drop at $U_{\mathrm{L}}=1.14 \mathrm{~m} / \mathrm{s}$. This is then followed by a sharp increase at $\mathrm{U}_{\mathrm{L}}=1.52$. The mutual information then proceeds to decline throughout the turbulent range and then hold fairly constant within the fast fluidization regime.

\section{Spectral Density Plots}

As stated in Chapter 1, the Power Spectral Density (PSD) plot depicts the power associated with each frequency contained within a given signal. In fluidized beds, fluctuations in pressure signals are caused primarily by bubbles passing the sensor. The bubbling and slugging regimes 
are characterized by a dominant frequency of bubble formation, but the turbulent regime has no dominant frequency. Figures 5-11 through 5-13 show the PSD plots for the Lbottom, Lmid and Ltop pressure transducer locations for all superficial velocities tested. In the Lbottom and Lmid location plots (Figures 5-11 and 5-12), the presence of one or more narrowly defined dominant frequencies with high levels of associated power can be seen for superficial velocities of 0.57 $\mathrm{m} / \mathrm{s}$ to $1.14 \mathrm{~m} / \mathrm{s}$. Over the turbulent fluidization range of velocities $(1.53 \mathrm{~m} / \mathrm{s}$ through 2.29$)$, the magnitude of power associated with a given frequency steadily decreases, and the range of frequencies over which the power is distributed expands. The core annular velocity range (2.67 $\mathrm{m} / \mathrm{s}$ through $3.43 \mathrm{~m} / \mathrm{s}$ ) is characterized by extremely low levels of power per frequency with the range of frequencies over which the power is distributed is shifted to slightly higher frequencies. The Ltop spectral density plots (Figure 5-13) show slightly different tendencies, but in general is characterized by the decreasing levels of power per frequency distributed over a wider range of frequencies.

While not readily apparent from examination of the standard deviation, skew, kurtosis and Shannon entropy, the autocorrelation and PSD data from the pressure transducers located within the lower riser stage of the scale model fluidized bed show differences between the Ltop location and what is seen in the Lbottom and Lmid locations. Specifically, the plots resulting from analysis of autocorrelation and PSD of the Ltop location is more in line with those seen in both the lower riser stage and upper riser stage fast fluidization data. This leads to the conclusion that lower riser stage contains a dense bed under turbulent fluidization conditions above which is a dilute, fast fluidization (core-annular) region. 


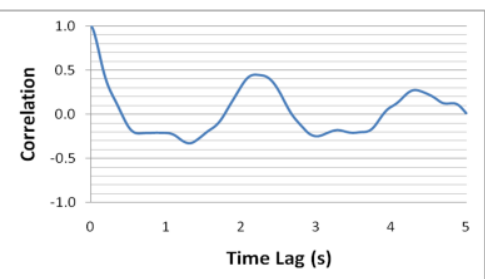

(a)

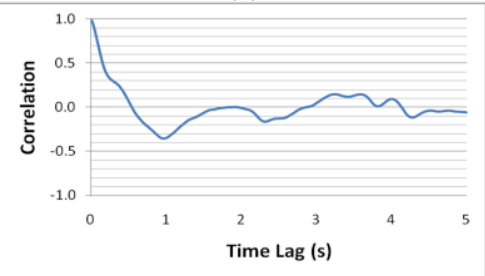

(d)

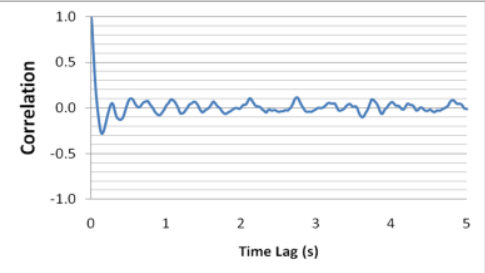

(g)

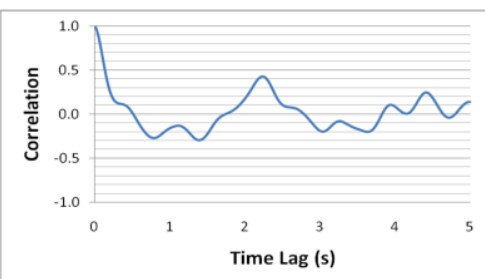

(b)

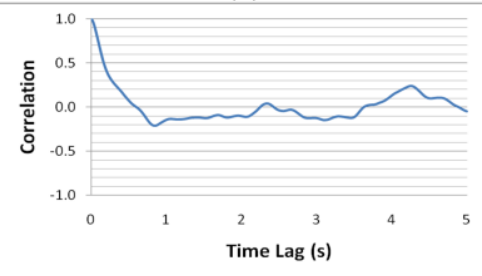

(e)

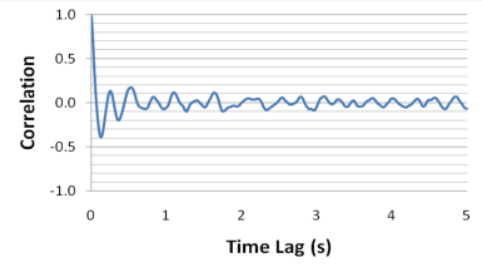

(h)

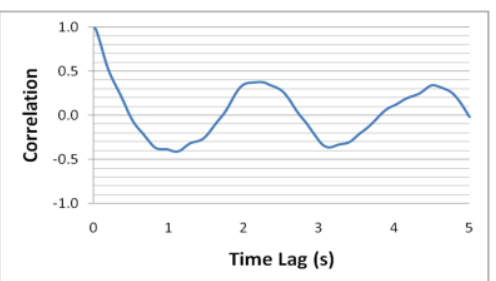

(c)

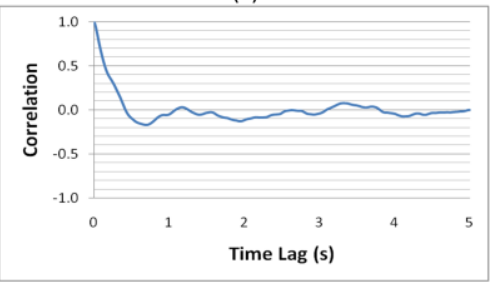

(f)

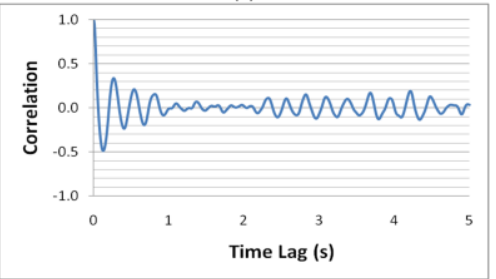

(i)

Figure 5-5: Autocorrelation of scale model Lbottom Pressure: poly-dispersed sand, 3.5 psig feed hopper pressure, no secondary air injection, $U_{L}=:$ (a) 0.57 (b) 0.76 (c) 1.14 (d) 1.52 (e) 1.90 (f) 2.29 (g) 2.67 (h) 3.05 (i) 3.43 m/s.

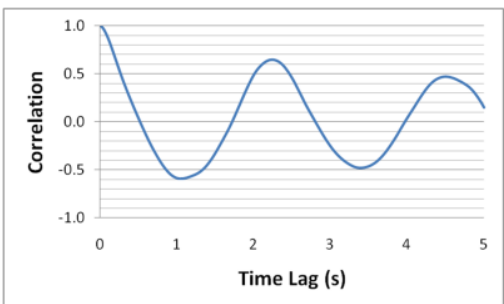

(a)

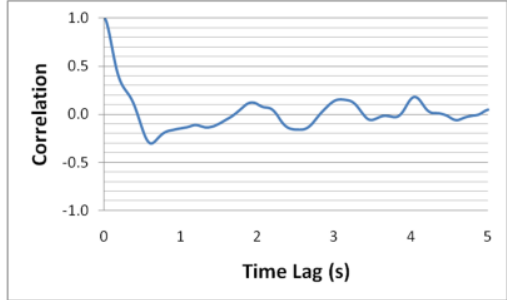

(d)

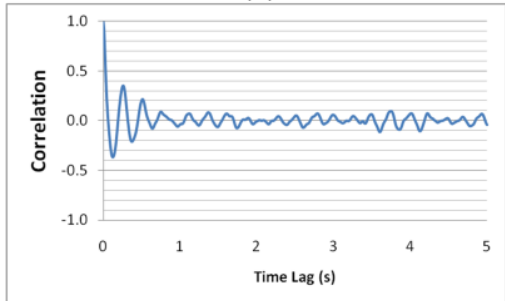

(g)

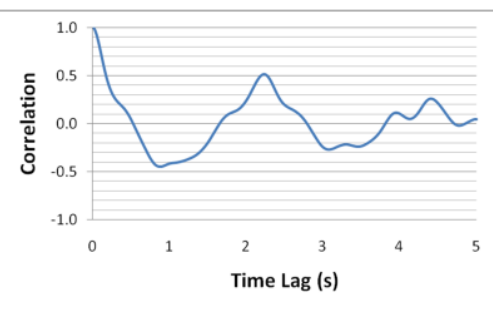

(b)

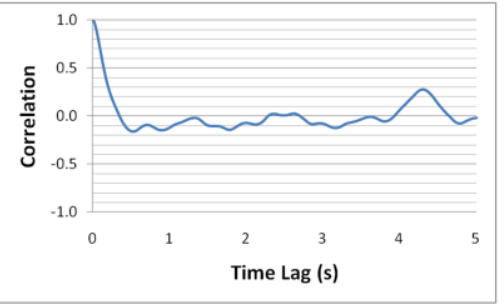

(e)

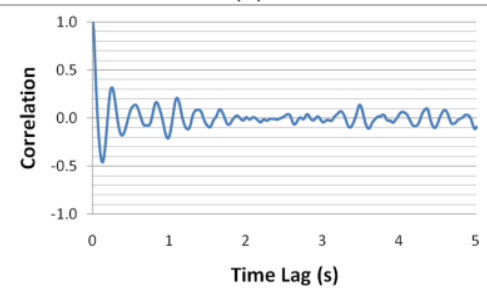

(h)

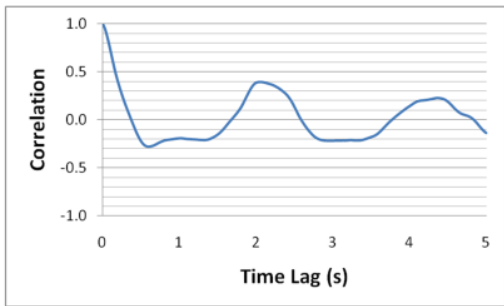

(c)

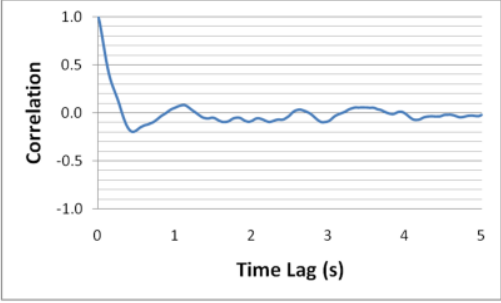

(f)

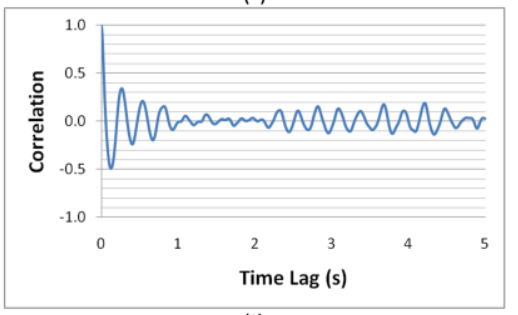

(i)

Figure 5-6: Autocorrelation of scale model Lmid Pressure: poly-dispersed sand, 3.5 psig feed hopper pressure, no secondary air injection, $U_{L}=:$ : (a) 0.57 (b) 0.76 (c) 1.14 (d) 1.52 (e) 1.90 (f) 2.29 (g) 2.67 (h) 3.05 (i) 3.43 m/s. 


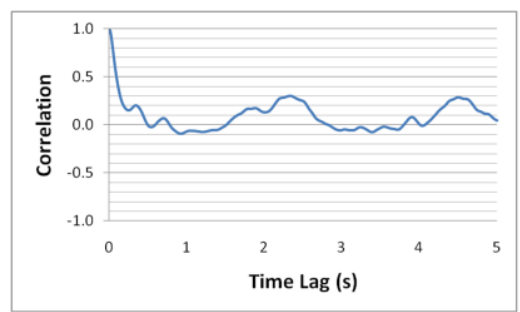

(a)

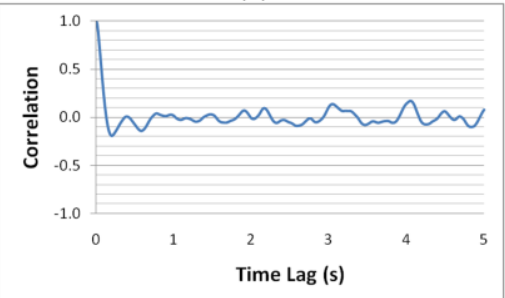

(d)

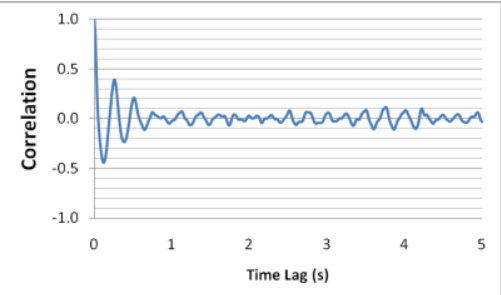

(g)

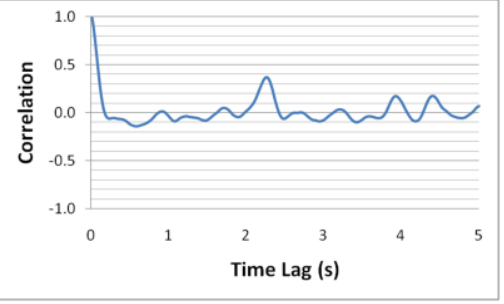

(b)

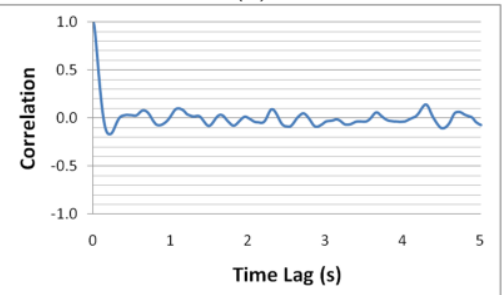

(e)

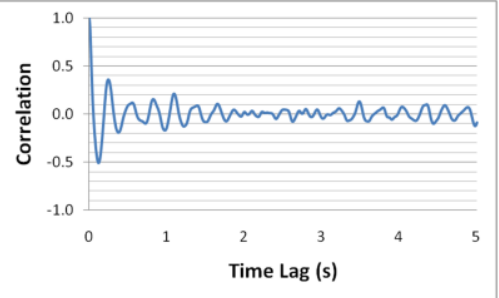

(h)

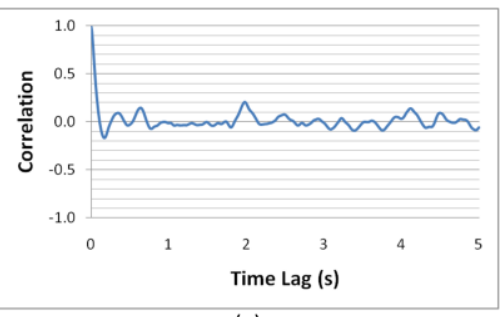

(c)

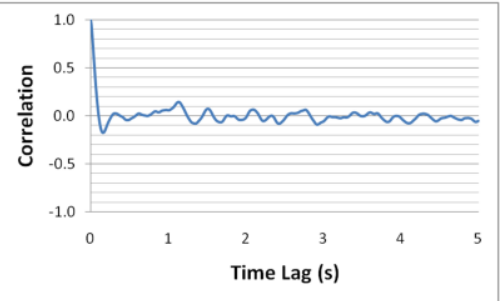

(f)

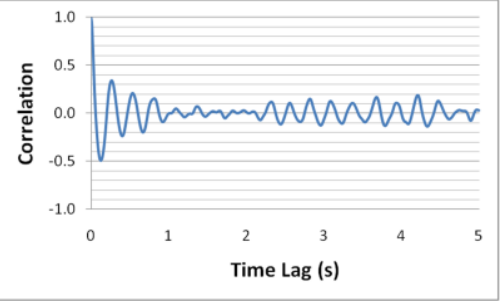

(i)

Figure 5-7: Autocorrelation of scale model Ltop Pressure: poly-dispersed sand, 3.5 psig feed hopper pressure, no secondary air injection, $U_{\mathrm{L}}=:$ : (a) 0.57 (b) 0.76 (c) 1.14 (d) 1.52 (e) 1.90 (f) 2.29 (g) 2.67 (h) 3.05 (i) 3.43 m/s.

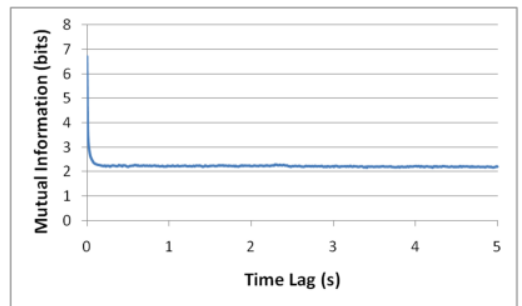

(a)

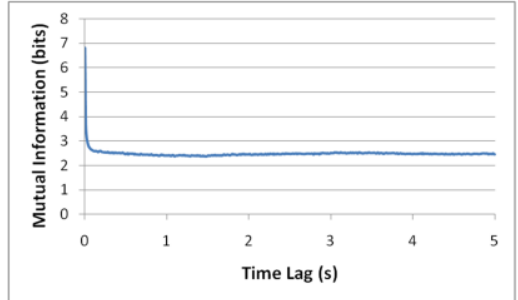

(d)

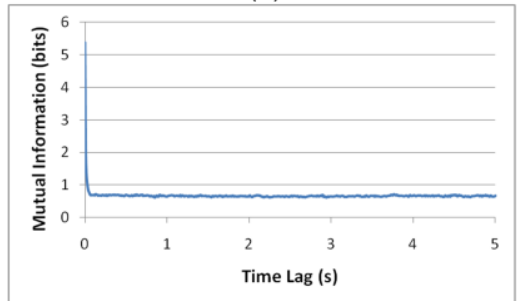

(g)

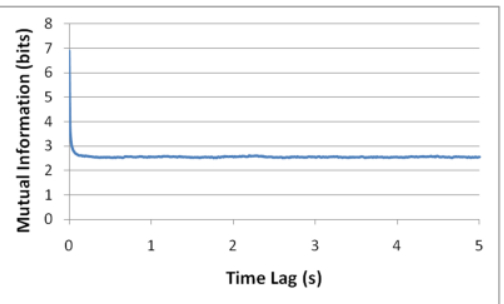

(b)

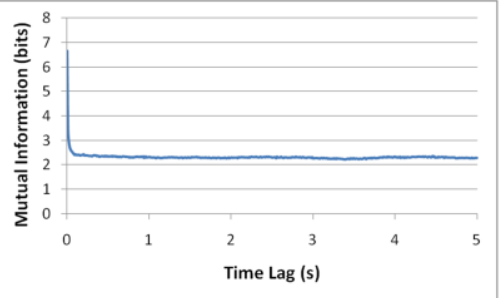

(e)

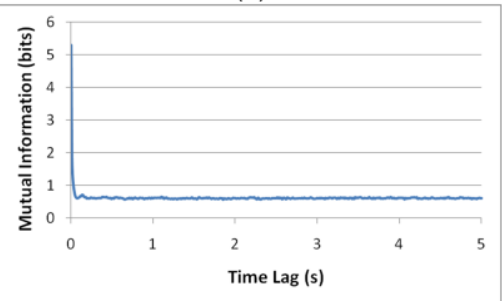

(h)

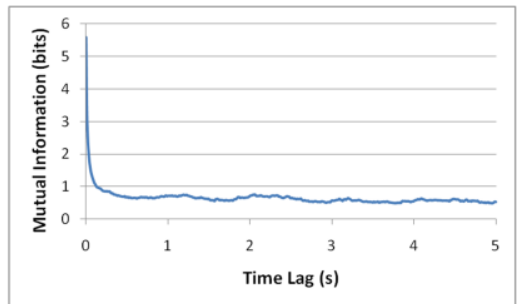

(c)

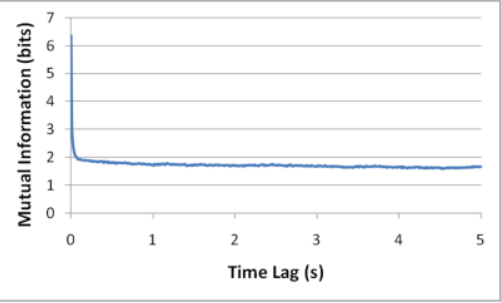

(f)

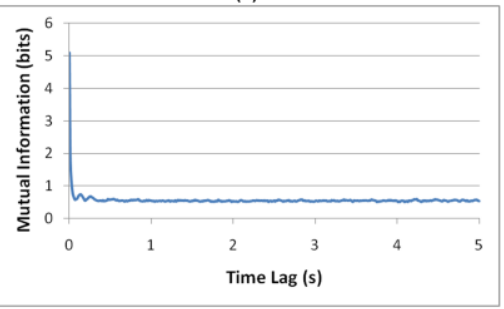

(i)

Figure 5-8: Mutual Information of scale model Lbottom Pressure: poly-dispersed sand, 3.5 psig feed hopper pressure, no secondary air injection, $U_{L}=:$ : (a) 0.57 (b) 0.76 (c) 1.14 (d) 1.52 (e) 1.90 (f) 2.29 (g) 2.67 (h) 3.05 (i) 3.43 m/s. 


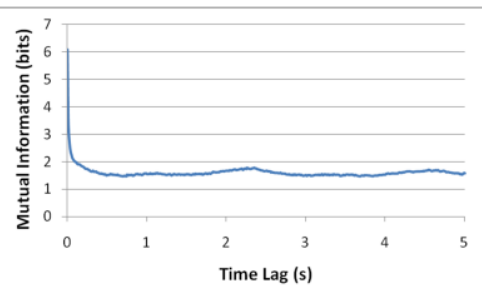

(a)

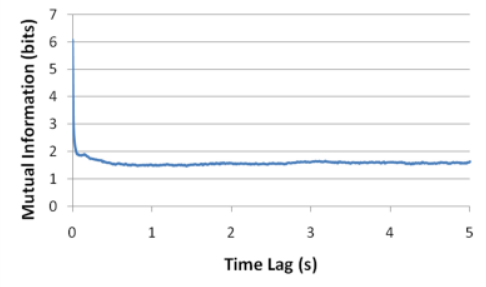

(d)

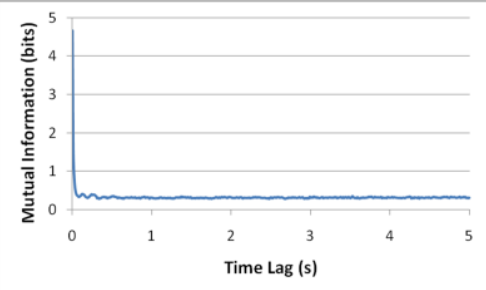

(g)

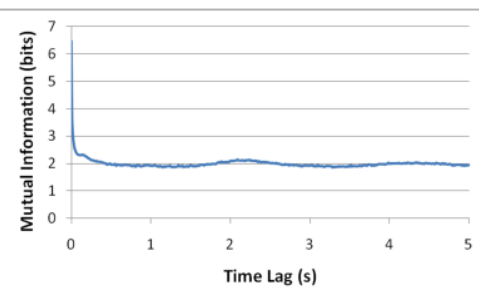

(b)

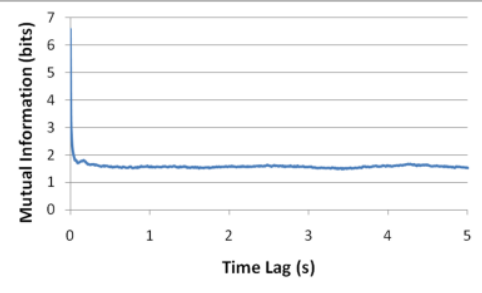

(e)

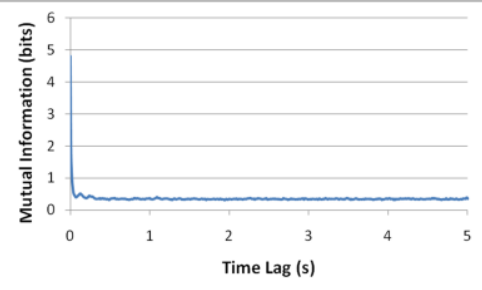

(h)

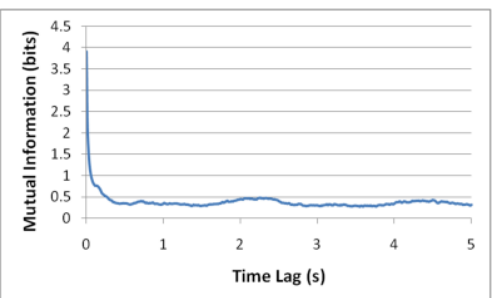

(c)

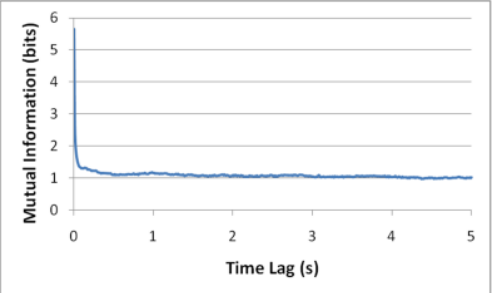

(f)

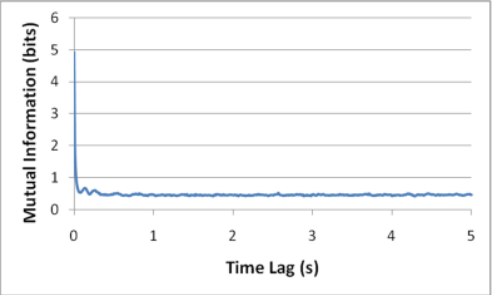

(i)

Figure 5-9: Mutual Information of scale model Lmid Pressure: poly-dispersed sand, 3.5 psig feed hopper pressure, no secondary air injection, $U_{L}=:$ (a) 0.57 (b) 0.76 (c) 1.14 (d) 1.52 (e) 1.90 (f) 2.29 (g) 2.67 (h) 3.05 (i) 3.43 m/s.

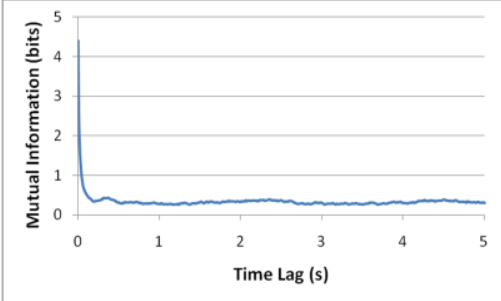

(a)

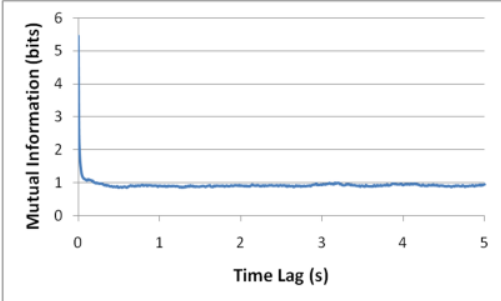

(d)

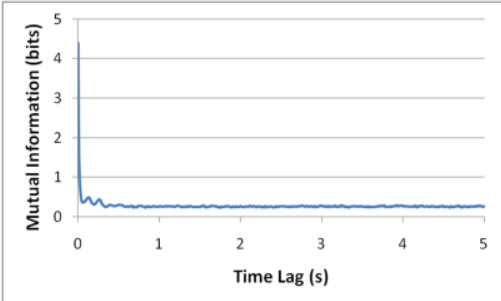

(g)

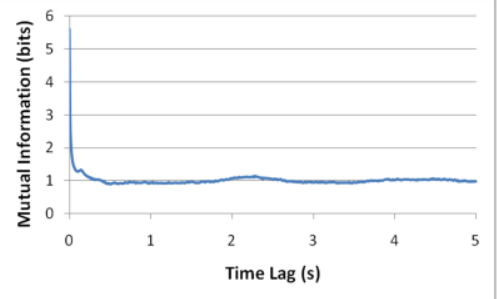

(b)

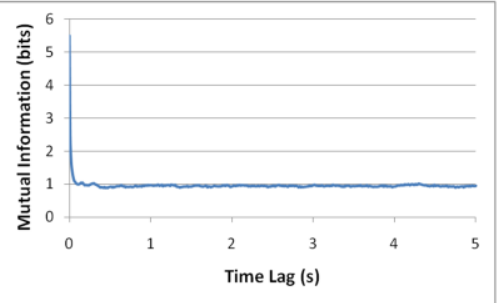

(e)

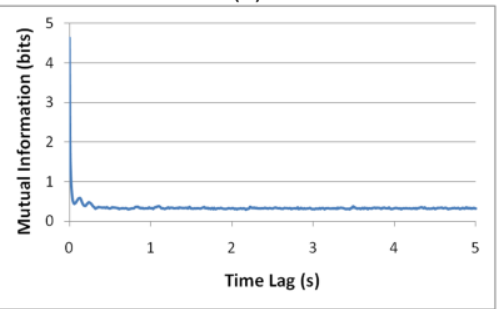

(h)

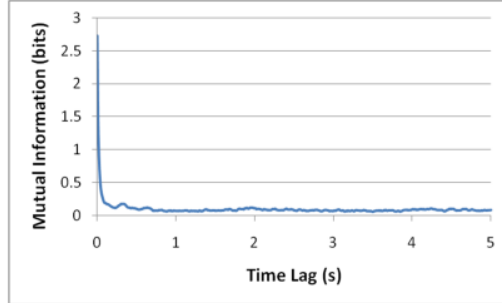

(c)

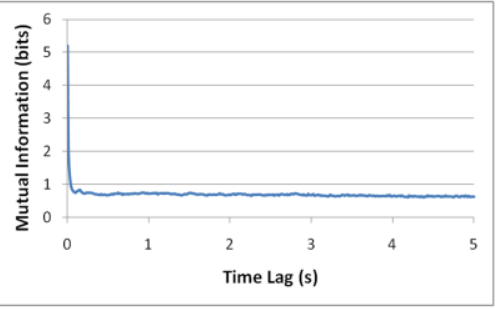

(f)

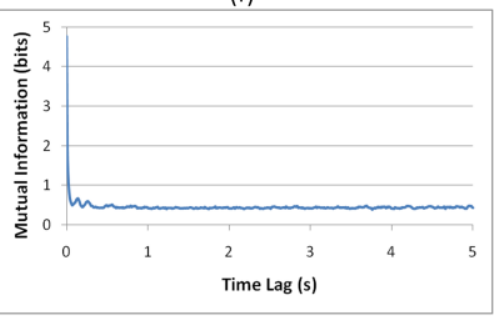

(i)

Figure 5-10: Mutual Information of scale model Ltop Pressure: poly-dispersed sand, 3.5 psig feed hopper pressure, no secondary air injection, $U_{L}=:$ : (a) 0.57 (b) 0.76 (c) 1.14 (d) 1.52 (e) 1.90 (f) 2.29 (g) 2.67 (h) 3.05 (i) 3.43 m/s. 


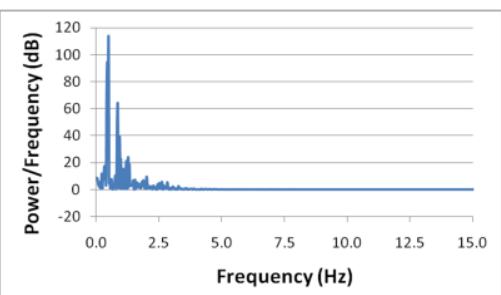

(a)

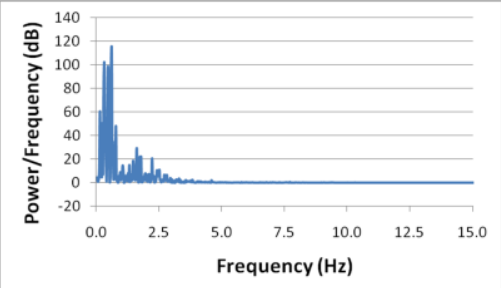

(d)

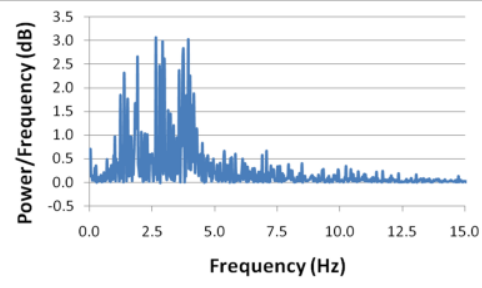

(g)

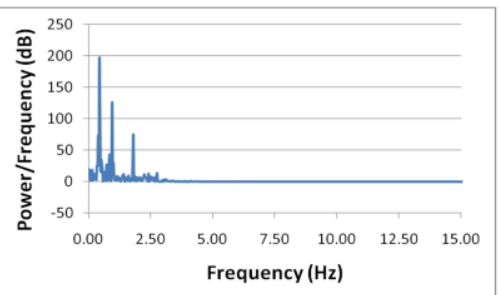

(b)

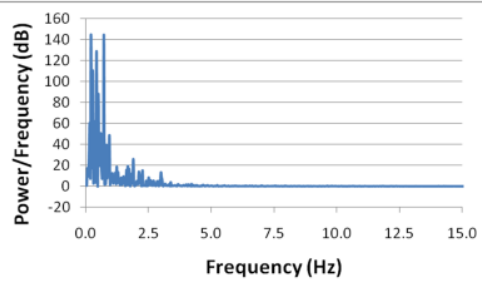

(e)

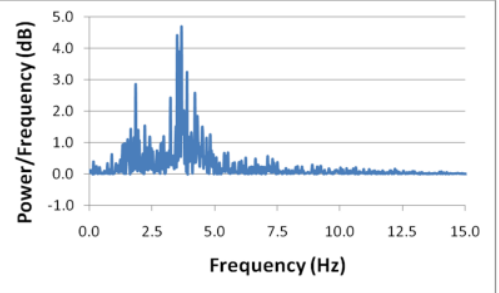

(h)

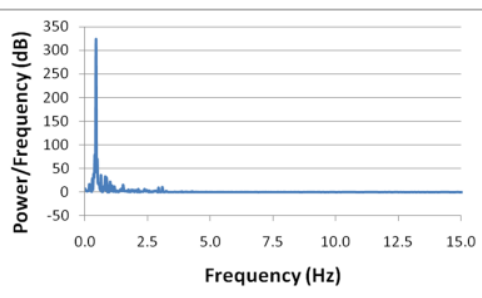

(c)

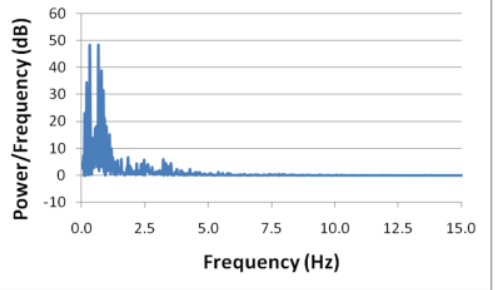

(f)

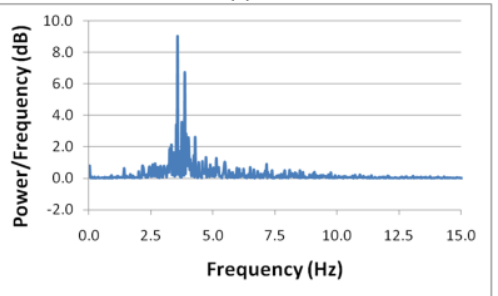

(i)

Figure 5-11: Power Spectral Density Plot of scale model Lbottom Pressure: poly-dispersed sand, 3.5 psig feed hopper pressure, no secondary air injection, $U_{L}=:$ : (a) 0.57 (b) 0.76 (c) 1.14 (d) 1.52 (e) 1.90 (f) 2.29 (g) 2.67 (h) 3.05 (i) 3.43 m/s.

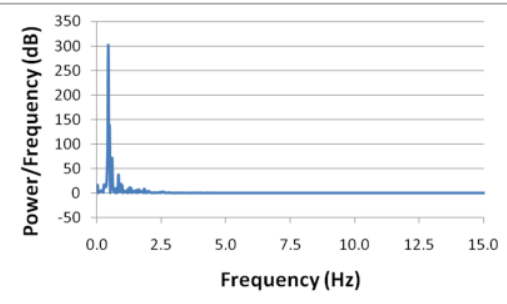

(a)

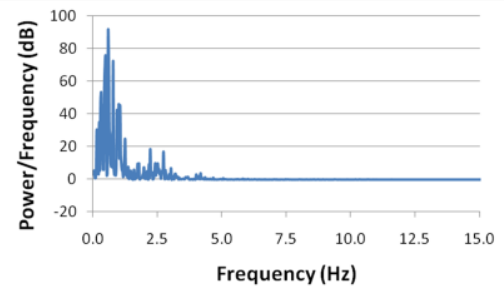

(d)

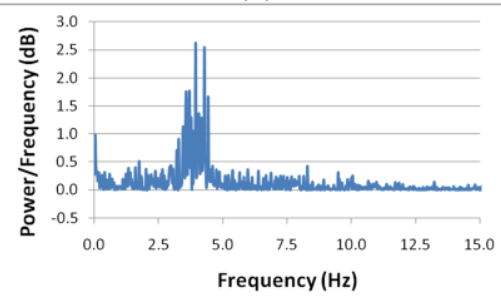

(g)

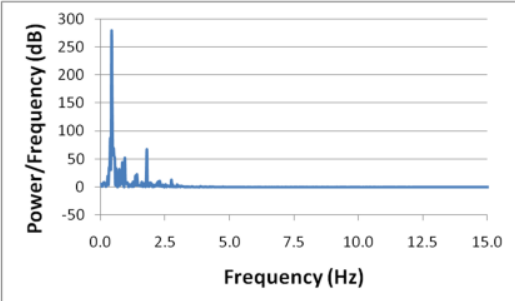

(b)

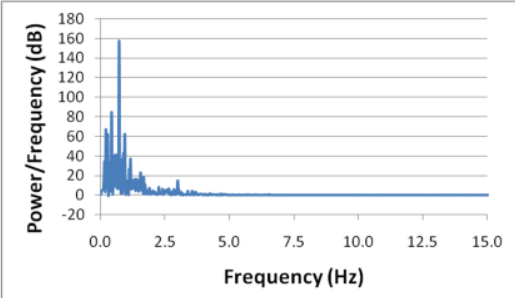

(e)

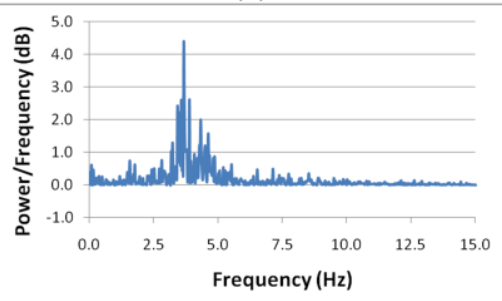

(h)

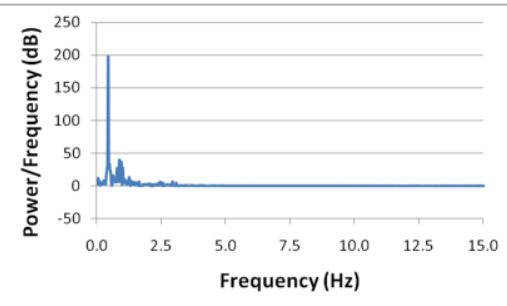

(c)

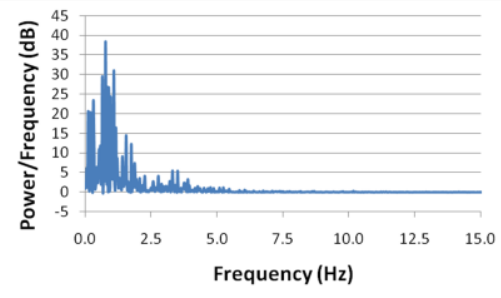

(f)

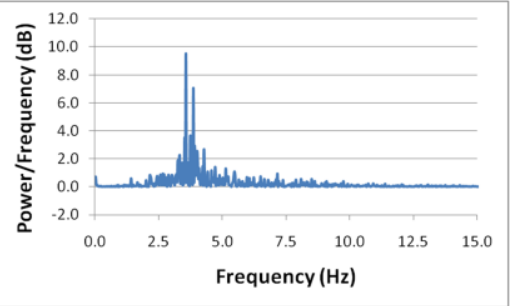

(i)

Figure 5-12: Power Spectral Density Plot of scale model Lmid Pressure: poly-dispersed sand, 3.5 psig feed hopper pressure, no secondary air injection, $\mathrm{U}_{\mathrm{L}}=$ : (a) 0.57 (b) 0.76 (c) 1.14 (d) 1.52 (e) 1.90 (f) 2.29 (g) 2.67 (h) 3.05 (i) $3.43 \mathrm{~m} / \mathrm{s}$. 


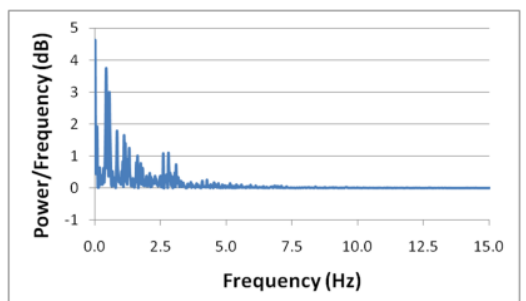

(a)

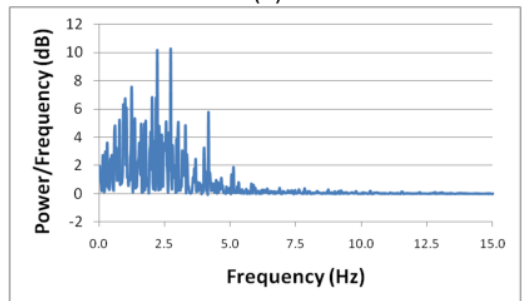

(d)

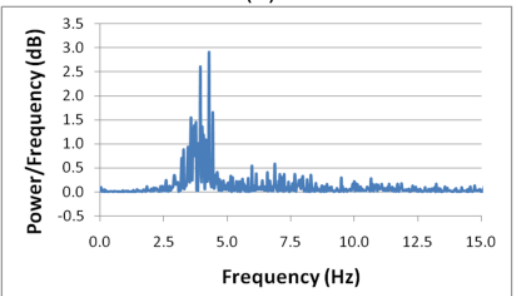

(g)

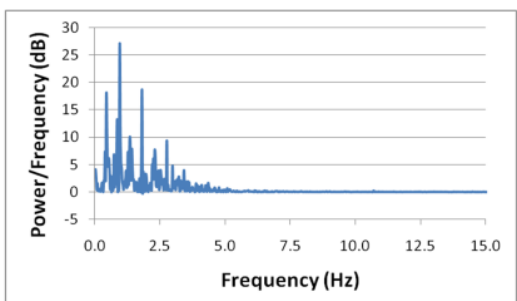

(b)

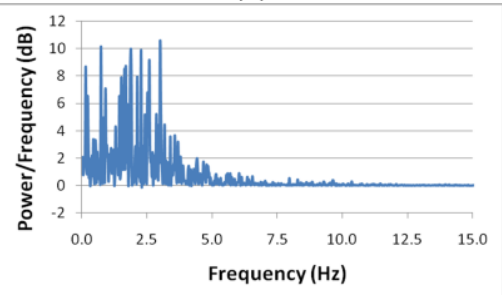

(e)

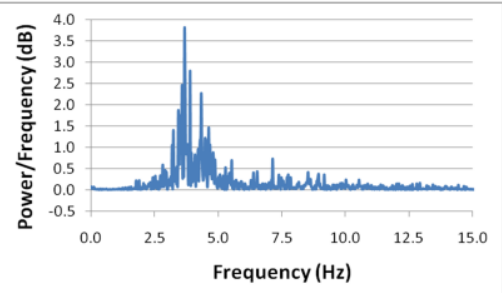

(h)

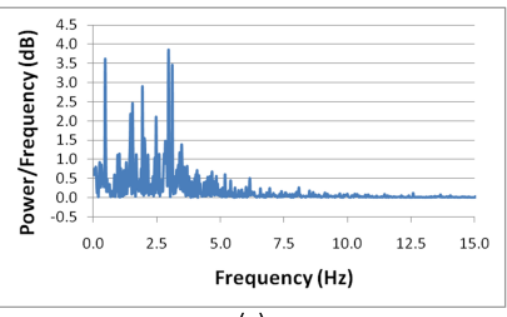

(c)

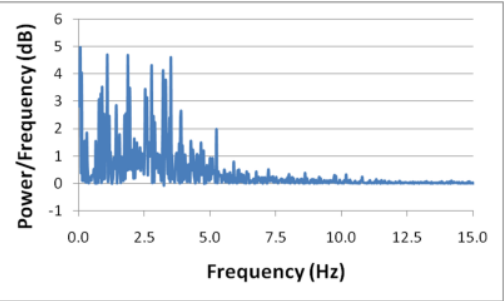

(f)

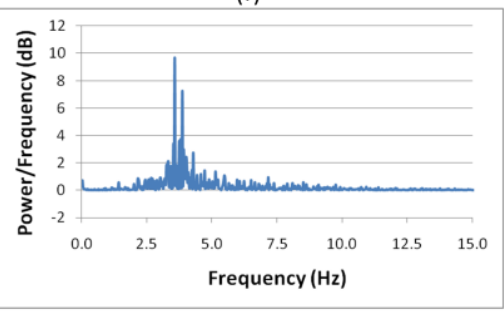

(i)

Figure 5-13: Power Spectral Density Plot of scale model Ltop Pressure: poly-dispersed sand, 3.5 psig feed hopper pressure, no secondary air injection, $U_{L}=:$ : (a) 0.57 (b) 0.76 (c) 1.14 (d) 1.52 (e) 1.90 (f) 2.29 (g) 2.67 (h) 3.05 (i) 3.43 m/s.

\section{Upper Riser Stage Fast Fluidization Mapping and Characterization}

The data presented in this section was obtained from experimental runs conducted with the polydispersed sand particles feed continuously with a feed hopper back pressure of 3.5 psi. The superficial velocity of the lower riser stage $\left(\mathrm{U}_{\mathrm{L}}\right)$ was held constant at $2.36 \mathrm{~m} / \mathrm{s}$ in order to maintain turbulent fluidization in this stage(as determined in the previous section.) The superficial velocity of the upper riser stage $\left(\mathrm{U}_{\mathrm{U}}\right)$ was tested over a range of velocities, as detailed in Table 5-3. As stated in Chapter 4, there are a total of two pressure transducers located in the upper riser stage. Table 5-4 lists these transducers, their designations and distances above the secondary air injection ring and lower injection ring.

\begin{tabular}{|c|c|c|c|c|c|c|c|}
\hline Test \# & 1 & 2 & 3 & 4 & 5 & 6 & 7 \\
\hline $\mathrm{U}_{\mathrm{L}}(\mathrm{m} / \mathrm{s})$ & 2.36 & 2.36 & 2.36 & 2.36 & 2.36 & 2.36 & 2.36 \\
\hline $\mathrm{U}_{\mathrm{U}}(\mathrm{m} / \mathrm{s})$ & 1.42 & 1.74 & 2.06 & 2.38 & 2.70 & 3.02 & 3.35 \\
\hline
\end{tabular}

Table 5-3: Upper Riser Stage Superficial Velocity Test Points 


\begin{tabular}{|c|c|c|c|c|}
\hline Transducer & $\begin{array}{c}\text { Pressure Range } \\
\text { (psi) }\end{array}$ & Designation & $\begin{array}{c}\text { Distance above } \\
\text { secondary air } \\
\text { injection ring } \\
\text { (inches) }\end{array}$ & $\begin{array}{c}\text { Distance above } \\
\text { lower injection } \\
\text { ring (inches) }\end{array}$ \\
\hline PX35K1-G030AV & $0-30$ & Ubottom & 2.0 & 62.0 \\
\hline PX35K1-G030AV & $0-30$ & Utop & 30.0 & 92.0 \\
\hline
\end{tabular}

Table 5-4: Upper Riser Stage Pressure Transducer Location

\section{Statistical Mapping}

Figures 5-14 through 5-17 show the effects of superficial velocity upon the standard deviation, skew and kurtosis of pressure signals of the Ubottom and Utop locations in the upper riser stage.

The standard deviation of pressure shows trends similar to that seen in the mapping of the lower riser section (as presented in the previous section). The peak occurring at $1.74 \mathrm{~m} / \mathrm{s}$ corresponds to the turbulent transition velocity $\left(\mathrm{U}_{\mathrm{C}}\right)$. This is followed by a rapid decline in standard deviation during the turbulent regime. The point at which the slope of the standard deviation curve levels out to nearly horizontal $(2.38 \mathrm{~m} / \mathrm{s})$ corresponds to the transition velocity for fast fluidization $\left(\mathrm{U}_{\mathrm{TR}}\right)$ for Geldart Type B particles.

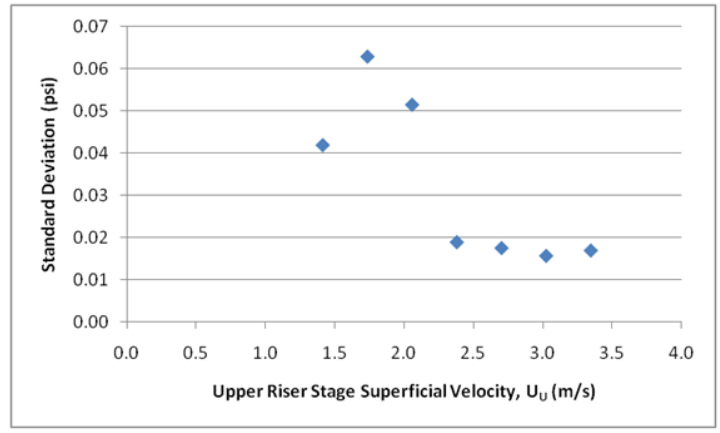

(a)

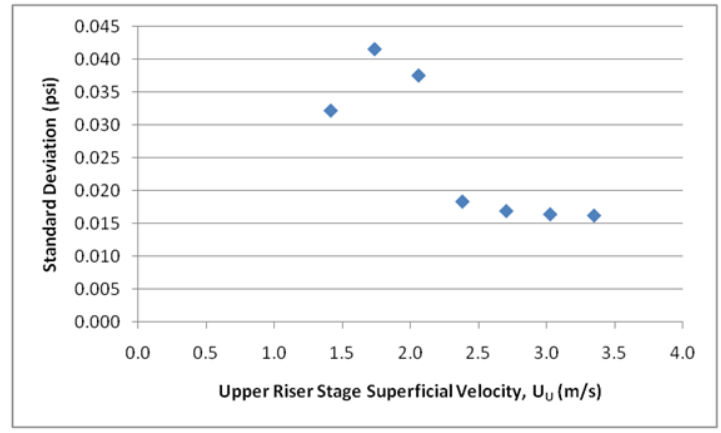

(b)

Figure 5-14: Standard Deviation of model upper riser stage pressures (a) Ubottom (b) Utop: poly-dispersed sand, feed hopper pressure $3.5 \mathrm{psig}, \mathrm{U}_{\mathrm{L}}=\mathbf{2 . 3 6} \mathrm{m} / \mathrm{s}$

As seen with the standard deviation plots in Figure 5-14, similar trends appear in the skew and kurtosis plots (Figures 5-15 and 5-16) to those seen in the previous section for the lower riser stage. As with the standard deviation, the analysis of both the skew and kurtosis of the pressure 
transducer signals indicated that the upper riser stage transitions to fast fluidization at a superficial velocity of approximately $2.38 \mathrm{~m} / \mathrm{s}$.

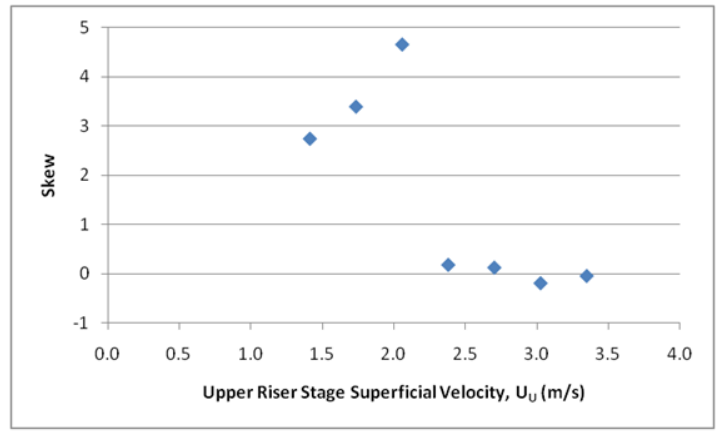

(a)

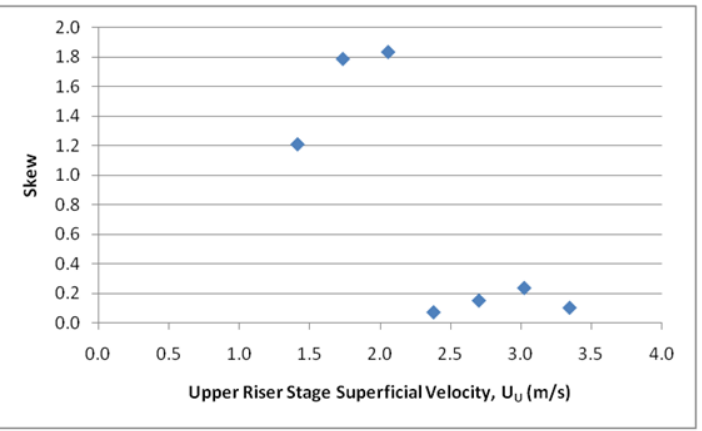

(b)

Figure 5-15: Skew of model upper riser stage pressures (a) Ubottom (b) Utop: poly-dispersed sand, feed hopper pressure $3.5 \mathrm{psig}, \mathrm{U}_{\mathrm{L}}=2.36 \mathrm{~m} / \mathrm{s}$

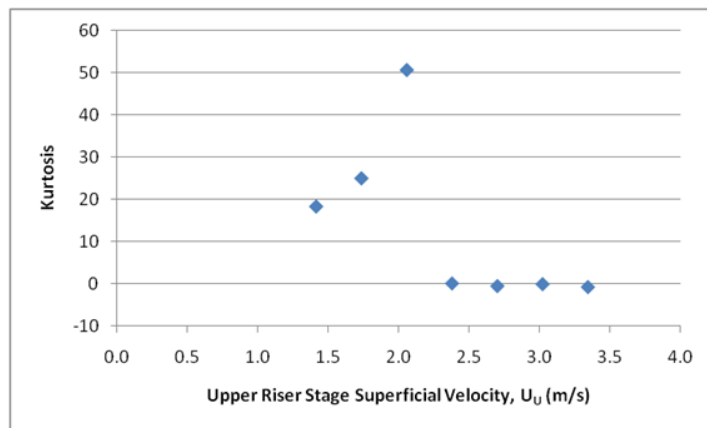

(a)

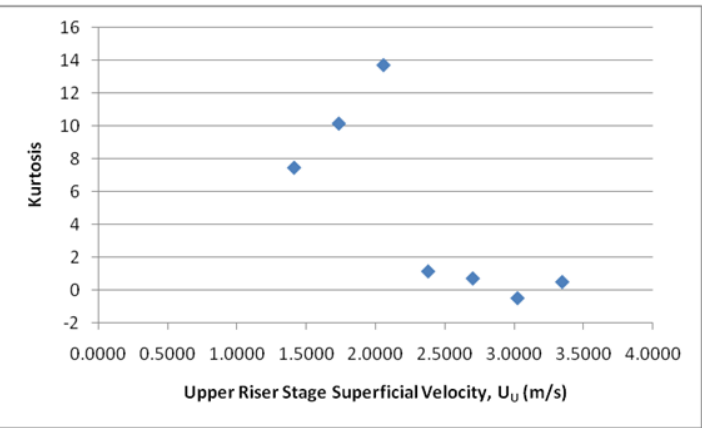

(b)

Figure 5-16: Kurtosis of model upper riser stage pressures (a) Ubottom (b) Utop: poly-dispersed sand, feed hopper pressure $3.5 \mathrm{psig}, \mathrm{U}_{\mathrm{L}}=2.36 \mathrm{~m} / \mathrm{s}$

It can be seen from these results that the upper riser stage begins to exhibit fast fluidization, or core-annular flow, when the superficial velocity in the upper riser stage, $\mathrm{U}_{\mathrm{U}}$, matches the superficial velocity in the lower riser stage, $U_{L}$. This suggests that the assumption that the addition of secondary air between the two riser stages divides the bed into two distinct regions that can be treated as individual fluidized beds is flawed. The will be discussed further following analysis of the effects of secondary air injection upon the lower riser stage.

\section{Shannon Entropy Analysis}

Figure 5-17 shows the effects of upper riser stage superficial velocity, $\mathrm{U}_{\mathrm{U}}$, on the Shannon entropy of pressure in the upper riser stage. As can be seen, the region bounded by the 
superficial velocities of 1.74 and $2.38 \mathrm{~m} / \mathrm{s}$ demonstrates a roughly linear downward trend characterized by a steep slope. Based upon the statistical analysis previously presented, this is the region over which turbulent fluidization exists in the upper stage of the riser. From statistical analysis it was determined that $\mathrm{U}_{\mathrm{U}}=2.38 \mathrm{~m} / \mathrm{s}$ corresponded to $\mathrm{U}_{\mathrm{TR}}$, or the transition to fast fluidization. This is supported in Figure 5-17 by pointing out this velocity is the point at which there is a significant change in the slope of the Shannon entropy curves.

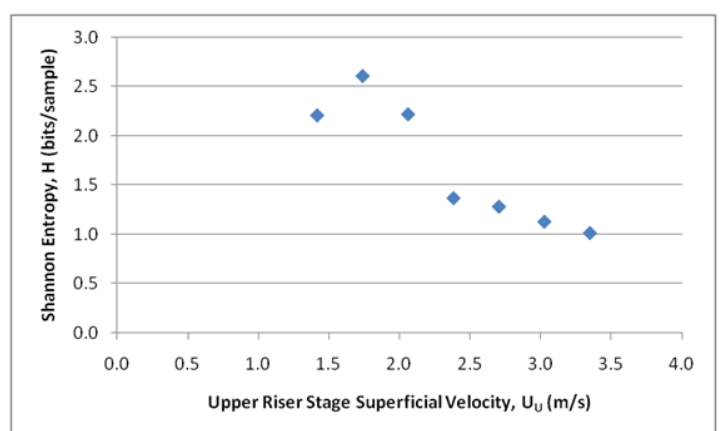

(a)

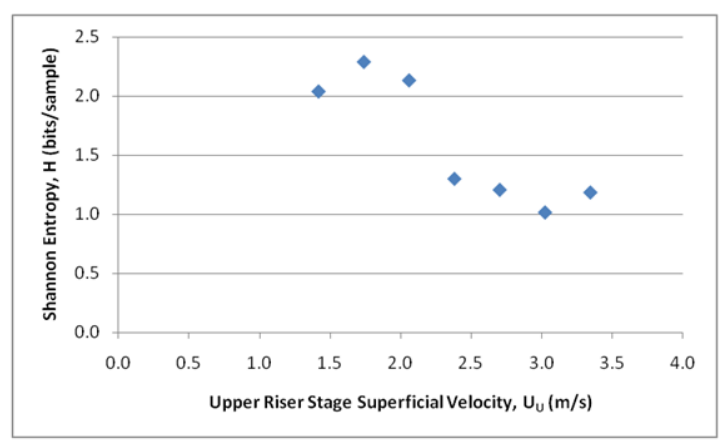

(b)

Figure 5-17: Shannon Entropy of model upper riser stage pressures (a) Ubottom (b) Utop: poly-dispersed sand, feed hopper pressure $3.5 \mathrm{psig}, \mathrm{U}_{\mathrm{L}}=2.36 \mathrm{~m} / \mathrm{s}$

\section{Autocorrelation, Mutual Information and Spectral Density Plots}

\section{Autocorrelation}

Figures 5-18 and 5-19 include autocorrelation plots for the Ubottom and Utop pressure transducer locations for all upper riser stage superficial velocities $\left(\mathrm{U}_{\mathrm{U}}\right)$ tested for the upper riser stage mapping. For all cases, there is very little change in the autocorrelation. For all velocities tested, the autocorrelation for the upper riser pressure locations exhibit the same form as seen in the lower riser stage test points corresponding to core annular flow.

\section{Mutual Information Function}

Figures 5-20 and 5-21 depict the effects of upper riser stage superficial velocity $\left(\mathrm{U}_{\mathrm{U}}\right)$ on the mutual information function for the Ubottom and Utop pressure locations. As seen with the 
autocorrelation plots in Figures 5-18 and 5-19, there is only a very marginal effect upon the mutual information for different values of $U_{U}$.

\section{Spectral Density Plots}

Figures 5-22 and 5-23 show the effects of upper riser stage superficial velocity on the power spectral density plots for the Ubottom and Utop pressure transducer locations. Both locations show a slight shift in power/frequency distribution towards lower frequencies between $U_{U}=1.42$ $\mathrm{m} / \mathrm{s}$ and $U_{U}=2.06 \mathrm{~m} / \mathrm{s}$. This trend is reversed beginning with $U_{U}=2.38$ and higher, where the power appears to be distributed almost normally between 2 and $10 \mathrm{~Hz}$ with decreasing magnitude as the superficial velocity increases.

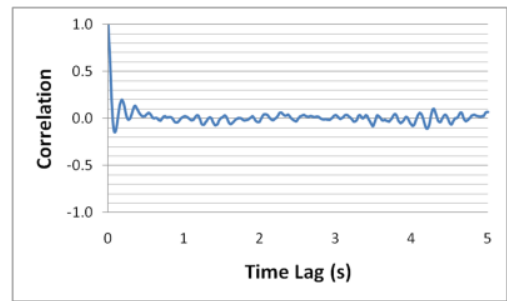

(a)

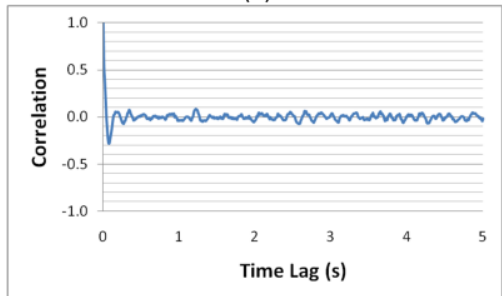

(d)

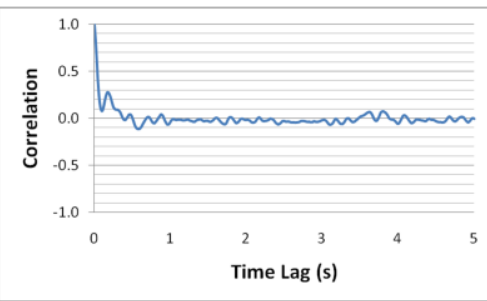

(b)

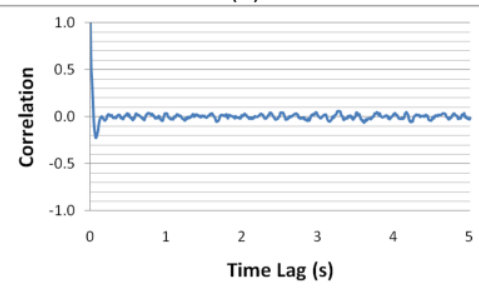

(e)

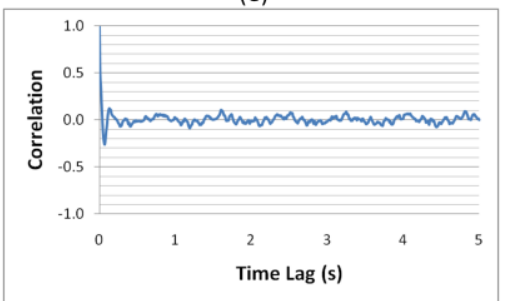

(g)

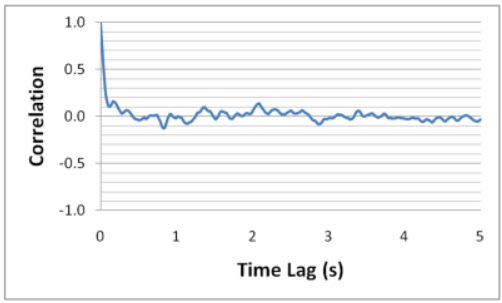

(c)

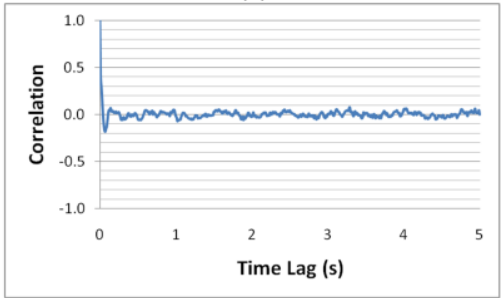

(f)

Figure 5-18: Autocorrelation of model Ubottom pressure: poly-dispersed sand, 3.5 psig feed hopper pressure, $U_{L}=2.36$ $\mathrm{m} / \mathrm{s}, \mathrm{U}_{\mathrm{U}}=:$ : (a) 1.42 (b) 1.74 (c) 2.06 (d) 2.38 (e) 2.70 (f) 3.02 (g) $3.35 \mathrm{~m} / \mathrm{s}$. 


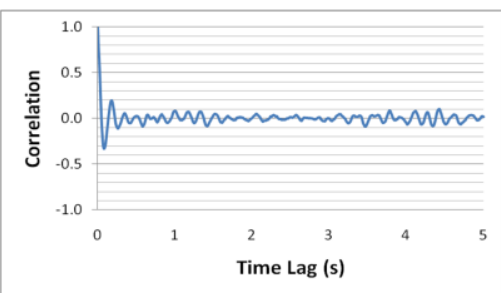

(a)

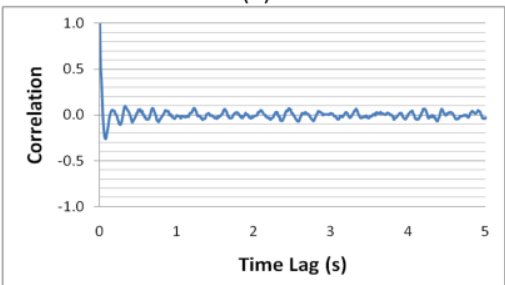

(d)

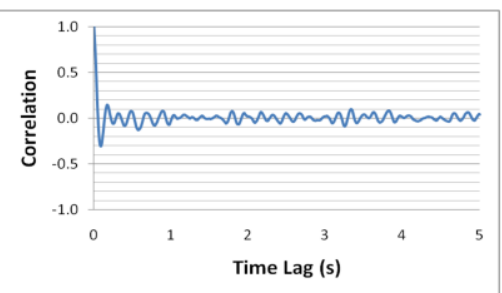

(b)

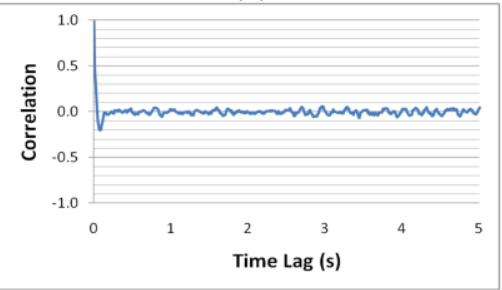

(e)

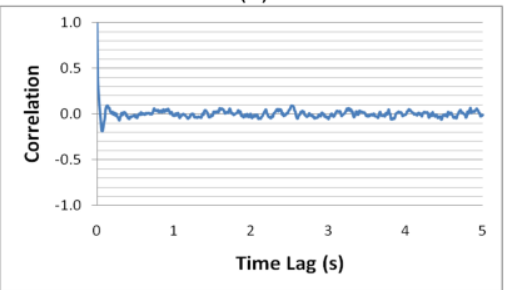

(g)

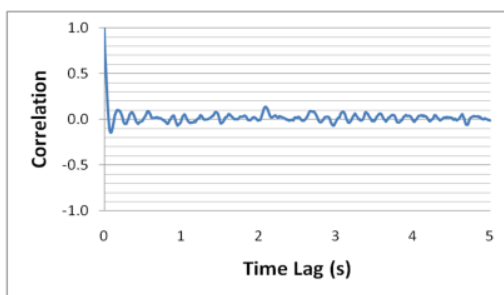

(c)

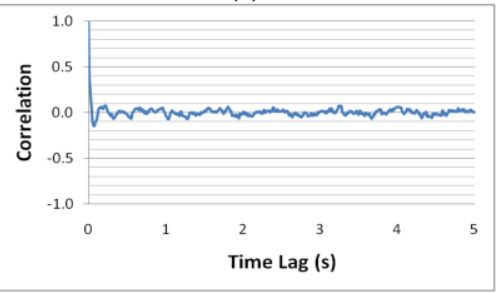

(f)

Figure 5-19: Autocorrelation of model Utop pressure: poly-dispersed sand, $3.5 \mathrm{psig}$ feed hopper pressure, $\mathrm{U}_{\mathrm{L}}=\mathbf{2 . 3 6} \mathrm{m} / \mathrm{s}$, $\mathrm{U}_{\mathrm{U}}=$ : (a) 1.42 (b) 1.74 (c) 2.06 (d) 2.38 (e) 2.70 (f) 3.02 (g) $3.35 \mathrm{~m} / \mathrm{s}$.

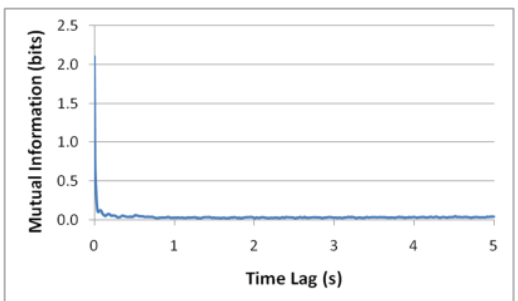

(a)

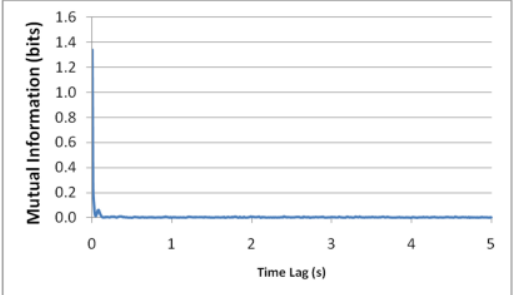

(d)

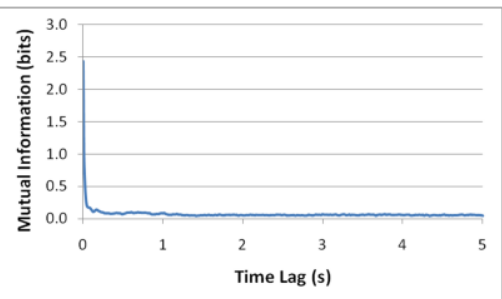

(b)

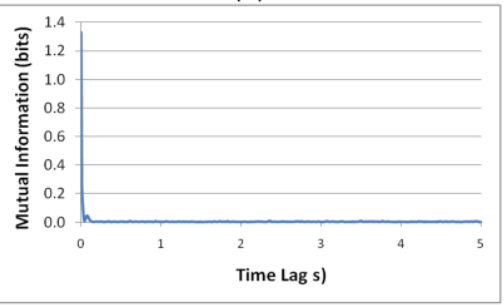

(e)

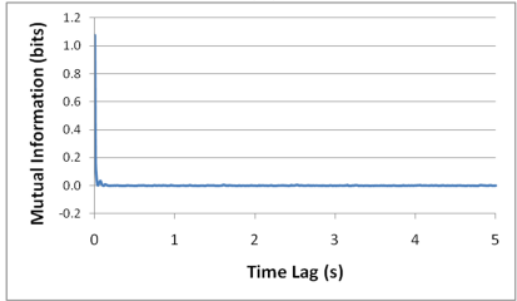

(g)

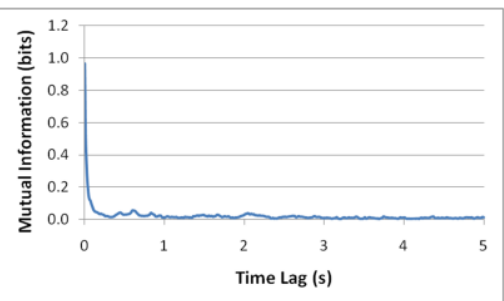

(c)

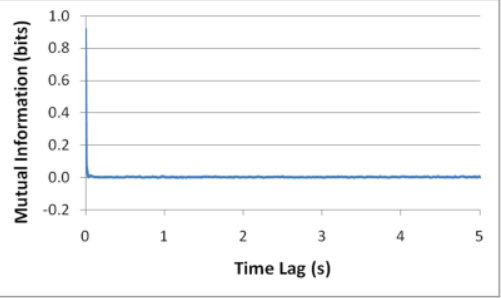

(f)

Figure 5-20: Mutual Information Function of model Ubottom pressure: poly-dispersed sand, 3.5 psig feed hopper pressure, $U_{\mathrm{L}}=2.36 \mathrm{~m} / \mathrm{s}, \mathrm{U}_{\mathrm{U}}=:$ : (a) 1.42 (b) 1.74 (c) 2.06 (d) 2.38 (e) 2.70 (f) 3.02 (g) $3.35 \mathrm{~m} / \mathrm{s}$. 


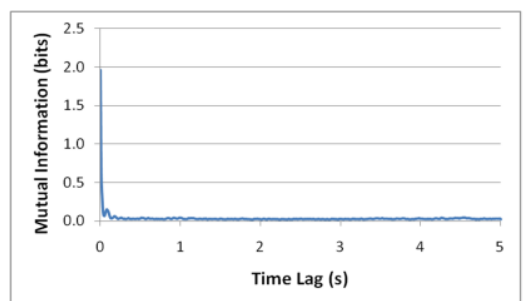

(a)

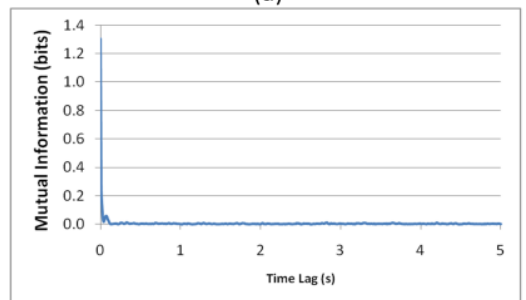

(d)

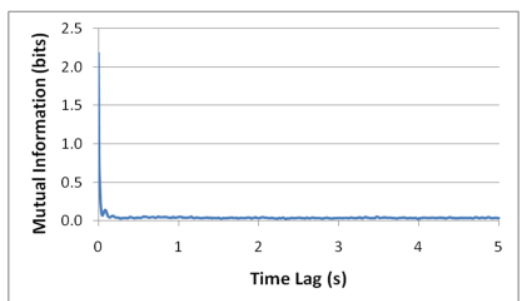

(b)

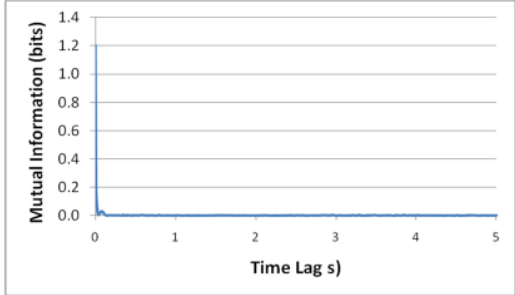

(e)

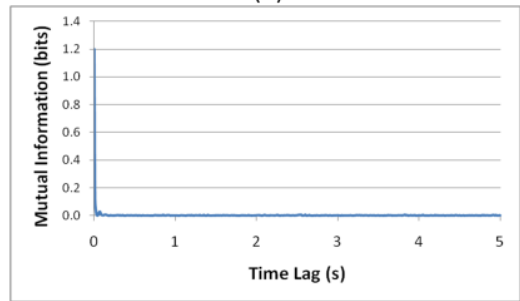

(g)

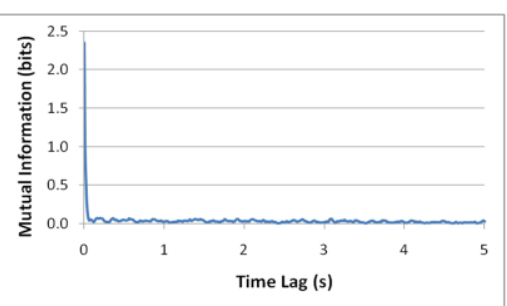

(c)

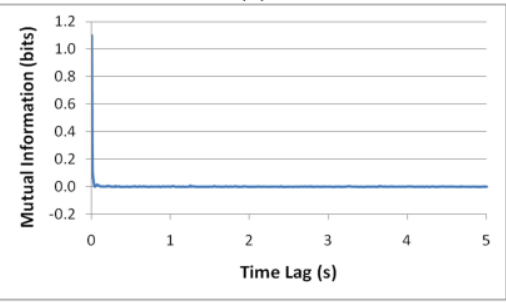

(f)

Figure 5-21: Mutual Information Function of model Utop pressure: poly-dispersed sand, 3.5 psig feed hopper pressure, $\mathrm{U}_{\mathrm{L}}=2.36 \mathrm{~m} / \mathrm{s}, \mathrm{U}_{\mathrm{U}}=:$ (a) 1.42 (b) 1.74 (c) 2.06 (d) 2.38 (e) 2.70 (f) 3.02 (g) $3.35 \mathrm{~m} / \mathrm{s}$.

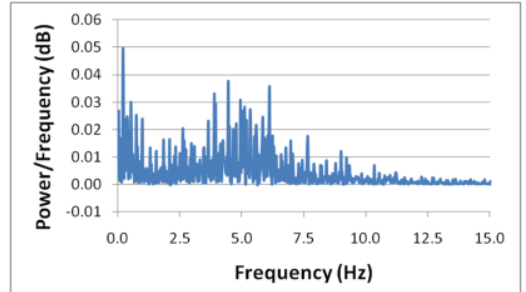

(a)

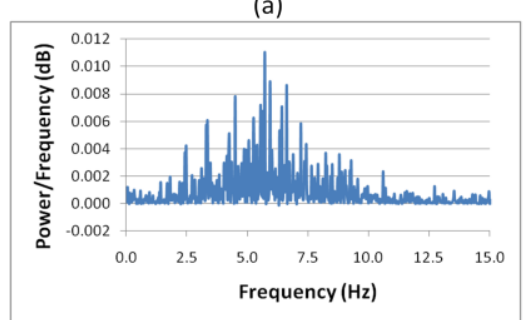

(d)

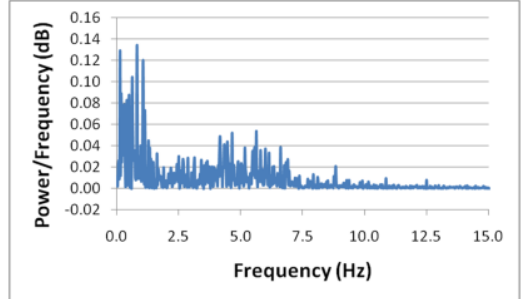

(b)

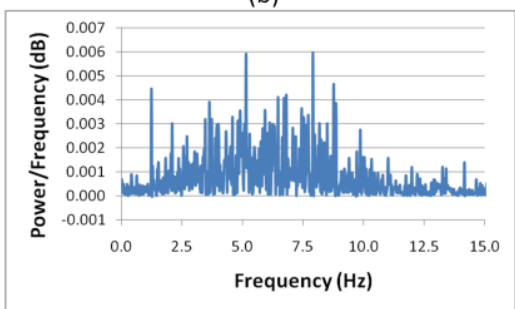

(e)

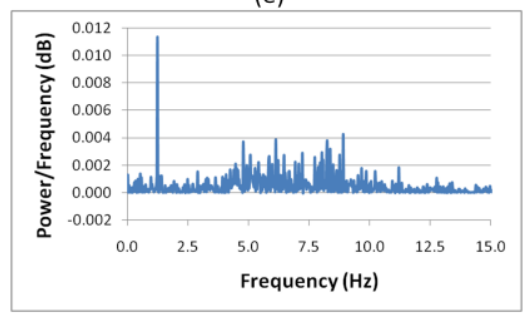

(g)

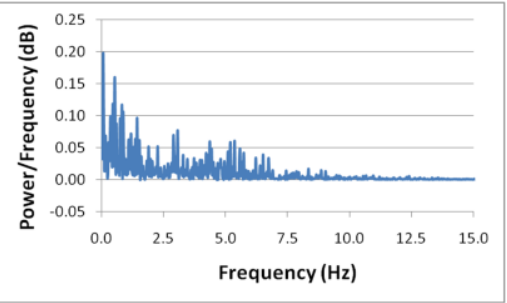

(c)

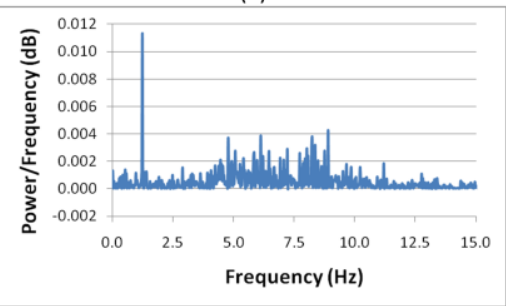

(f)

Figure 5-22: Spectral Density Plot for model Ubottom pressure: poly-dispersed sand, 3.5 psig feed hopper pressure, $U_{L}=$ $2.36 \mathrm{~m} / \mathrm{s}, \mathrm{U}_{\mathrm{U}}=$ : (a) 1.42 (b) 1.74 (c) 2.06 (d) 2.38 (e) 2.70 (f) 3.02 (g) $3.35 \mathrm{~m} / \mathrm{s}$. 


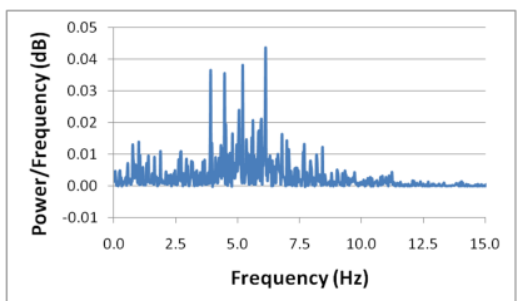

(a)

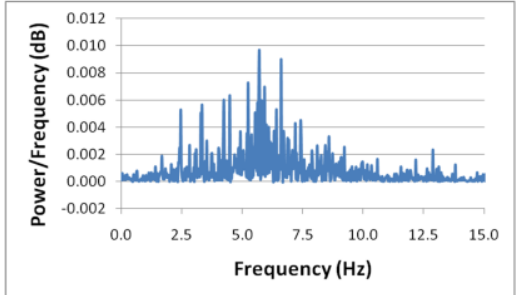

(d)

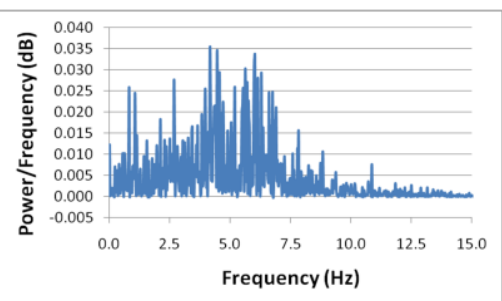

(b)

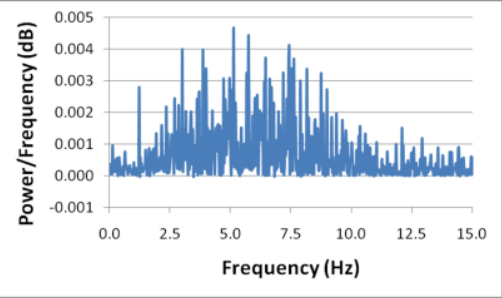

(e)

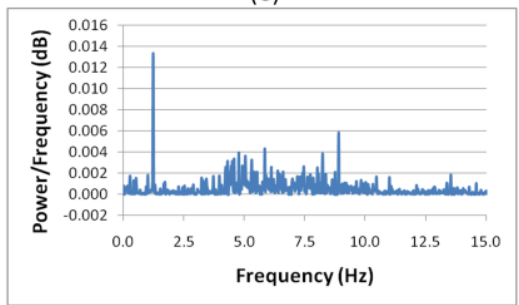

(g)

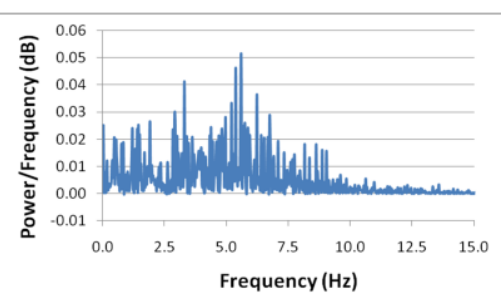

(c)

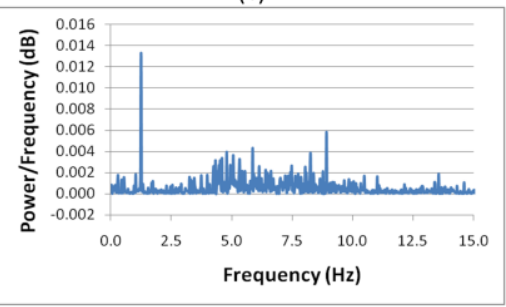

(f)

Figure 5-23: Spectral Density Plot for model Utop pressure: poly-dispersed sand, 3.5 psig feed hopper pressure, $U_{L}=2.36$ $\mathrm{m} / \mathrm{s}, \mathrm{U}_{\mathrm{U}}=$ : (a) 1.42 (b) 1.74 (c) 2.06 (d) 2.38 (e) 2.70 (f) 3.02 (g) $3.35 \mathrm{~m} / \mathrm{s}$.

\section{Effects of Secondary Air Injection on the Lower Riser Stage Fluidization}

The regime mapping and characterization of the lower riser stage was initially carried out without the addition of secondary air through the injection ring located between the smaller diameter lower riser stage and the larger diameter upper riser stage. In order to more fully understand the physical mechanisms at work within the two-stage fluidized bed under normal operation conditions (i.e. with secondary air injection), the effects of varying levels of secondary air injection (quantified by increasing superficial velocity in the upper riser stage, $\mathrm{U}_{\mathrm{U}}$ ) are presented throughout this section.

\section{Average Pressure and Bed Voidage Profiles}

Figure 5-24 shows the effect of secondary air injection on the average pressure at each of the three lower riser stage pressure transducer locations. The Lbottom and Lmid locations exhibit a 
slight increasing trend for $U_{U}$ values of $1.42,1.74$ and $2.06 \mathrm{~m} / \mathrm{s}$. This is then followed by a slight decrease at $U_{U}=2.38$. The average pressures for subsequent superficial velocities appear to remain relatively constant. The Ltop location exhibits a constant value for average pressure and appears to be mostly unaffected by secondary air injection.

Figure 5-25 shows the effect of secondary air injection upon the average bed voidage profile for the lower riser stage. The figure shows a slight decrease as the upper riser stage undergoes transition to turbulent fluidization at $U_{U}=1.74 \mathrm{~m} / \mathrm{s}$ and remains constant for the remainder of the turbulent regime. The voidage, as expected, then increases over the velocities corresponding to the fast fluidization regime.

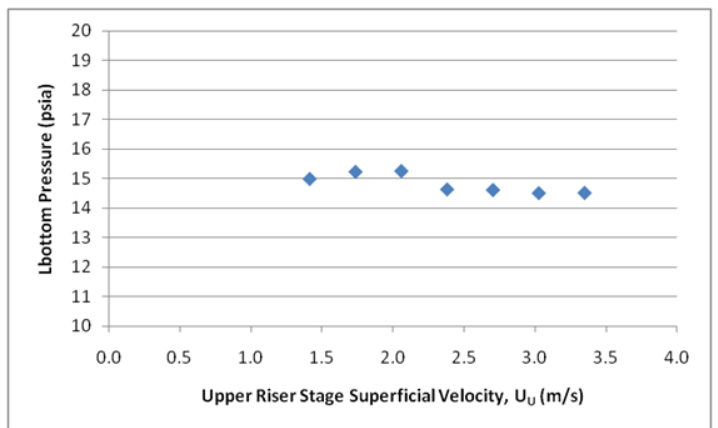

(a)

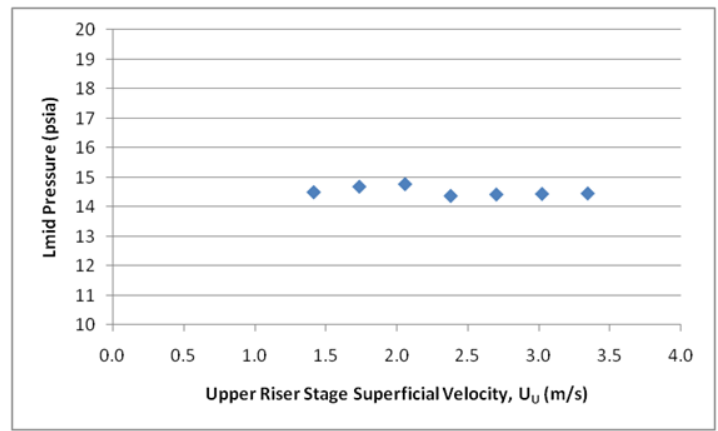

(b)

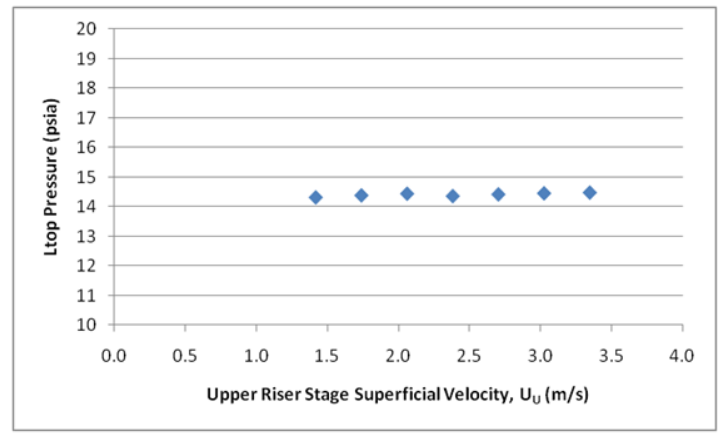

(c)

Figure 5-24: Effect of varying secondary air injection on lower riser stage average pressures (a) Lbottom (b) Lmid (c) Ltop: poly-dispersed sand, $3.5 \mathrm{psig}$ feed hopper pressure, $U_{L}=2.36 \mathrm{~m} / \mathrm{s}$. 


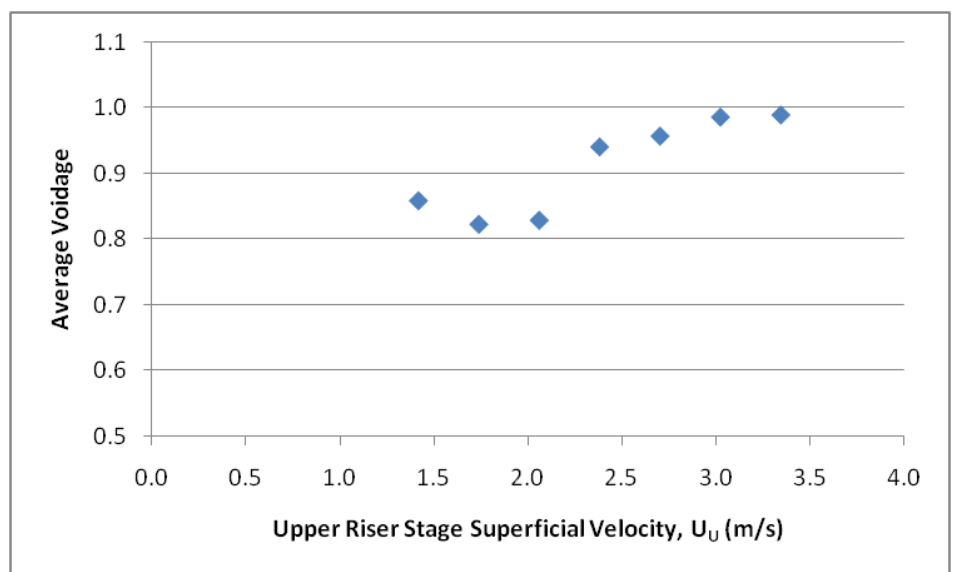

Figure 5-25: Effect of secondary air injection on lower riser voidage profile: poly-dispersed sand, 3.5 psig feed hopper

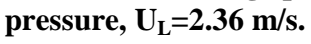

\section{Statistical Functions}

Figure 5-1 showed the effects of superficial velocity on the standard deviation of pressures in the lower riser stage when no secondary air was introduced between the lower and upper riser stages. Figure 5-14 showed the effects of superficial velocity on the standard deviation of pressures in the upper riser stage when the superficial velocity in the lower riser is held constant and secondary air injection was utilized to vary the superficial velocity in the upper riser stage, $\mathrm{U}_{\mathrm{U}}$. Figure 5-26 shows the effects on the standard deviation of pressure in the lower riser stage when secondary air injection is used to vary $\mathrm{U}_{\mathrm{U}}$ (with $\mathrm{U}_{\mathrm{L}}$ held constant).

As can be seen from the figures, variation of $\mathrm{U}_{\mathrm{U}}$ has a direct impact upon the standard deviation of pressures in the lower riser stage as well as those of the upper riser stage. The Lmid and Ltop locations exhibit identical trends as those seen in the Ubottom and Utop locations when secondary air injection is used. The primary difference between these is a decrease in the relative magnitudes of standard deviation at the same $U_{U}$ with increasing height in the riser. This suggests that the lower riser stage transitions to fast fluidization upon establishing that fluidization regime in the upper riser stage. The plot of the Lbottom location shows a more 
gradual trend towards transition from turbulence to fast fluidization, but it too eventually transitions from dense to dilute phase fluidization as the superficial velocity in the upper riser stage is increased via secondary air injection.

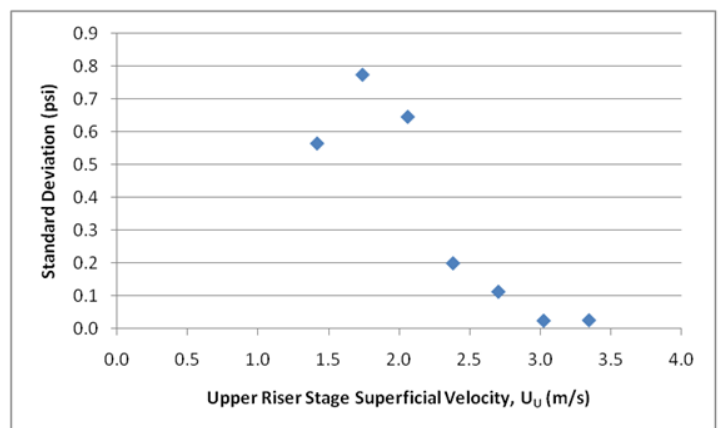

(a)

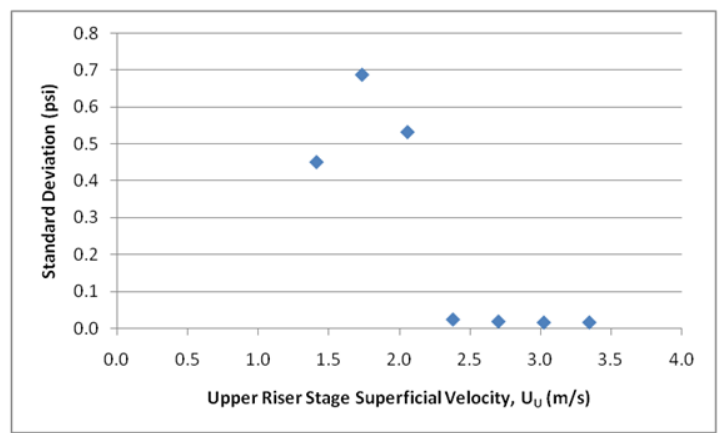

(b)

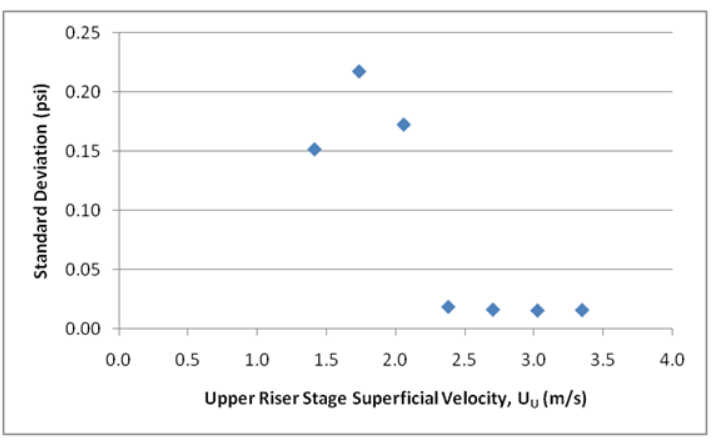

(c)

Figure 5-26: Effects of varying secondary air injection on model lower riser stage standard deviation of pressures (a) Lbottom (b) Lmid (c) Ltop: poly-dispersed sand, 3.5 psig feed hopper pressure, $U_{L}=2.36 \mathrm{~m} / \mathrm{s}$.

The evidence that increasing $U_{U}$ via secondary air injection causes the lower riser stage to transition from turbulent to fast fluidization can also be seen in the following skew and kurtosis plots for the lower riser stage when $U_{L}$ is held constant and $U_{U}$ is increased via secondary air injection. The skew and kurtosis plots for the Lmid and Ltop locations show higher values prior to $\mathrm{U}_{\mathrm{U}}=2.38 \mathrm{~m} / \mathrm{s}$, and a virtually constant value of 0 afterwards. The skew and kurtosis plots for the Lbottom location show a considerable amount of scatter, but lack the sudden drop to 0 that are characteristic of the other pressure transducer locations. Because of this, it is concluded that as $\mathrm{U}_{\mathrm{U}}$ increases beyond $2.38 \mathrm{~m} / \mathrm{s}$, there is still a dense bed in the bottom of the riser, but it 
decreases in bed height due to more and more of the lower riser stage transitioning to dilute fast fluidization.

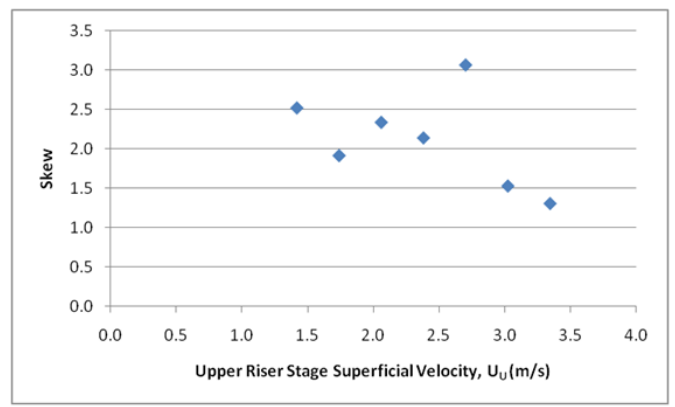

(a)

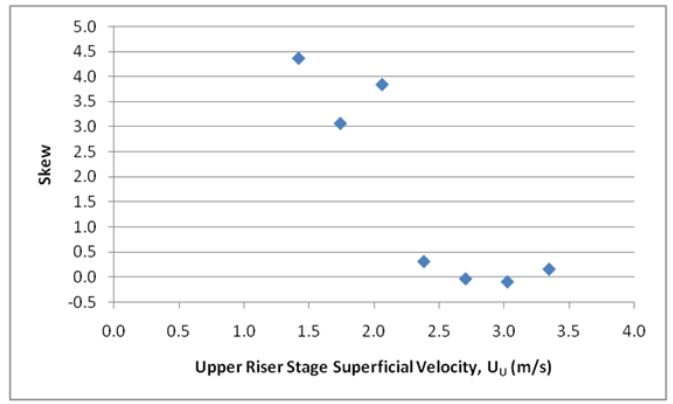

(b)

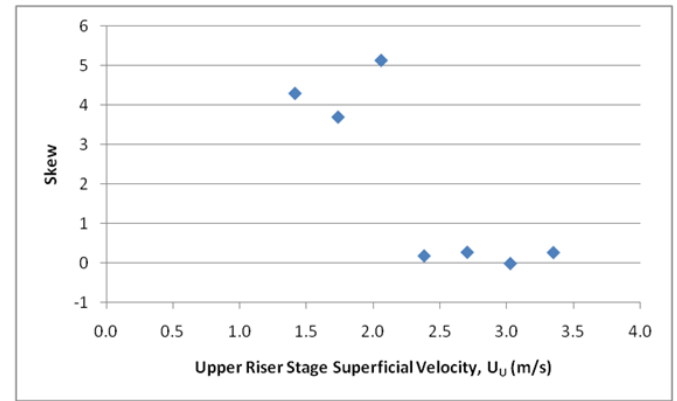

(c)

Figure 5-27: Effects of varying secondary air injection on model lower riser stage skew of pressures (a) Lbottom (b) Lmid (c) Ltop: poly-dispersed sand, 3.5 psig feed hopper pressure, $U_{L}=2.36 \mathrm{~m} / \mathrm{s}$.

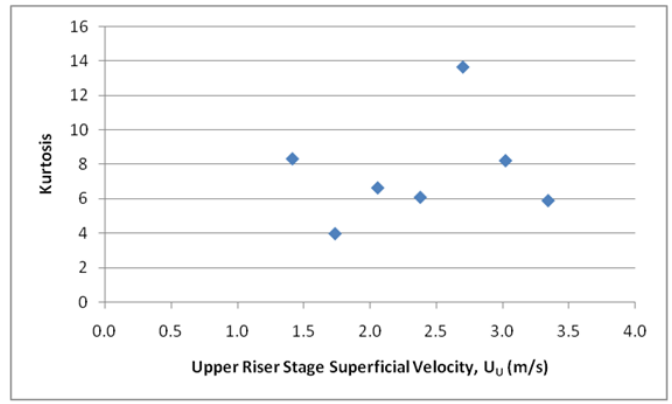

(a)

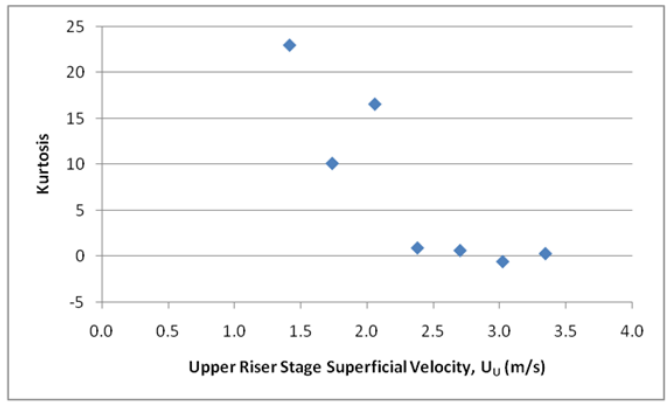

(b)

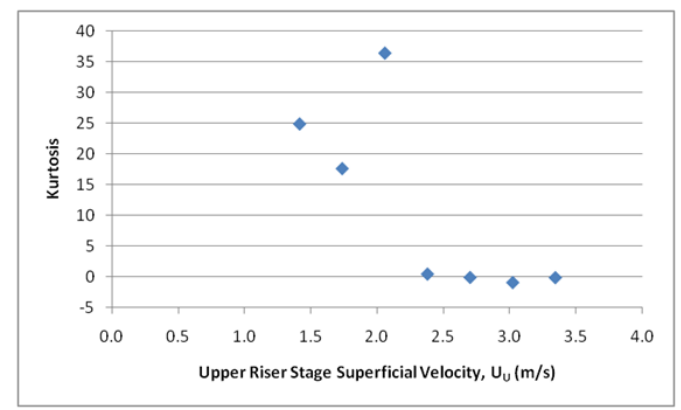

(c)

Figure 5-28: Effects of varying secondary air injection on model lower riser stage kurtosis of pressures (a) Lbottom (b) Lmid (c) Ltop: poly-dispersed sand, 3.5 psig feed hopper pressure, $U_{L}=2.36 \mathrm{~m} / \mathrm{s}$. 


\section{Shannon Entropy}

Figure 5-29 shows the effects of secondary air injection upon the Shannon entropy data of the pressure transducers located in the lower riser stage. In general, it appears that the changes in entropy follow a similar pattern to that seen in the standard deviation of pressure, as seen earlier in Figure 5-26. For each transducer location, there is a slight increase in entropy between $\mathrm{U}_{\mathrm{U}}=$ $1.42 \mathrm{~m} / \mathrm{s}$ and $\mathrm{U}_{\mathrm{U}}=1.74 \mathrm{~m} / \mathrm{s}$. This increase is then followed by a decrease towards a minimum value across the turbulent regime. The Ltop and Lmid locations exhibit a leveling off of the value of entropy corresponding to the fast fluidization regime. The lack of such a trend at the Lbottom location suggests that even at the higher $\mathrm{U}_{\mathrm{U}}$ velocities, the dense bed at the bottom of the lower riser stage still exists, just at a much reduced bed height.

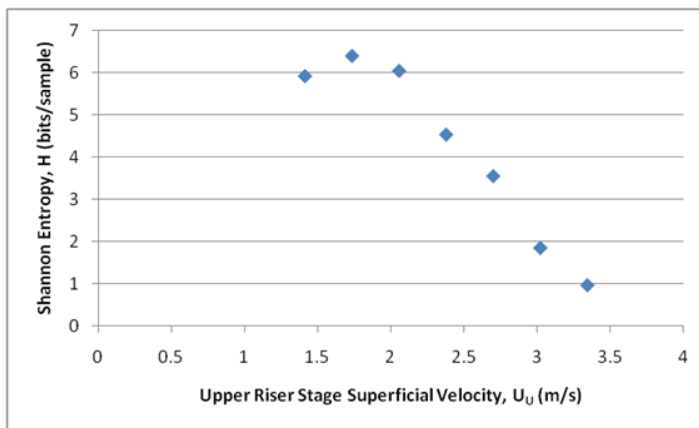

(a)

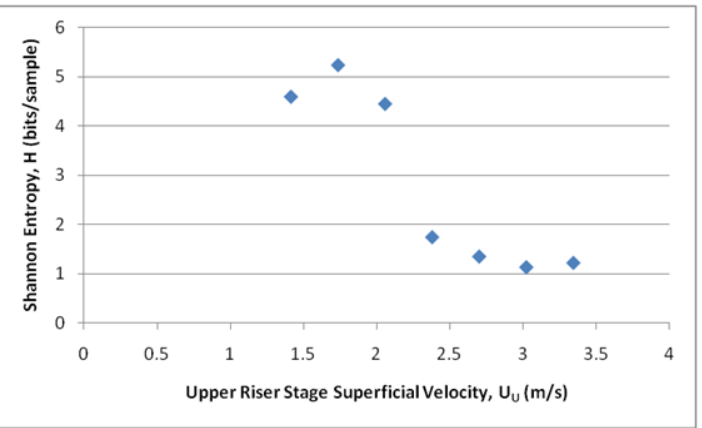

(b)

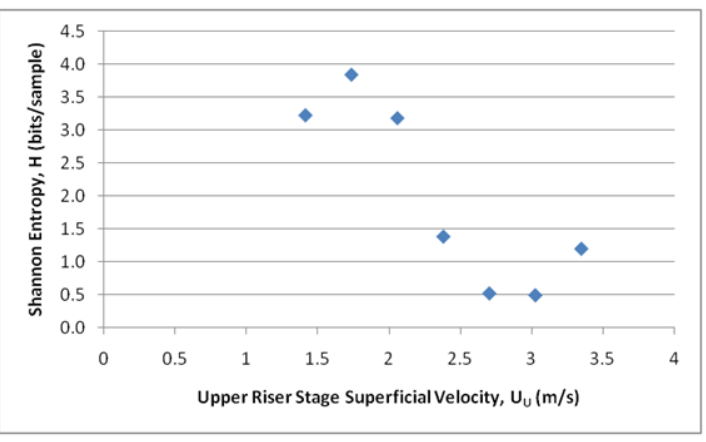

(c)

Figure 5-29: Effects of varying secondary air injection on model lower riser stage Shannon entropy of pressures (a) Lbottom (b) Lmid (c) Ltop: poly-dispersed sand, 3.5 psig feed hopper pressure, $U_{L}=2.36 \mathrm{~m} / \mathrm{s}$.

\section{Autocorrelation, Mutual Information Function and Power Spectral Density Plots}

\section{Autocorrelation}


Figures 5-30 and 5-31 show the effects of secondary air injection on the autocorrelation function for each of the lower riser stage pressure transducers. The autocorrelation plots for the Lbottom and Lmid locations for $\mathrm{U}_{\mathrm{U}}=1.42 \mathrm{~m} / \mathrm{s}$ through $\mathrm{U}_{\mathrm{U}}=2.06 \mathrm{~m} / \mathrm{s}$ are similar to that seen previously for the turbulent fluidization regime. The autocorrelation for those locations appear similar to that seen previously for the fast fluidization regime. The Ltop location autocorrelations appear to be more closely related to those associated with fast fluidization for all values of $U_{U}$.

\section{Mutual Information Function}

Figures 5-33 through 5-35 show the effect of secondary air injection on the mutual information function for each of the pressure transducer locations in the lower riser stage. The value of mutual information for a given pressure transducer location sees a pattern of variation that matches that seen in the corresponding standard deviation of pressure shown in Figure 5-26.

\section{Spectral Density Plots}

Figures 5-36 through 5-38 show the effects of secondary air injection on the spectral density plots of the lower riser stage pressure fluctuations. As seen previously, the frequencies with the highest levels of associated power are located between 0 and $2.5 \mathrm{~Hz}$ across the dense phase fluidization regimes. Once the bed transitions to a dilute regime (i.e. fast fluidization), the concentration of high-power frequencies spreads further to the right on the frequency axis and the amount of power associated with each frequency drops by as much as 3 orders of magnitude less than that seen in the dense fluidization regimes. 


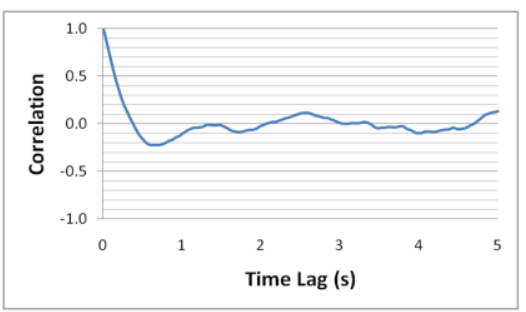

(a)

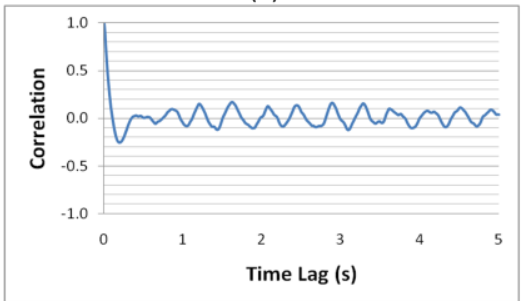

(d)

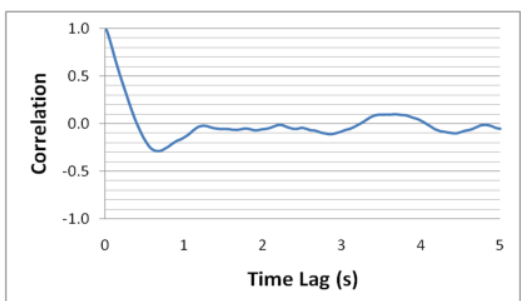

(b)

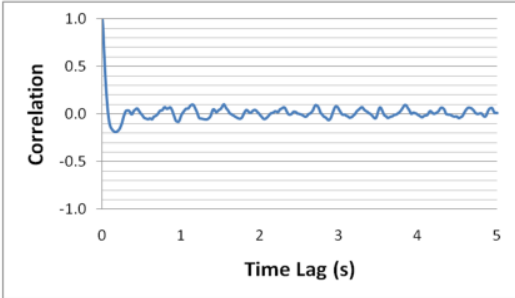

(e)

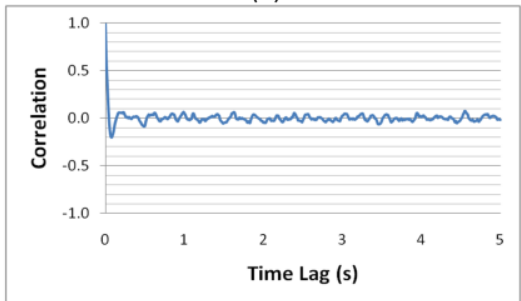

(g)

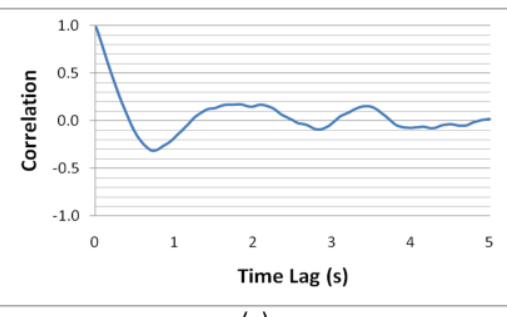

(c)

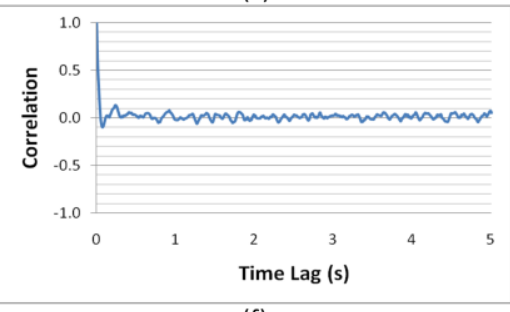

(f)

Figure 5-30: Autocorrelation plots for model Lbottom Pressure with Secondary Air Injection, poly-dispersed sand, 3.5 psig feed hopper pressure, $U_{L}=2.36 \mathrm{~m} / \mathrm{s}, U_{U}=:$ (a) 1.42 (b) 1.74 (c) 2.06 (d) 2.38 (e) 2.70 (f) 3.02 (g) $3.35 \mathrm{~m} / \mathrm{s}$.

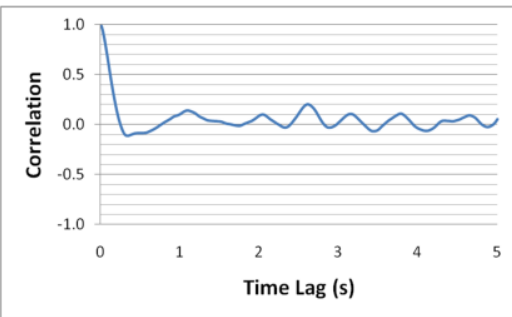

(a)

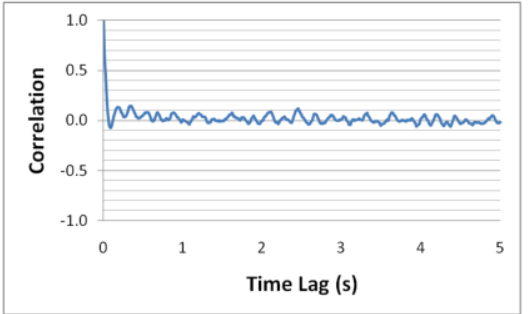

(d)

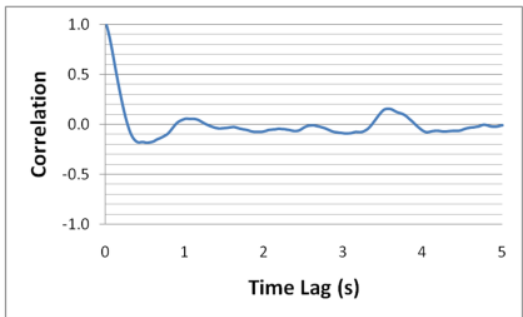

(b)

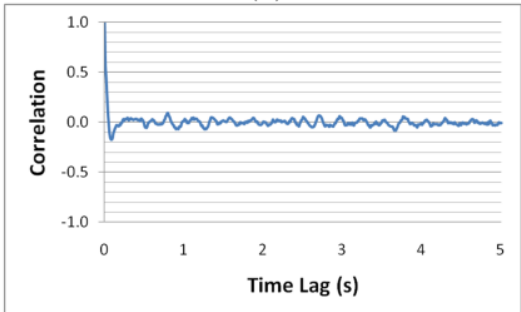

(e)

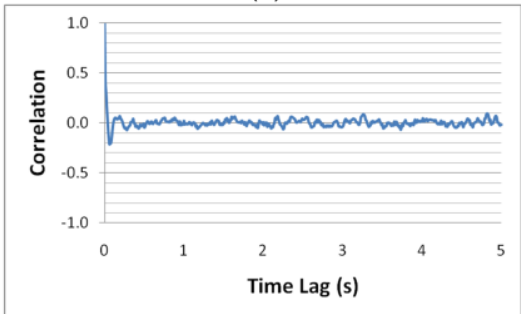

(g)

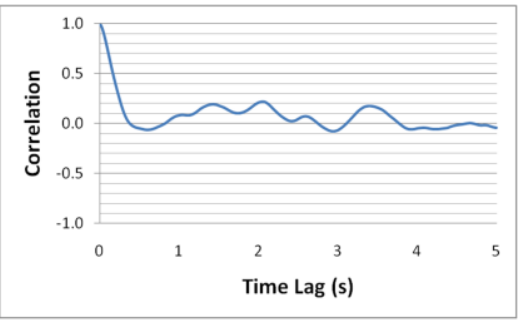

(c)

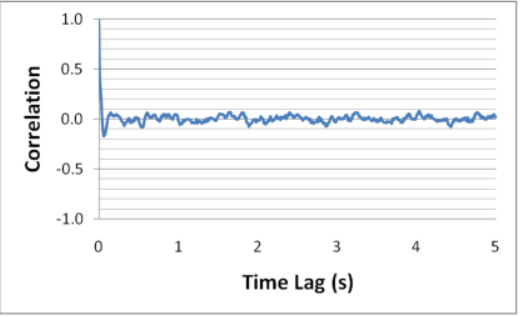

(f)

Figure 5-31: Autocorrelation plots for model Lmid Pressure with Secondary Air Injection, poly-dispersed sand, 3.5 psig feed hopper pressure, $U_{L}=2.36 \mathrm{~m} / \mathrm{s}, \mathrm{U}_{\mathrm{U}}=:$ : (a) 1.42 (b) 1.74 (c) 2.06 (d) 2.38 (e) 2.70 (f) 3.02 (g) $3.35 \mathrm{~m} / \mathrm{s}$. 


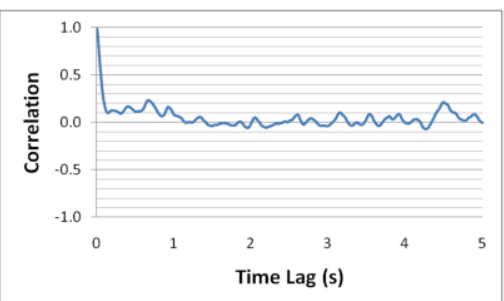

(a)

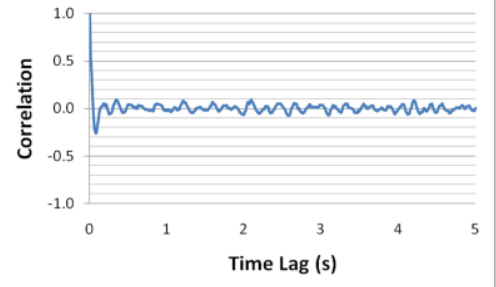

(d)

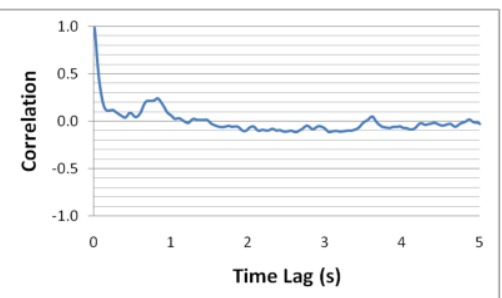

(b)

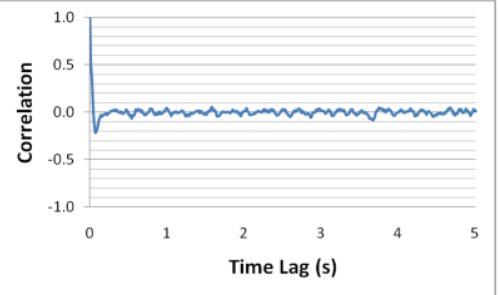

(e)

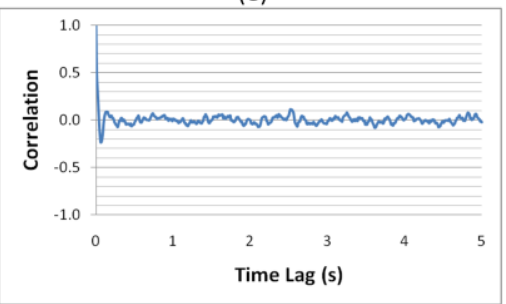

(g)

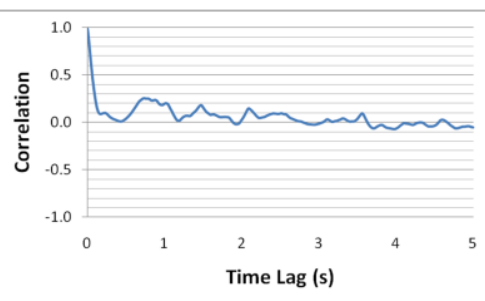

(c)

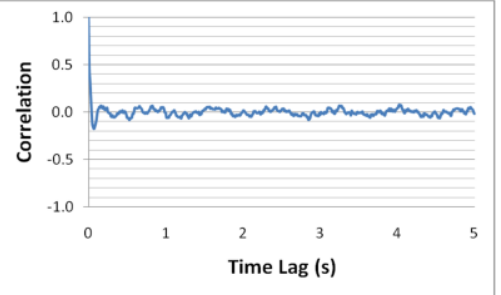

(f)

Figure 5-32: Autocorrelation plots for model Ltop Pressure with Secondary Air Injection, poly-dispersed sand, 3.5 psig feed hopper pressure, $U_{L}=2.36 \mathrm{~m} / \mathrm{s}, \mathrm{U}_{\mathrm{U}}=:$ : (a) 1.42 (b) 1.74 (c) 2.06 (d) 2.38 (e) 2.70 (f) 3.02 (g) $3.35 \mathrm{~m} / \mathrm{s}$.

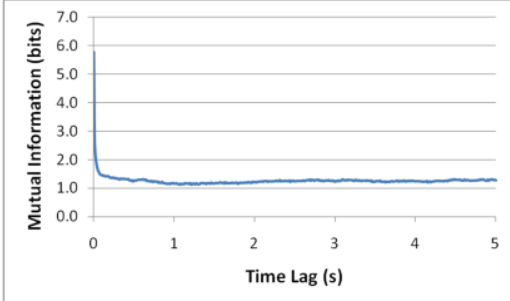

(a)

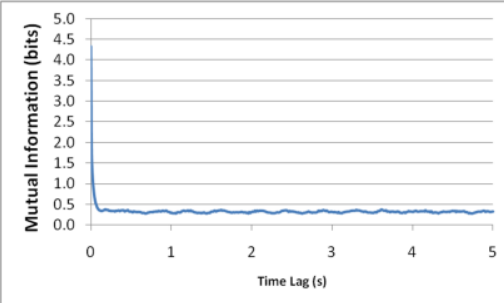

(d)

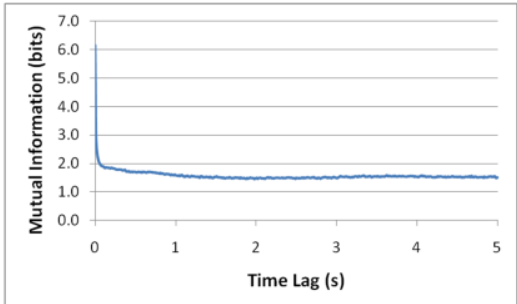

(b)

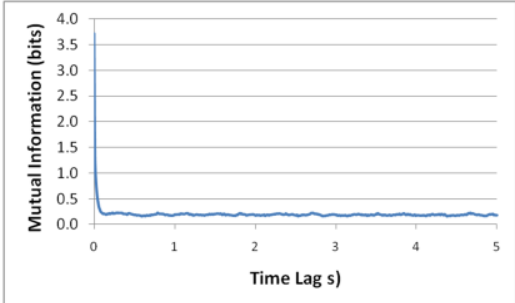

(e)

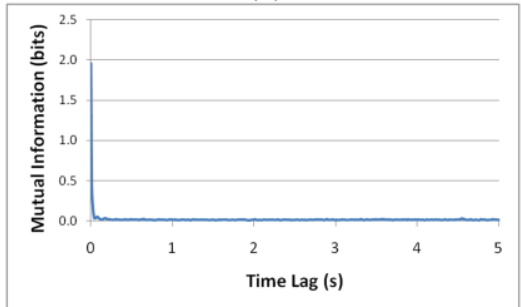

(g)

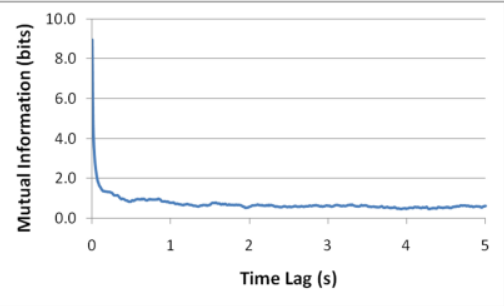

(c)

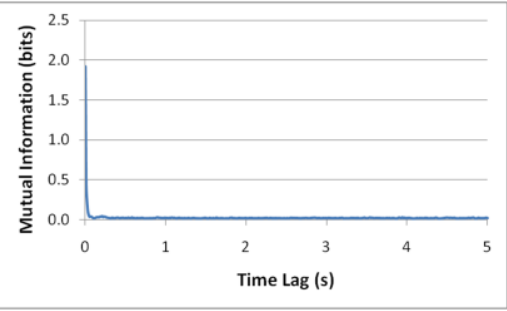

(f)

Figure 5-33: Mutual Information plots for model Lbottom pressure with secondary air injection, poly-dispersed sand, 3.5 psig feed hopper pressure, $U_{L}=2.36 \mathrm{~m} / \mathrm{s}, U_{U}=:$ (a) 1.42 (b) 1.74 (c) 2.06 (d) 2.38 (e) 2.70 (f) 3.02 (g) $3.35 \mathrm{~m} / \mathrm{s}$. 


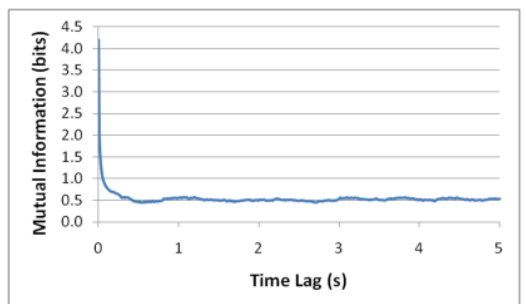

(a)

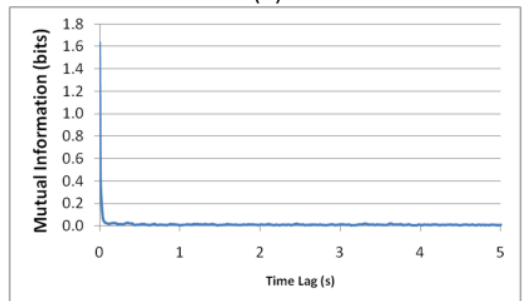

(d)

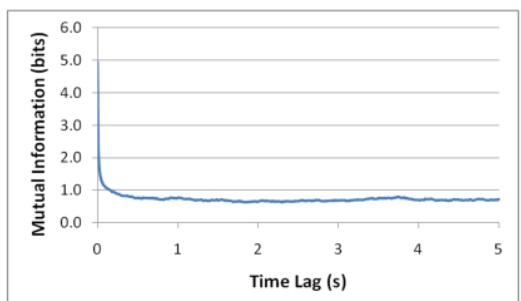

(b)

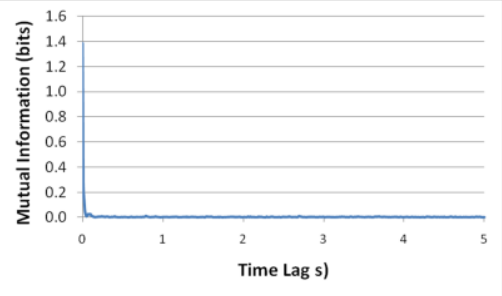

(e)

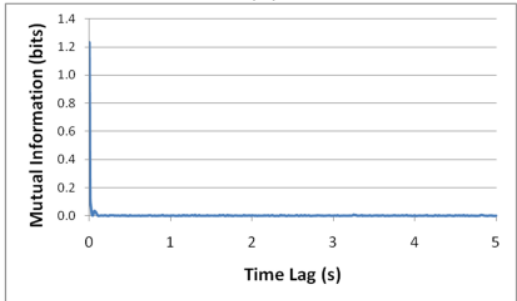

(g)

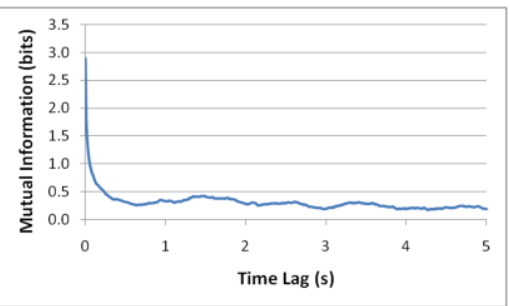

(c)

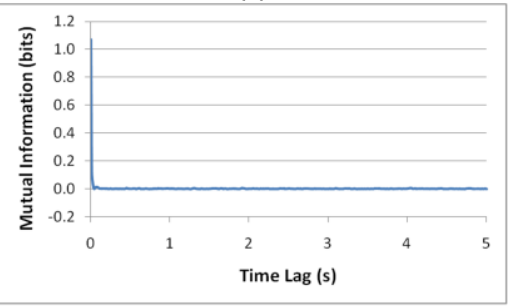

(f)

Figure 5-34: Mutual Information plots for model Lmid pressure with secondary air injection, poly-dispersed sand, 3.5 psig feed hopper pressure, $U_{L}=2.36 \mathrm{~m} / \mathrm{s}, U_{U}=:$ (a) 1.42 (b) 1.74 (c) 2.06 (d) 2.38 (e) 2.70 (f) 3.02 (g) $3.35 \mathrm{~m} / \mathrm{s}$.

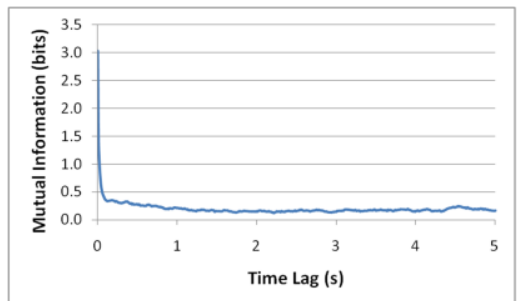

(a)

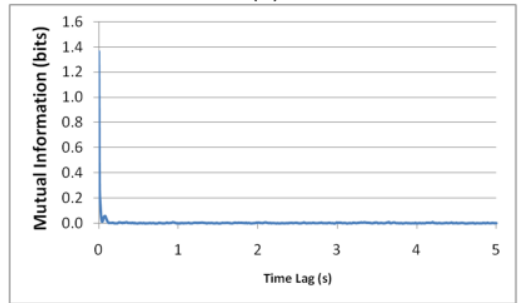

(d)

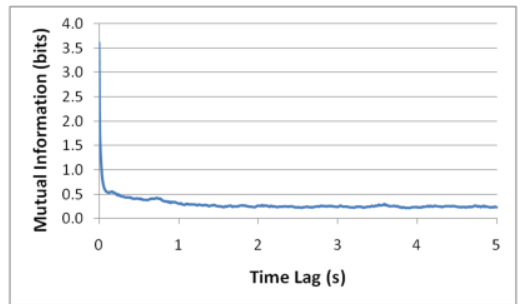

(b)

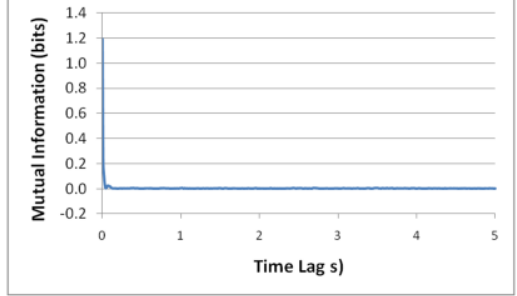

(e)

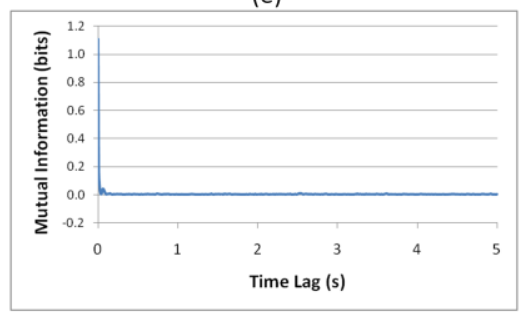

(g)

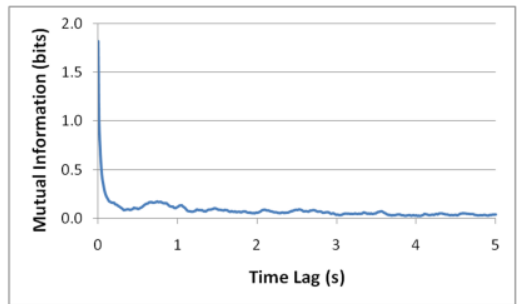

(c)

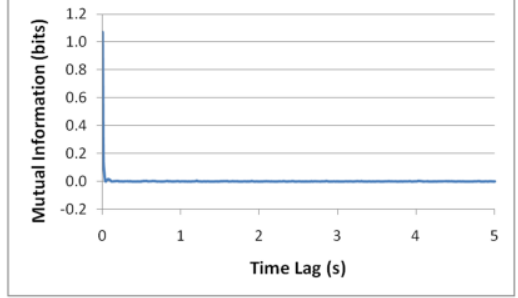

(f)

Figure 5-35: Mutual Information plots for model Ltop pressure with secondary air injection, poly-dispersed sand, 3.5 psig feed hopper pressure, $U_{\mathrm{L}}=2.36 \mathrm{~m} / \mathrm{s}, \mathrm{U}_{\mathrm{U}}=:$ (a) 1.42 (b) 1.74 (c) 2.06 (d) 2.38 (e) 2.70 (f) 3.02 (g) $3.35 \mathrm{~m} / \mathrm{s}$. 


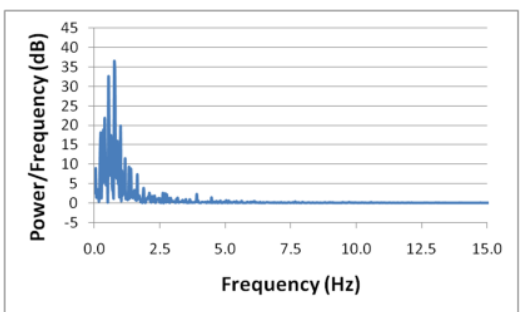

(a)

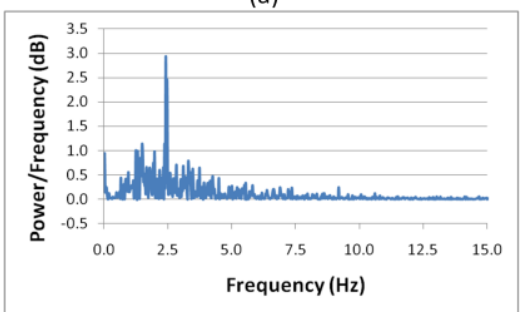

(d)

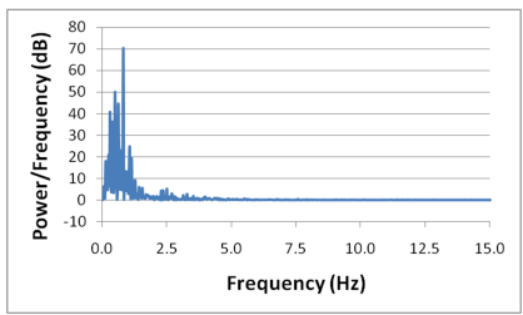

(b)

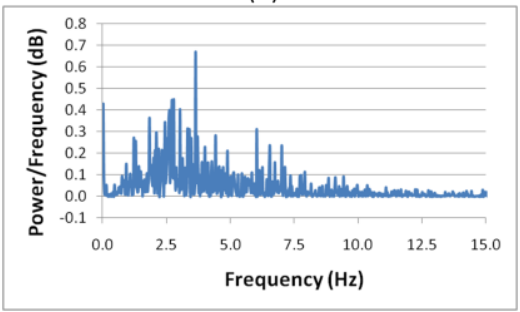

(e)

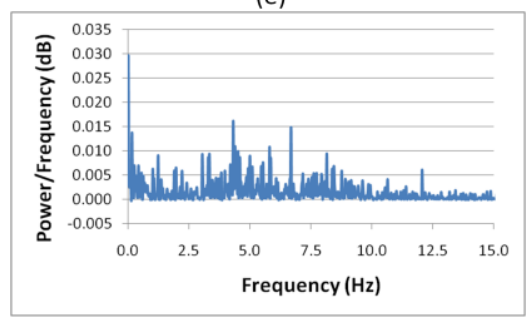

(g)

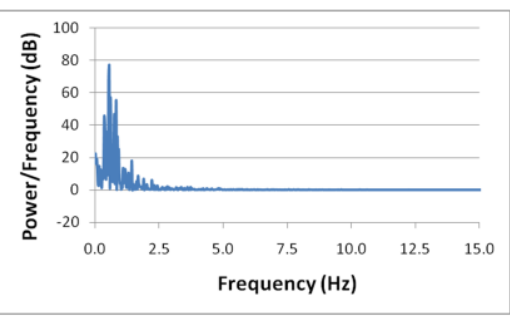

(c)

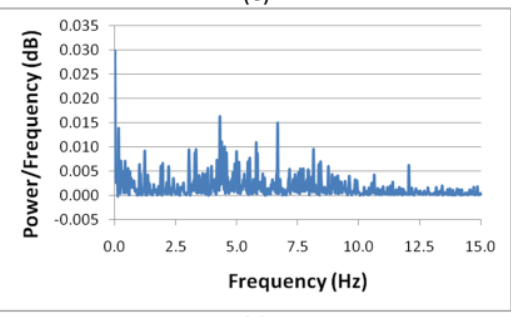

(f)

Figure 5-36: Spectral Density plots for model Lbottom pressure with secondary air injection, poly-dispersed sand, 3.5 psig feed hopper pressure, $U_{L}=2.36 \mathrm{~m} / \mathrm{s}, U_{U}=:$ (a) 1.42 (b) 1.74 (c) 2.06 (d) 2.38 (e) 2.70 (f) 3.02 (g) $3.35 \mathrm{~m} / \mathrm{s}$.

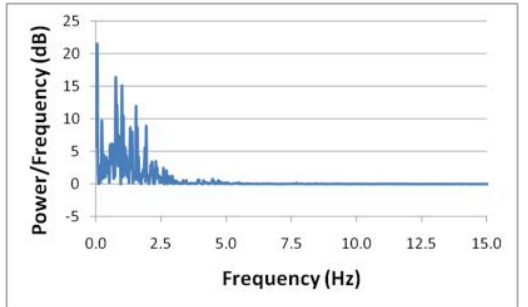

(a)

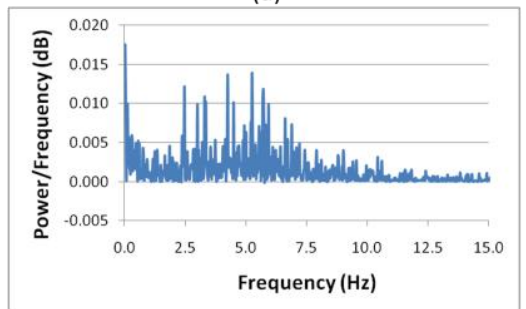

(d)

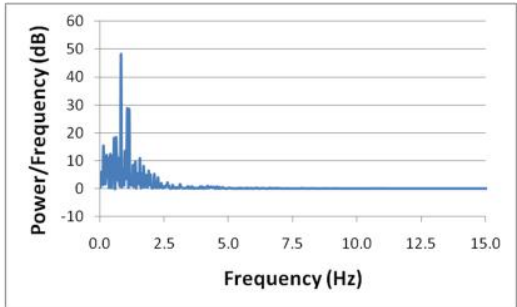

(b)

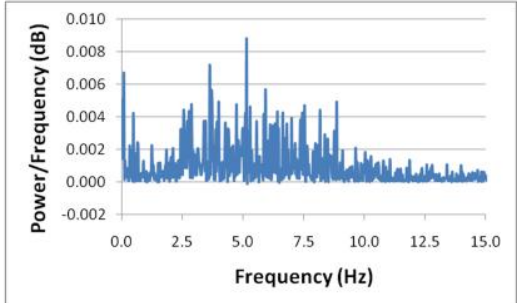

(e)

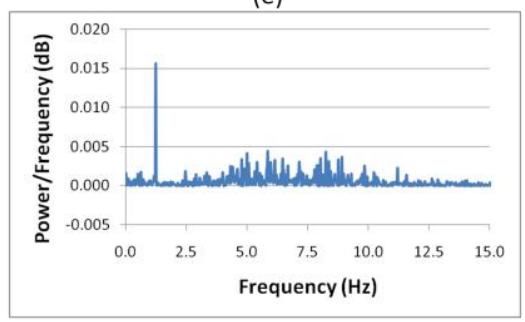

(g)

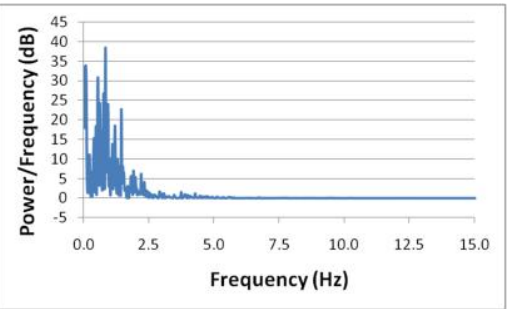

(c)

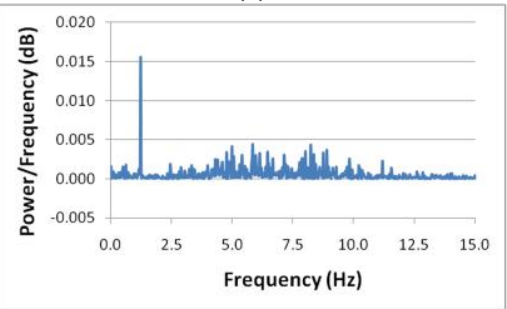

(f)

Figure 5-37: Spectral Density plots for model Lmid pressure with secondary air injection, poly-dispersed sand, 3.5 psig feed hopper pressure, $U_{L}=2.36 \mathrm{~m} / \mathrm{s}, U_{U}=:$ (a) 1.42 (b) 1.74 (c) 2.06 (d) 2.38 (e) 2.70 (f) 3.02 (g) $3.35 \mathrm{~m} / \mathrm{s}$. 


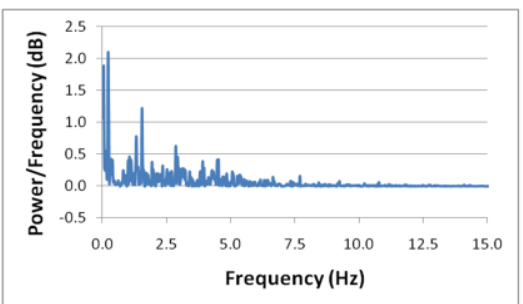

(a)

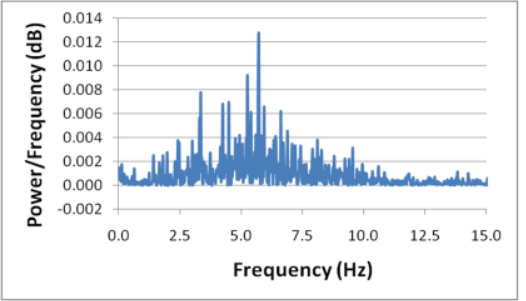

(d)

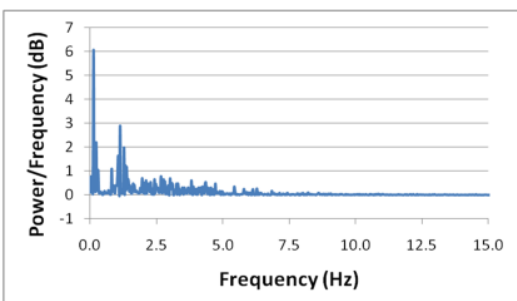

(b)

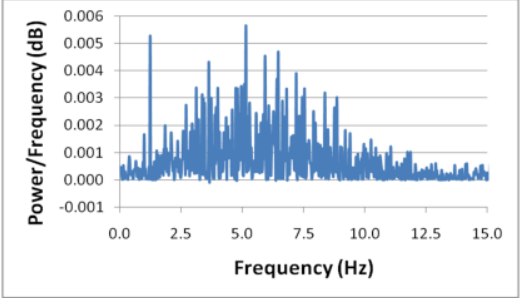

(e)

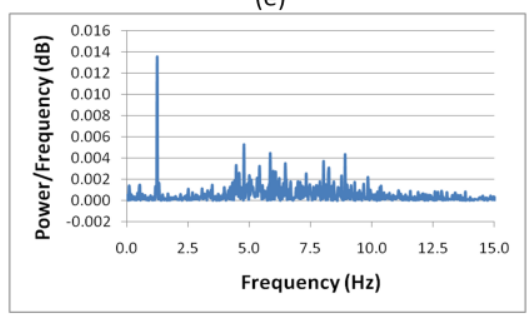

(g)

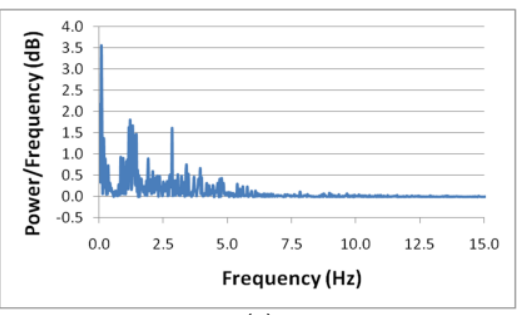

(c)

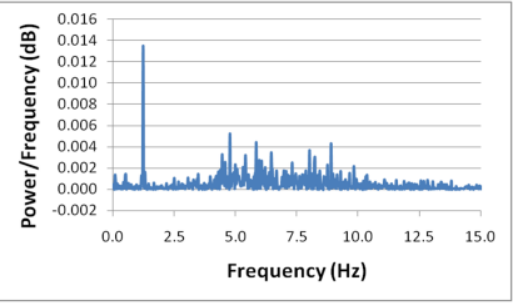

(f)

Figure 5-38: Spectral Density plots for model Ltop pressure with secondary air injection, poly-dispersed sand, 3.5 psig feed hopper pressure, $U_{\mathrm{L}}=2.36 \mathrm{~m} / \mathrm{s}, \mathrm{U}_{\mathrm{U}}=:$ : (a) 1.42 (b) 1.74 (c) 2.06 (d) 2.38 (e) 2.70 (f) 3.02 (g) $3.35 \mathrm{~m} / \mathrm{s}$.

\section{Comparison of Standard Deviation of Pressure with Riser Stage Pressure Drop}

The relationship between the standard deviation of the Lbottom and Ubottom pressure signals and the lower and upper riser stage pressure drops are shown in Figures 5-39 and 5-40. The first plot in each figure shows data without secondary air injection, and the second shows data with secondary air injection. As can be seen, the standard deviation follows the trends seen in the average pressure drop in all cases except for Figure 5-39(a).

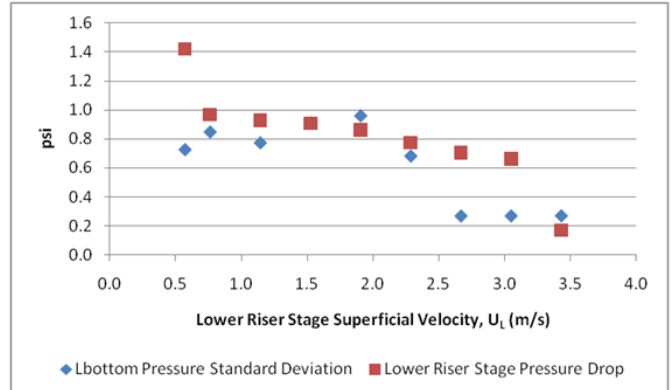

(a)

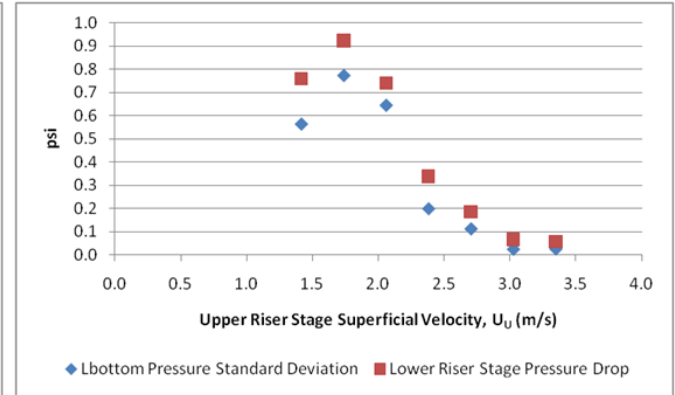

(b)

Figure 5-39: Relationship between Lbottom standard deviation of pressure and lower riser stage pressure drop for (a) no secondary air injection (b) secondary air injection. 


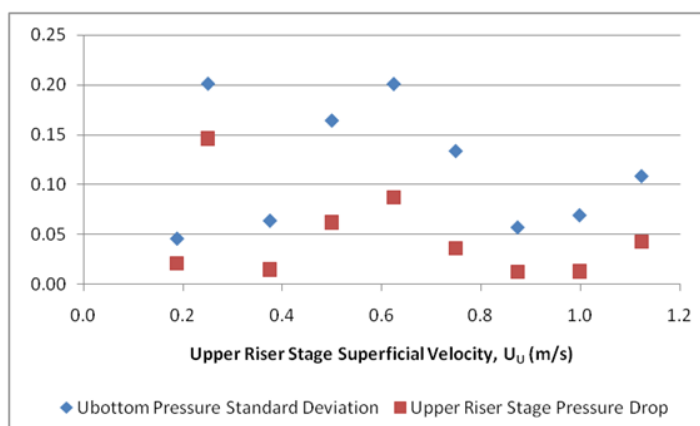

(a)

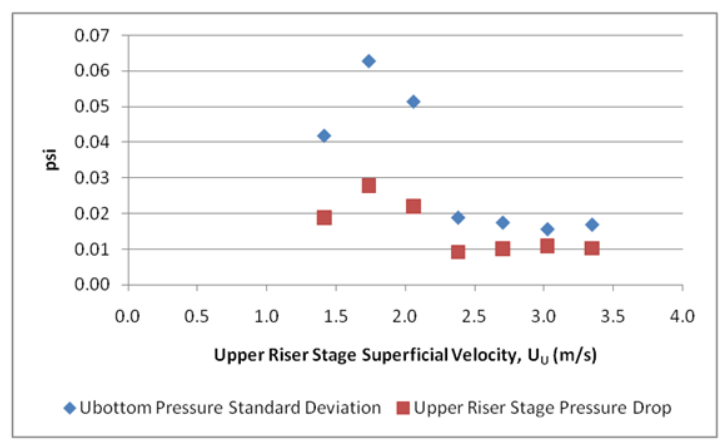

(b)

Figure 5-40: Relationship between Ubottom standard deviation of pressure and upper riser stage pressure drop for (a) no secondary air injection (b) secondary air injection.

\section{Repeatability of Results}

In addition to the data presented throughout this dissertation, additional test data was obtained using $200 \mu \mathrm{m}$ spherical glass beads. The results of these additional tests will be presented in journal articles to be published at a later date. However, it should be noted that all of the trends presented and discussed for the poly-dispersed sand experiments were also seen in the glass bead data. The primary differences between the two materials were in the superficial velocities associated with the transition points between fluidization regimes.

Additionally, while the test conditions for sand were not run in duplicate, enough data was collected at each test condition to perform the various statistical analysis methods upon different segments of the collected data. In general, the results were consistent over differing data segments as long as the system was operating in a steady state condition (as evidence by a "level" pressure time history profile). The results over differing data time segments showed little variation over the bubbling, slugging and fast fluidization regimes. The largest spread in results was seen when comparing the standard deviation values over the turbulent fluidization regime. Given the chaotic nature of turbulent fluidization this is to be expected, as the turbulent regime is 
the least stable of the fluidization regimes studied due to the wide range of bubble frequencies and heightened sensitivity to minor changes in initial conditions.

\section{Still Images}

Figures 5-41 and 5-42 depict still images from the lower and upper riser stages, respectively. In Figure 5-41, the slugging regime is clearly visible; however it is difficult to see the difference between the turbulent and fast fluidization regimes. For the turbulent regime, the bubbles form and rise upwards, while material moves downward along the walls in fast fluidization. The differences in Figure 5-42 are much easier to see. The turbulent still image in Figure 5-42(a) shows a dense bed area, while the fast fluidization still image in Figure 5-42(b) shows a very dilute amount of solids.

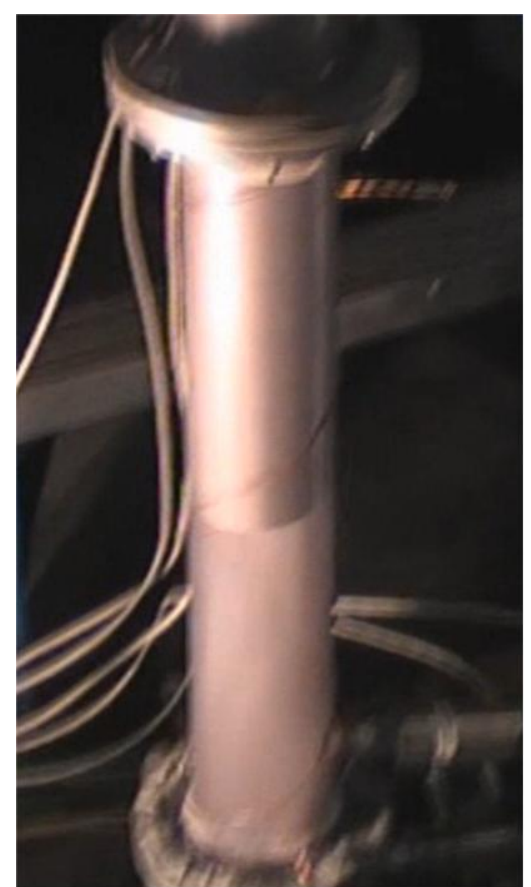

(a)

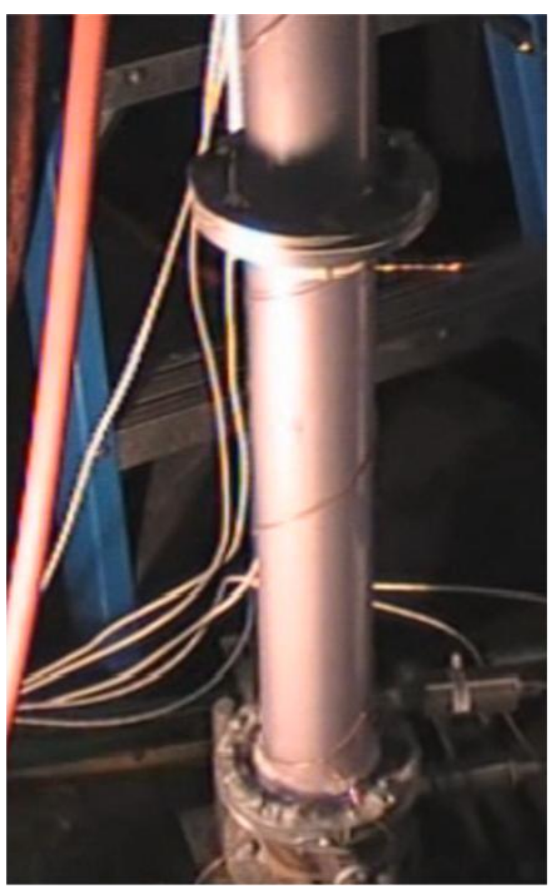

(b)

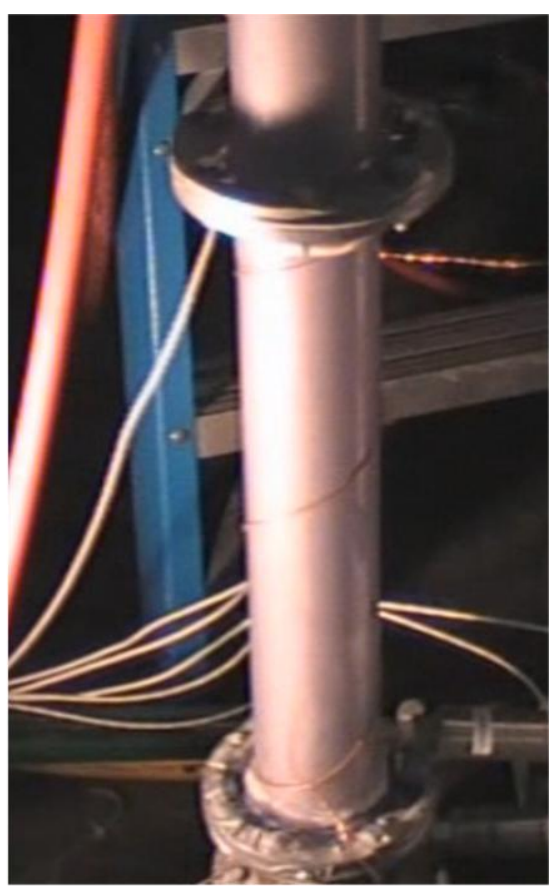

(c)

Figure 5-41: Still images for lower riser stage mapping (a) slugging (b) turbulent (c) fast fluidization 


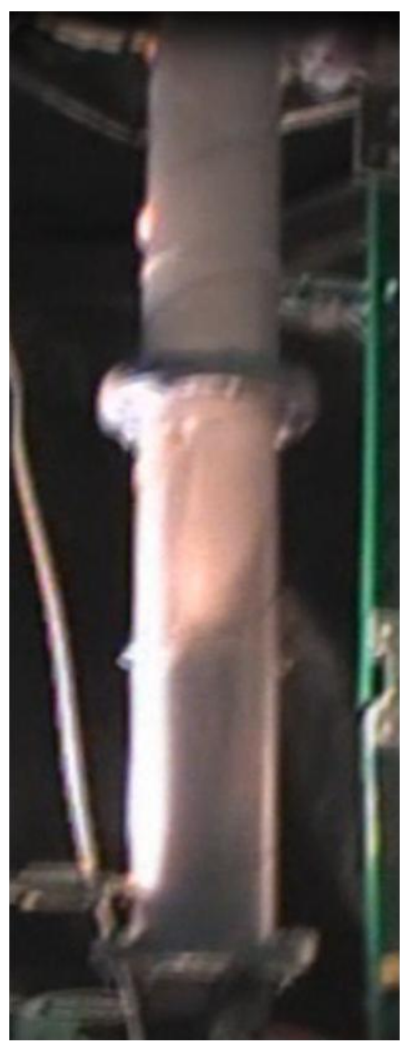

(a)

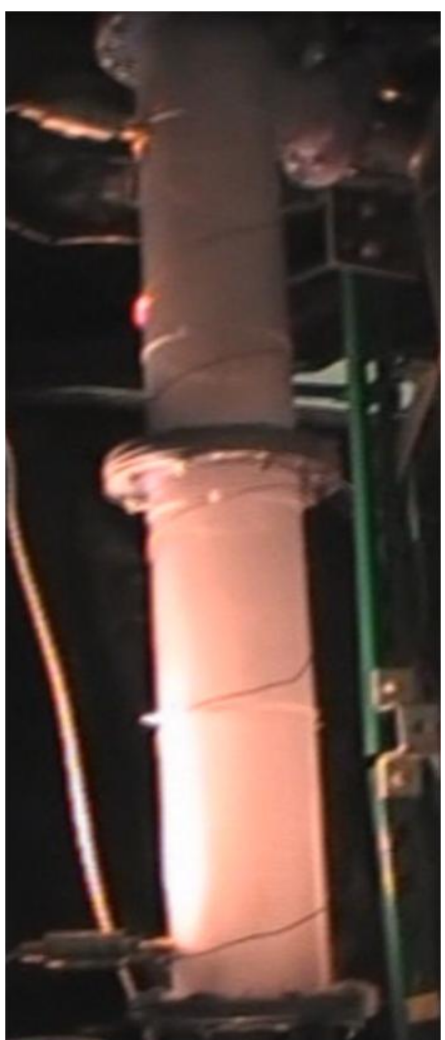

(b)

Figure 5-42: Still pictures of upper riser stage mapping (a) turbulent (b) fast fluidization

\section{Conclusions}

The primary purpose for constructing and performing tests with the scale model was to obtain an understanding of the underlying operating characteristics of a variable area, multi-stage fluidized bed design like that employed by the Warm Air Dryer for Fine Particles (WADFP). Because it is not possible to view what transpires within the WADFP unit during operation, it was decided to construct a small scale transparent model that would allow for visual observation. This visual observation was intended as a means of providing additional insight into what transpires within the fluidized bed and as a supplement to data collected from the pressure transducers installed within the system. While video records of each experimental run were taken, priority has been 
given throughout this chapter to the pressure data results and analysis as that is the primary source of comparison between the WADFP and the scale model.

For fluidization regime mapping, the time series data collected via the various pressure transducers was analyzed via statistical moments (standard deviation, skew and kurtosis), autocorrelation, mutual information, PSD and Shannon entropy. Of the statistical moments, it was found that the standard deviation was best able to indicate the onset of the turbulent and fast fluidization regimes. In addition, while it was possible to determine different fluidization regimes via Shannon entropy, the trends exhibited on the Shannon entropy plots were slightly less distinct than those evident in the standard deviation data. In fact, Shannon entropy tended to follow whatever trend was visible in the standard deviation of pressure.

Finally, given the results of the effects of secondary air injection upon the lower riser section, the assumption that secondary air injection can be used to separate the upper and lower riser stages into two independent fluidized beds (based upon Ersoy [14]) is not valid. The data clearly shows that secondary air injection affects the statistical moments, Shannon entropy, autocorrelation, mutual information and spectral density plots of the lower riser stage pressure transducers. In addition, the regime mapping data when secondary air injection was in use showed that the fluidization regime present in the lower riser stage was driven to change in order to match the regime present in the upper riser stage. Given this information, it has been determined that, in order to maintain turbulent fluidization in the lower riser stage, the upper riser stage must be operated at a superficial velocity that falls within the range whose standard deviation of pressures is indicative of turbulent fluidization. 


\section{Chapter 6 Warm Air Dryer Experimental System}

The scale model experimental system has been described in chapter 4 . The description of the Warm Air Dryer for Fine Particles, or WADFP, is presented in Chapter 6. The WADFP and scale model systems share many common basic design elements, with the primary differences between the two systems detailed throughout the remainder of this chapter.

\section{General Design Concepts}

Figure 6-1 depicts the basic design of the WADFP fluidized bed. This fluidized bed is of the same general two-stage, variable diameter design as the scale model fluidized bed described in

Chapter 4. The WADFP unit is constructed primarily of aluminum and has a total riser height of 200 inches. The small diameter lower stage consists of three 36-3/4 inch long, 5 inch ID pipe sections and the larger diameter upper stage consists of two $36-3 / 4$ inch long, 8 inch ID sections. Each of these sections consists of an outer pipe as well as an inner pipe with the previously mentioned inside diameter. The riser sections are attached to one another via bolt patterns in the flange at each end of the section. The cavity between the inner and outer pipe of each riser section forms a steam jacket which is used to heat the inside wall of the riser to prevent moisture condensation on the wall surface during operation. Steam enters this cavity through steam pipes connected to a $1 \frac{1}{2}$-inch fitting at the top of each riser section; steam and condensed water exit the steam jacket via drain pipes connected to a $1 \frac{1}{2}$-inch pipe fitting at the bottom of each riser section. As with the scale model riser, the lower and upper riser stages are connected via a conical-shaped air injection ring that allows for secondary air injection between the two riser stages. In addition, there is also a conical-shaped injection ring that forms a plenum chamber and air distributor plate located at the bottom of the lower riser section. 
Solid material is introduced into the bottom of the fluidized bed via a motor-driven feed hopper mounted next to the riser. Sand or coal is forced out of the feed hopper by a mechanical auger and into a short vertical pipe. This vertical pipe is connected to a second pipe that is angled at approximately 70 degrees from the horizontal axis. When the solid material enters this pipe, gravity and a small jet of high temperature air blows it downwards into a vertical transport tube leading into the bottom of the riser. A second jet of high temperature air blows the material upwards into the riser.

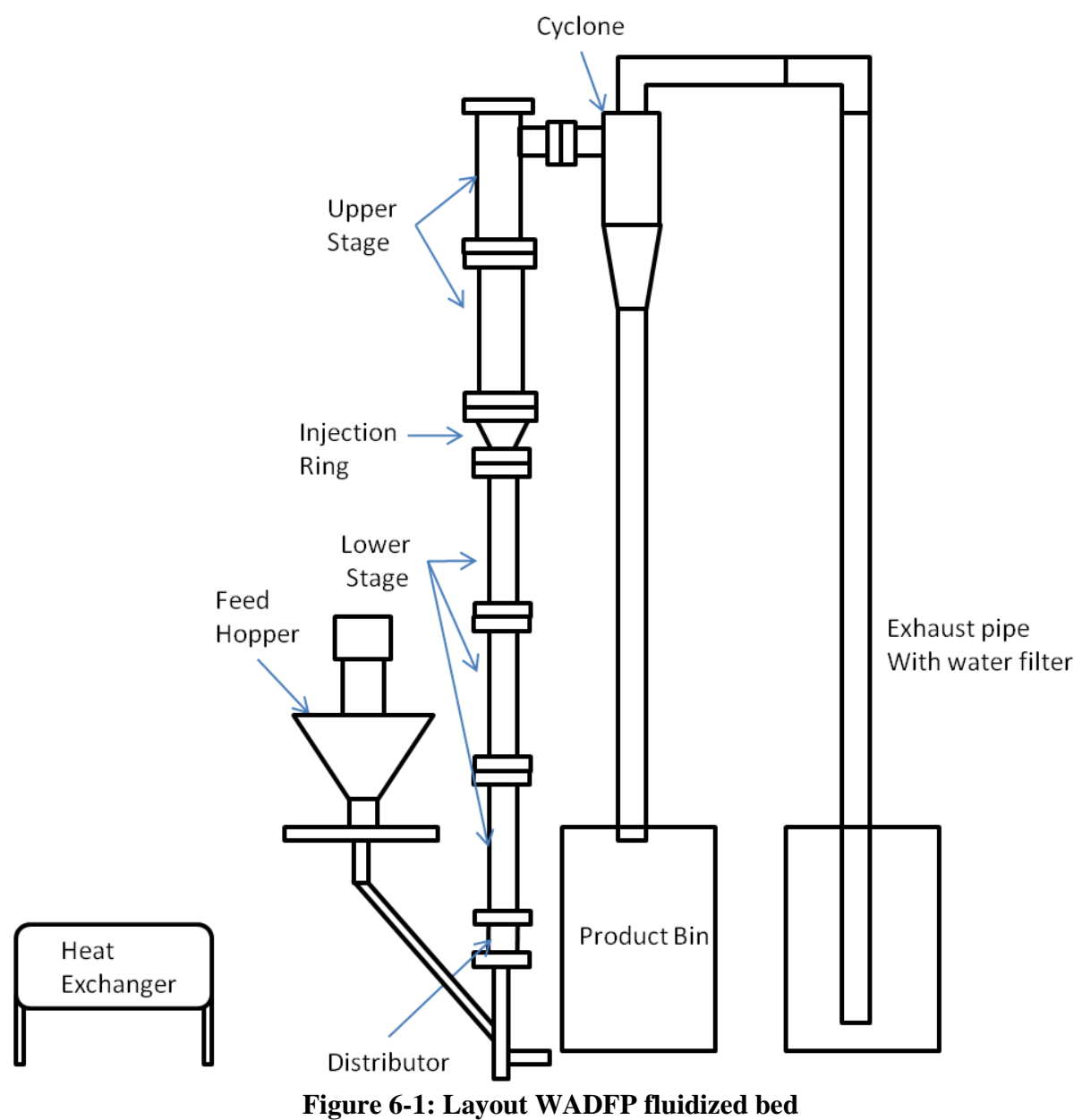

Upon exiting the top of the riser via a 4-inch ID horizontal pipe, the solid material and transporting air enter a cyclone that separates solid particles from the air. The solid particles exit 
the bottom of the cyclone, fall through the down-comer made of 3-inch ID schedule $80 \mathrm{pvc}$ pipe, and are collected in a collection bin constructed from a 55 gallon steel drum. The air exits the top of the cyclone and is piped via 4-inch ID schedule 80 pvc pipe into a second drum containing water. As air bubbles through this water, any remaining particulate matter is trapped within the drum.

\section{Air Feed System}

Figure 6-2 demonstrates the general airflow for the WADFP fluidized bed riser unit. The supply air is provided via a compressor capable of providing up to 750 SCFM at 125 psi. This house air is regulated to a maximum of $100 \mathrm{psi}$ via a regulator valve and then is introduced into a manifold with three exit ports. At each of the exit ports is a 0-300 SCFM piston style flow meter. High pressure rubber hose connects these flow meters to a basic shell and tube style heat exchanger. One of the high pressure rubber hoses connecting the center flow meter to the heat exchanger is connected to a ball valve that can redirect the flow of air to a second, smaller $(6-60 \mathrm{scfm})$ flow meter to allow for lower flow rates of air to the heat exchanger and the lower air distributor. High temperature steam flows through the outer shell while air flows through the three horizontal tubes passing through the shell. The two upper tubes have an inside diameter of 3 inches and are filled with $1 / 4$-inch steel ball bearings in order to increase the heat transfer surface area to which the passing air is exposed. Upon exiting these tubes, one of the air lines feeds the lower air injection ring and the second feeds air to the secondary air injection ring. The third horizontal tube has an inside diameter of 1-inch and is filled with 0.177-inch ID copper BB's. Air passing through this smaller heat exchanger tube is then split into three separate flows that provide high temperature air to the feed hopper, angled transport tube and the horizontal transport tube leading to the bottom of the lower air injection ring. 


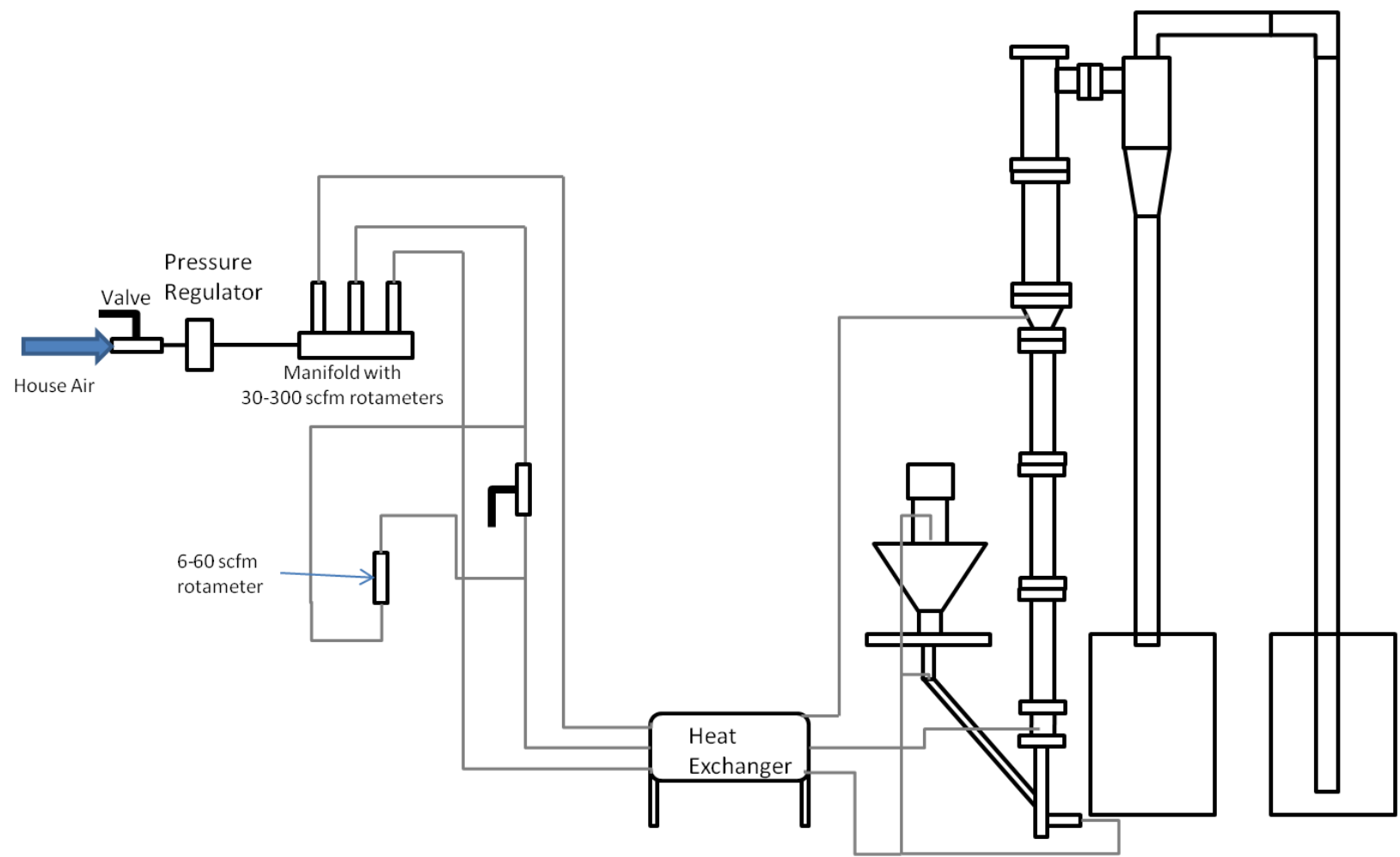

Figure 6-2: Airflow Diagram for WADFP Fluidized Bed

\section{Steam System Design}

Figure 6-3 shows the basic layout and design of the WADFP steam system. House steam enters the system at the location shown and is regulated to approximately 10 psig by a pressure regulator after it passes the first valve. This low pressure steam is then fed into the heat exchanger and the top of each of the steam-jacketed sections of both riser stages. Steam and condensed water exit out the bottom of the heat exchanger and each section of both riser stages. Condensation traps on each of the drain pipes allow the condensed water to flow into the building's storm drain. Multiple valves are installed within the system in order to facilitate purging air from the pipes by filling them with water prior to operation of the unit. 


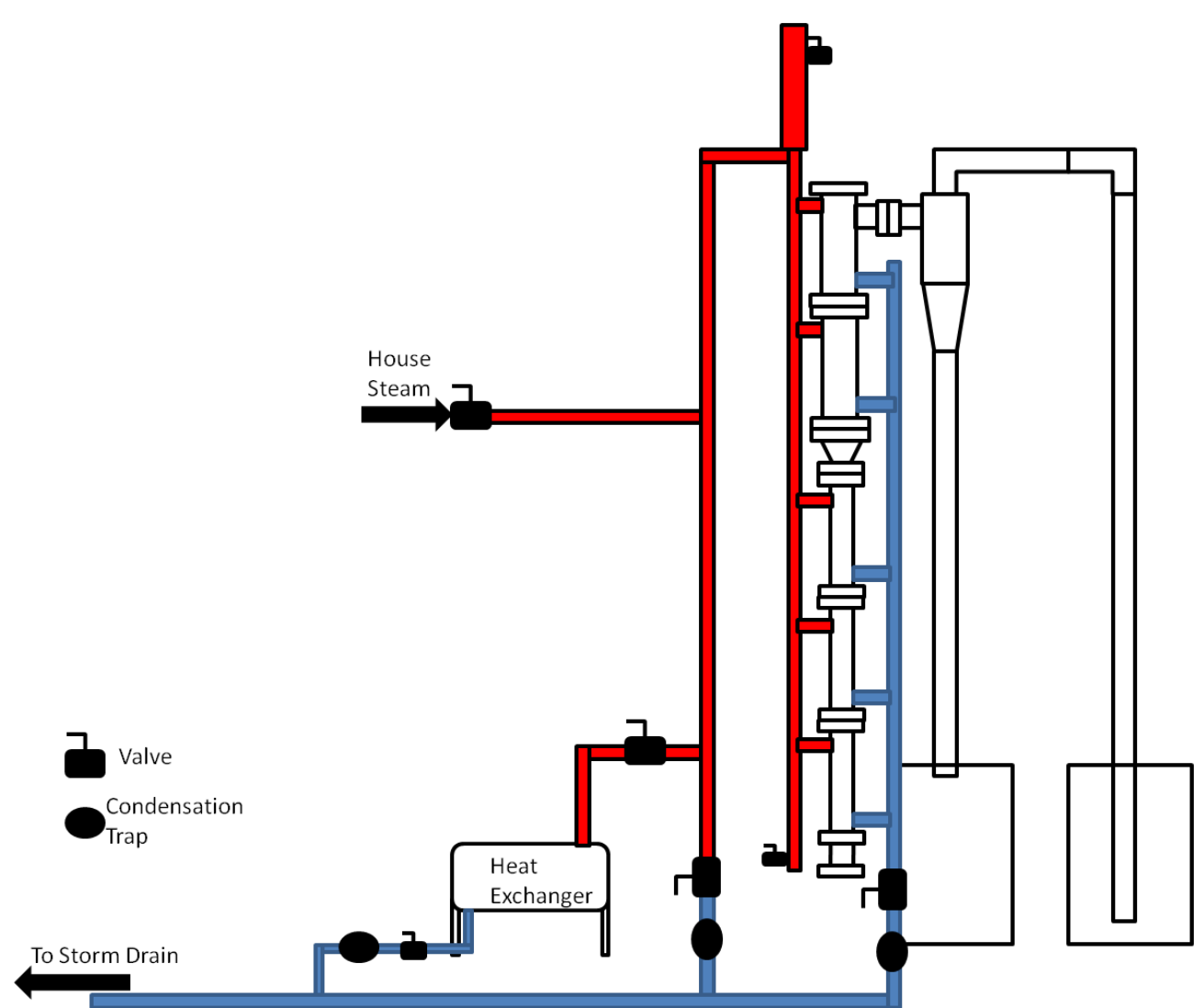

Figure 6-3: WADFP Steam System Diagram

\section{Data Acquisition System and Instrumentation}

The WADFP fluidized bed system makes use of the same data acquisition system and pressure transducers as detailed in the description of the scale model riser in Chapter 4. Additional instrumentation, described below, include a low temperature relative humidity/temperature sensor installed upstream of the air manifold, a thermocouple in each of the air lines exiting the heat exchanger and a high temperature relative humidity/temperature sensor installed in the pipe at the upper exit from the cyclone. For details on the data acquisition system and pressure transducers, see the appropriate sections of Chapter 4.

Low Temperature Relative Humidity Sensor 
The relative humidity and temperature of the air supplied to the flow meter manifold by the air compressor is measured by an Omega Engineering HX-93AV relative humidity and temperature transmitter. This sensor has range of $3-95 \%$ relative Humidity and $-4^{\circ}$ to $167^{\circ} \mathrm{F}$ and an accuracy of $+/-2.5 \% \mathrm{RH}$ and $0.6^{\circ} \mathrm{F}$.

\section{High Temperature Relative Humidity Sensor}

The relative humidity and temperature of the air exiting the system cyclone is measured by an HF-734 Hygroflex humidity temperature transmitter from Rotronic. This sensor has a range of 0 $-100 \%$ relative humidity and $-148^{\circ}$ to $302^{\circ} \mathrm{F}$ with a factory programmed output of $0-5 \mathrm{~V}$ and an accuracy of $+/-1.0 \% \mathrm{RH}$ and $+/-0.2^{\circ} \mathrm{F}$.

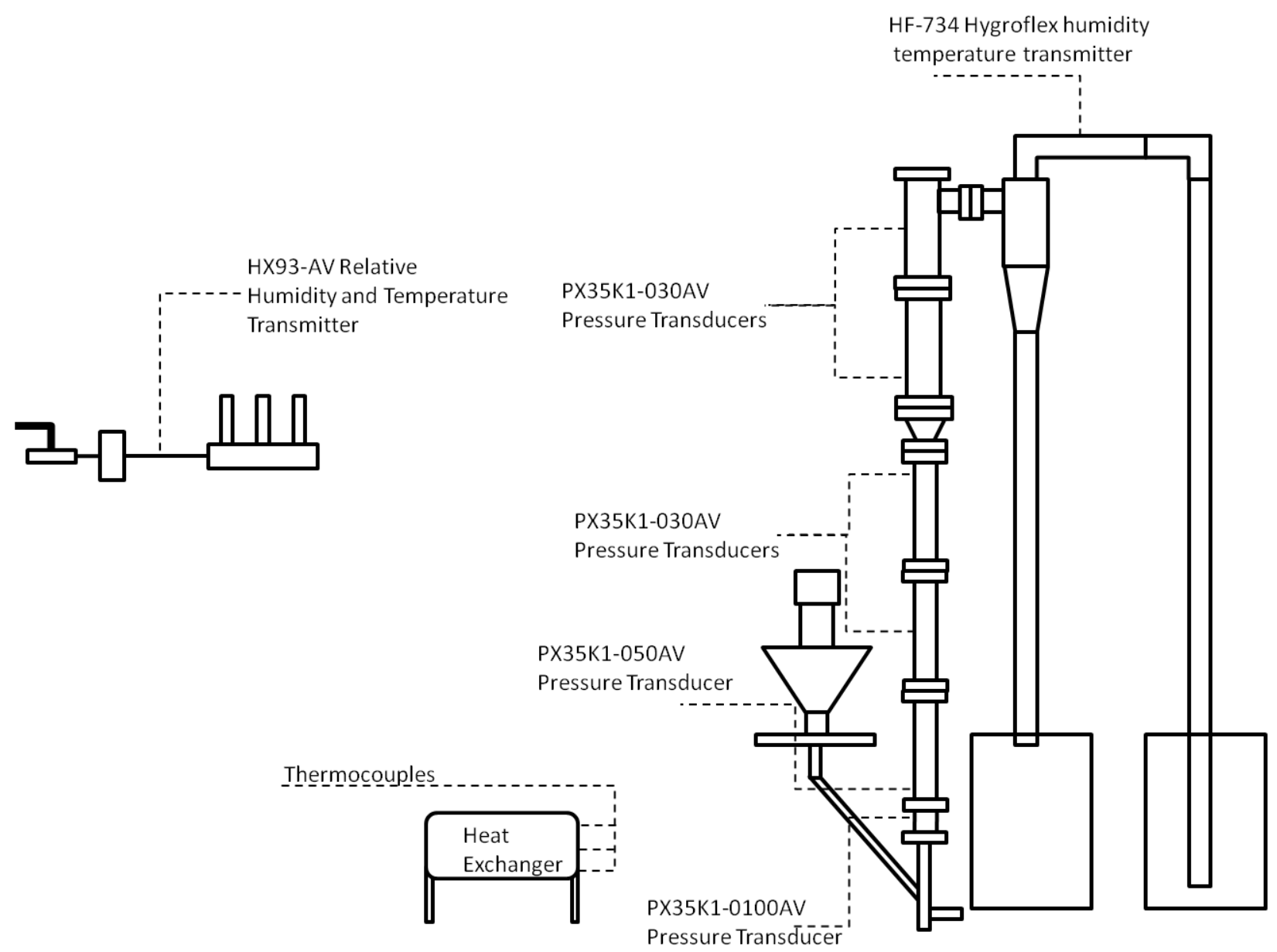

Figure 6-4: Instrumentation Diagram for WADFP Fluidized Bed 


\section{Thermocouples}

The temperature of the three air streams exiting the heat exchanger is measured by three Omega Engineering K type thermocouples that are connected to an Omega Engineering HH501DK handheld thermometer display. This unit has an accuracy of $0.3 \%+2^{\circ} \mathrm{F}$.

\section{Procedures}

The following directions describe the startup, shutdown and observation procedures adhered to while operating the small scale model fluidized bed riser.

\section{Start-up Procedure}

The start-up procedure for the WADFP fluidized bed is the same as given in Chapter 4 with the exception of setting the feed hopper back pressure is replaced by setting the feed system motor to the desired speed setting.

\section{Shutdown Procedures}

The shutdown procedure for the WADFP fluidized bed is the same as given in Chapter 4 with the addition of turning off the feed hopper motor.

\section{Calibration}

Prior to the start of testing with the scale model fluidized bed riser, the pressure transducers and were calibrated as described in Chapter 4. Factory provided calibrations were used for the thermocouples and relative humidity/temperature sensors.

\section{Test Matrix}

The following paragraphs provide a brief description of the solids materials used for testing in the WADFP fluidized bed, as well as two primary test procedures for determination of turbulent fluidization in the lower stage of the riser, and core-annular flow in the upper stage. 


\section{Turbulent Regime Investigation}

The test procedure for the lower riser stage mapping was essentially the same as that given for the continuous feed case in Chapter 4. The volumetric flow rate of air into the bottom of the lower air distributor was held at a constant $20 \mathrm{scfm}$ while the flow rate of air into the side of the lower distributor was set to one of the following scfm values for a given test: $6,10,14,18,30$, 40 and 50.

\section{Fast Fluidization Regime Investigation}

For this phase of testing, the superficial velocity in the lower stage of the riser was maintained within the upper and lower bounds for turbulent fluidization as determined in the previous section. The operating conditions were held constant within the lower (turbulent) section of the riser while the secondary air inlet volumetric flow rate was set to the following values (in scfm): $30,40,50,60,70,80,90$ and 100 .

\section{Coal Drying}

Test conditions during the drying of coal are detailed in Chapter 7. 


\section{Chapter 7 WADFP Experimental Results}

Presented in this chapter are the experimental results for the WADFP fluidized bed dryer. These results are separated into several sections: lower riser stage regime mapping with sand, upper riser stage mapping with sand, effects of secondary air injection on the lower riser stage, scaling comparison between WADFP system and the scale model fluidized bed, and thermodynamic analysis of coal drying.

\section{Lower Riser Stage Turbulent Fluidization Mapping and Characterization}

The data presented in this section was obtained from experimental runs conducted with the polydispersed sand particles ( size distribution given in Table 4-1) with a continuous solid feed rate of $120 \mathrm{lb} / \mathrm{hr}$. As with the lower riser mapping runs conducted on the scale model riser, no secondary air injection was used.

As stated in Chapter 6, there are a total of 3 pressure transducers located in the lower riser stage between the lower and upper air injection rings. Table 7.1 lists these transducers, as well as their designations and distances above the lower injection ring.

\begin{tabular}{|c|c|c|c|}
\hline Transducer & Pressure Range (psi) & Designation & $\begin{array}{c}\text { Distance above lower } \\
\text { injection ring (inches) }\end{array}$ \\
\hline PX35K1-G050AV & $0-50$ & Lbottom & 4.0 \\
\hline PX35K1-G030AV & $0-30$ & Lmid & 55 \\
\hline PX35K1-G030AV & $0-30$ & Ltop & 108 \\
\hline
\end{tabular}

Table 7-1: WADFP Lower Riser Stage Pressure Transducer Locations

Equation 1.1 describes the method of determining the superficial velocity of a fluidized bed riser that is most commonly found in fluidization literature. This method, when the volumetric flow rate of air is corrected to standard air temperature and pressure, serves well for determination of superficial velocity for fluidized bed systems that operate at those conditions. However, when a system operates at non-standard temperatures and pressures, there can be a drastic difference 
between the operating air density and standard density at which most flow meters are calibrated. To address this issue in the WADFP fluidized bed, the following modified superficial velocity equation is used.

$$
U_{g}=\frac{\dot{m}}{\rho_{\text {air }} A_{\text {riser }}}
$$

Where $\dot{m}$ is the total mass flow rate of air into the riser stage, $A_{\text {riser }}$ is the cross-sectional area of the riser and $\rho_{\text {air }}$ is the density of air leaving the riser. The density of air leaving the riser was selected based upon the assumption of a homogeneous temperature distribution within the riser.

Table 7-2 lists the lower riser stage superficial velocities for which data is presented in this section.

\begin{tabular}{|c|c|c|c|c|c|c|c|}
\hline Test \# & 1 & 2 & 3 & 4 & 5 & 6 & 7 \\
\hline $\mathrm{U}_{\mathrm{L}}(\mathrm{m} / \mathrm{s})$ & 1.43 & 1.65 & 1.93 & 2.22 & 2.79 & 3.50 & 4.10 \\
\hline
\end{tabular}

Table 7-2: WADFP Lower Riser Stage Superficial Velocity Test Points

\section{Standard Deviation}

Figure 7-1 shows the effects of superficial velocity on the standard deviation of pressure within the lower riser stage of the dryer. In the Lbottom and Lmid plots, the standard deviation reaches a peak between 1.93 and $2.22 \mathrm{~m} / \mathrm{s}$, the Ltop location reaches a maximum standard deviation near $2.22 \mathrm{~m} / \mathrm{s}$. As stated in Chapter 1, this peak corresponds to the onset of turbulent fluidization. This is normally followed by a sharp decline in standard deviation with increasing superficial velocity, with a leveling off of standard deviation as the bed transitions to fast fluidization. That trend does not appear in Figure 7-1. However, it is assumed that this lack of evidence of a fast 
fluidization regime at higher velocities is due to a lack of sufficient high velocity test points (due to instrumentation limitations). Pressure time history plots for superficial velocities 3.50 and $4.10 \mathrm{~m} / \mathrm{s}$ suggest that the lower riser stage is operating within a dilute (fast fluidization or pneumatic transport) fluidization regime at those velocities. This leads to the conclusion that the lower riser stage undergoes transition from turbulence to fast fluidization between 2.79 and 3.50 $\mathrm{m} / \mathrm{s}$.

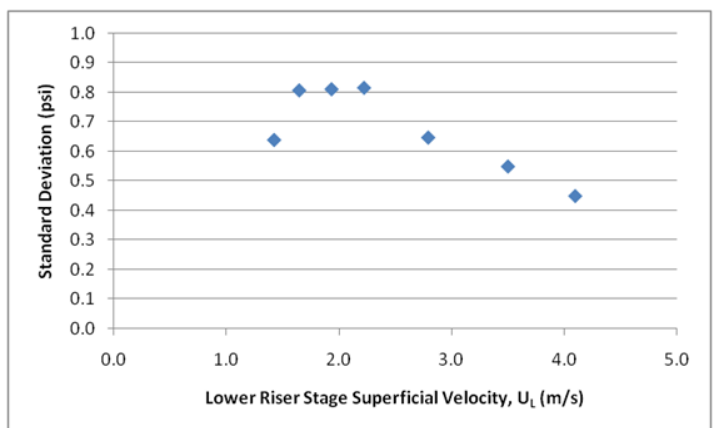

(a)

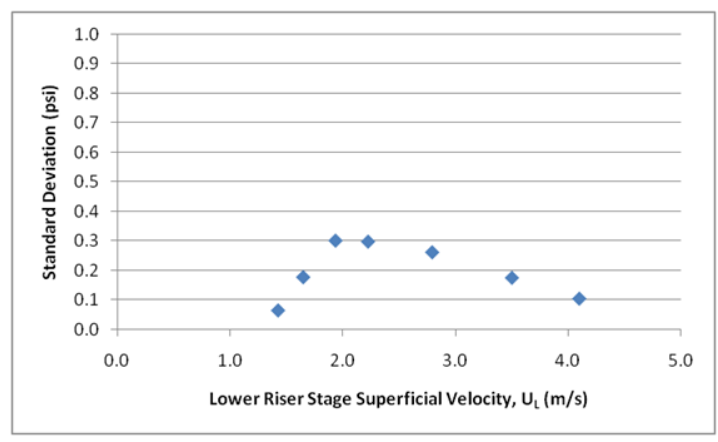

(b)

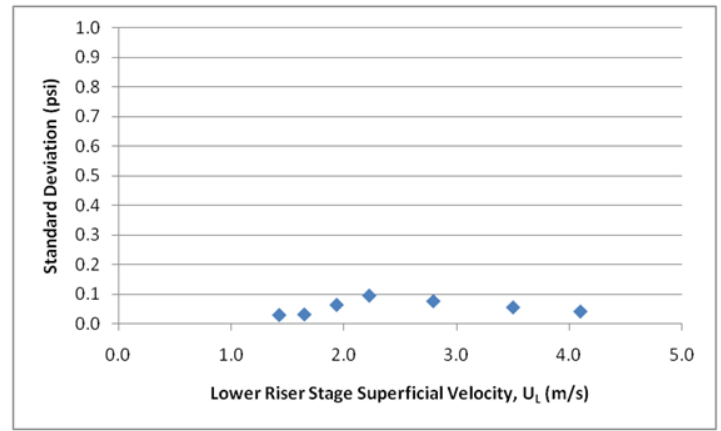

(c)

Figure 7-1: Standard deviation of WADFP lower riser stage pressures (a) Lbottom (b) Lmid (c) Ltop: poly-dispersed sand, feed rate $120 \mathrm{lb} / \mathrm{hr}$, no secondary air injection.

\section{Shannon Entropy}

Figure 7-2 depicts the effects of superficial velocity on the Shannon entropy of the lower riser stage pressure signals. As discussed in Chapter 5, the Shannon entropy plots seem to follow the same general trends seen in the standard deviation plots in Figure 7-1. 


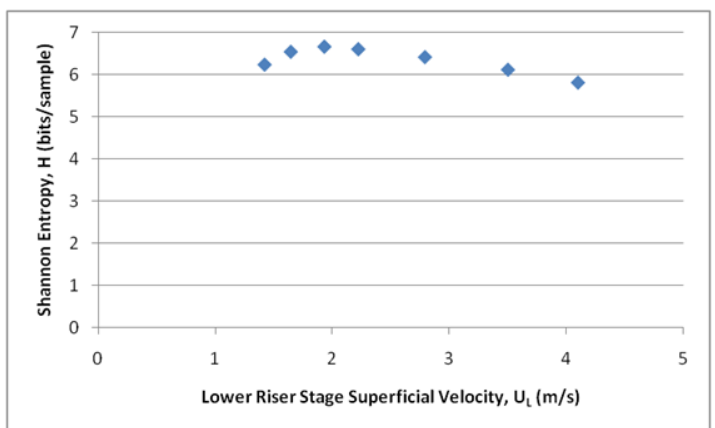

(a)

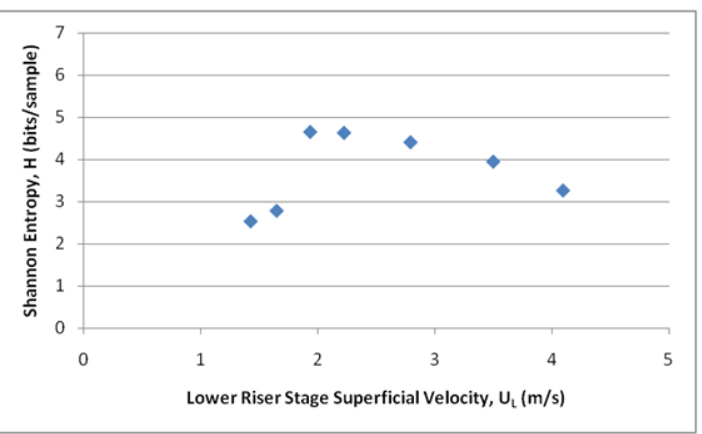

(b)

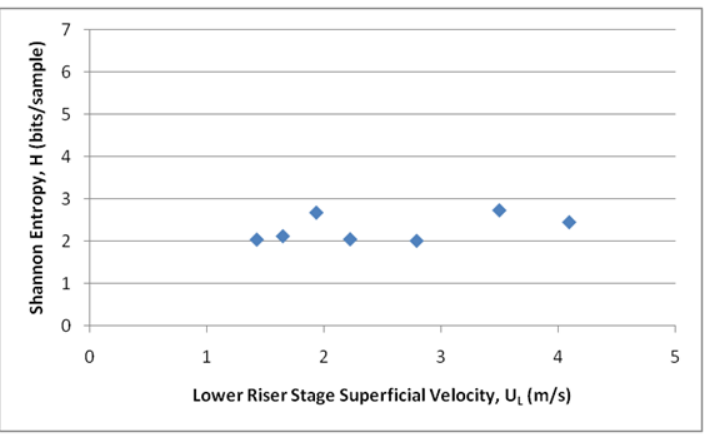

(c)

Figure 7-2: Shannon entropy of WADFP lower riser stage pressures (a) Lbottom (b) Lmid (c) Ltop: poly-dispersed sand, feed rate $120 \mathrm{lb} / \mathrm{hr}$, no secondary air injection.

\section{Autocorrelation, Mutual Information Function and Power Spectral Density Plots}

\section{Autocorrelation}

Figures 7-3 through 7-5 show the autocorrelation of the three lower riser stage pressure transducers for each superficial velocity tested. In most cases, there appears to be very little evidence of any periodic correlation of the pressure signals as a function of time.

\section{Mutual Information}

Figures 7-6 through 7-9 show the mutual information function of the lower riser stage pressure signals for each superficial velocity tested. As can be seen from the figures, the mutual information exhibits an increase between 1.43 and $1.65 \mathrm{~m} / \mathrm{s}$. At $1.93 \mathrm{~m} / \mathrm{s}$ there is a significant decrease in mutual information, followed by an increase to a maximum value at $2.22 \mathrm{~m} / \mathrm{s}$ and a further decrease with increasing superficial velocity. The decrease at $1.93 \mathrm{~m} / \mathrm{s}$ suggests that the 
level of dependency between the actual pressure time series and the time-delayed series is much less than at the superficial velocities to either side. It is suspected that this is an indicator of the onset of the transition from bubble coalescence within the riser to bubble breakup that occurs when a fluidized bed undergoes transition to turbulent fluidization.

\section{Spectral Density}

Figures 7-9 through 7-11 show the power spectral density plots for the three lower riser stage pressure transducer locations for the tested superficial velocities. In general, the trends seen in the spectral density of the WADFP is similar to those seen the scale model. There is an increase in spectral density magnitude and evidence of a dominant frequency as superficial velocity increases towards the transition to turbulent fluidization between 1.93 and $2.22 \mathrm{~m} / \mathrm{s}$. Beyond this point, this trend is reversed and the magnitude of power associated with each frequency decreases with increasing superficial velocity and the existence of dominant frequencies becomes less defined.

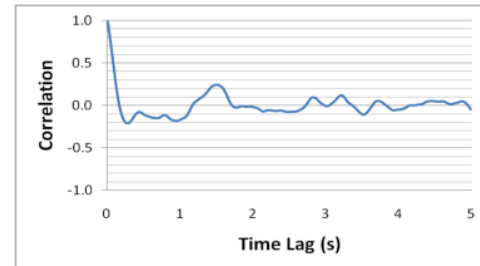

(a)

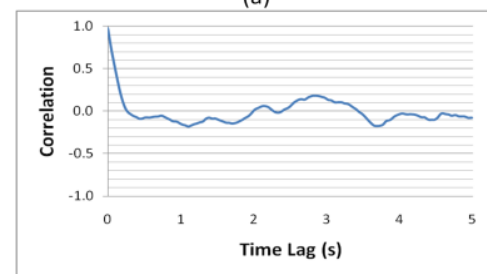

(d)

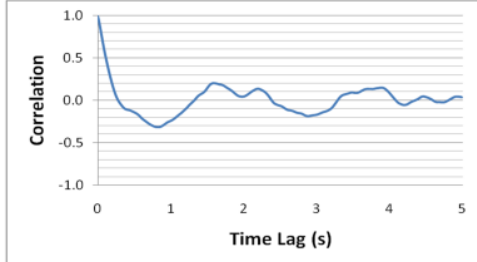

(b)

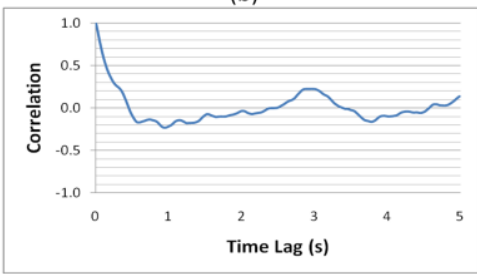

(e)

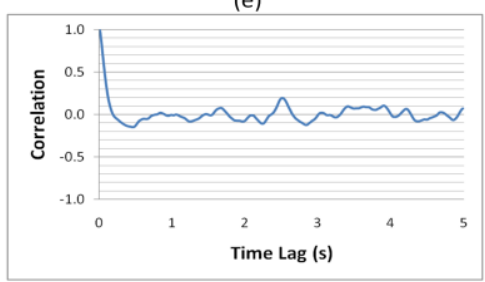

(g)

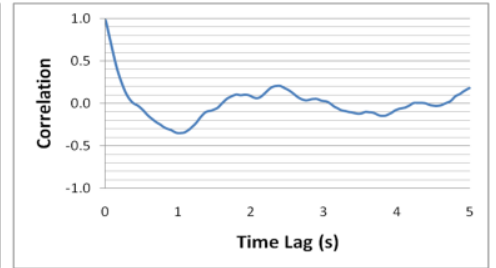

(c)

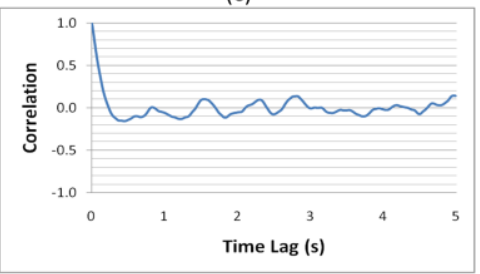

(f)

Figure 7-3: Autocorrelation of WADFP Lbottom pressure, poly-dispersed sand, feed rate $120 \mathrm{lb} / \mathrm{hr}$, no secondary air injection, $U_{L}=$ : (a) 1.43 (b) 1.65 (c) 1.93 (d) 2.22 (e) 2.79 (f) 3.50 (g) 4.10 m/s. 


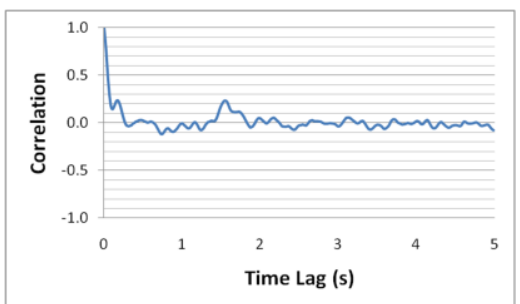

(a)

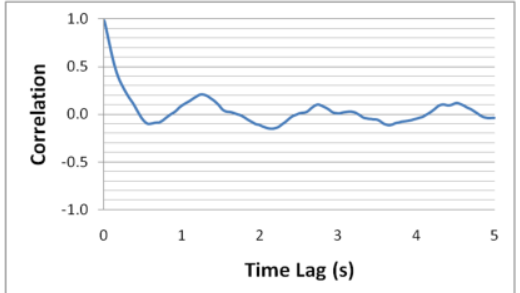

(d)

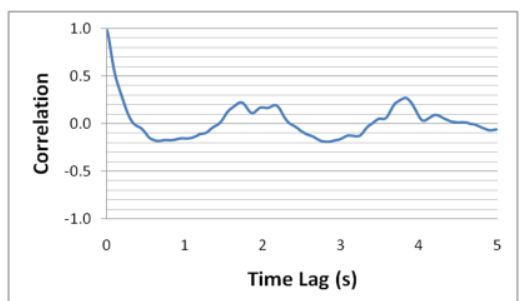

(b)

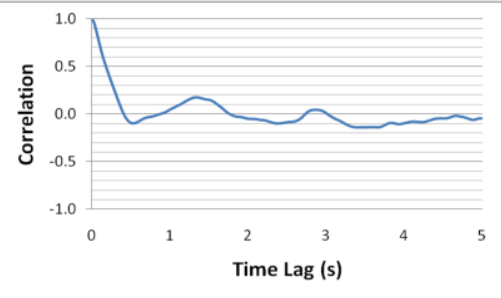

(e)

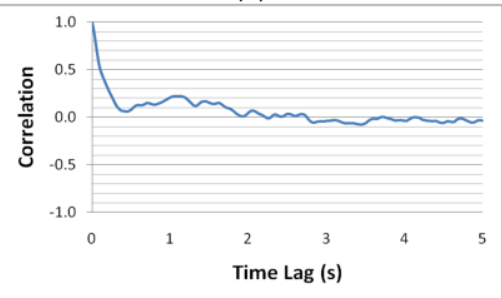

(g)

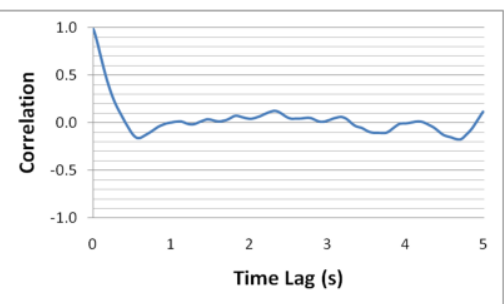

(c)

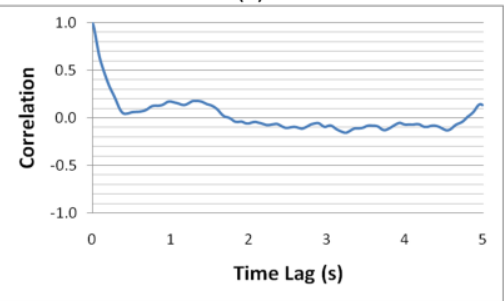

(f)

Figure 7-4: Autocorrelation of WADFP Lmid pressure, poly-dispersed sand, feed rate $120 \mathrm{lb} / \mathrm{hr}$, no secondary air injection, $U_{L}=$ : (a) 1.43 (b) 1.65 (c) 1.93 (d) 2.22 (e) 2.79 (f) 3.50 (g) $4.10 \mathrm{~m} / \mathrm{s}$.

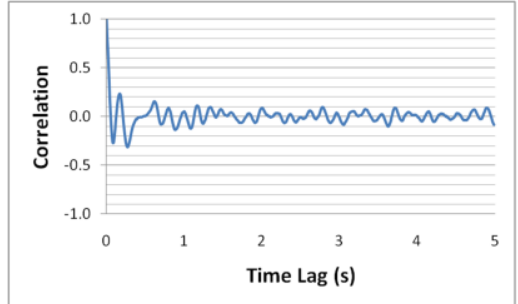

(a)

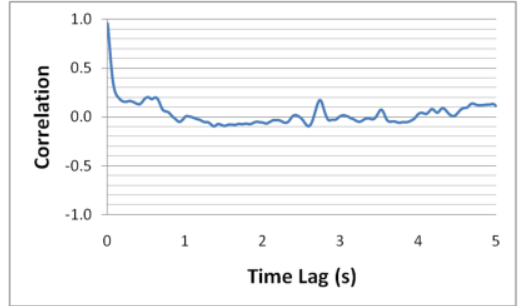

(d)

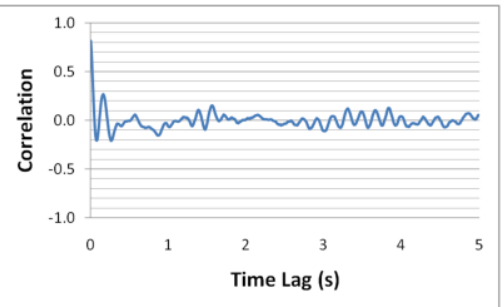

(b)

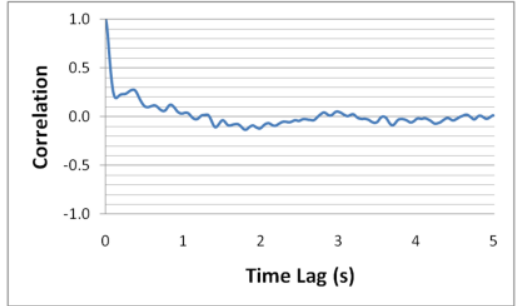

(e)

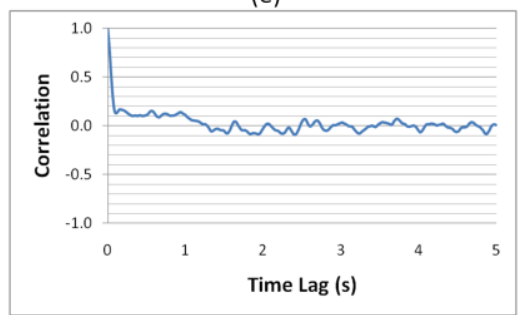

(g)

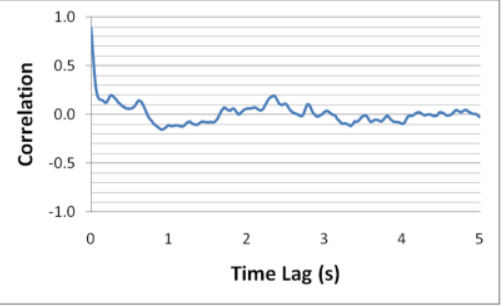

(c)

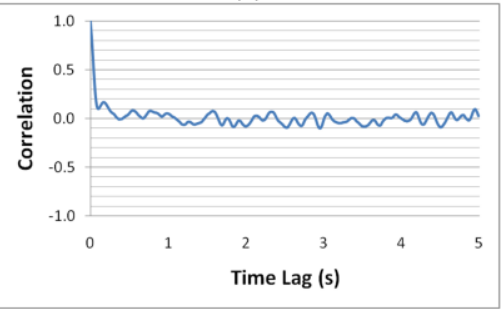

(f)

Figure 7-5: Autocorrelation of WADFP Ltop pressure, poly-dispersed sand, feed rate $120 \mathrm{lb} / \mathrm{hr}$, no secondary air injection, $U_{L}=$ : (a) 1.43 (b) 1.65 (c) 1.93 (d) 2.22 (e) 2.79 (f) 3.50 (g) 4.10 m/s. 


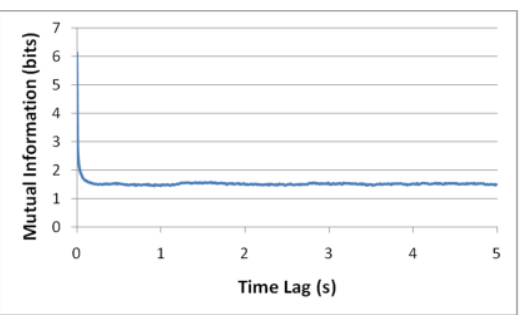

(a)

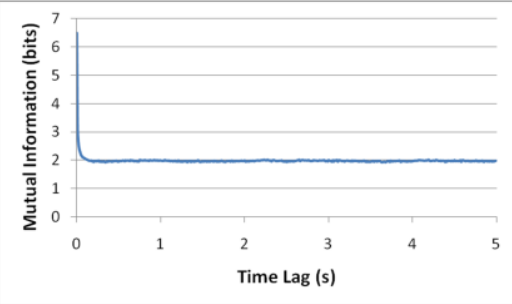

(d)

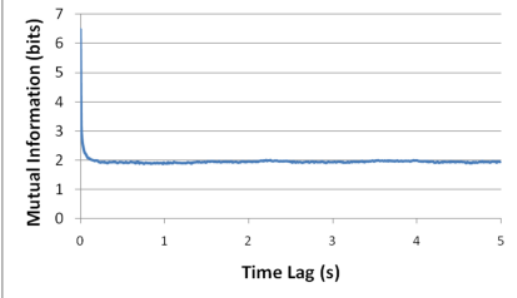

(b)

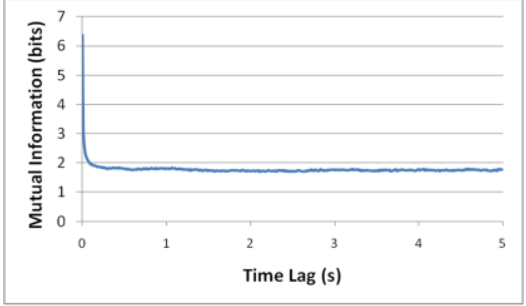

(e)

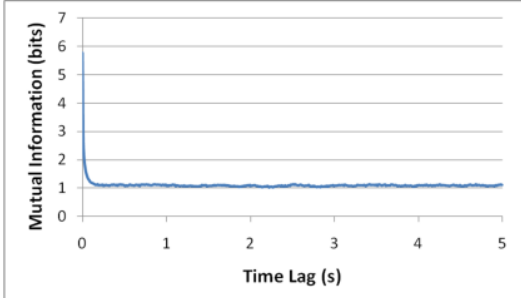

(g)

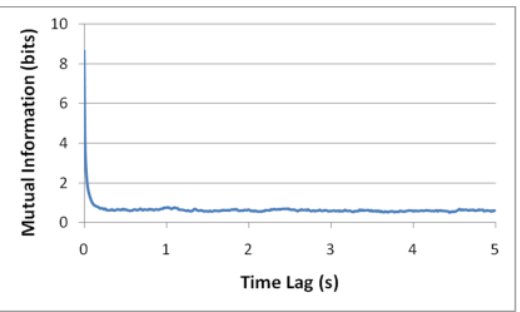

(c)

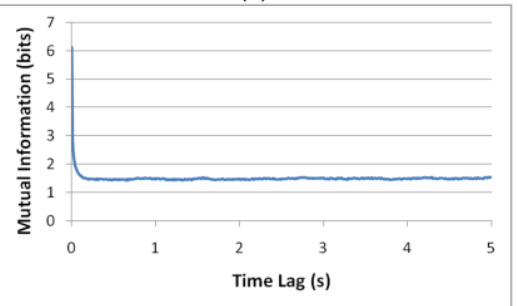

(f) injection, $U_{L}=:$ (a) 1.43 (b) 1.65 (c) 1.93 (d) 2.22 (e) 2.79 (f) 3.50 (g) $4.10 \mathrm{~m} / \mathrm{s}$.

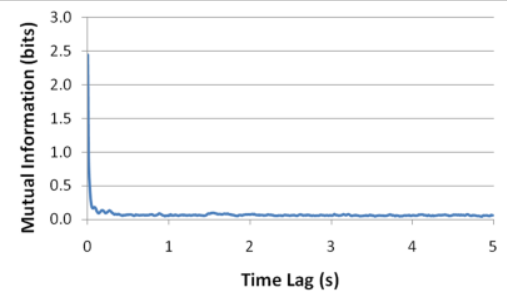

(a)

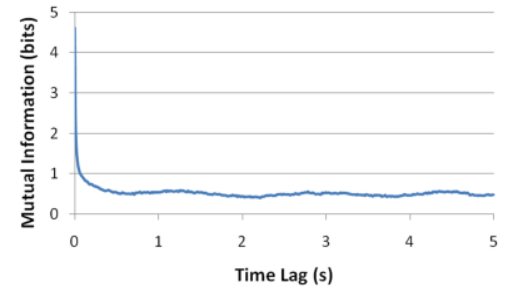

(d)

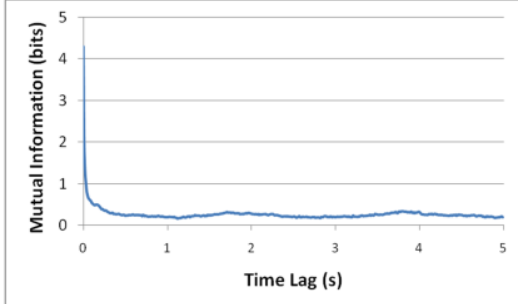

(b)

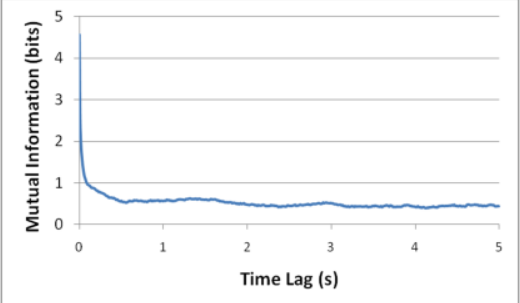

(e)

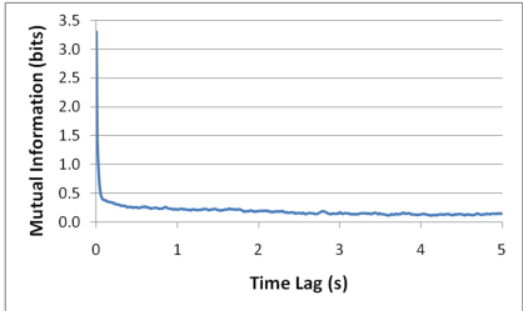

(g)

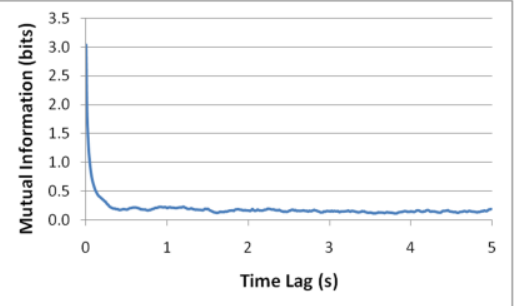

(c)

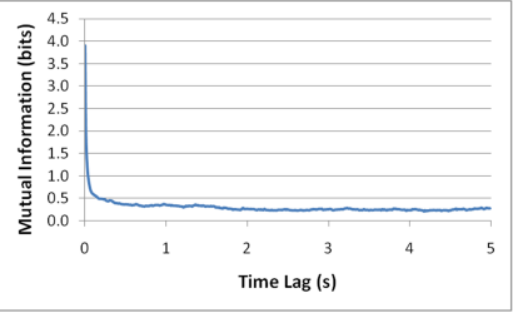

(f)

Figure 7-7: Mutual Information of WADFP Lmid Pressure, poly-dispersed sand, feed rate $120 \mathrm{lb} / \mathrm{hr}$, no secondary air injection, $\mathrm{U}_{\mathrm{L}}=$ : (a) 1.43 (b) 1.65 (c) 1.93 (d) 2.22 (e) 2.79 (f) 3.50 (g) $4.10 \mathrm{~m} / \mathrm{s}$. 


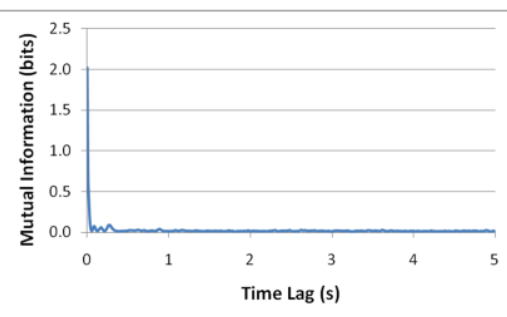

(a)

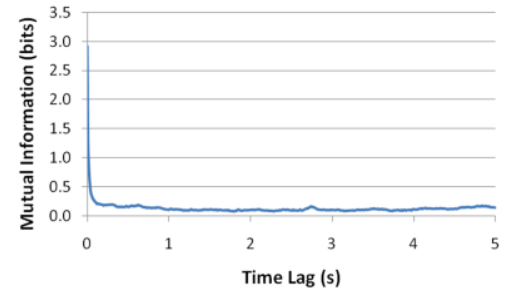

(d)

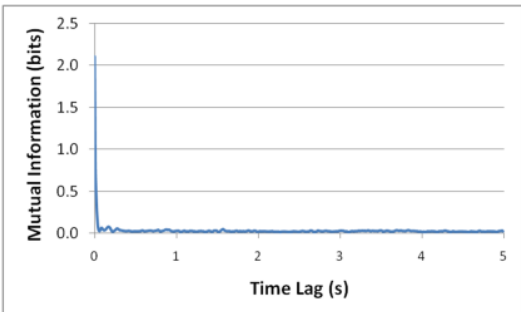

(b)

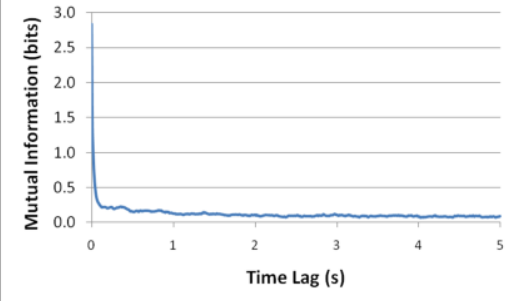

(e)

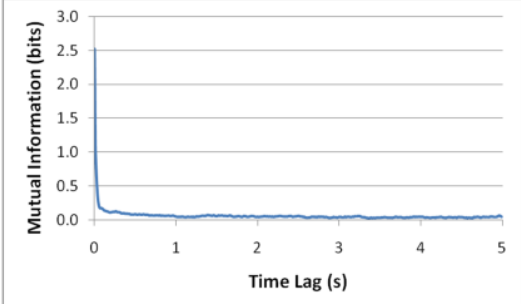

(g)

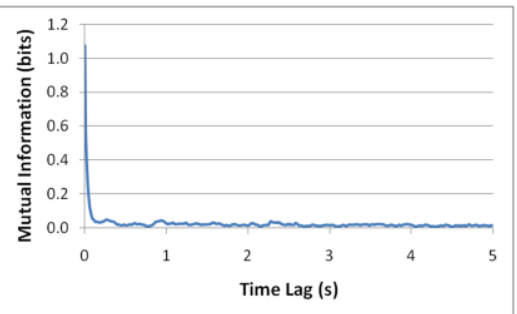

(c)

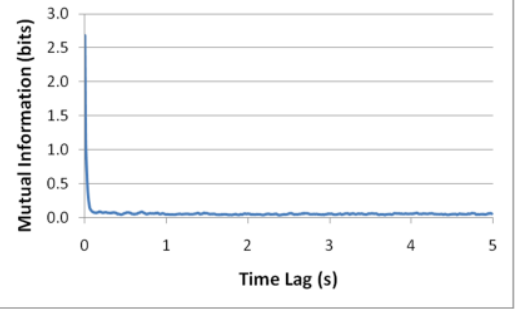

(f)

Figure 7-8: Mutual Information of WADFP Ltop Pressure, poly-dispersed sand, feed rate $120 \mathrm{lb} / \mathrm{hr}$, no secondary air injection, $U_{L}=$ : (a) 1.43 (b) 1.65 (c) 1.93 (d) 2.22 (e) 2.79 (f) 3.50 (g) 4.10 m/s.

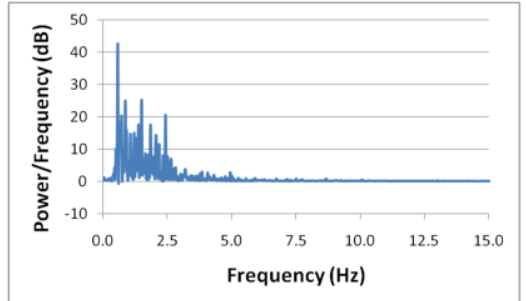

(a)

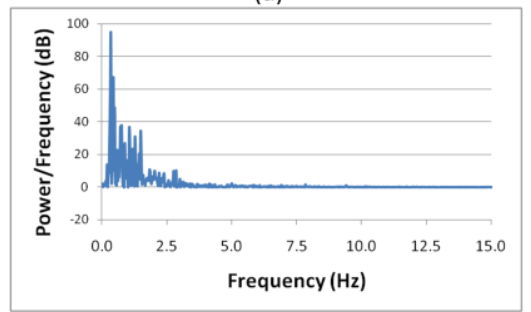

(d)

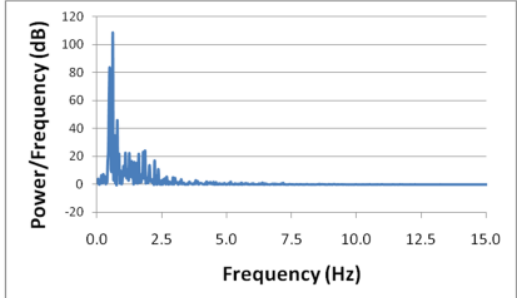

(b)

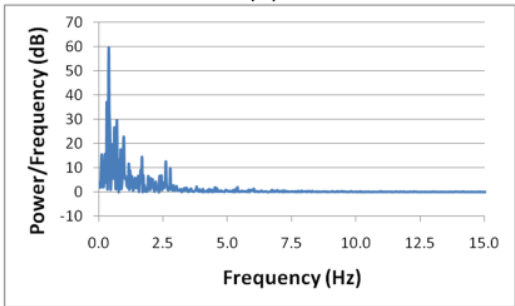

(e)

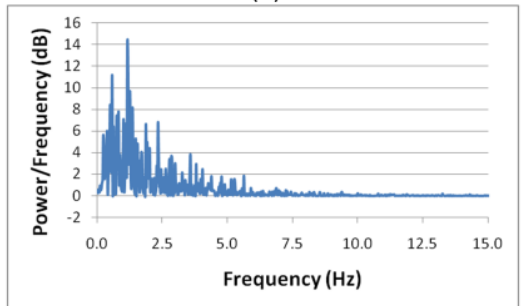

(g)

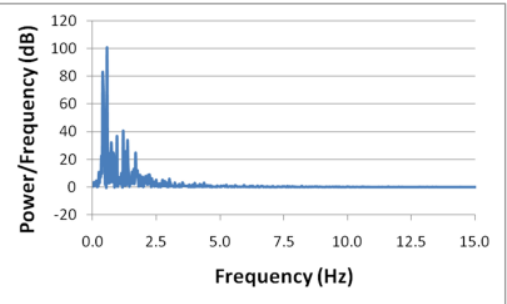

(c)

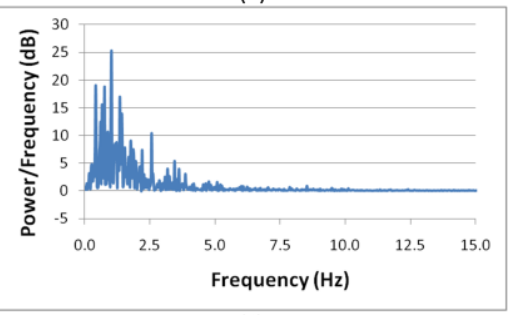

(f)

Figure 7-9: Spectral Density Plots of WADFP Lbottom Pressure, poly-dispersed sand, feed rate $120 \mathrm{lb} / \mathrm{hr}$, no secondary air injection, $\mathrm{U}_{\mathrm{L}}=$ : (a) 1.43 (b) 1.65 (c) 1.93 (d) 2.22 (e) 2.79 (f) 3.50 (g) $4.10 \mathrm{~m} / \mathrm{s}$. 


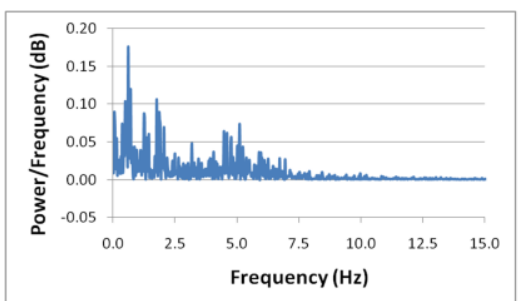

(a)

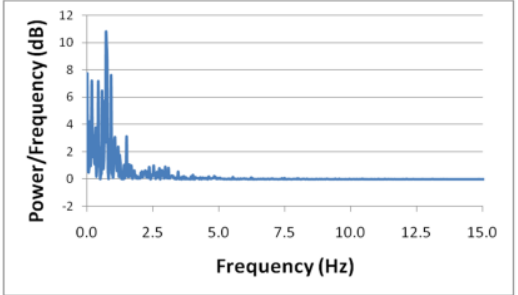

(d)

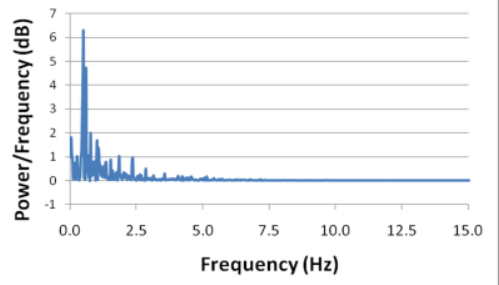

(b)

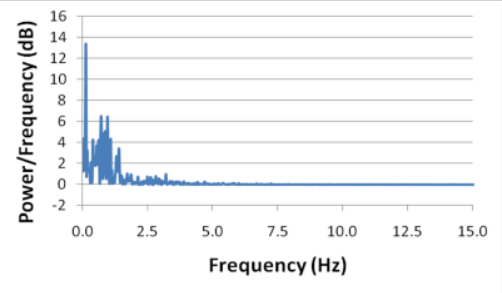

(e)

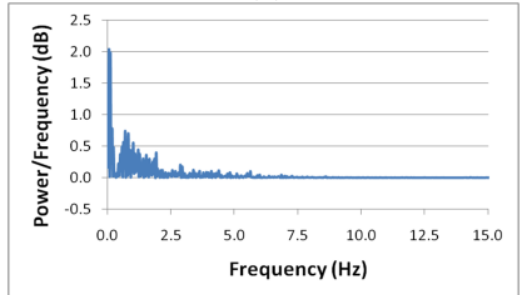

(g)

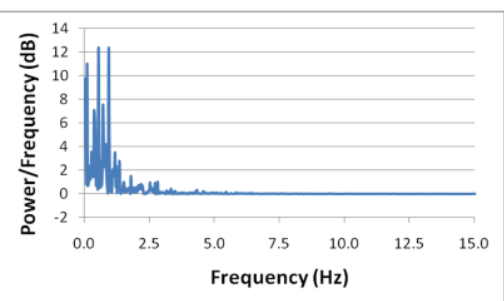

(c)

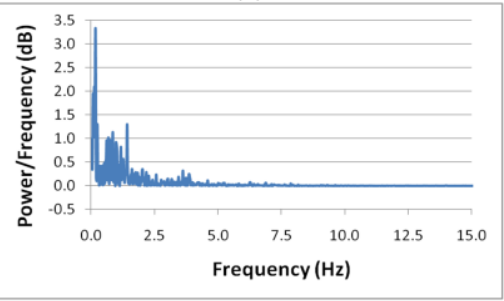

(f)

Figure 7-10: Spectral Density Plots of WADFP Lmid Pressure, poly-dispersed sand, feed rate $120 \mathrm{lb} / \mathrm{hr}$, no secondary air injection, $U_{L}=$ : (a) 1.43 (b) 1.65 (c) 1.93 (d) 2.22 (e) 2.79 (f) 3.50 (g) $4.10 \mathrm{~m} / \mathrm{s}$.

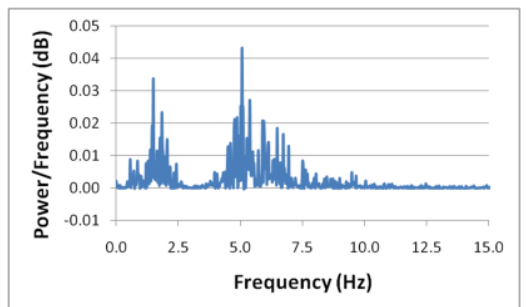

(a)

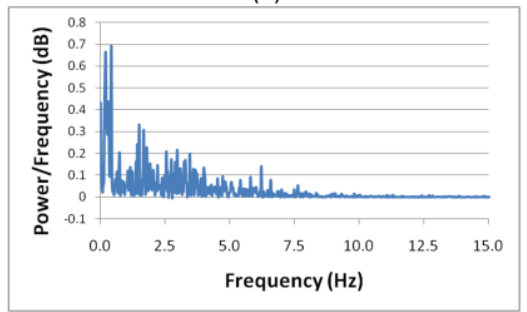

(d)

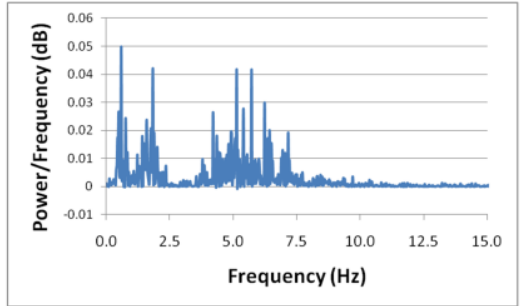

(b)

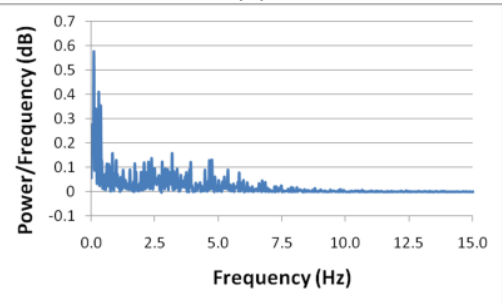

(e)

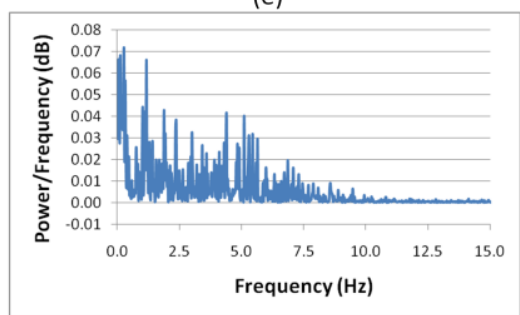

(g)

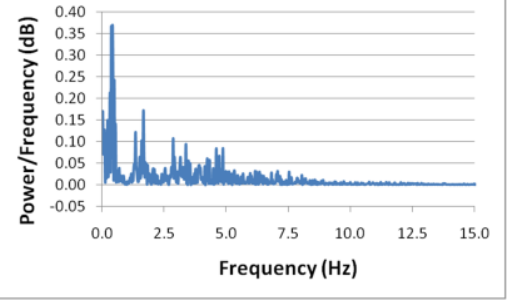

(c)

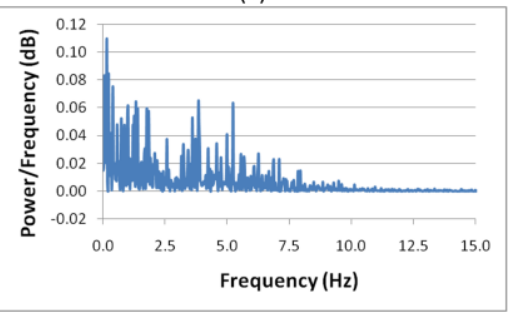

(f)

Figure 7-11: Spectral Density Plots of WADFP Ltop Pressure, poly-dispersed sand, feed rate $120 \mathrm{lb} / \mathrm{hr}$, no secondary air injection, $U_{L}=$ : (a) 1.43 (b) 1.65 (c) 1.93 (d) 2.22 (e) 2.79 (f) 3.50 (g) $4.10 \mathrm{~m} / \mathrm{s}$. 


\section{Upper Riser Stage Fast Fluidization Mapping and Characterization}

The data presented in this section was obtained from experimental runs with the poly-dispersed sand particles with a continuous solid feed rate of $120 \mathrm{lb} / \mathrm{hr}$. The lower riser stage superficial velocity, $\mathrm{U}_{\mathrm{L}}$ was held constant at $2.90 \mathrm{~m} / \mathrm{s}$ and the upper riser stage superficial velocity, $\mathrm{U}_{\mathrm{U}}$, was varied by increasing amounts of secondary air injection at the injection ring located between the upper and lower riser stages.

Table 7-3 details the pressure transducers located within the upper riser stage and Table 7-4 lists the upper and lower riser stage superficial velocities tested.

\begin{tabular}{|c|c|c|c|c|}
\hline Transducer & $\begin{array}{c}\text { Pressure Range } \\
(\mathrm{psi})\end{array}$ & Designation & $\begin{array}{c}\text { Distance above } \\
\text { secondary air } \\
\text { injection ring } \\
\text { (inches) }\end{array}$ & $\begin{array}{c}\text { Distance above } \\
\text { lower injection } \\
\text { ring (inches) }\end{array}$ \\
\hline PX35K1-G030AV & $0-30$ & UBOTTOM & 4.0 & 124.0 \\
\hline PX35K1-G030AV & $0-30$ & UTOP & 65.0 & 185.0 \\
\hline
\end{tabular}

Table 7-3: WADFP Upper Riser Stage Pressure Transducer Location

\begin{tabular}{|c|c|c|c|c|c|c|c|c|}
\hline Test \# & 1 & 2 & 3 & 4 & 5 & 6 & 7 & 8 \\
\hline $\mathrm{U}_{\mathrm{L}}(\mathrm{m} / \mathrm{s})$ & 2.90 & 2.90 & 2.90 & 2.90 & 2.90 & 2.90 & 2.90 & 2.90 \\
\hline $\mathrm{U}_{\mathrm{U}}(\mathrm{m} / \mathrm{s})$ & 1.81 & 2.04 & 2.27 & 2.49 & 2.72 & 2.95 & 3.17 & 3.40 \\
\hline
\end{tabular}

Table 7-4: WADFP Upper Riser Stage Superficial Velocity Test Points

\section{Standard Deviation and Shannon Entropy}

Figures 7-12 and 7-13 show the effects of superficial velocity on the upper riser stage pressure standard deviation and Shannon entropy, respectively. As can be seen, there is very little change in the standard deviation. This suggests a lack of sufficient particles within the upper riser stage to form a dense bed region and thus an absence of bubble formation. Once again, the Shannon entropy plots, seen in Figure 7-13, follow trends evident in the corresponding pressure standard deviation plots. 


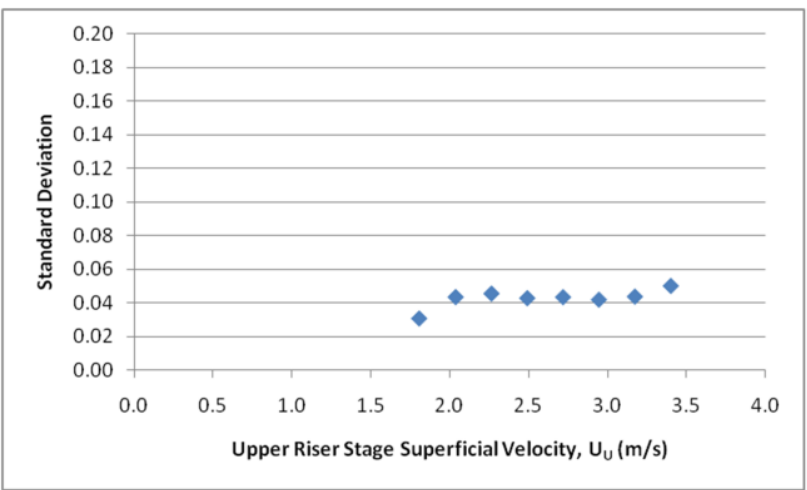

(a)

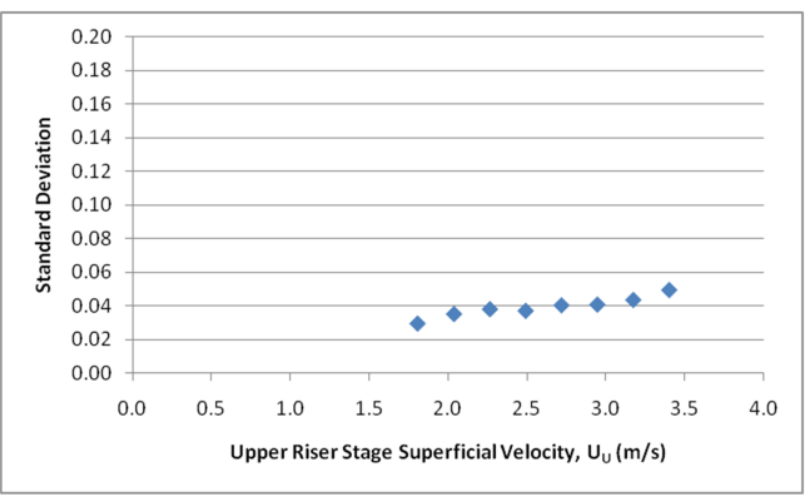

(b)

Figure 7-12: Standard deviation of WADFP upper riser stage pressures (a) Ubottom (b) Utop: poly-dispersed sand, feed rate $120 \mathrm{lb} / \mathrm{hr}, \mathrm{U}_{\mathrm{L}}=2.90 \mathrm{~m} / \mathrm{s}$.

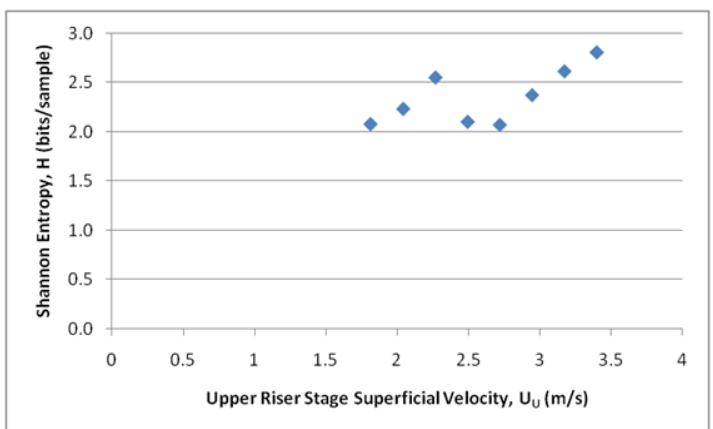

(a)

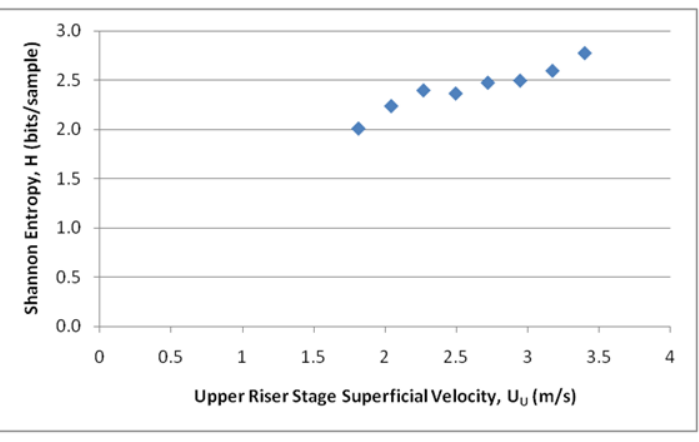

(b)

Figure 7-13: Shannon entropy of WADFP upper riser stage pressures (a) Ubottom (b) Utop: poly-dispersed sand, feed rate $120 \mathrm{lb} / \mathrm{hr}, \mathrm{U}_{\mathrm{L}}=2.90 \mathrm{~m} / \mathrm{s}$.

\section{Autocorrelation, Mutual Information and Spectral Density}

Figures 7-14 and 7-15 show the autocorrelations of the Ubottom and Utop location pressures.

Interestingly, the strongest evidence of good correlation with respect to time occurs at the two highest superficial velocities. However, the mutual information (Figures 7-16 and 7-17) lacks a corresponding increase in value as exhibited in other tests. The spectral density plots (F7igures 7-18 and 7-19) exhibits trends similar to those seen in other test conditions with fast fluidization present. Additionally, both transducer locations show what appears to be a dominant frequency near $2 \mathrm{~Hz}$. 


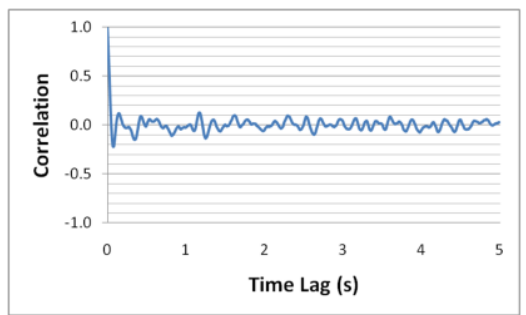

(a)

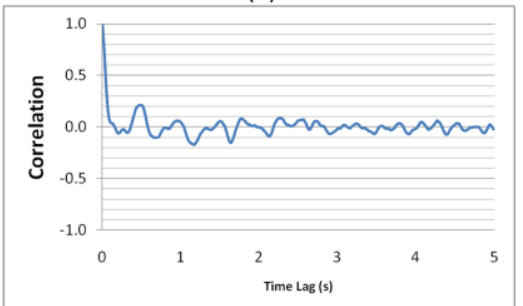

(d)

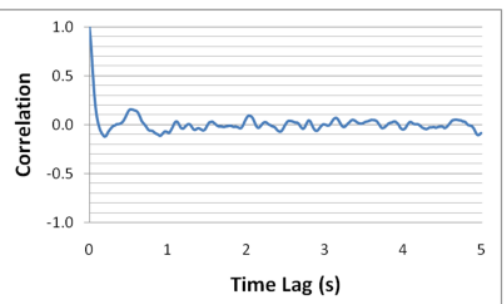

(b)

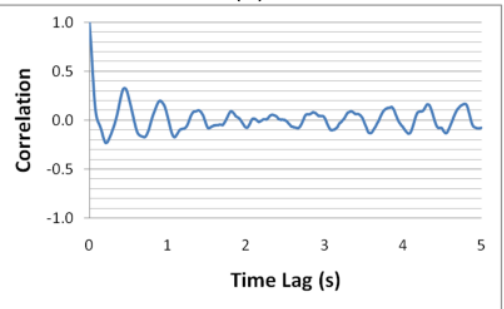

(e)

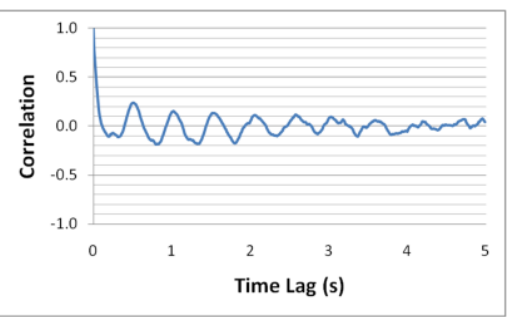

(c)

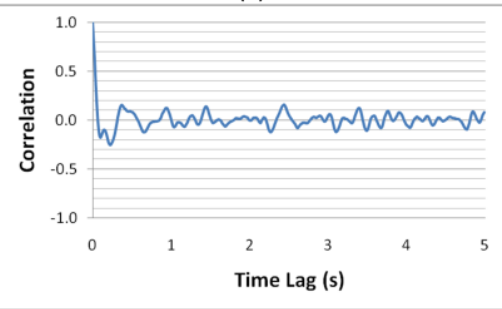

(f)

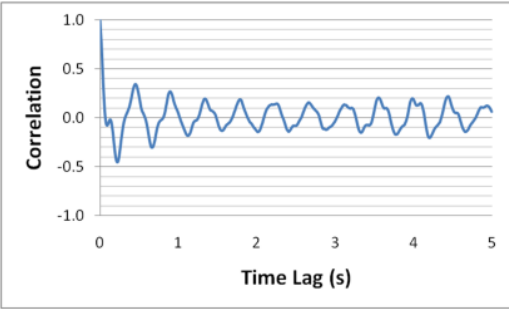

(g)

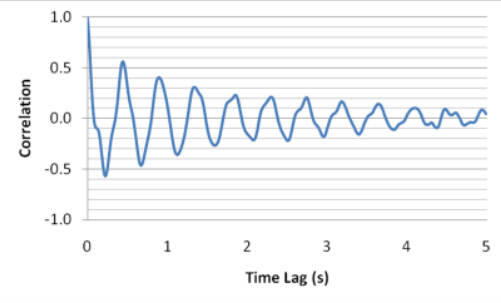

(h)

Figure 7-14: Autocorrelation of WADFP Ubottom pressure, poly-dispersed sand, feed rate $120 \mathrm{lb} / \mathrm{hr}, \mathrm{U}_{\mathrm{L}}=2.90 \mathrm{~m} / \mathrm{s}, \mathrm{U}_{\mathrm{U}}=$ :

(a) 1.81 (b) 2.04 (c) 2.27 (d) 2.49 (e) 2.72 (f) 2.95 (g) 3.17 (h) $3.40 \mathrm{~m} / \mathrm{s}$.

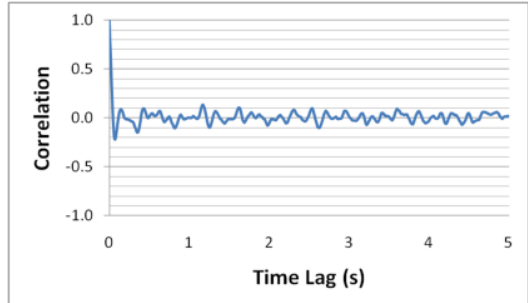

(a)

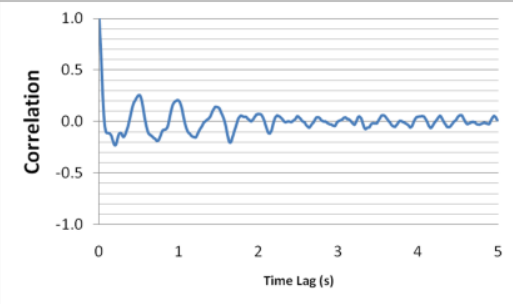

(d)

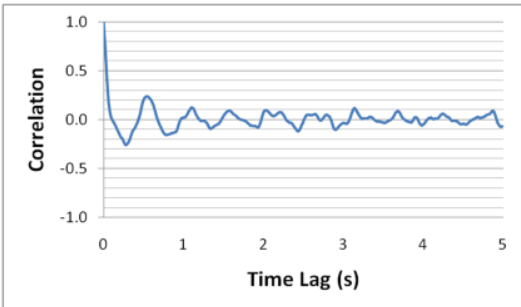

(b)

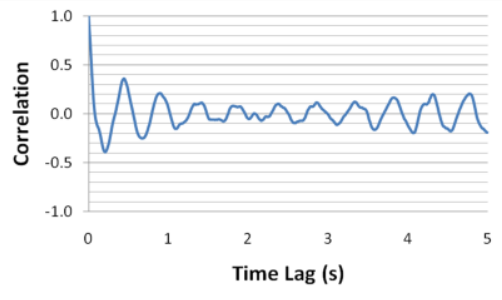

(e)

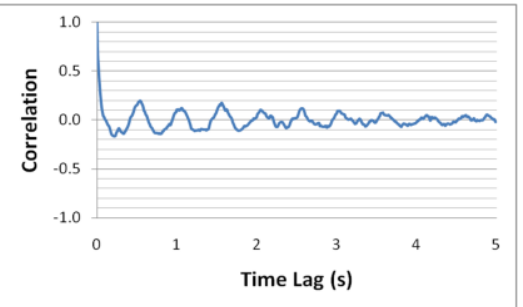

(c)

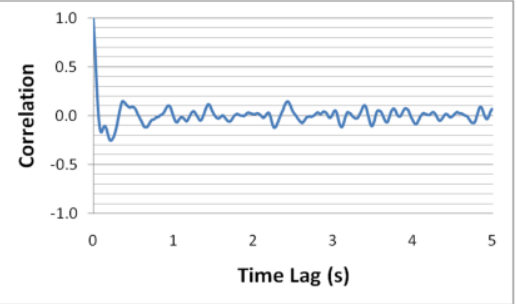

(f)

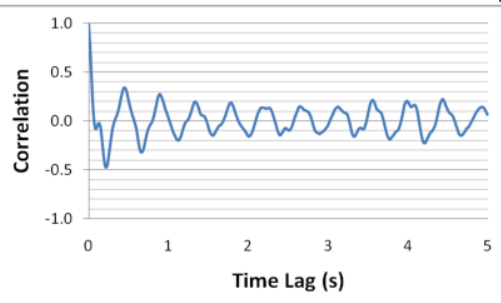

(g)

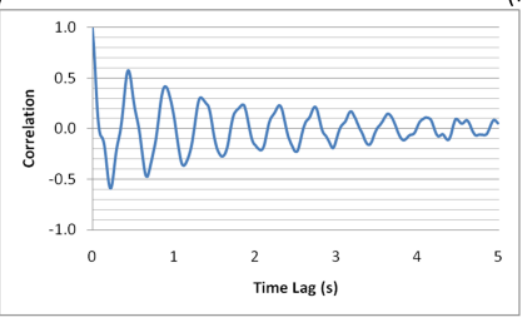

(h)

Figure 7-15: Autocorrelation of WADFP Ubottom pressure, poly-dispersed sand, feed rate $120 \mathrm{lb} / \mathrm{hr}, \mathrm{U}_{\mathrm{L}}=2.90 \mathrm{~m} / \mathrm{s}, \mathrm{U}_{\mathrm{U}}=\mathbf{\text { : }}$ (a) 1.81 (b) 2.04 (c) 2.27 (d) 2.49 (e) 2.72 (f) 2.95 (g) 3.17 (h) $3.40 \mathrm{~m} / \mathrm{s}$. 


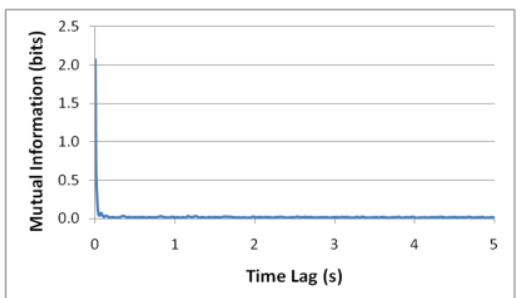

(a)

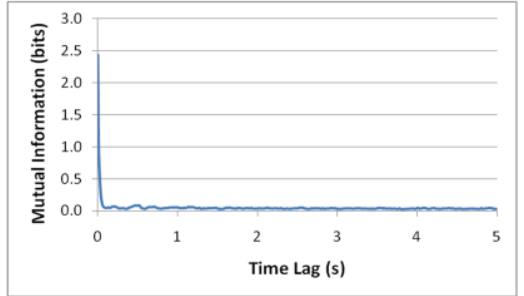

(d)

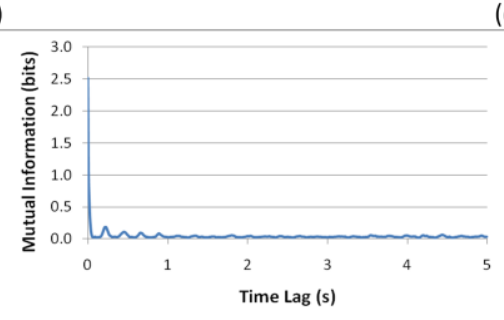

(g)

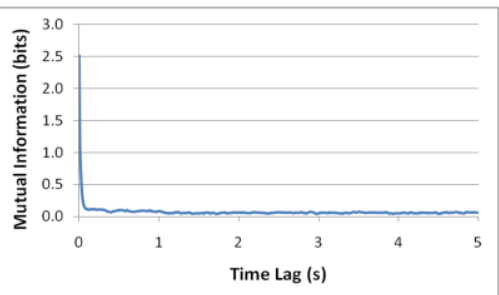

(b)

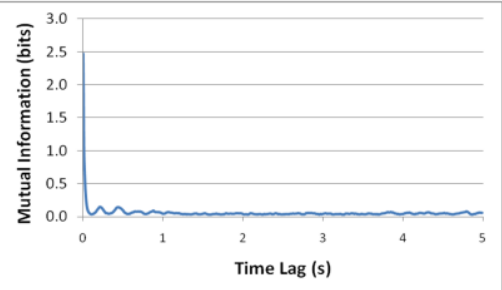

(e)

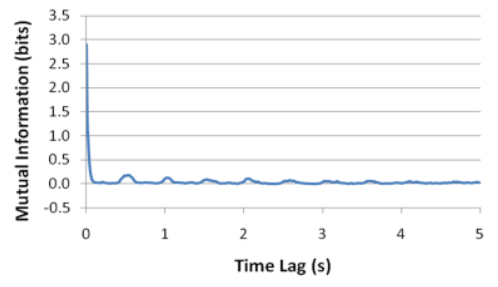

(c)

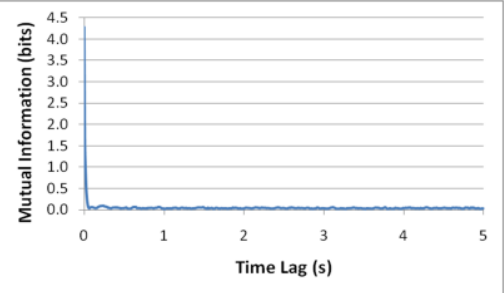

(f)

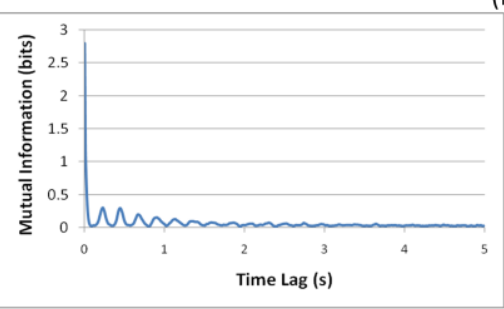

(h)

Figure 7-16: Mutual Information of WADFP Ubottom pressure, poly-dispersed sand, feed rate $120 \mathrm{lb} / \mathrm{hr}, \mathrm{U}_{\mathrm{L}}=\mathbf{2 . 9 0} \mathrm{m} / \mathrm{s}$, $\mathrm{U}_{\mathrm{U}}=$ : (a) 1.81 (b) 2.04 (c) 2.27 (d) 2.49 (e) 2.72 (f) 2.95 (g) 3.17 (h) $3.40 \mathrm{~m} / \mathrm{s}$.

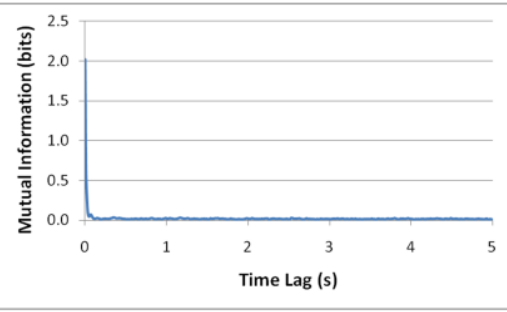

(a)

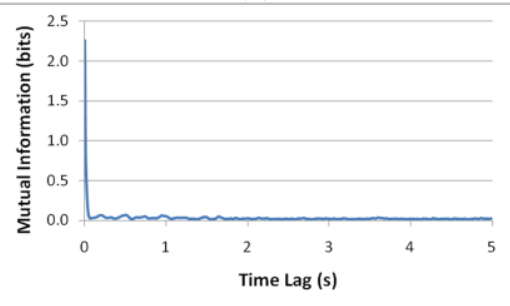

(d)

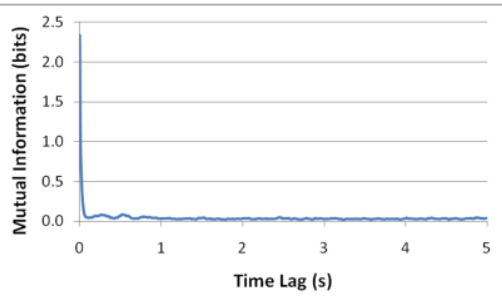

(b)

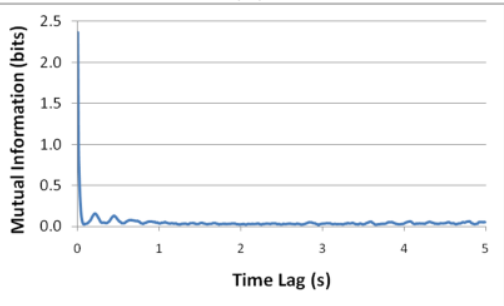

(e)

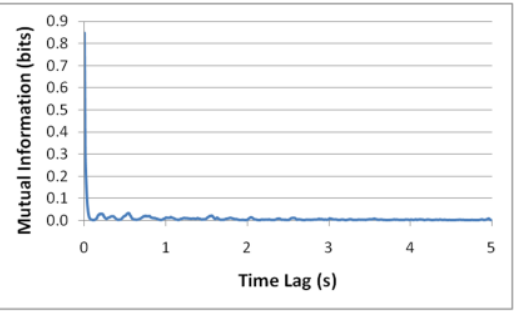

(c)

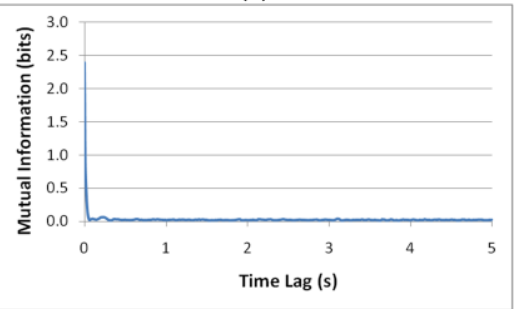

(f)

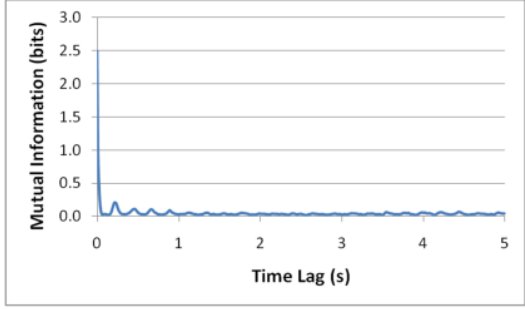

(g)

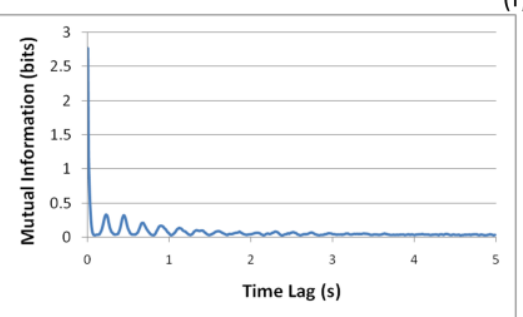

(h)

Figure 7-17: Mutual Information of WADFP Utop pressure, poly-dispersed sand, feed rate $120 \mathrm{lb} / \mathrm{hr}, \mathrm{U}_{\mathrm{L}}=2.90 \mathrm{~m} / \mathrm{s}, \mathrm{U}_{\mathrm{U}}=$ : (a) 1.81 (b) 2.04 (c) 2.27 (d) 2.49 (e) 2.72 (f) 2.95 (g) 3.17 (h) $3.40 \mathrm{~m} / \mathrm{s}$. 


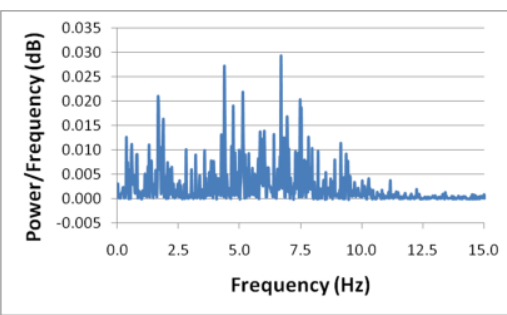

(a)

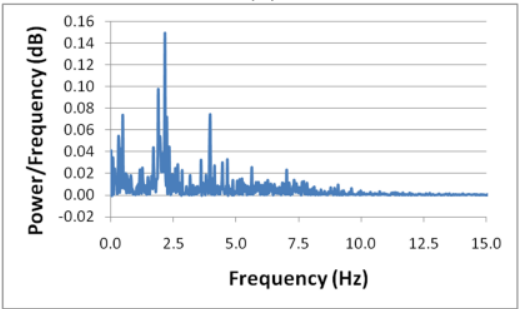

(d)

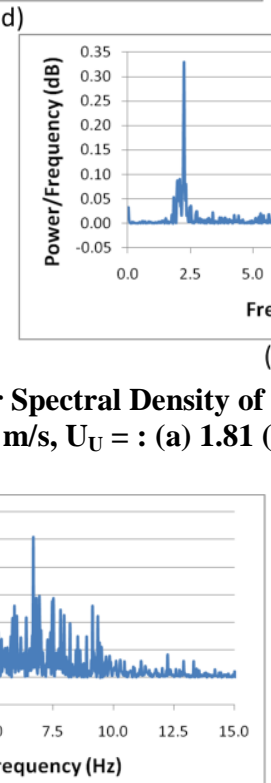

(a)

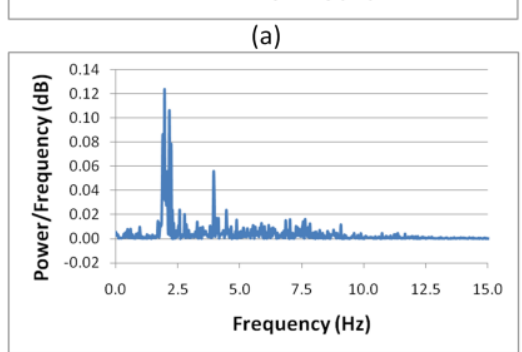

(d)

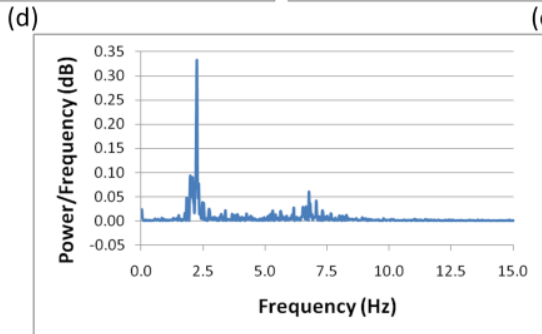

(g)

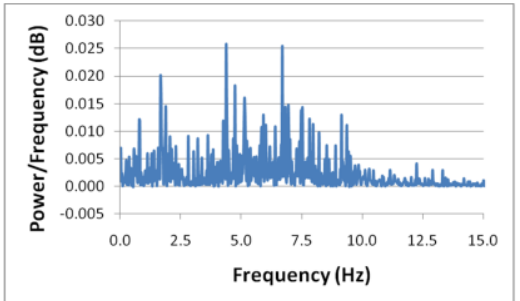

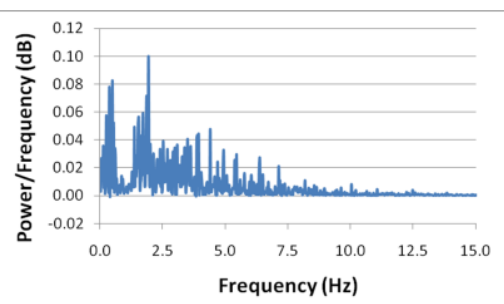

(b)

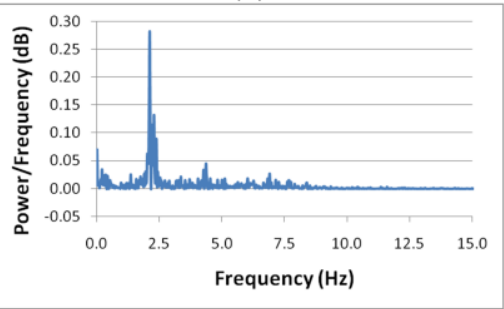

(e)

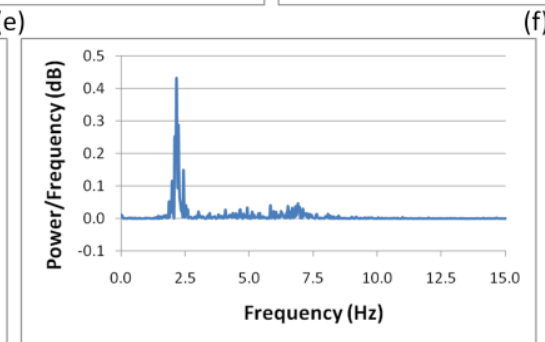

(h)

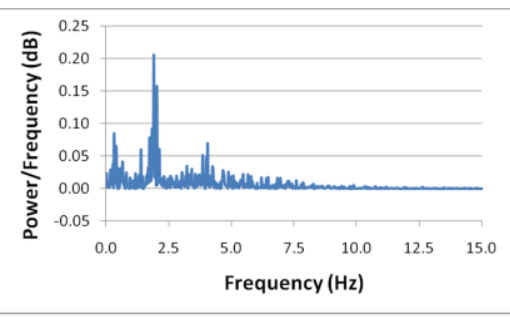

(c)

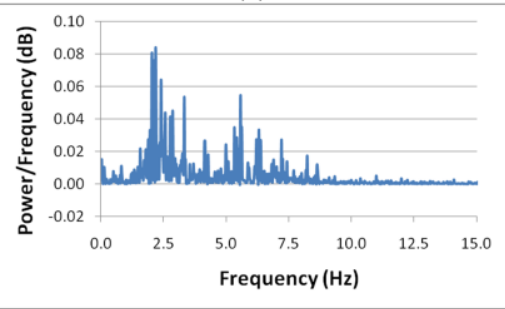

(f)

Figure 7-18: Power Spectral Density of WADFP Ubottom pressure, poly-dispersed sand, feed rate $120 \mathrm{lb} / \mathrm{hr}, \mathrm{U}_{\mathrm{L}}=2.90$

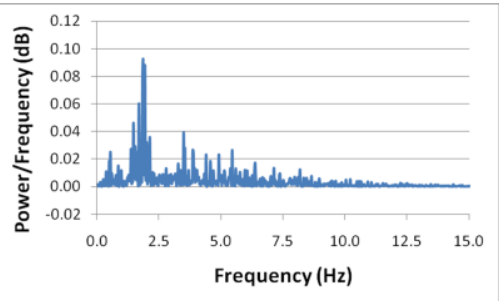

(b)

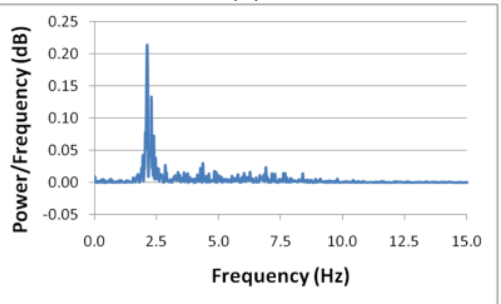

(e)

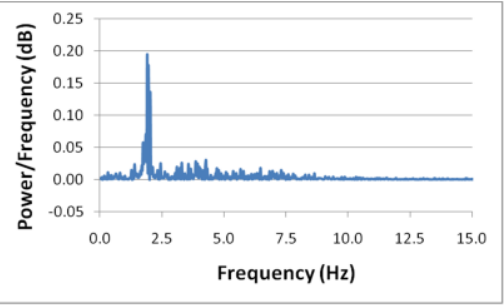

(c)

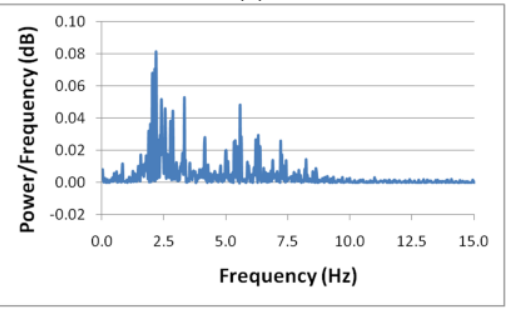

(f)

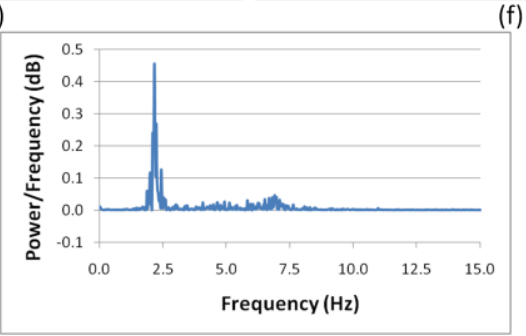

(h)

Figure 7-19: Power Spectral Density of WADFP Ubottom pressure, poly-dispersed sand, feed rate $120 \mathrm{lb} / \mathrm{hr}, \mathrm{U}_{\mathrm{L}}=2.90$ $\mathrm{m} / \mathrm{s}, \mathrm{U}_{\mathrm{U}}=$ : (a) 1.81 (b) 2.04 (c) 2.27 (d) 2.49 (e) 2.72 (f) 2.95 (g) 3.17 (h) $3.40 \mathrm{~m} / \mathrm{s}$. 


\section{Effects of Secondary Air Injection on Lower Riser Stage Fluidization}

The data presented in this section depicts the effects of secondary air injection (during upper riser stage mapping) on the WADFP's lower riser stage.

\section{Average Pressure and Bed Voidage Profiles}

As seen in Figure 7-20, the average pressure in the WADFP lower riser section undergoes minor variations as the level of secondary air injection is changed (as represented by changing $U_{U}$ ).

The average location pressure increases to a maximum value near $\mathrm{U}_{U}=2.27 \mathrm{~m} / \mathrm{s}$ and then steadily decreases with increasing $\mathrm{U}_{\mathrm{U}}$. This effect is lessened in intensity at the higher transducer locations.

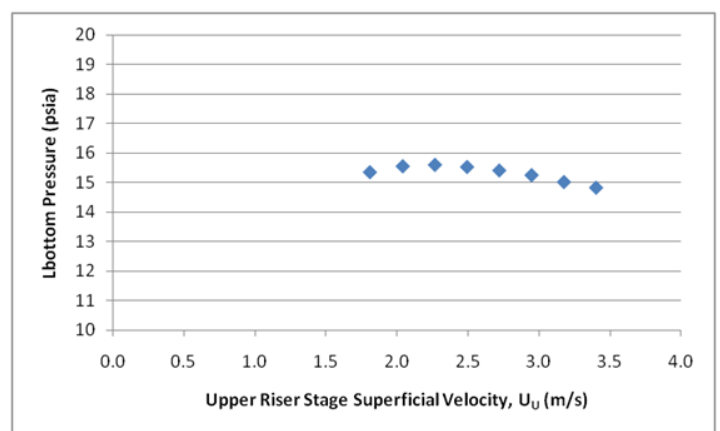

(a)

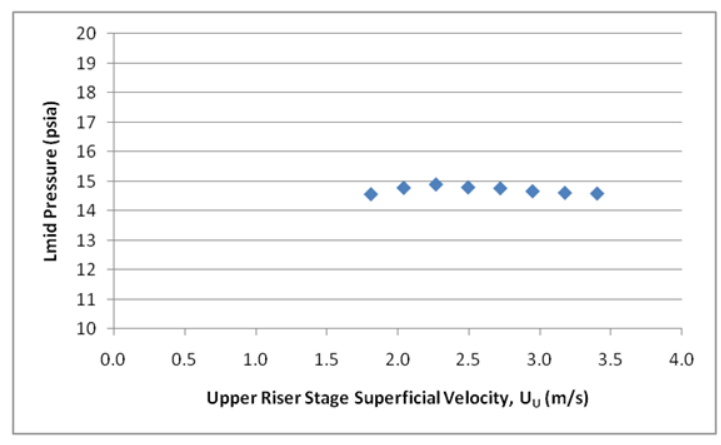

(b)

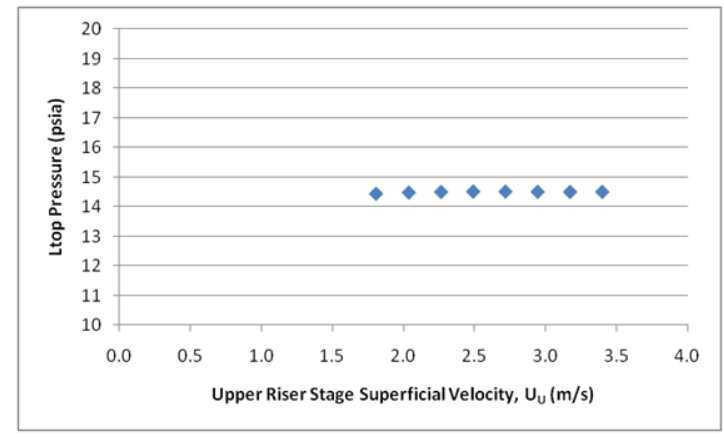

(c)

Figure 7-20: Effects of varying secondary air injection on WADFP lower riser stage average pressures (a) Lbottom (b) Lmid (c) Ltop: poly-dispersed sand, feed rate $120 \mathrm{lb} / \mathrm{hr}, \mathrm{U}_{\mathrm{L}}=2.90 \mathrm{~m} / \mathrm{s}$.

Figure 7-21 shows the effect of secondary air injection on the lower riser stage bed voidage.

Initially, as $\mathrm{U}_{\mathrm{U}}$ increases, the voidage decreases. However, voidage increases with increasing $\mathrm{U}_{U}$ 
beyond $U_{U}=2.27 \mathrm{~m} / \mathrm{s}$. This suggests that, initially, secondary air injection increases the amount of solids retained in the lower riser section until the voidage reaches a minimum. Beyond this minimum $(2.27 \mathrm{~m} / \mathrm{s})$, this trend is reversed and increased secondary air injection causes a drop in the amount of solids retained in the lower riser stage.

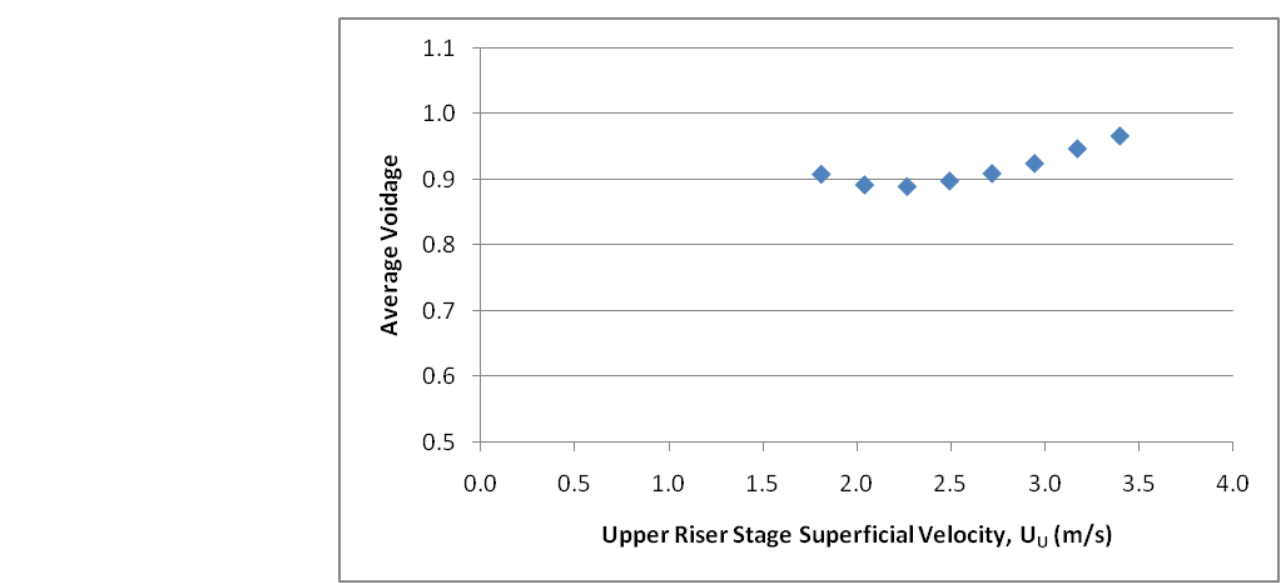

Figure 7-21: Effects of varying secondary air injection on WADFP lower riser stage average voidage: poly-dispersed sand, feed rate $120 \mathrm{lb} / \mathrm{hr}, \mathrm{U}_{\mathrm{L}}=2.90 \mathrm{~m} / \mathrm{s}$.

\section{Standard Deviation and Shannon Entropy}

Figure 7-22 shows the effects of secondary air injection on the standard deviation of lower riser stage pressures. As was seen in the scale model testing, the standard deviation increases to a maximum value, followed by a steady decline with increasing secondary air injection. In addition, the data again shows that the lower riser stage incrementally transitions to fast fluidization from the top down. Figure 7-23 shows a similar trend in Shannon entropy.

\section{Autocorrelation, Mutual Information and Power Spectral Density}

Figures 7-24 through 7-26 show the effects of secondary air injection on the autocorrelation function of the three lower riser stage pressure transducer locations. As upper riser stage superficial velocity, $\mathrm{U}_{\mathrm{U}}$, increases to $2.27 \mathrm{~m} / \mathrm{s}$, the correlation curves for the Lbottom and Lmid locations tend to become more "smooth" and periodic in nature. Beyond $2.27 \mathrm{~m} / \mathrm{s}$, this structure 
begins to decay. This initial increase followed by a decline in time correlation is mirrored in the mutual information data (Figures 7-27 through 7-29).

The power spectral density plots for the lower riser stage pressure transducers (Figures 7-30 through 7-32) exhibit trends similar to that seen in the examination of secondary air injection with the scale model riser in Chapter 5. Lower levels of secondary air injection leads to an increase in the magnitude of power associated with frequencies less than $2.5 \mathrm{~Hz}$. At these lower levels of secondary air injection, the power/frequency tends to coalesce around a dominant frequency. As larger amounts of secondary air injection are used, this dominant frequency becomes much less profound and the power associated with each frequency decreases by as much as an order of magnitude from the maximums seen at $2.27 \mathrm{~m} / \mathrm{s}$.

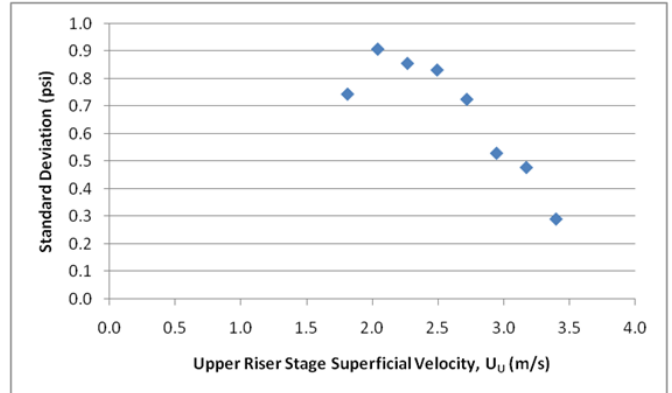

(a)

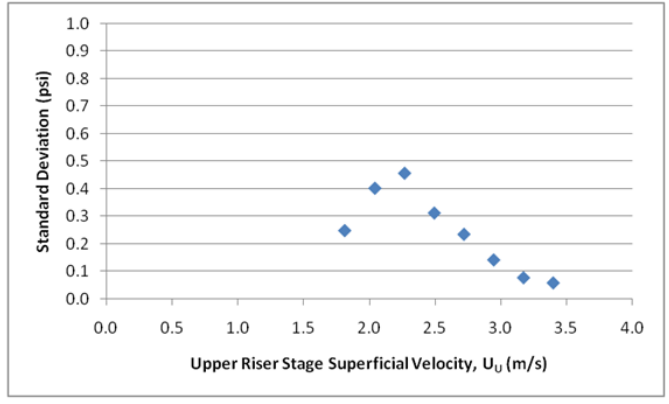

(b)

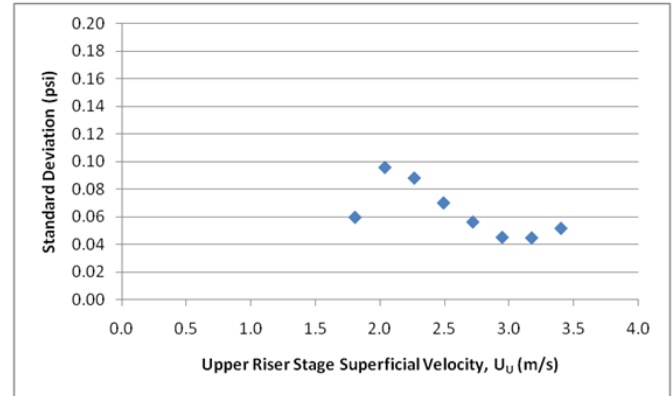

(c)

Figure 7-22: Effects of varying secondary air injection on WADFP lower riser stage standard deviation of pressures (a) Lbottom (b) Lmid (c) Ltop: poly-dispersed sand, feed rate $120 \mathrm{lb} / \mathrm{hr}, \mathrm{U}_{\mathrm{L}}=2.90 \mathrm{~m} / \mathrm{s}$. 


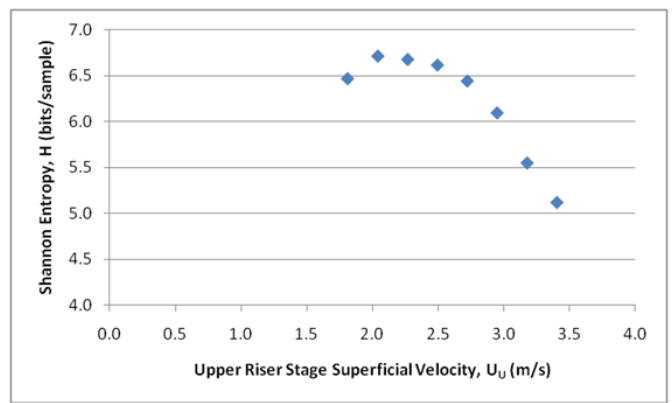

(a)

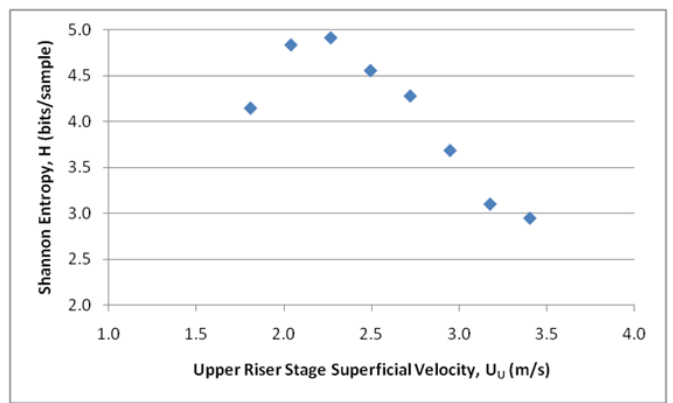

(b)

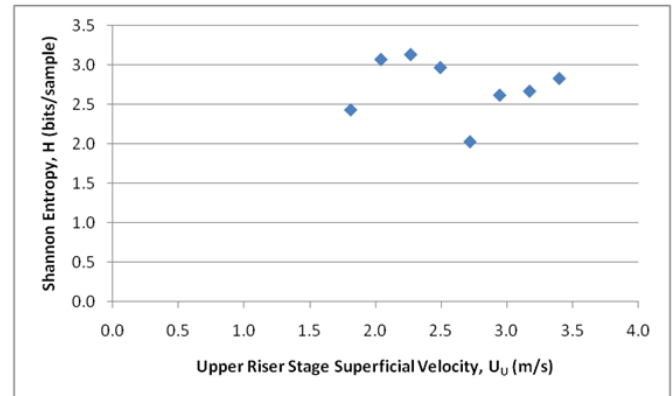

(c)

Figure 7-23: Effects of varying secondary air injection on WADFP lower riser stage Shannon entropy of pressures (a) Lbottom (b) Lmid (c) Ltop: poly-dispersed sand, feed rate $120 \mathrm{lb} / \mathrm{hr}, \mathrm{U}_{\mathrm{L}}=\mathbf{2 . 9 0} \mathrm{m} / \mathrm{s}$.

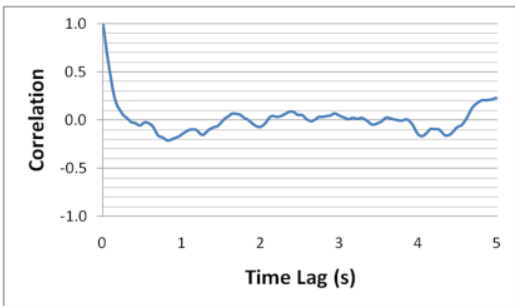

(a)

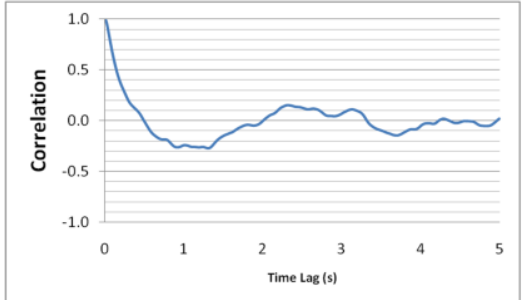

(d)

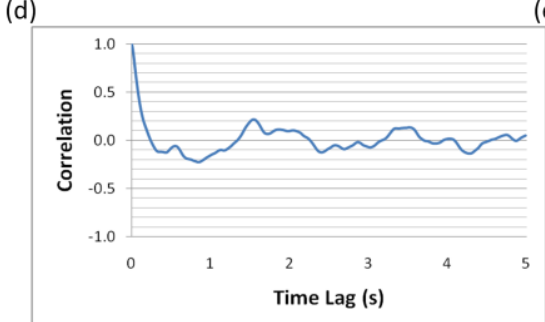

(g)

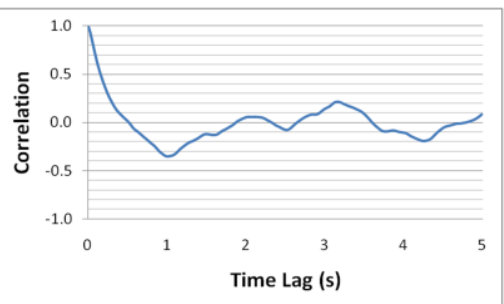

(b)

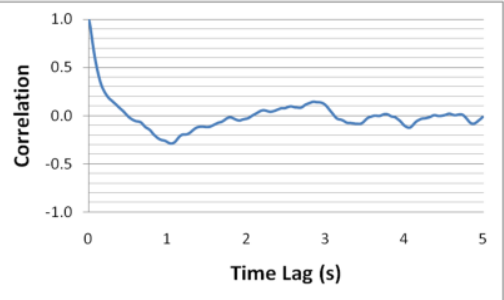

(e)

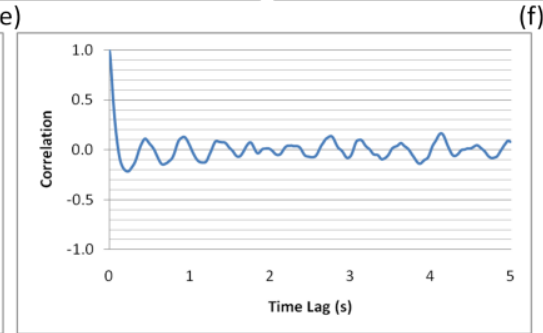

(h)

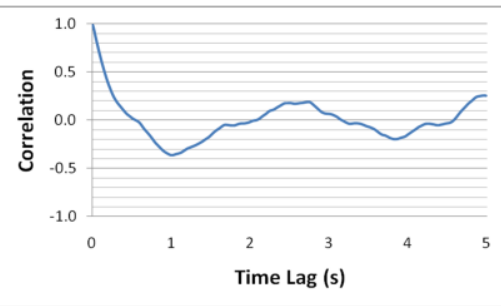

(c)

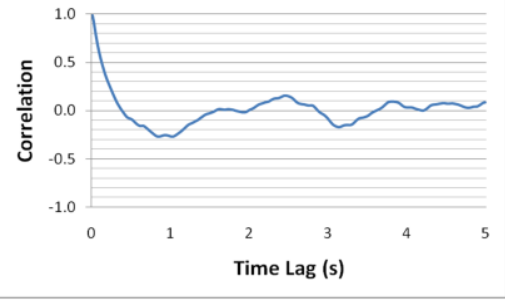

(f)

Figure 7-24: Autocorrelation of WADFP Lbottom pressure, poly-dispersed sand, feed rate $120 \mathrm{lb} / \mathrm{hr}, \mathrm{U}_{\mathrm{L}}=2.90 \mathrm{~m} / \mathrm{s}, \mathrm{U}_{\mathrm{U}}=$ : (a) 1.81 (b) 2.04 (c) 2.27 (d) 2.49 (e) 2.72 (f) 2.95 (g) 3.17 (h) 3.40. 


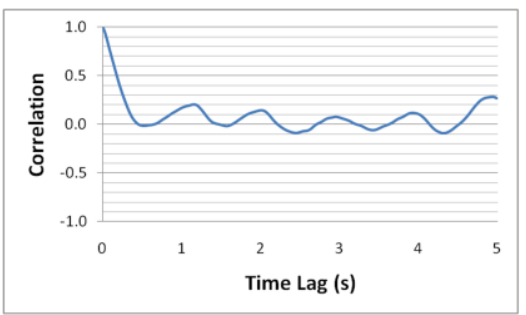

(a)

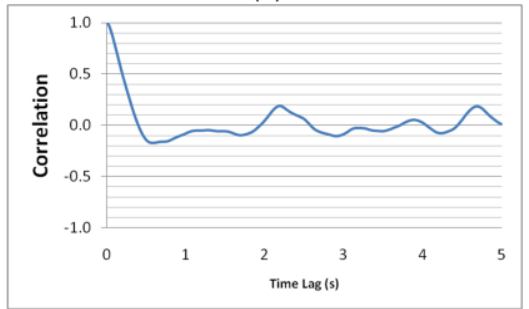

(d)

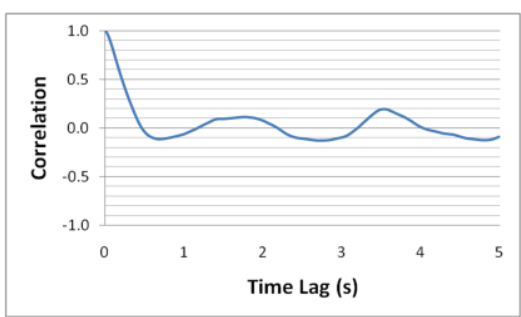

(b)

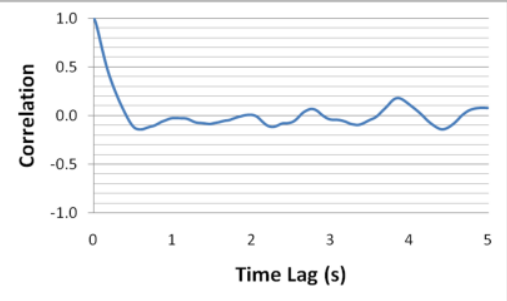

(e)

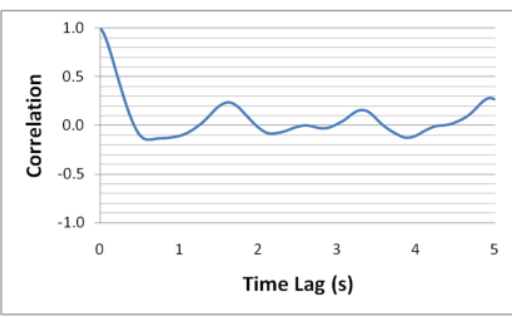

(c)

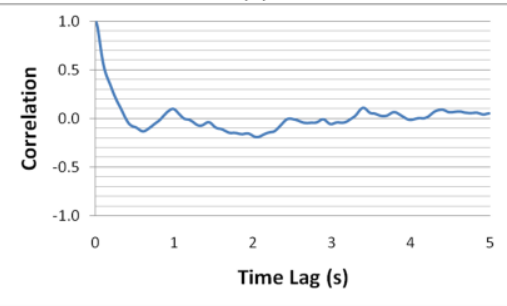

(f)

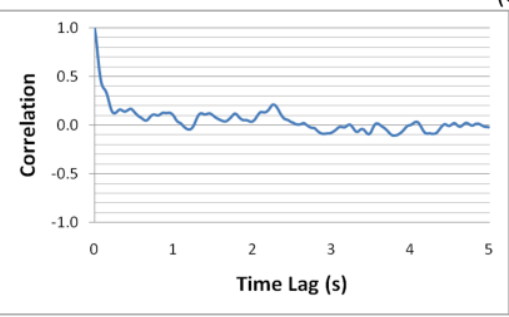

(g)

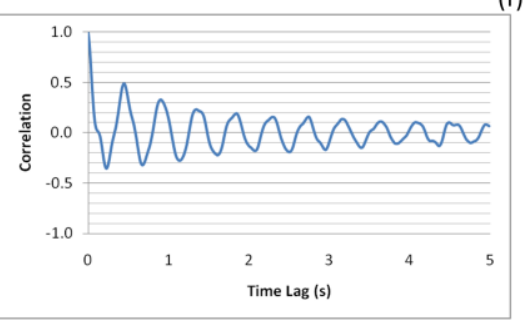

(h)

Figure 7-25: Autocorrelation of WADFP Lmid pressure, poly-dispersed sand, feed rate $120 \mathrm{lb} / \mathrm{hr}, \mathrm{U}_{\mathrm{L}}=2.90 \mathrm{~m} / \mathrm{s}, \mathrm{U}_{\mathrm{U}}=:(\mathrm{a})$ 1.81 (b) 2.04 (c) 2.27 (d) 2.49 (e) 2.72 (f) 2.95 (g) 3.17 (h) 3.40 .

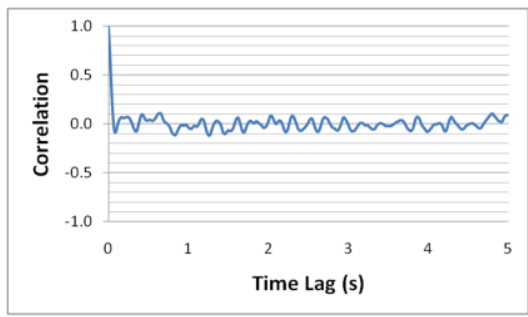

(a)

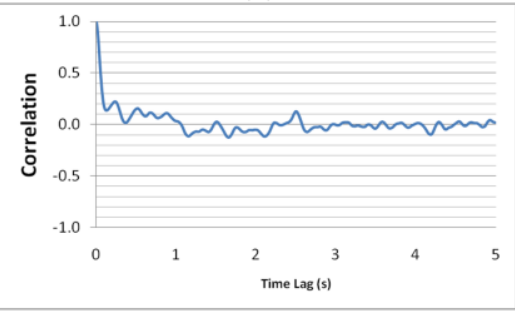

(d)

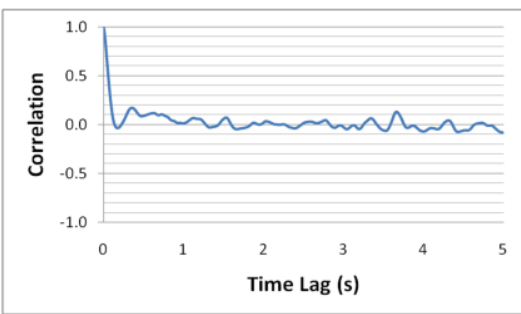

(b)

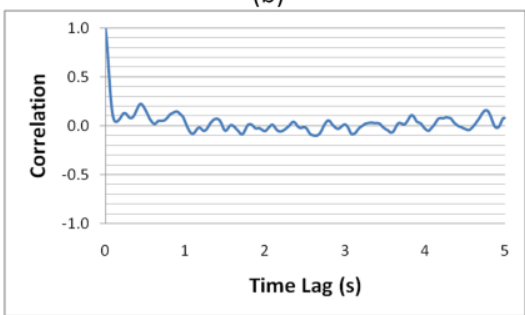

(e)

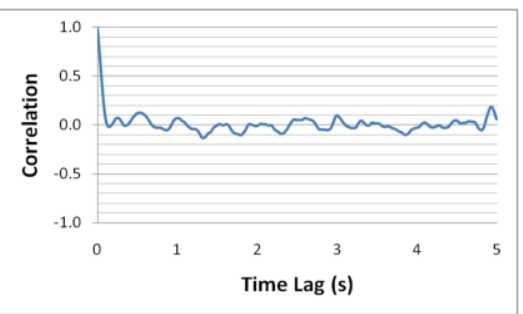

(c)

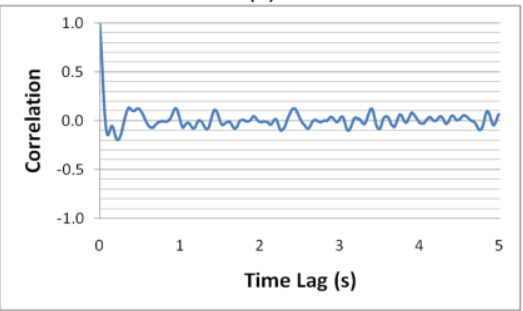

(f)

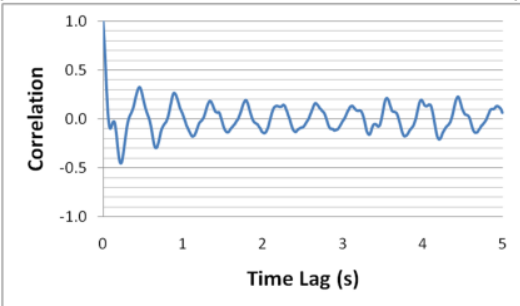

(g)

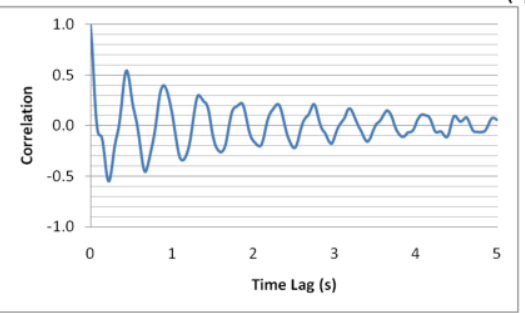

(h)

Figure 7-26: Autocorrelation of WADFP Ltop pressure, poly-dispersed sand, feed rate $120 \mathrm{lb} / \mathrm{hr}, \mathrm{U}_{\mathrm{L}}=2.90 \mathrm{~m} / \mathrm{s}$, $\mathrm{U}_{\mathrm{U}}=$ : (a) 1.81 (b) 2.04 (c) 2.27 (d) 2.49 (e) 2.72 (f) 2.95 (g) 3.17 (h) 3.40. 


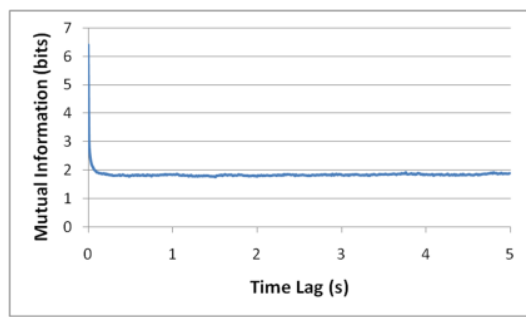

(a)

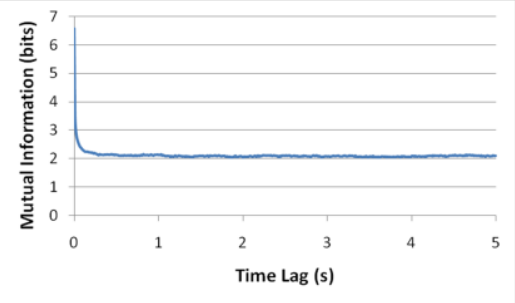

(d)

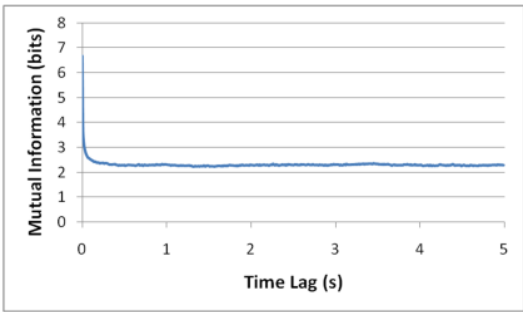

(b)

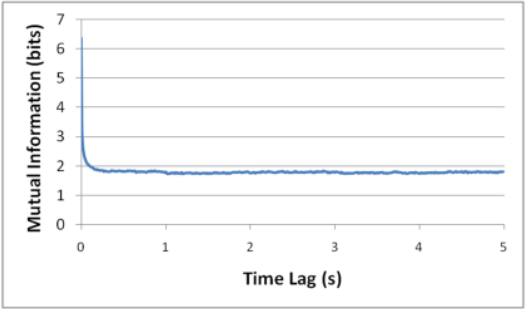

(e)

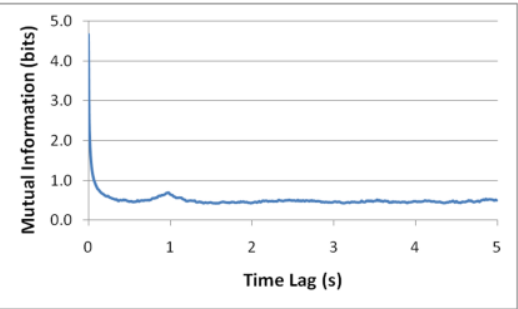

(c)

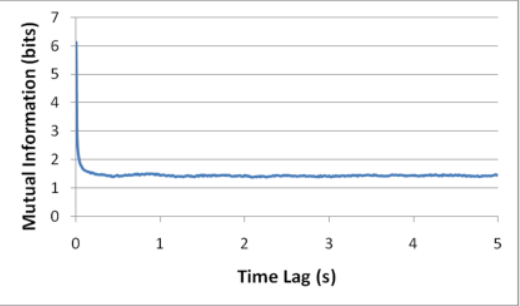

(f)

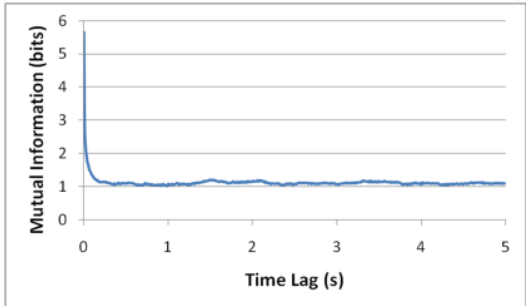

(g)

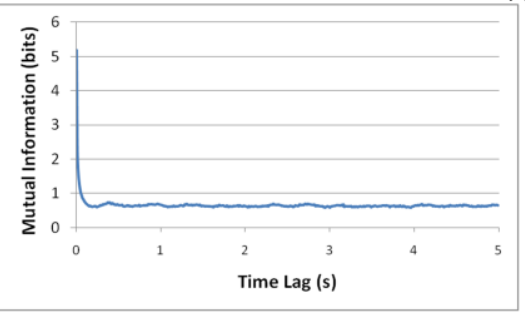

(h)

Figure 7-27: Mutual Information of WADFP Lbottom pressure, poly-dispersed sand, feed rate $120 \mathrm{lb} / \mathrm{hr}, \mathrm{U}_{\mathrm{L}}=2.90 \mathrm{~m} / \mathrm{s}$, $\mathrm{U}_{\mathrm{U}}=$ : (a) 1.81 (b) 2.04 (c) 2.27 (d) 2.49 (e) 2.72 (f) 2.95 (g) 3.17 (h) 3.40.

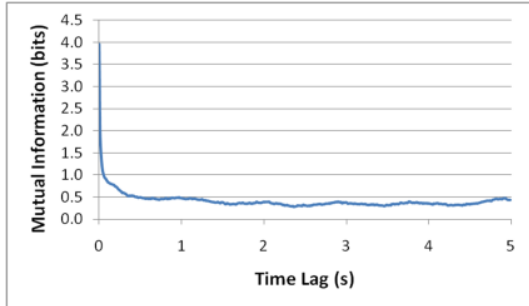

(a)

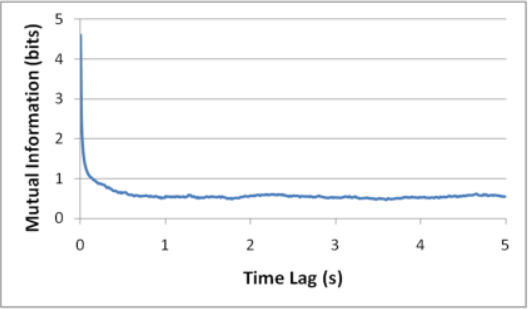

(d)

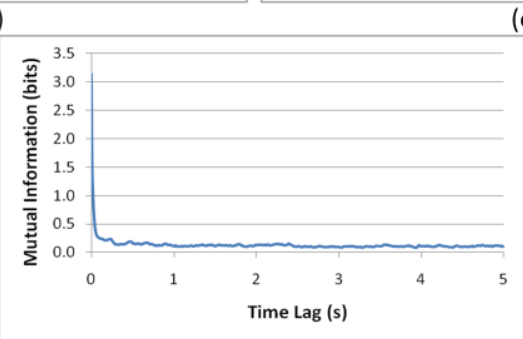

(g)

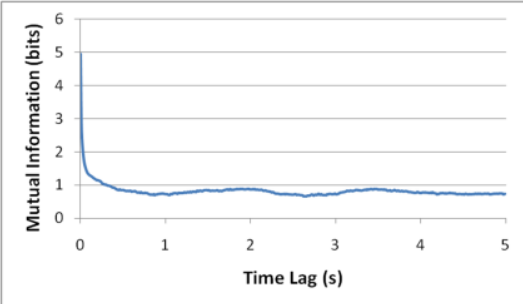

(b)

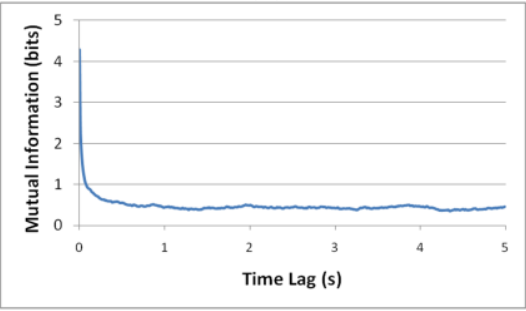

(e)

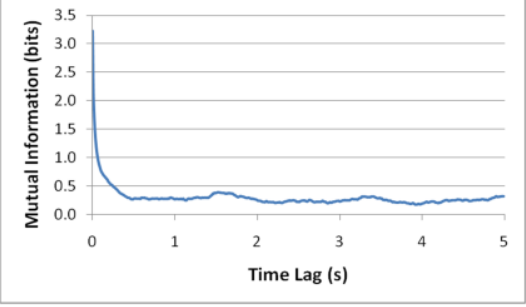

(c)

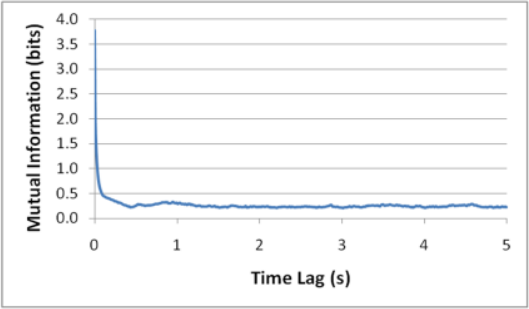

(f)

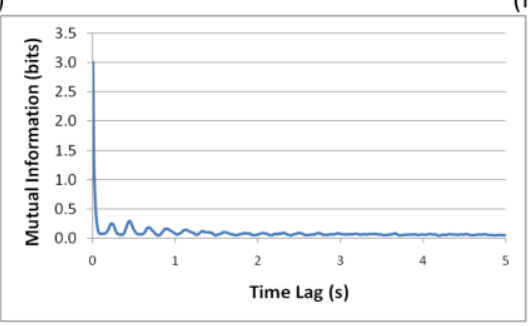

(h)

Figure 7-28: Mutual Information of WADFP Lmid pressure, poly-dispersed sand, feed rate $120 \mathrm{lb} / \mathrm{hr}, \mathrm{U}_{\mathrm{L}}=2.90 \mathrm{~m} / \mathrm{s}$, $\mathrm{U}_{\mathrm{U}}=:$ : (a) 1.81 (b) 2.04 (c) 2.27 (d) 2.49 (e) 2.72 (f) 2.95 (g) 3.17 (h) 3.40 . 


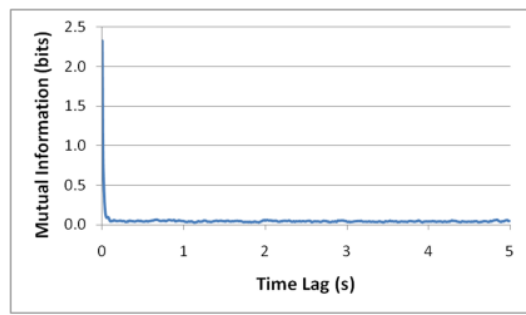

(a)

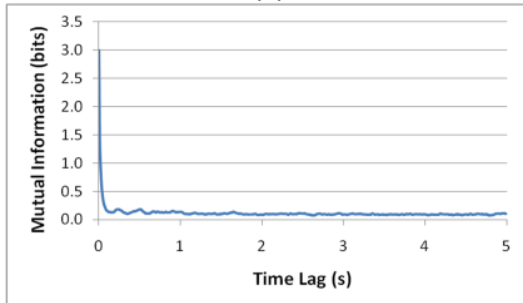

(d)

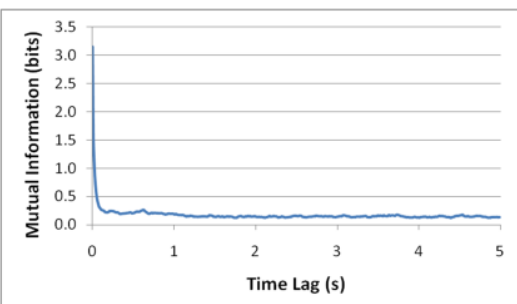

(b)

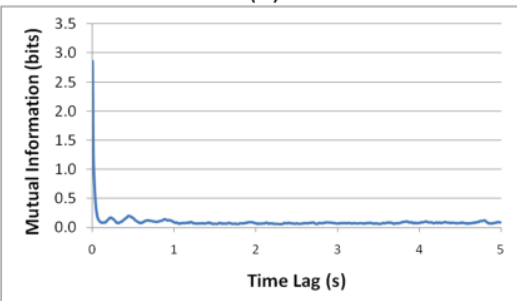

(e)

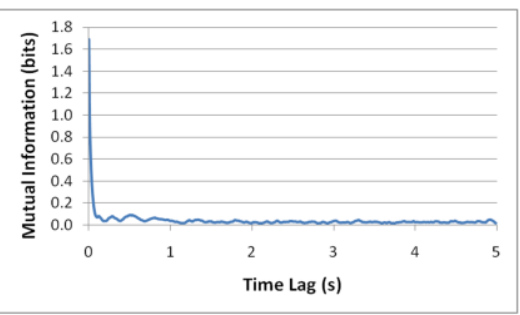

(c)

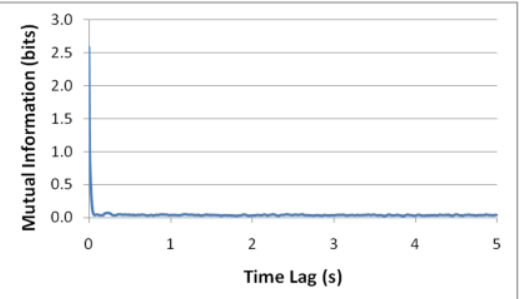

(f)

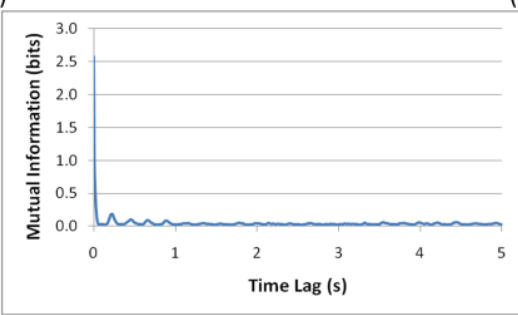

(g)

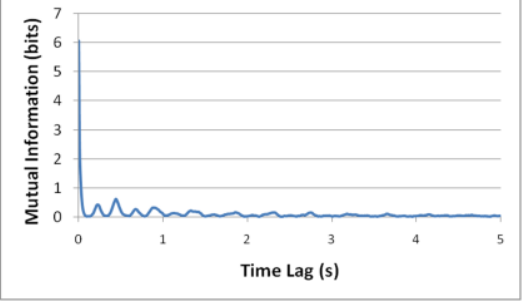

(h)

Figure 7-29: Mutual Information of WADFP Ltop pressure, poly-dispersed sand, feed rate $120 \mathrm{lb} / \mathrm{hr}, \mathrm{U}_{\mathrm{L}}=2.90 \mathrm{~m} / \mathrm{s}$, $\mathrm{U}_{\mathrm{U}}=:$ : (a) 1.81 (b) 2.04 (c) 2.27 (d) 2.49 (e) 2.72 (f) 2.95 (g) 3.17 (h) 3.40.

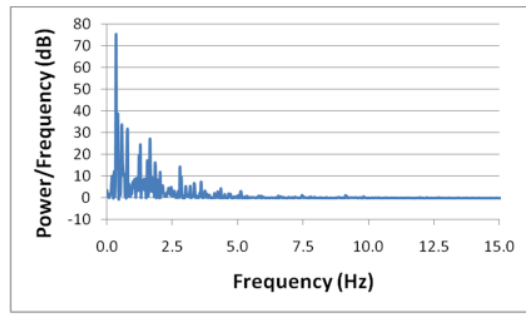

(a)

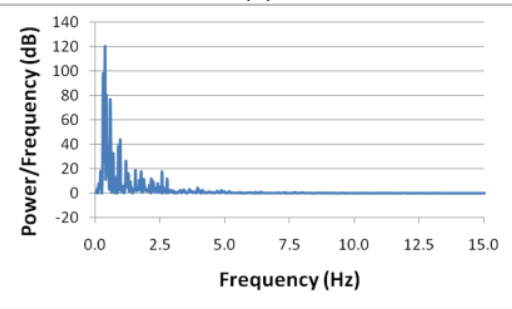

(d)

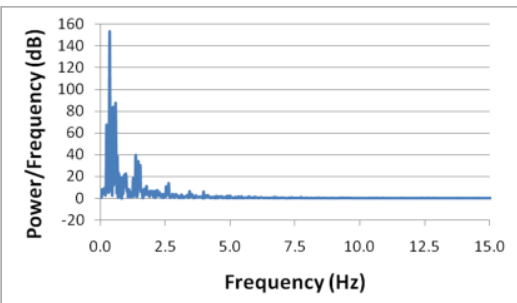

(b)

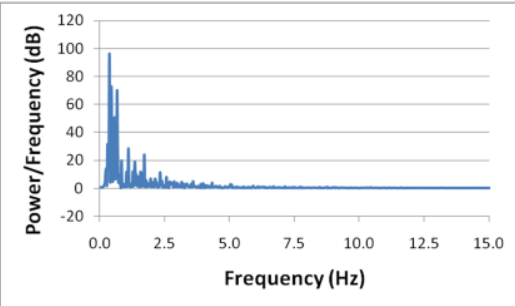

(e)

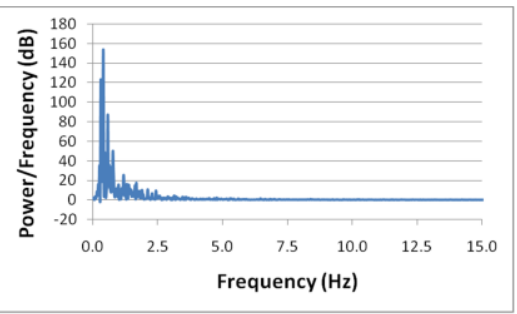

(c)

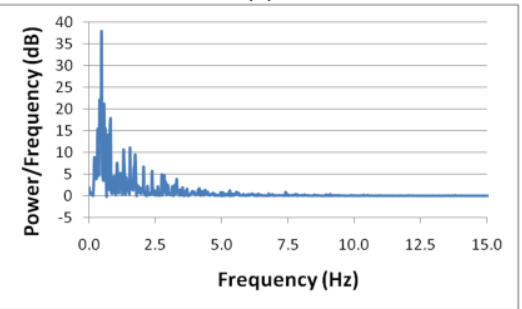

(f)

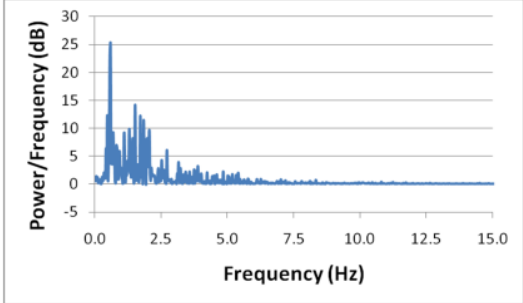

(g)

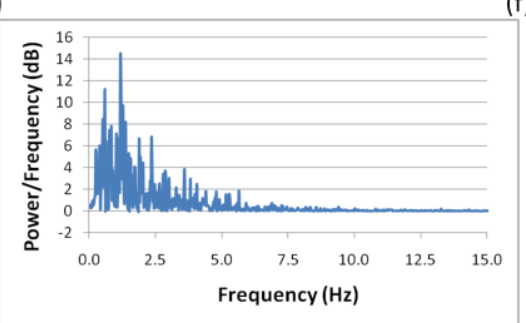

(h)

Figure 7-30: Spectral Density Plots of WADFP Lbottom pressure, poly-dispersed sand, feed rate $120 \mathrm{lb} / \mathrm{hr}, \mathrm{U}_{\mathrm{L}}=2.90 \mathrm{~m} / \mathrm{s}$, $\mathrm{U}_{\mathrm{U}}=$ (a) 1.81 (b) 2.04 (c) 2.27 (d) 2.49 (e) 2.72 (f) 2.95 (g) 3.17 (h) 3.40 . 


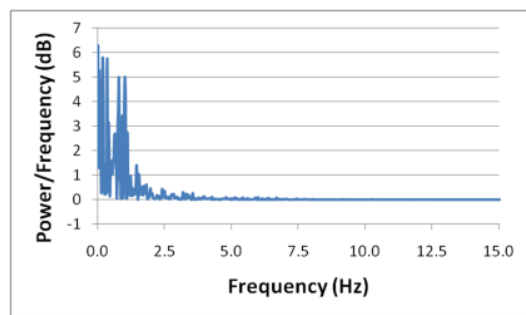

(a)

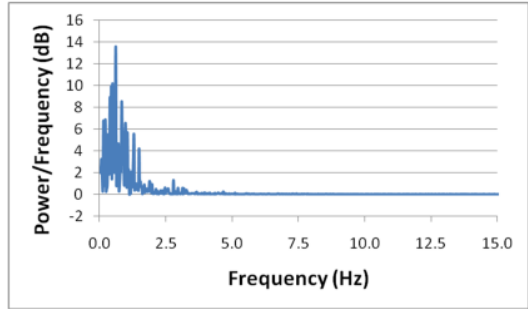

(d)
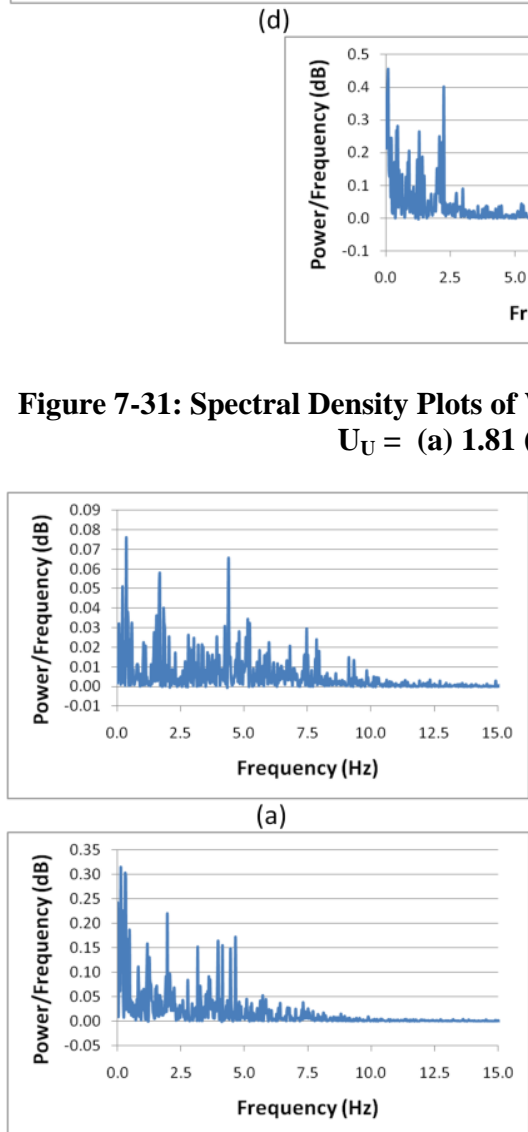

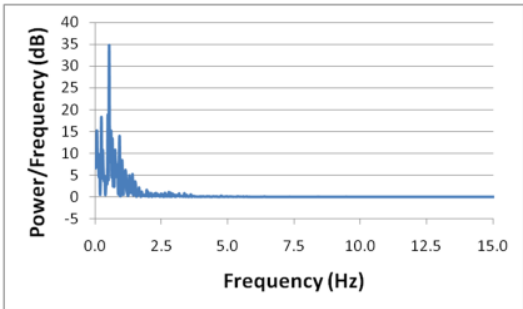

(b)

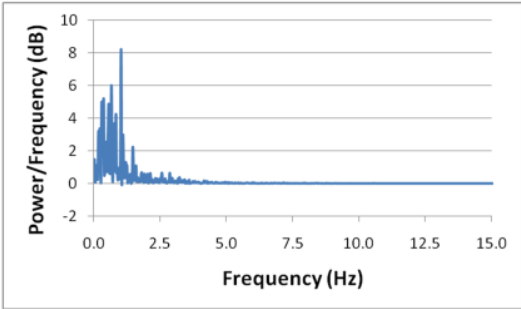

(e)

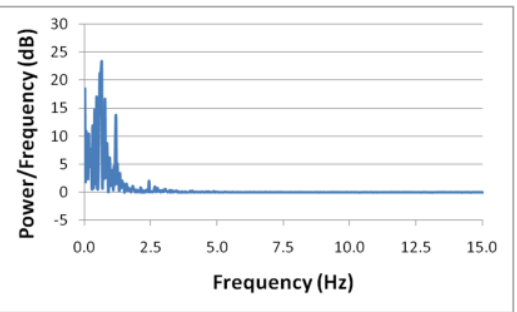

(c)

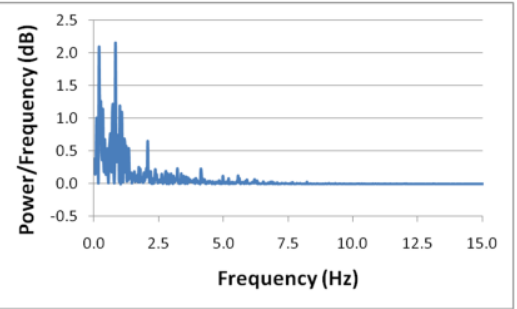

(f)

Figure 7-31: Spectral Density Plots of WADFP Lmid pressure, poly-dispersed sand, feed rate $120 \mathrm{lb} / \mathrm{hr}, \mathrm{U}_{\mathrm{L}}=2.90 \mathrm{~m} / \mathrm{s}$,

(a)

(d)

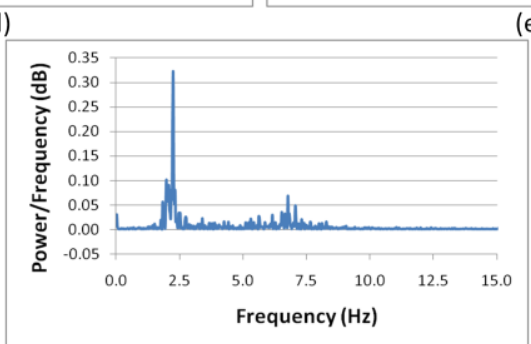

(g)
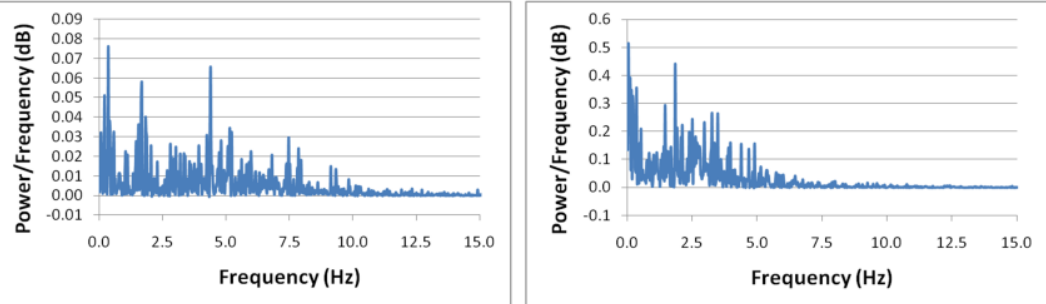

(b)

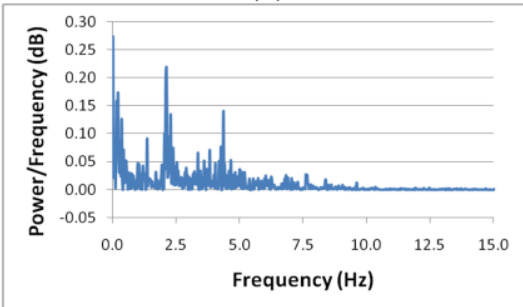

(e)

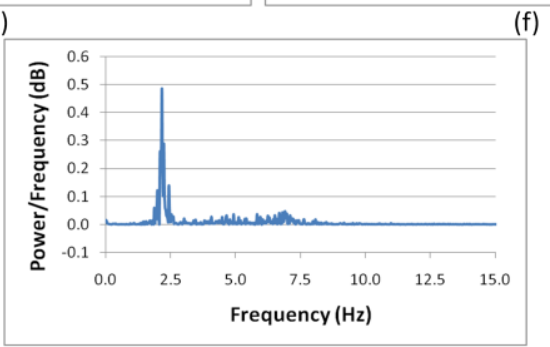

(h)

Figure 7-32: 7-33: Spectral Density Plots of WADFP Ltop pressure, poly-dispersed sand, feed rate $120 \mathrm{lb} / \mathrm{hr}, \mathrm{U}_{\mathrm{L}}=\mathbf{2 . 9 0}$ $\mathrm{m} / \mathrm{s}, \quad \mathrm{U}_{\mathrm{U}}=(\mathrm{a}) 1.81$ (b) 2.04 (c) 2.27 (d) 2.49 (e) 2.72 (f) 2.95 (g) 3.17 (h) 3.40 . 


\section{Preliminary Scaling Results}

Unlike the previous researchers who have examined hydrodynamic scaling in fluidized beds (as detailed in Chapter 3), the goal of the scaling portion of this research is to derive a method of scaling only the operating conditions corresponding to fluidization regime transition points for industrial applications while using the same material in both fluidized beds.

As a starting point, it was noted that Glicksman et al. [62] utilized the ratio of bed superficial gas velocity to minimum fluidization velocity as part of their simplified scaling laws. In terms of the fluidized bed systems used in this study, this leads to the following:

$$
\left(\frac{u_{0}}{u_{m f}}\right)_{\bmod e l}=\left(\frac{u_{o}}{u_{m f}}\right)_{\text {WADFP }} .
$$

With a little manipulation, equation (7.2) can be rewritten as:

$$
u_{o_{-} \bmod e l}=u_{o_{-} W A D F P}\left(\frac{u_{m f_{-} \bmod e l}}{u_{m f_{-} W A D F P}}\right)
$$

In addition, it was proposed that the superficial velocity terms in equation (7.3) be rewritten in terms of a mass flux.

$$
\left(\frac{\dot{m}_{\text {air }}}{A_{\text {riser }}}\right)_{\text {mod } e l}=\left(\frac{\dot{m}_{\text {air }}}{A_{\text {riser }}}\right)\left(\frac{u_{m f_{-} \bmod e l}}{u_{m f_{-} W A D F P}}\right)
$$

This substitution was made in order to facilitate scaling in terms of mass flow rates, which are used when performing a thermodynamic analysis of the system, as described in the following section as well as Chapter 2. 
Finally, in order to allow comparison of standard deviation and Shannon entropy between the lower riser sections of the scale model and WADFP fluidized bed, a scaling term utilizing a generic form of equation (7.4) is introduced.

$$
\Pi_{1}=\left(\frac{\dot{m}_{\text {air_lower }}}{A_{\text {riser_lower }}}\right)^{*}\left(\frac{u_{m f_{-} \text {model }}}{u_{m f_{-} *}}\right)
$$

Where "**" is used to denote the fluidized bed for which the standard deviation and Shannon entropy data is plotted. For example, when data is plotted for the scale model riser, equation (7.5) becomes:

$$
\Pi_{1}=\left(\frac{\dot{m}_{\text {air_lower }}}{A_{\text {riser_lower }}}\right)^{\bmod e l}\left(\frac{u_{m f_{\_} \bmod e l}}{u_{m f_{-} \bmod e l}}\right) \text {, }
$$

and

$$
\Pi_{1}=\left(\frac{\dot{m}_{\text {air_lower }}}{A_{\text {riser_lower }}}\right)^{\text {WADFP }}\left(\frac{u_{m f_{\_} \text {model } l}}{u_{m f_{-} \text {WADFP }}}\right)
$$

when data is plotted for the WADFP fluidized bed. In each case, $\Pi_{1}$ has units of $\mathrm{kg} / \mathrm{s}-\mathrm{m}^{2}=$ or $\mathrm{lbm} / \mathrm{s}-\mathrm{ft}^{2}$.

In Figures 7-33 and 7-34, comparisons of standard deviation and Shannon entropy of pressure for the two systems (using this method) are shown. 


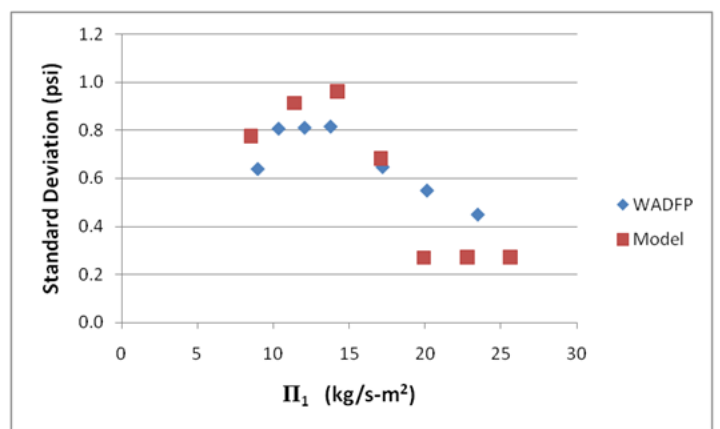

(a)

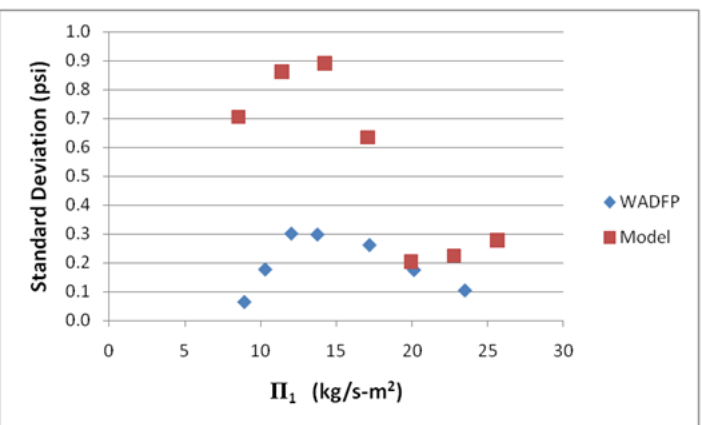

(b)

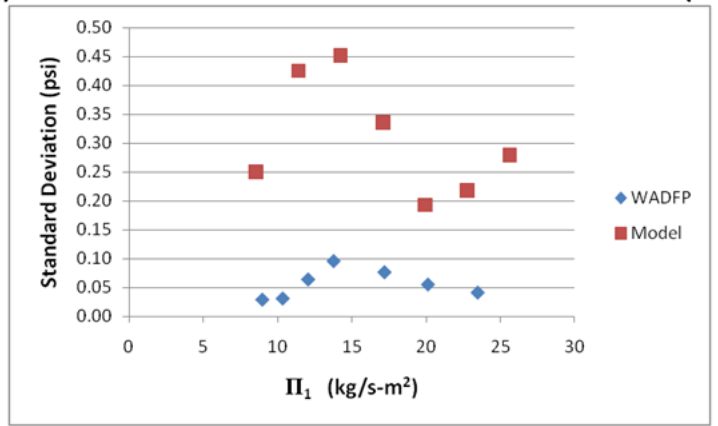

(c)

Figure 7-34: Scaling comparisons of WADFP and scale model standard deviation of pressure as a function of $U_{\mathrm{mf}}$ normalized mass flux rate, lower riser mapping: (a) Lbottom (b) Lmid (c) Ltop.

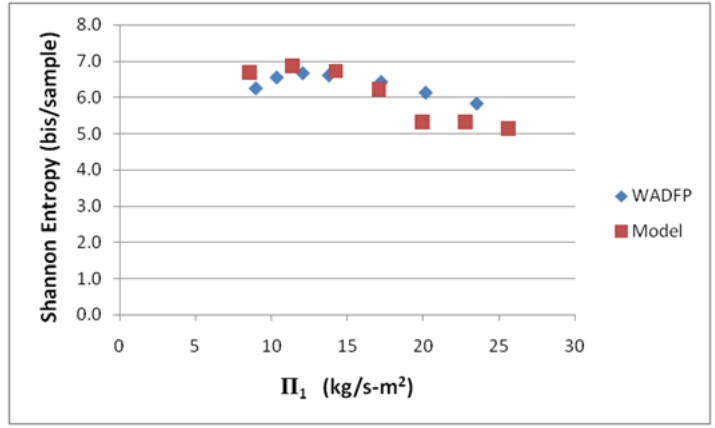

(a)

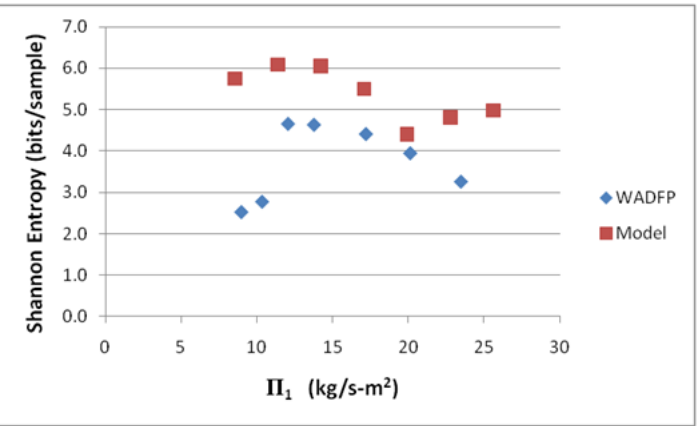

(b)

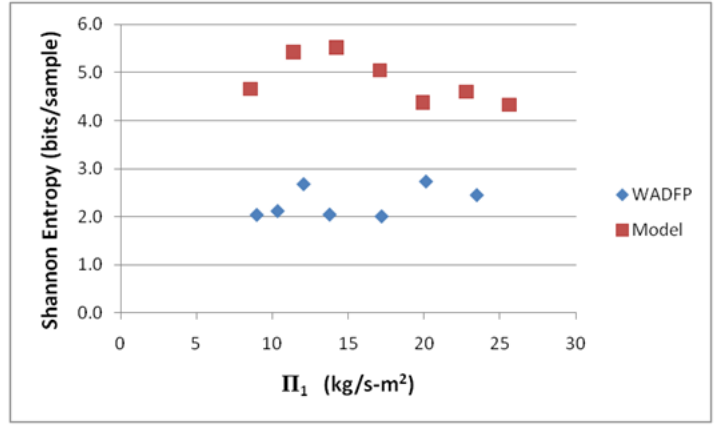

(c)

Figure 7-35: Scaling comparisons of WADFP and scale model Shannon entropy of pressure as a function of $U_{\mathrm{mf}}$ normalized mass flux rate, lower riser mapping: (a) Lbottom (b) Lmid (c) Ltop. 
As can be seen, the Lbottom location data shows good matching in pattern and magnitude of standard deviation over the dense fluidization regimes. The value of standard deviation at $\Pi_{1}=$ 20 is higher in the WADFP dryer than in the model, but further analysis of data shows a transition to core annular flow, as is the case in the scale model riser. In addition, it can also be seen that while the transition points continue to match at higher transducer locations, the magnitude of standard deviation when plotted in this fashion becomes less similar between the two systems. It is believed that this is due to a lack of similar relative dense bed heights between the two. It is further believed that more closely matching the dense bed heights (by matching solids flux) between the two beds would lead to closer matching of the standard deviation magnitudes. Figure 7-34 shows fairly good matching in the Shannon entropy values of both risers for the lower riser pressure transducer locations.

To illustrate the effects of varying amounts of secondary air injection, Figures 7-35 and 7-36 compare the standard deviation and Shannon entropy of pressures for both fluidized beds at all five lower and upper riser stages as a function of the ratio of mass flow rate of secondary air injected into the upper riser stage to the mass flow rate of air into the lower riser stage, defined below as the dimensionless $\Pi_{2}$.

$$
\Pi_{2}=\frac{\dot{m}_{S A I}}{\dot{m}_{\text {Air_Lower }}}
$$

The plots in Figure 7-35 once again show a similar trend between the two systems, with differences in the magnitude of standard deviation in the lower riser stage increasing with bed height. 
Figure 7-36 shows the effects of varying secondary air injection upon the Shannon entropy of the pressures within both risers. As can be seen, the entropy response between the two beds is similar for dense phase fluidization regimes, but appears to diverge with transition to dilute fluidization. This divergence follows what is seen in standard deviation (figure 7-35), but to a much greater and more evident extent. Upon further examination, it was noted that the spectral density data for the WADFP riser showed evidence of a low power "dominant" frequency of approximately $2 \mathrm{~Hz}$, which was not seen in the model riser. This dominant frequency becomes more evident as the system transitions to a state of dilute fluidization (i.e. in the absence of pressure fluctuations caused by bubbles passing the pressure transducers.) This is also evidenced by a similar trend towards periodicity in the autocorrelation data.

The cause of this was not immediately known. However, it should be noted that the compressor that supplied the compressed air for the initial testing with the scale model riser was replaced prior to the start of testing on the WADFP system. While unlikely (the air pressure supplying the WADFP system was regulated via a pressure regulator valve), it is possible that operating differences between the old and new compressors is responsible. Another possible cause is that the bubbling of exhaust air through the water filtration drum might have created pressure fluctuations or vibrations that propagated back into the WADFP. 


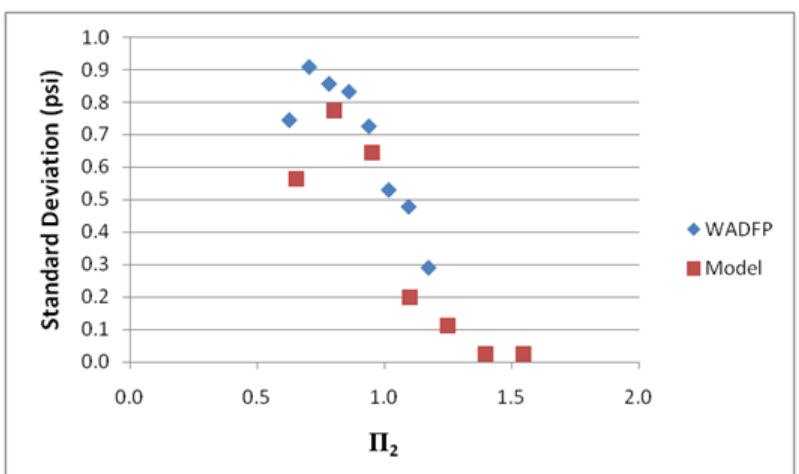

(a)

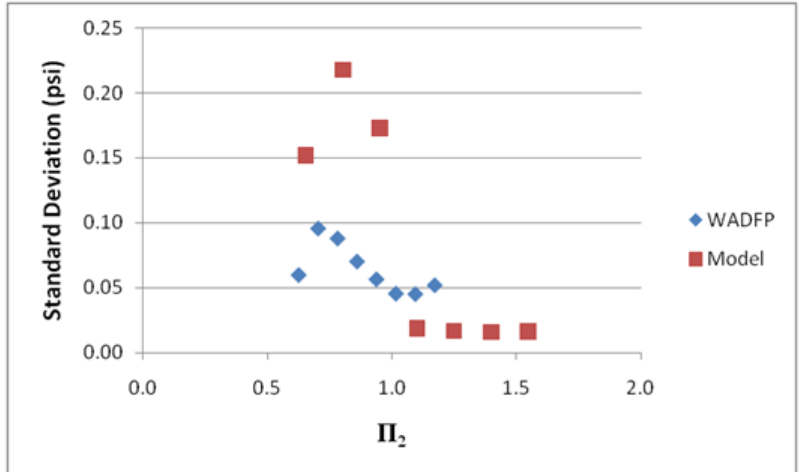

(c)

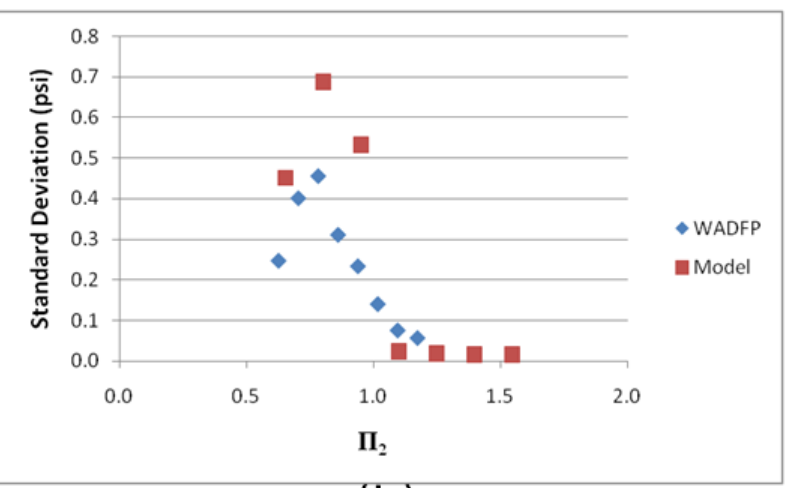

(b)

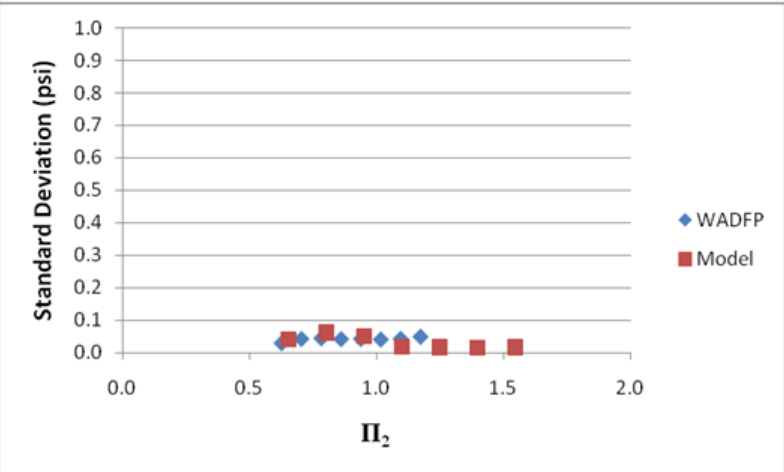

(d)

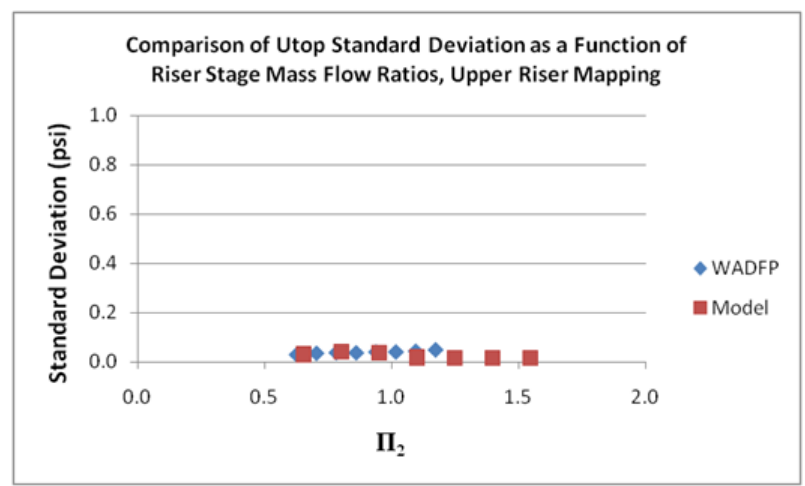

(e)

Figure 7-36: Scaling comparisons of WADFP and scale model standard deviation of pressure as a function of $U_{m f}$ normalized mass flux rate, upper riser mapping: (a) Lbottom (b) Lmid (c) Ltop (d) Ubottom (e) Utop. 


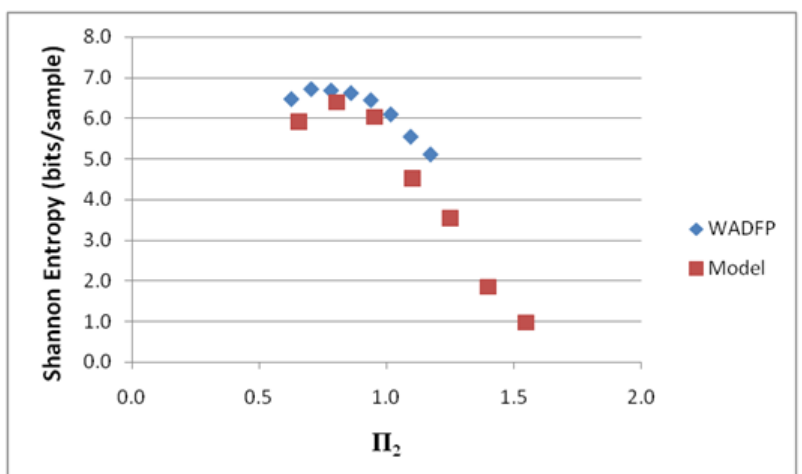

(a)

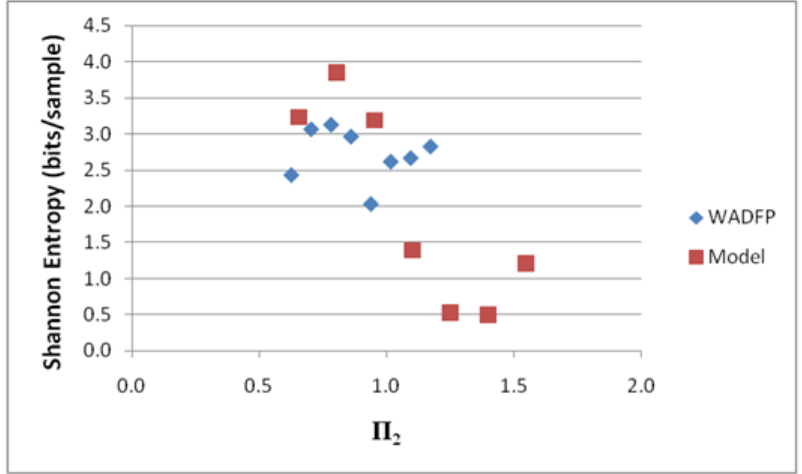

(c)

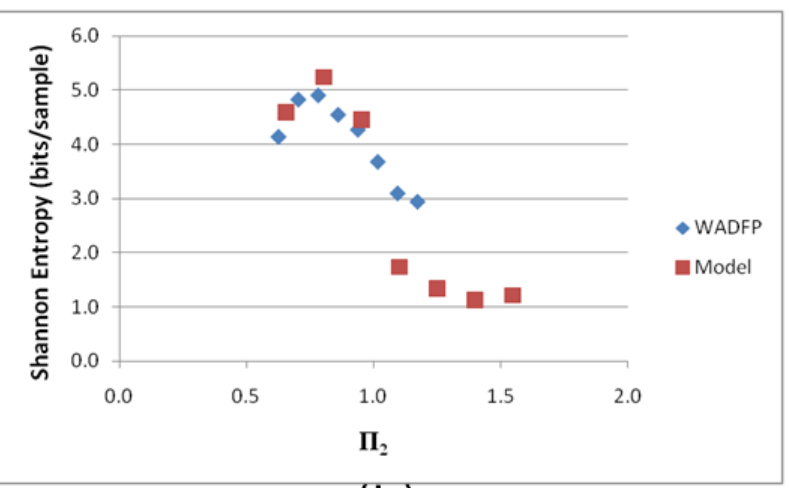

(b)

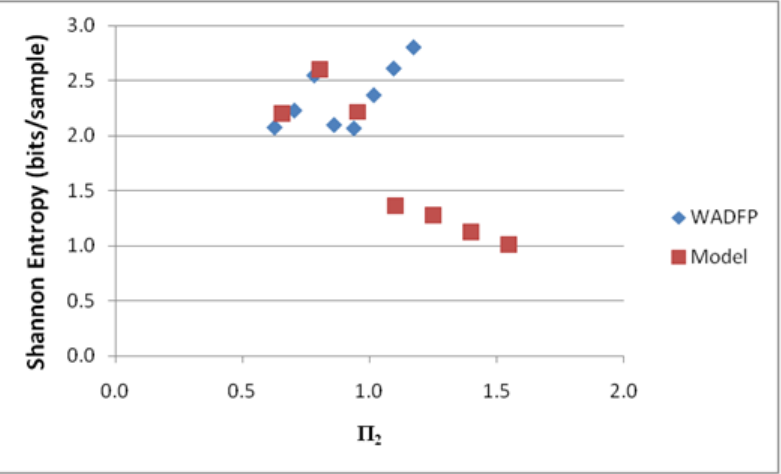

(d)

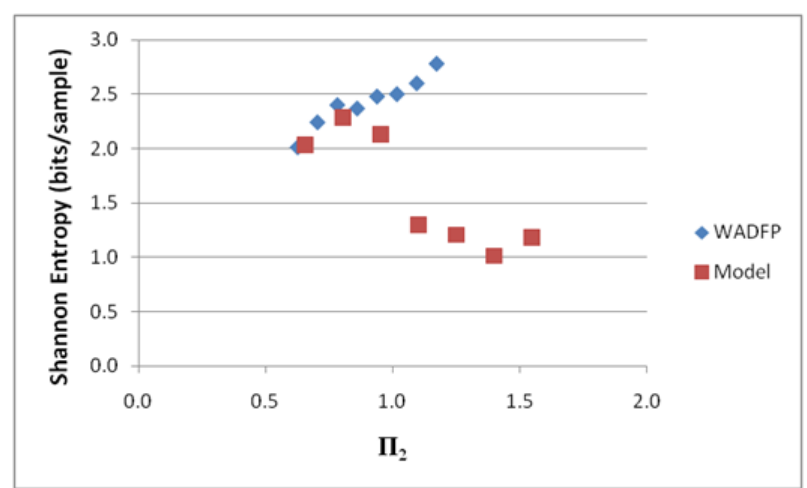

(e)

Figure 7-37: Scaling comparisons of WADFP and scale model Shannon entropy of pressure as a function of $U_{\mathrm{mf}}$ normalized mass flux rate, upper riser mapping: (a) Lbottom (b) Lmid (c) Ltop (d) Ubottom (e) Utop.

In conclusion, the data presented supports the notion that the fluidization regime transition points can be scaled between two geometrically similar fluidized beds (of different scale) operating at different temperatures with particles that are identical in size distribution and density. The method used for doing so involved matching the parameters given in Equations 7.5 and 7.6. 


\section{Application of Scaling Method to Coal}

The previous data presented in this scaling section was obtained from a comparison of sand in the scale model with the same type and size distribution of sand in the WADFP dryer. The scaling parameters listed in equations 7.5 and 7.6 were also applied to clean coal with specific gravity of 1.2 (compared to 2.65 for the sand) and the particle size distribution presented in table 7-5. Two experimental runs were carried out with scaling values of approximately $(15,1)$ and $(20,1)$, respectively. These values corresponded to the onset of turbulence and core annular flow in the sand mapping data. The solids feed rate for the experimental runs with coal were approximately $55 \mathrm{lb} / \mathrm{hr}$ compared to $120 \mathrm{lb} / \mathrm{hr}$ with the sand, leading to solids fluxes of 404 and $882 \mathrm{lb} / \mathrm{ft}^{2}-\mathrm{hr}$, respectively.

\begin{tabular}{|c|c|}
\hline Screen Size $(\mu \mathrm{m})$ & \% Retained \\
\hline 315 & 35 \\
\hline 300 & 5 \\
\hline 250 & 20 \\
\hline 210 & 15 \\
\hline 150 & 25 \\
\hline
\end{tabular}

Table 7-5: Scaling comparison coal particle size distribution

Figure 7-37 depicts the autocorrelation and spectral density plots of the Lbottom pressure location for the two comparison runs with coal. For the turbulent regime condition, the autocorrelation shows very little in the way of periodicity, as expected. For the core annular regime condition, the autocorrelation once again shows the periodicity that was seen in the examination of sand data from the WADFP system. Similarly, the frequency spectra for the core annular regime test point show a similar dominant frequency as seen earlier. In both cases, these 
plots more closely match the response at the Lmid or Ltop location for sand at similar operating conditions. This leads to the conclusion that the lower feed rates of coal, compared with sand, resulted once again in a smaller dense bed region. This consequently led to differences in the autocorrelation and frequency spectra.

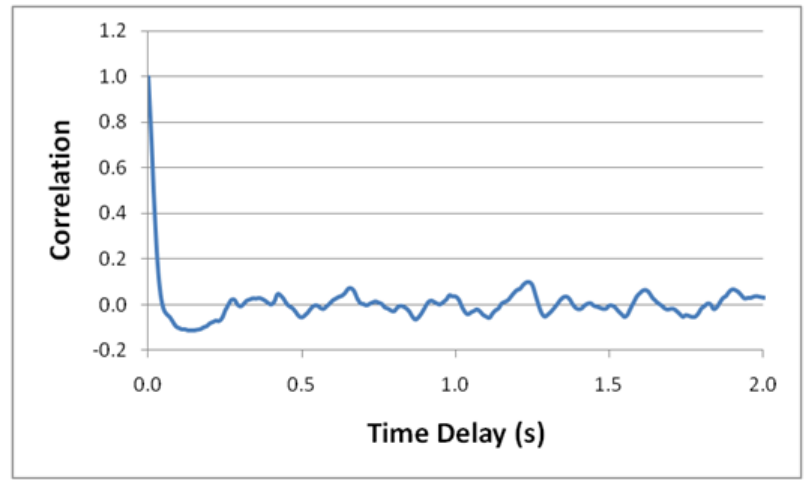

(a)

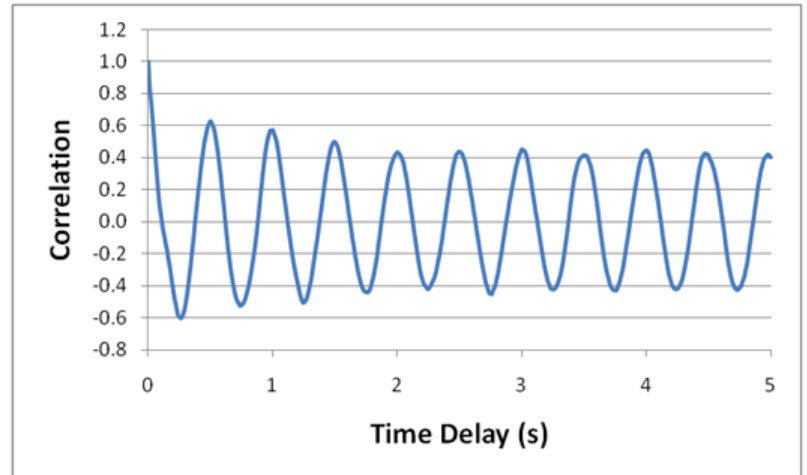

(c)

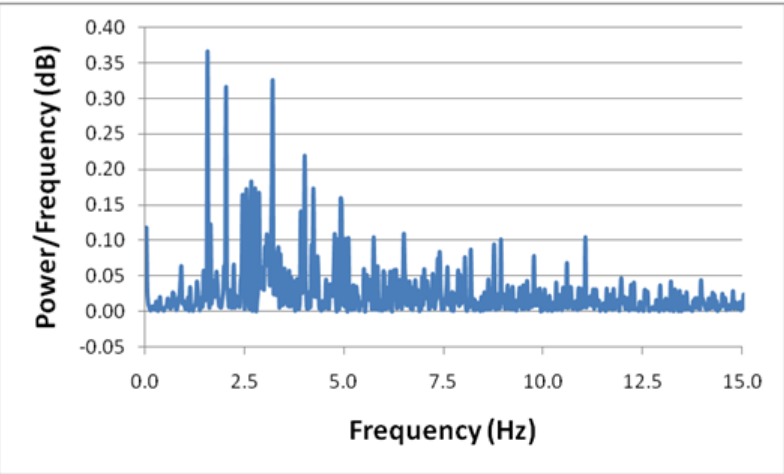

(b)

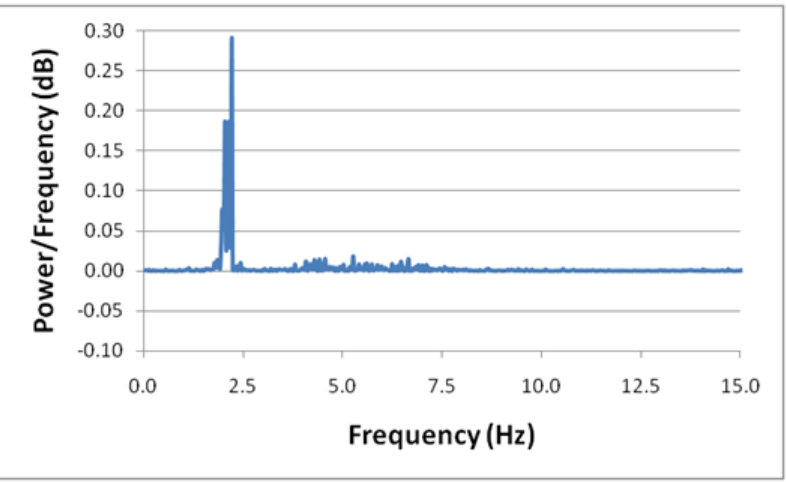

(d)

Figure 7-38: Results of applying scaling method to coal, Lbottom pressure location, cleaned coal, feed rate $55 \mathrm{lb} / \mathrm{hr}$; $U_{L}=2.0 \mathrm{~m} / \mathrm{s}, U_{U}=1.65 \mathrm{~m} / \mathrm{s}$ (a) autocorrelation (b) spectral density; $U_{L}=3.13 \mathrm{~m} / \mathrm{s}, U_{U}=2.56 \mathrm{~m} / \mathrm{s}$ (c) autocorrelation (d) spectral density

\section{Coal Drying Results}

In addition to the two runs with coal discussed in the previous section, additional experimental runs were carried out with Sub-Bituminous underflow tailings and lignite. The lignite had a specific gravity of approximately 1.2 and was screened to be between 150 and $350 \mu \mathrm{m}$. The underflow tailings had a specific gravity of 1.77 and had the particle size distribution given in Table 7-6. 


\begin{tabular}{|c|c|}
\hline Screen Size & \% retained \\
\hline 315 & 30 \\
\hline 300 & 5 \\
\hline 250 & 5 \\
\hline 210 & 30 \\
\hline 150 & 5 \\
\hline 75 & 20 \\
\hline$<75$ & \\
\hline
\end{tabular}

Table 7-6: Sub-bituminous Underflow Tailings Particle Size Distribution

Tables 7-7 and 7-8 show the effects of drying on moisture content and heating value, as well as the thermal and exergy efficiencies (equations 2.37 and 2.45) for these tests.

\section{Sample Proximate Analysis}

Samples of coal were collected before and after testing and subjected to proximate analysis to obtain initial and final moisture content. These results are presented in Table 7-7. For the tests with the floatation column underflow tailings, the air flow rates into the WADFP riser were held constant and the moisture content of the wet coal was varied. In both cases, the final moisture content of the product was $0.69 \%$. In contrast, in the case of the cleaned coal tests, the initial moisture was held constant and the system was operated in the turbulent (test 1) and fast fluidization (test 2) regimes. As can be seen from Table 7-7, the turbulent case resulted in nearly twice the amount of drying as did the fast fluidization test condition. However, the most impressive drying results were clearly from the Texas lignite samples with an initial moisture content of 59\%. Lignite and clean Kingwood Clean Coal samples were subjected to calorimetry tests to determine initial and final heating values. Initial heating values for the lignite were not 
able to be determined due to inability of the analytical lab to get the samples to burn during testing. In the case of the cleaned coal, calorimetry results suggested a $5 \%$ decrease in heating value for the first condition and a $10 \%$ decrease for the second. These results seem to contradict the assertion made by Leonard [10] that reduction of moisture content leads to an increase in heating value. However, upon further examination of the proximate analysis results for the cleaned coal, it was noted that the dried samples showed a decrease in volatile content and an increase in ash content over what was seen in the pre-dried samples.

\begin{tabular}{|c|c|c|c|c|c|c|c|}
\hline Coal Sample & Test \# & $\dot{m}_{\text {air }}$ & $\begin{array}{c}\dot{m}_{\text {coal }} \\
1 \mathrm{bm} / \mathrm{s}\end{array}$ & $\begin{array}{c}\text { Initial } \\
\text { Moisture } \\
\text { Content } \\
(\%)\end{array}$ & $\begin{array}{c}\text { Final } \\
\text { Moisture } \\
\text { Content } \\
(\%)\end{array}$ & $\begin{array}{c}\text { Initial } \\
\text { Heating } \\
\text { Value } \\
(\mathrm{btu} / \mathrm{lbm})\end{array}$ & $\begin{array}{c}\text { Final } \\
\text { Heating } \\
\text { Value } \\
(\mathrm{btu} / \mathrm{lbm})\end{array}$ \\
\hline $\begin{array}{c}\text { Underflow Tailings } \\
\text { (Blacksville WV) }\end{array}$ & 1 & 0.58 & 0.017 & 3.2 & 0.69 & -- & -- \\
\hline Lignite (Texas) & 2 & 0.58 & 0.017 & 7.57 & 0.69 & -- & -- \\
\hline Clean Coal (Kingwood WV) & 1 & 0.28 & 0.0026 & 59 & 2.7 & $*$ & 3843 \\
\hline & 2 & 0.31 & 0.0026 & 59 & 3.54 & $*$ & 8622 \\
\hline
\end{tabular}

Table 7-7: Coal Sample Proximate Analysis Moisture Content Results (* samples not ignitable at analysis lab)

\section{Thermal and Exergy Efficiencies}

Table 7-8 presents the thermal and exergy efficiencies of WADFP coal drying tests. Efficiencies were calculated from equations 2.37 and 2.45. As can be seen from Table 7-8, both thermal and exergy efficiencies were higher in the turbulent fluidization regime than in fast fluidization (cleaned coal), and increased with higher initial moisture contents (underflow tailings). The lignite exhibited the highest efficiency values, and varied minimally.

\begin{tabular}{|c|c|c|c|c|c|}
\hline Coal Sample & Test \# & $\dot{m}_{\text {air }}$ & $\dot{m}_{\text {coal }}$ & $\begin{array}{c}\text { Thermal } \\
\text { Efficiency } \\
\eta_{\text {th }} \\
(\%)\end{array}$ & $\begin{array}{c}\text { Exergy } \\
\text { Efficiency } \\
\eta_{\text {ex }} \\
(\%)\end{array}$ \\
\hline Underflow Tailings (Blacksville WV) & 1 & 0.58 & 0.017 & 4.66 & 1.63 \\
\hline Lignite (Texas) & 2 & 0.58 & 0.017 & 8.3 & 4.47 \\
\hline & 1 & 0.28 & 0.0026 & 15.91 & 3.48 \\
\hline Cleaned Coal (Kingwood WV) & 2 & 0.31 & 0.0026 & 14.16 & 3.43 \\
\hline & 1 & 0.63 & 0.011 & 2.35 & .66 \\
\hline
\end{tabular}

Table 7-8: WADFP Thermal and Exergy Efficiencies for Coal Drying Runs 


\section{Chapter 8 Conclusions and Recommendations}

\section{Conclusions}

The primary objective of this study was to utilize a transparent scale model of a two-stage, variable area fluidized bed with secondary air injection to describe the unique fluidization characteristics of this novel design. This incorporated not only mapping of the turbulent and core-annular fluidization regimes, but also a survey of the effects of varying levels of secondary air injection. Incorporated into this was a comparison of the viability of using principles of information theory and chaos analysis (Shannon/Kolmagorov entropy) and more traditional statistical moments (standard deviation, skew, kurtosis) of pressure signals for fluidization regime mapping. This data was used to obtain an understanding of the hydrodynamics occurring in a non-transparent steam-jacketed riser of a similar design (i.e. the WADFP fluidized bed). Previous fluidization literature involving these topics has utilized constant-area risers and analysis of differential pressure signals. The current study contributes to the body of fluidization literature not only in that it incorporates a unique fluidized bed riser configuration, but also in that the pressure signals analyzed were local absolute pressures instead of differential ones.

The experiments conducted with the small scale fluidized bed gave solid evidence that there is a strong coupling between the characteristics of fluidization of the upper and lower riser stages of a variable area two stage fluidized bed design. The assumption that the use of secondary air injection would separate the two riser stages and allow each to be treated as distinct, independent systems [14] was proven to be incorrect for a fluidized bed riser of this unique two-stage, variable area design. The fact that varying the amounts of secondary air injected between the two stages (thus resulting in varying upper riser stage superficial velocities) had a direct and 
visible impact on the standard deviation and Shannon entropy of the pressure transducer signals shows that this is true. Similarly, it was seen that varying amounts of secondary air injection also had effects on the autocorrelation, mutual information function and power spectral density plots of the lower riser stage pressure signals.

It was also seen that in these systems, where absolute pressures were recorded at each transducer location (instead of differential pressures found in previous literature), the Shannon entropy of the pressure signals followed patterns that closely matched those seen by plotting the standard deviation of pressure against superficial velocity. While the published results of previous studies have shown Shannon entropy to be an effective means of determining fluidization regime boundaries when applied to differential pressures, it was not shown to provide any additional information (from a regime mapping perspective) that could not likewise be seen when examining the standard deviation of an absolute pressure signal.

Examination of power spectral density (PSD) data exhibited unique trends as the fluidized bed riser operated over a range of dense and dilute fluidization regimes. These same trends have been seen in previous literature.

Additionally, examination of the mutual information function of pressure data showed a distinct trend of increasing value as superficial velocity increased through the bubbling and slugging regimes. Just before transition to turbulence, a significant decrease in mutual information was observed; followed by an increase at the turbulent transition velocity. The mutual information then proceeded to decrease throughout the turbulent regime until reaching a minimum in the core-annular regime. 
Upon completion of testing with the scale model riser, similar data was obtained from the WADFP riser using the same type of sand particles as used in the scale model. It was found that similar trends were seen in both risers.

Of all the analysis methods examined, determination of fluidization regime boundaries is most consistent when done via analysis of the standard deviation of pressure, although there were slight discrepancies between comparisons of standard deviation and spectral density in showing transition to turbulence.

Finally, a simplified scaling method was proposed for the two stage riser design. The data presented in Chapter 7 clearly showed that two fluidized beds of the same design but of different scales could be made to operate within the same fluidization regime with identical solids material by matching the scaling ratios listed in equations 7.5 and 7.6. For sand, it was shown that matching these parameters led to good matching in the operating conditions at which the two risers underwent transition to turbulent and core-annular fluidization. It was further proposed that a better hydrodynamic similarity could be achieved by also better matching the dense bed heights via matching solids flux rate.

The same scaling parameters were tested with coal and compared to WADFP system performance with sand at similar values. The coal data for the Lbottom riser location more closely resembled either the Lmid or Ltop locations from the sand runs. It is assumed that this was caused by the presence of a significantly smaller dense bed of coal at either operating condition, resulting in different fluidization characteristics.

Preliminary drying testing was carried out with cleaned coal, underflow tailings and high moisture lignite. Samples of each coal were taken before and after drying and analyzed for 
moisture content and heating value. In each case, the coal samples exhibited a reduction in the moisture content after drying. The system showed increased thermal and exergy efficiencies with increasing initial moisture content. In addition, the efficiencies were higher in tests corresponding to turbulent fluidization in the riser than in the more dilute fast fluidization regime. Previous literature involving the use of a single stage fluidized bed for drying of coal $[19,20,57,59]$ are difficult to compare directly to this study due to the fact that all of the previous studies have involved batch drying in a bubbling bed, whereas this study examined continuous feed drying in turbulent and fast fluidization regimes.

\section{Recommendations}

The current feed system design for the WADFP fluidized bed placed a number of limitations upon the work detailed herein. The primary (and most restrictive) limitation was the fact that the current feed system design was unable to successfully introduce coal with moisture contents above $10 \%$ at sufficient feed rates to conduct testing. Before a more thorough examination of the drying characteristics (and optimization of the drying process) can be carried out, the current feed system needs to be replaced with something capable of handling significantly higher moisture contents. Increasing the overall feed rate is desirable as well. Based upon experience obtained from the testing discussed in previous chapters, it is recommended that a new feed system be designed with a maximum feed rate of wet/dry coal of about $150 \mathrm{lb} / \mathrm{hr}$. It is also recommended that solids material be introduced into the riser at a location above the lower injection ring instead of below.

It was also noted during this study that the current WADFP system cyclone experienced a significant decrease in particle capture efficiency $(\sim 60 \%)$ with particles less than $150 \mu \mathrm{m}$ in diameter. To address this, a secondary cyclone or electro-static precipitator should be 
incorporated into the design, as well as a better particle filtration system on the gases exiting the cyclone. At $150 \mu \mathrm{m}$ and larger, the capture efficiency of the current cyclone exceeded $95 \%$.

Autocorrelation and frequency spectra data for the WADFP system provided evidence of the existence of a low power dominant frequency appearing during dilute fluidization conditions. This was not seen with the scale model and should be examined in more detail. Once the cause of this has been determined, system modifications necessary to address this should be carried out to facilitate better matching between the two riser systems.

The current heat exchanger design leads to large pressure drops across the heat exchanger, resulting in significant reductions in the maximum flow rates of air into the WADFP riser. While this did not have a significant impact upon the current study, attempts to fluidize larger particles (or ones of greater density) will require higher air flow rates than are currently available. Similarly, increasing the diameter of the house air supply line to the flow meter manifold from 1" to at least 2" will allow for higher regulated back pressures.

Finally, it was noted upon comparison of data from the two fluidized beds that there was significant differences in the magnitudes of the standard deviation of pressure fluctuations between the scale model and the WADFP system. These differences tended to increase with increasing bed height. While the proposed scaling terms accurately predicted the fluidization regime transition points for the WADFP, better hydrodynamic similarity between the systems may be achieved by better matching the ratio of dense bed height to riser diameter, as proposed by van den Bleek et al [50]. To facilitate this, additional testing with higher solids flux rates should be carried out after a new, higher capacity, feed system is available. 


\section{Chapter 9 Bibliography}

1 Patwardhan, a., Chugh, Y.P, Arnold, B.J., Terblanche, A.N. Dewatering ultrafine clean coal in a T. H. Filter Press. Coal Preparation, 26 (2006), 33-54.

2 Mohanty, M.K, Wang, z., Huang, A. Steel belt filter: a suitable technology for dewatering fine clean coal and tailings. Coal Preparation, 25 (2005), 1-14.

3 Asmatulu, R., Luttrell, G.H., Yoon, R. Dewatering of fine coal using hyberbaric centrifugation. Coal Preparation, 25 (2005), 117-127.

4 NATIONAL ENERGY TECHNOLOGY LABORATORY. Low-rank western coal baseline study: background analysis document. 2007.

5 Banerjee, P.K., Das, A., Gupta, A., Prasad, A., Misra, A.K., Misra, A.M. Challenges in dewatering of Indian medium coking coals: case studies with chemical reagents. Coal Preparation, 27 (2007), 167-189.

6 Tao, D., Parekh, B.K., Liu, J.T., Chen, S. An investigation on dewatering kinetics of ultrafine coal. International Journal of Mineral Processing, 72 (2003), 235-249.

7 Friedmann, T., Lustenberger, C., Windhab, E.J. Filtration experiments with compressible filter cakes in centrifugal fields with superimposed static pressure. International Journal of Mineral Processing, 73 (2004), 261-267.

8 Mohanty, M.K., Wang, Z., Huang, A. Optimization of the dewatering performance of a steel belt filter. Coal Preparation, 24 (2004), 53-68.

9 Nonhebel, M.A., Moss, A.A.H. Drying of solids in the Chemical Industry. Butterworth \& Co. Publishers, 1971.

10 Leonard, J.W., ed. Coal Preparation, 4th edition. The American Institute of Mining, Metallurgical and Petroleum Engineers, Inc., New York, 1979.

11 Ranz, W.E. and Marshall, J.R. Evaporation from Drops. Chem. Eng. Prog., 48 (1952), 141.

12 Lavender, W.J. and Pei, D.C.T. The Effect of Fluid Turbulence on the Rate of Heat Transfer from Spheres. International Journal of Heat \& Mass Transfer, 10 (1967), 529-539.

13 Hayward, G.L. and Pei, D.C.T. Local Heat Transfer From a Single Sphere to a Turbulent Air Stream. International Journal of Heat \& Mass Transfer, 21 (1978), 35-41.

14 Ersoy, L.E., Golriz, M.R., Koksal, M., Hamdullahpur, F. Circulating fluidized bed 
hydrodynamics with air staging: an experimental study. Powder Technology, 145 (2004), 2533.

15 Balasubramanian, N., Srinivasakannan, C. Drying of granular materials in circulating fluidized beds. Advanced Powder Technology, 18 (2007), 135-142.

16 Jumah, R.Y., Mujumdar, A.S., Raghavan, G.S.V. Batch drying kinetics of corn in a novel rotating jet spouted bed. The Canadian Journal of Chemical Engineering, 74 (1996), 479486.

17 Kannan, C.S., and Subramanian, N.B. Some drying aspects of multistage fluidized beds. Chemical Engineering Technology, 21 (1998), 961-966.

18 Tatemoto, Y., Mawatari, Y., Sugita, K., Noda, K., Komatsu, N. Drying characteristics of porous materials in a fluidized bed under reduced pressure. Drying Technology, 23 (2005), 1257-1272.

19 Calban, T. and Ersahan, H. Drying of a Turkish lignite in a batch fluidized bed. Energy Sources, 25 (2003), 1129-1135.

20 Calban, $\mathrm{T}$. The effects of bed height and initial moisture concentration on drying lignite in a batch fluidized bed. Energy Sources, 28 (2006), 479-485.

21 Diamond, N.C., Magee, T.R.A., McKay, G. The effect of temperature and particle size on the fluid bed drying of northern Ireland lignite. Fuel, 69 (1990), 189-193.

22 Chen, Z., Agarwal, P.K., Agnew, J.B. Steam drying of coal, Part 2. Modeling the operation of a fluidized bed drying unit. Fuel, 80 (2001), 209-223.

23 Stakic, M. and Tsotsas, E. Modeling and numerical analysis of an atypical convective coal drying process. Drying Technology, 22 (2004), 2351-2373.

24 Geldart, D. Types of Gas Fluidization. Powder Technology, 7 (1973), 285.

25 Fan, L.S. and Zhu, C. Principles of gas-solid flow. Cambridge University Press, 1998.

$26 \mathrm{Bi}$, H.T. and Grace, J.R. Flow regime diagrams for gas-solid fluidization and upward transport. International Journal of Multiphase Flow, 21 (1995), 1229-1236.

27 Brzic, D., Ahchieva, D., Piskova, E., Heinrich, S. and Grbavcic, Z. Hydrodynamics of shallow fluidized bed of coarse particles. Chemical Engineering Hournal, 114 (2005), 47-54. 
$28 \mathrm{Ge}, \mathrm{W}$. and Li, J. Physical mapping of fluidization regimes - the EMMS approach. Chemical Engineering Science, 57 (2004), 3993-4004.

29 Monazam, E.R. and Shadle, L.J. A transient method for characterizing flow regimes in a circulating fluidized bed. Powder Technology, 139 (2004), 89-97.

30 Piskova, E. and Morl, L. Characterization of spouted bed regimes using pressure fluctuation signals. Chemical Engineering Science, 63 (2008), 2307-2316.

31 Smolders, K. and Baeyens, J. Gas fluidized bed operating at high velocities: a critical review of occuring regimes. Powder Technology, 119 (2001), 269-291.

32 Zijerveld, R.C., Johnsson, F., Marzocchella, A., Schouten, J.C., van dem Bleck, C.M. Fluidization regimes and transitions from fixed bed to dilute transport flow. Powder Technology, 95 (1998), 185-204.

33 Wen, C.Y. and Yu, Y.H. Mechanics of Fluidization. ( 1966), Chemical Engineering Prog. Symp.

34 Cai, P., DeMichele, G., Traniello Gradassi, A. and Miccio, M. A generalized method for predicting gas flow distribution between the phases in FBC. In Rubow, L., ed., FBC's Role in the World Energy Mix. ASME, New York, 1993.

35 Abrahamsen, A.R. and Geldart, D. Behavior of gas fluidized beds of fine powders. Powder Technology, 26 (1980), 35.

36 Cai, P., Chen, S.P., Jin, Y., Yu, Z.Q., Wang, Z.W. Effect of operating temperature and pressure on the transition from bubbling to turbulent fluidization. AECHE Symp. Ser., 85, 270 (1989), 297.

37 Bi, H.T. and Fan, L.S. Existence of turbulent regime in gas-solid fluidization. AICHE, 38 (1992), 297.

38 Monazam, E.R., Shadle, L.J., Mei, J.S. and Spenik, J. Identification and characteristics of different flow regimes in a circulating fluidized bed. Powder Technology, 155 (2005), 17-25.

39 Bai, D., Jin, Y. and Yu, Z. Flow regimes in circulating fluidized beds. Chemical Engineering Technology, 16 (1993), 307.

40 Yerushalmi, J. and Cankurt, N.T. Further studies of the regimes of fluidization. Powder Technology, 24 (1979), 187. 
41 Rhodes, M.J. and Geldart, D. Transition to Turbulence? In Fluidization V (New York 1986), Engineering Foundation, 281-288.

42 Bi, H.T., and Grace, J.R. Effect of measurement method on the velocities used to demarcate the onset of turbulent fluidization. Chemical Engineering Journal, 57 (1995), 261-271.

43 Lee, G.S. and Kim, S.D. Pressure fluctuations in turbulent fluidized beds. Chemical Engineering Journal of Japan, 28, 515-521.

44 Johnsson, F., Zijerveld, R.C., Scouten, J.C., van den Bleek, C.M., Leckner, B. Characterization of fluidization regimes by time-series analysis of pressure fluctuations. International Journal of Multiphase Flow, 26 (2000), 663-715.

45 Kang, Y., Cho, Y.J., Woo, K.J., Kim, K.I. and Kim, S.D. Bubble properties and pressure fluctuations in pressurized bubble columns. Chemical Engineering Science, 55 (2000), 411419.

46 Zhong, W., Jin, B., Zhang, Y. Wang, X., Zhang, M. and Xiao, R. Description of dynamic behavior of a fluidized bed with biomass fuels by Shannon Entropy Increment Analysis. Energy \& Fuels, 23 (2009), 3167-3171.

47 Zhong, W. and Zhang, M. Characterization of dynamic behavior of a spout-fluid bed with shannon entropy analysis. Powder Technology, 159 (2005), 121-126.

48 Kang, Y., Woo, K-J., Ko, M-H., Cho, Y-J. and Kim, S-D. Particle flow behavior in threephase fluidized beds. Korean Journal of Chemical Engineering, 16 (1999), 784-788.

49 Zhang, Z., and Shi, L. Shannon entropy characteristics of two-phase flow systems. Journal of Applied Physics, 85 (1999), 7544-7551.

50 van den Bleek, C.M., Coppens, M-O. and Schouten, J.C. Application of chaos analysis to multiphase reactors. Chemical Engineering Science, 57 (2002), 4763-4778.

51 Cengel, Y.A. and Boles, M.A. Thermodynamics: An Engineering Approach. McGraw-Hill, Inc., New York, 1994.

52 Shannon, C.E. and Weaver, W. The Mathematical Theory of Communication. University of Illinois Press, 1949.

53 Daw, C.S., Lawkins, W.F., Downing, D.J. and Clapp, N.E. Chaotic characteristics of a complex gas-solids flow. Physical Review, 41 (1990), 1179-1181. 
54 Chandran, A.N., Subba Rao, S. and Varma, Y.B.G. Fluidized Bed Drying of Solids. AICHE Journal, 36 (1990), 29-38.

55 Johnson, E. Lecture Notes: Multiphase Flows. 2007.

56 Giner, S.A. and Calvelo, A. Modeling of Wheat Drying in Fluidized Bed. Journal of Food Science, 52, 5 (1987), 1358-1363.

57 Syahrul, S., Hamdullahpur, f. and Dincer, I. Energy analysis in fluidized-bed drying of large wet particles. International Journal of Energy Research, 26 (2002), 507-525.

58 Cengel, Y. A. and Boles, M.A. Thermodynamics: Engineering Approach 2nd ed. McGrawHill, Inc., New York, 1989.

59 Syrahrul, S., Hamdullahpur, F. and Dincer, I. Exergy analysis of fluidized bed drying of moist particles. Exergy, an International Journal, 2 (2002), 87-98.

60 Glicksman, L.R. Scaling Relationships for Fluidized Beds. Chemical Engineering Science, 39 (1984), 1373-1379.

61 Glicksman, L.R. Scaling Relationships for Fluidized Beds. Chemical Engineering Science, 43 (1988), 1419-1421.

62 Glicksman, L.R., Hyre, M. and Woloshun, K. Simplified Scaling Relationships for Fluidized Beds. Powder Technology, 77 (1993), 177-199.

63 Nicastro, M.T. and Glicksman, L.R. Experimental Verification of Scaling Relationships for Fluidized Beds. Chemical Engineering Science, 39 (1984), 1381-1391.

64 Horio, , M., Nonaka, A., Sawa, Y. and Muchi, I. A New Similarity Rule for Fluidized Bed Scale-up. AICHE Journal, 32 (1986), 1466-1482.

65 Zhang, M.C. and Yang, R.Y.K. On the Scaling Laws for Bubbling Gas-Fluidized Bed Dynamics. Powder Technology, 51 (1987), 159-165.

66 Westphalen, D. Experimental Verification of Scaling Relationships for Circulating Fluidized Beds. Electrical Power Research Institute, 1991.

67 Ellis, N., Bi, H.T., Lim, C.J. and Grace, J.R. Hydrodynamics of turbulent fluidized beds of different diameters. Powder Technology, 141 (2004), 124-136.

68 Diks, C., van Zwet, W.R., Takens, F. and DeGoede, J. Detecting differences between delay 
vector distributions. Physical Review E, 53 (1996), 2169-2176.

69 Diks, C., van Zwet, W.R., Takens, F. and DeGoede, J. Detecting differences between delay vector distributions. Physical Review E, 53, 3 (March 1996), 2169-2176.

70 Musser, Jordan M.H. Development of a separation riser with flow pulsations for small coal particles. West Virginia University, Morgantown, 2007.

71 Veerloop, J. and Heertjes, P.M. Periodic Pressure Fluctuations in Fluidized Beds. Chemical Engineering Science, 29 (1974), 426.

72 Avidian, A.A. and Yerushalmi, J. Bed expansion in high velocity fluidization. Powder Technology, 32 (1993), 223.

73 Bird, R.B., Stewart, W.E. and Lightfoot, E.N. Transport Phenomena, 2nd ed. John Wiley \& Sons, New York, 2007.

74 Al-Sood, M.M.A. and Birouk, M. Droplet heat and mass transfer in a turbulent hot airstream. International Journal of Heat \& Mass Transfer, 51 (2008), 1313-1324.

75 Birouk, M. and Gokalp, I. Current status of droplet evaporation in turbulent flows. Prog. Energy Combustion Science, 32 (2006), 408-423.

76 Peyrin, F. and Kondjoyan, A. Effect of turbulent integral length scale on heat transfer around a circular cylinder placed cross to an airflow. Experimental Thermal and Fluid Science, 26 (2002), 455-460.

77 Barret, M.J. and Hollingsworth, D.K. On the calculation of length scales for turbulent heat transfer correlation. Transactions of the ASME, 2001 (2001), 878-883.

78 Sak, C., Liu, R., Ting, D.S.-K. and Rankin, G.W. The role of turbulence length scale and turbulence intensity on forced convection from a heated horizontal circular cylinder. Experimental Thermal and Fluid Science, 31 (2007), 279-289.

79 Monazam, E.R., Shadle, L.J., Evans, R. and Schroeder, K. Water Adsorption and Desorption by Coals and Chars. Energy \& Fuels, 12 (1998), 1299-1304. 
Supplementary video files

\author{
$\underline{\text { LRMT1.WmV }}$ \\ LRMT2.wmV \\ LRMT3.wmv \\ $\underline{\text { LRMT4.wmv }}$ \\ LRMT5.WmV \\ LRMT6.wmv \\ $\underline{\text { LRMT7.wmv }}$ \\ LRMT8.wmv \\ LRMT9.wmv \\ $\underline{\text { URMT1.wmV }}$ \\ $\underline{\text { URMT2.wmV }}$ \\ $\underline{\text { URMT3.wmV }}$ \\ $\underline{\text { URMT4.wmV }}$ \\ $\underline{\text { URMT5.wmV }}$ \\ $\underline{\text { URMT6.wmv }}$ \\ $\underline{\text { URMT7.wmv }}$
}

